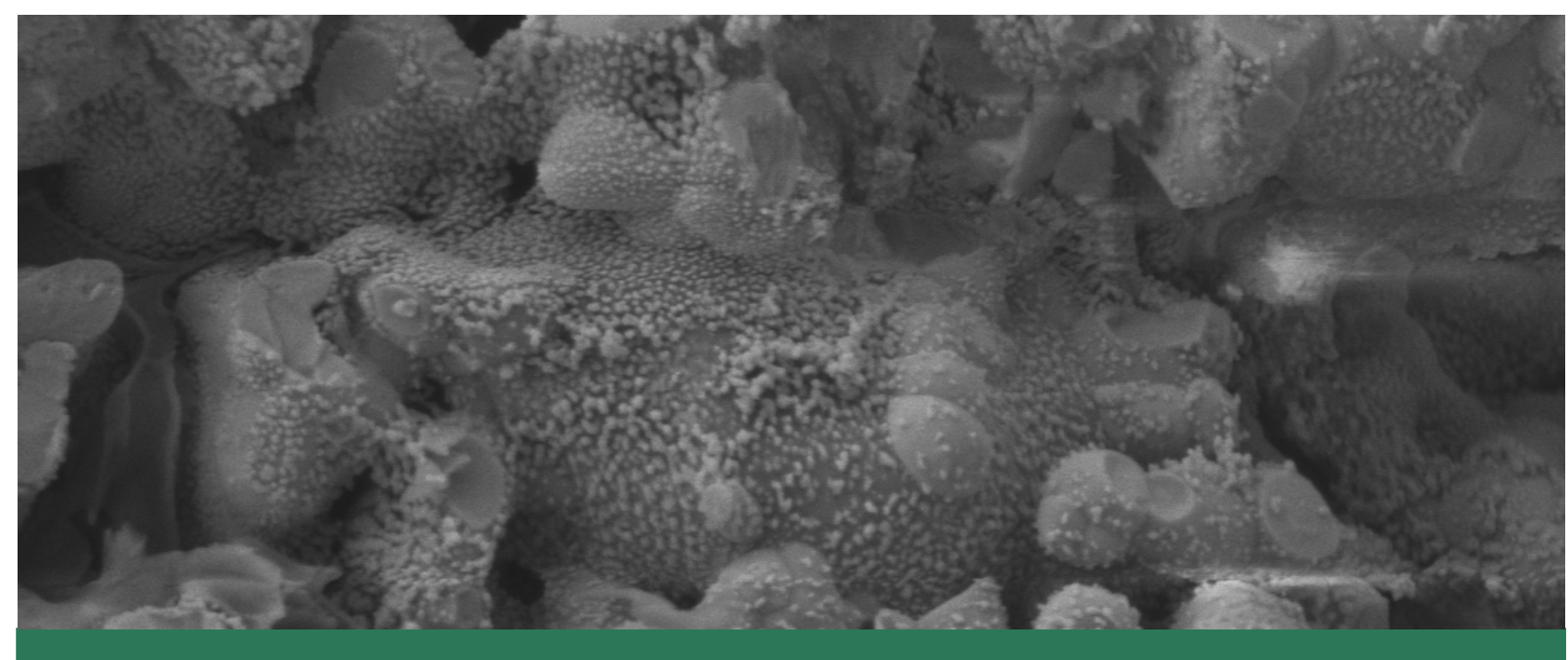

\title{
Development of electrochemical devices for hydrocarbon sensing purposes in car exhaust gases
}

\section{Thesis submitted by}

Fidel Toldrá Reig

To apply for the Degree of Doctor

Supervisor:

Prof. José Manuel Serra Alfaro

Valencia, September 2018

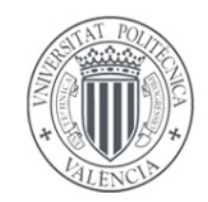

UNIVERSITAT POLITÉCNICA DE VALÈNCIA

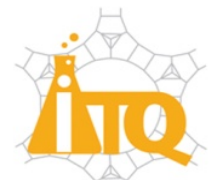

INSTITUTO DE TECNOLOGÍA Q U II M | C A

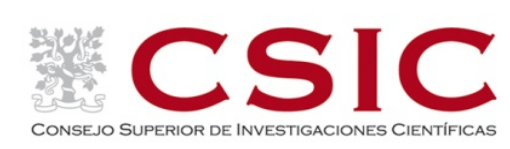




\section{Outline}

\section{Table of Contents}

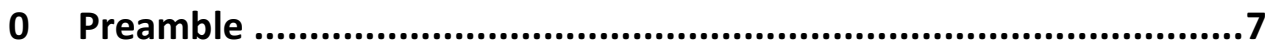

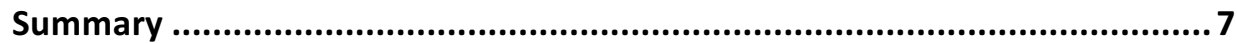

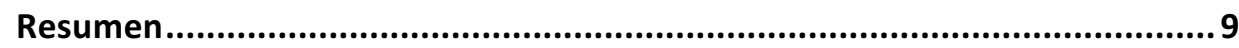

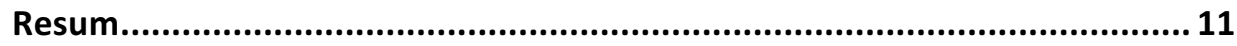

Context and objectives of the Thesis ......................................................... 13

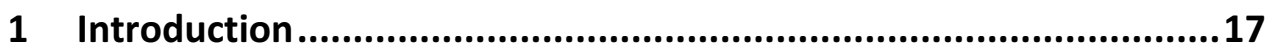

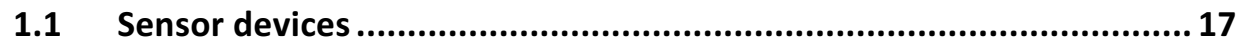

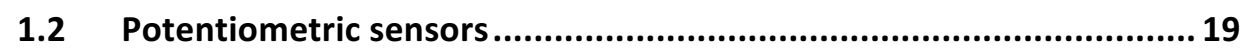

1.2.1 Sensor mechanism: the vacant mechanism ................................. 19

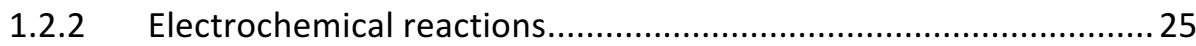

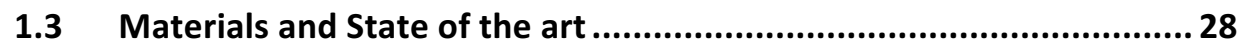

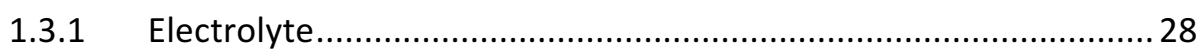

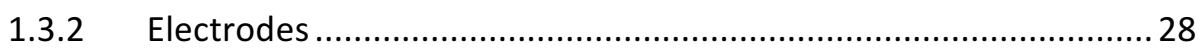

1.4 Electrochemical activation of oxygen ........................................... 31

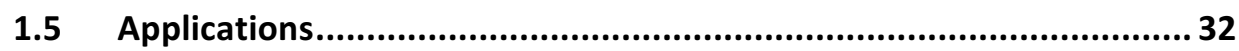

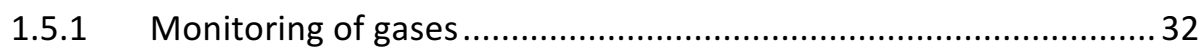

1.5.2 Monitoring of diesel exhaust gases ................................................ 33

1.5.3 Other applications: Industrial gases monitoring............................. 40

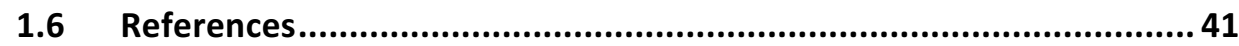

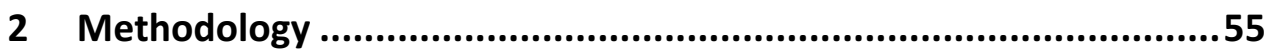

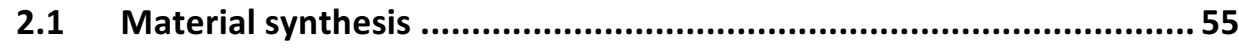

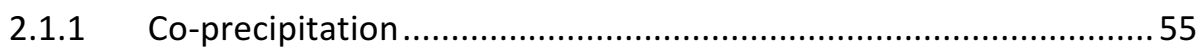

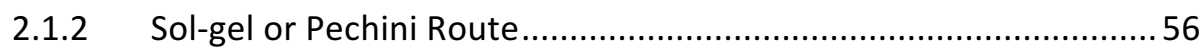

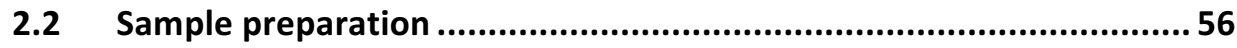

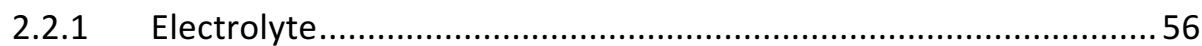

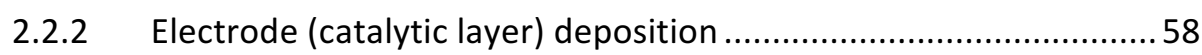

2.3 Structural characterization ..............................................................59

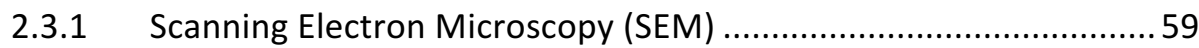

2.3.2 Transmission Electron Microscopy (TEM) ......................................... 60

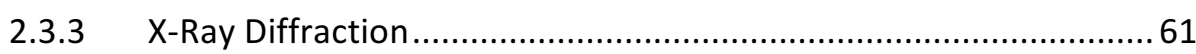




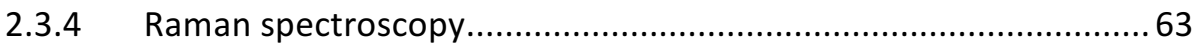

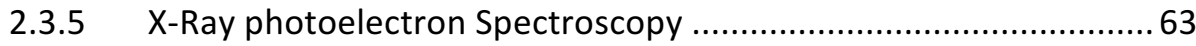

2.4 Electrochemical characterization. Sensor performance .......................64

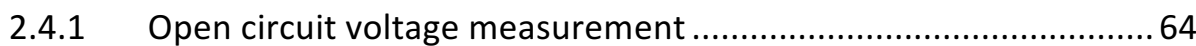

2.4.2 Electrochemical Impedance Spectroscopy (EIS) .............................67

2.4.3 Experimental set-up and sensing............................................... 70

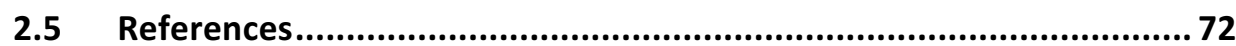

3 Study of working electrode materials for a selective $\mathrm{C}_{2} \mathrm{H}_{4}$ response 77

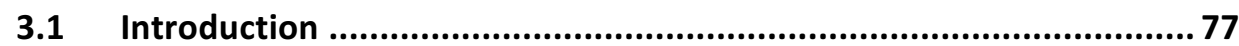

3.2 Device structure and materials selection ........................................ 78

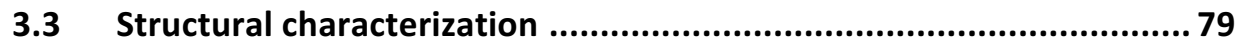

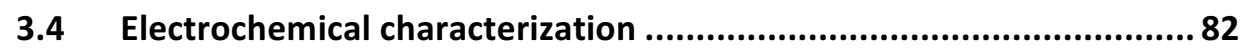

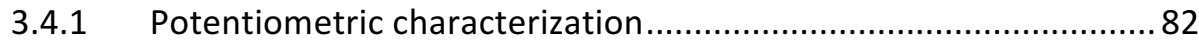

3.4.2 Electrochemical Impedance Spectroscopy ................................... 91

3.5 Device configuration: working electrode material selection ................ 93

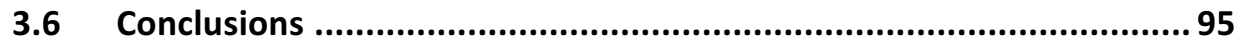

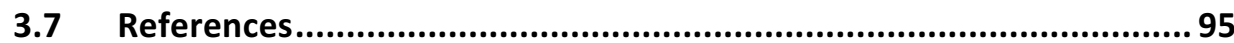

4 Water and polyaromatic hydrocarbons influence on sensor response. Reference Electrode improvement strategies .....................101

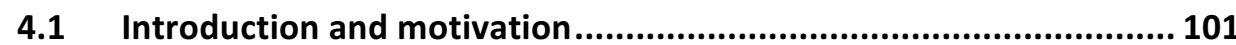

4.2 Water and polyaromatic hydrocarbons influence on sensor response 102

4.2.1 Electrochemical characterization .............................................. 102

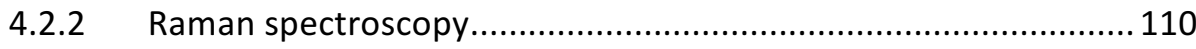

4.3 Reference electrode improvement strategies ................................. 111

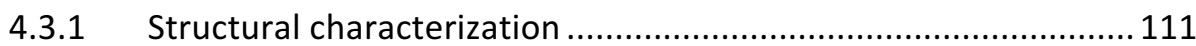

4.3.2 Electrochemical characterization ........................................... 113

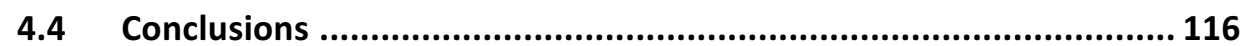

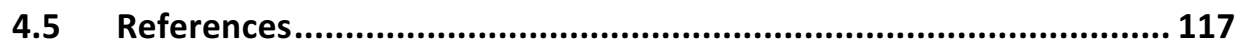

5 Optimization of $\mathrm{Fe}_{0.7} \mathrm{Cr}_{1.3} \mathrm{O}_{3}$ working electrode through surface activation by several compounds nanoparticles deposition ................123

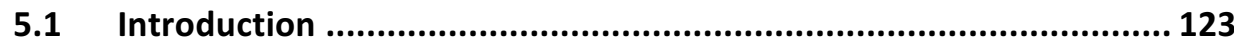

5.2 Selection of materials for surface activation ................................ 124

5.3 Electrochemical characterization .................................................. 125 


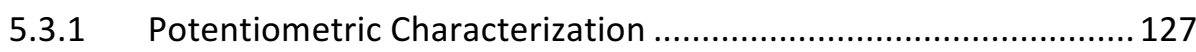

5.3.1.1 First batch: Ni and Ru infiltration ................................................. 127

5.3.1.2 Second batch: Ti and Al infiltration .............................................. 130

5.3.1.3 Third batch: Niobium, barium and palladium infiltration.................... 132

5.3.2 Electrochemical impedance spectroscopy ............................... 135

5.4 Structural characterization ..................................................... 143

5.5 Conclusions ................................................................. 146

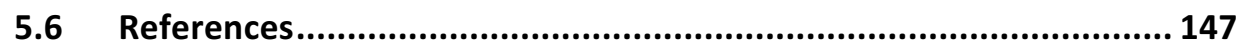

6 Influence of 8YSZ electrolyte thickness on the sensor performance 153

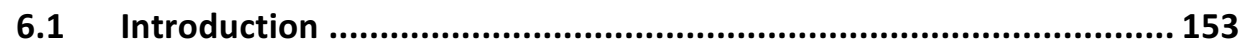

6.2 Electrochemical characterization .................................................. 154

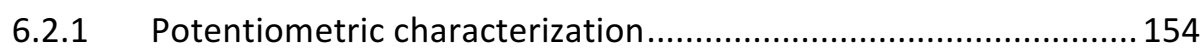

6.2.2 Electrochemical Impedance Spectroscopy ................................159

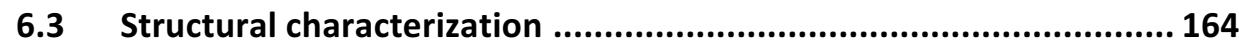

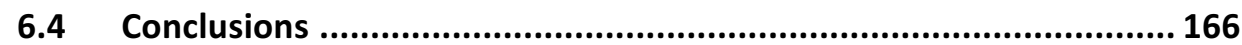

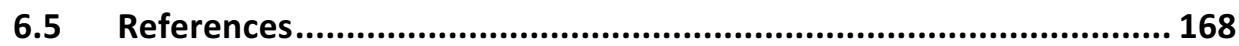

7 Alternatives to 8YSZ as electrolyte: CGO and ScSZ .....................173

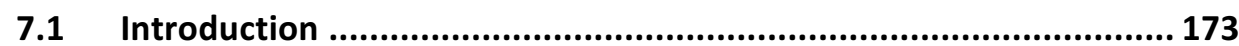

7.2 Electrochemical characterization ................................................... 174

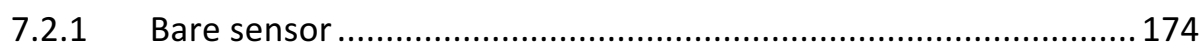

7.2.1.1 Influence of temperature ............................................................... 175

7.2.2 Surface activation of working electrode by nickel nanoparticles 177

7.2.3 Electrochemical impedance Spectrometry............................... 181

7.3 Structural characterization ..................................................... 187

7.4 Conclusions .................................................................... 188

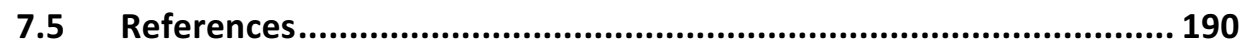

8 Optimization of the sensor performance and mechanism of action 195

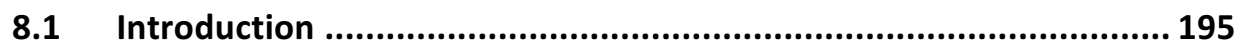

8.2 Mixed conductor electrode and $\mathrm{NO}_{2}$ effect $\mathrm{LSC} / 8 \mathrm{YSZ}$ as Working Electrode ....................................................................................... 197

8.2.1 LSC/8YSZ as working electrode............................................. 197

8.2.1.1 Structural characterization ........................................................... 197

8.2.1.2 Electrochemical characterization .................................................. 198 
8.2.2 $\mathrm{NO}_{2}$ effect on reference configuration sensor.

8.3 Sensor mechanism of action and discussion.................................. 207

8.4 Conclusions ..................................................................... 216

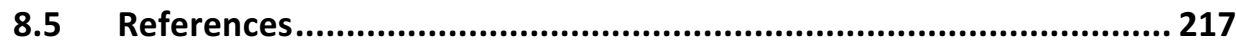

9 Conclusions and remarks..................................................223

10 Acronyms.....................................................................229

11 Figures list...................................................................233

12 Tables list....................................................................... 245

13 Scientific Contribution ..................................................247 
Chapter 0

Preamble 



\section{Preamble}

\section{Summary}

The present thesis is focused on the development of solid-state electrochemical devices for the selective detection of hydrocarbons in car exhaust gases. For this purpose, several materials were tested as electrodes and electrolytes. Catalytic activation of the working electrode has also been taken into account to boost the electrochemical reaction of the target analyte.

Ethylene is one of the most abundant hydrocarbons in an exhaust gas and was selected as the target analyte to quantify the total amount of hydrocarbons. Not only the device has to be selective to ethylene but it must also have a low crosssensitivity toward other pollutants abundant in an exhaust gas such as carbon monoxide, water, other hydrocarbons, nitrogen dioxide, etc. Thus, a solid-state potentiometric sensor was selected based on 8\% Yttria-stabilized Zirconia (8YSZ) as electrolyte. Two electrodes were screen-printed on top of each face.

First, several metal oxides were tested as working electrode with platinum $(\mathrm{Pt})$ as reference electrode at $550^{\circ} \mathrm{C}$. Most of the materials were discarded because of their lack of selectivity to ethylene, high cross-sensitivity toward carbon monoxide or problems regarding stability. $\mathrm{Fe}_{0.7} \mathrm{Cr}_{1.3} \mathrm{O}_{3}$ mixed with $8 \mathrm{YSZ}$ was finally selected as the most promising material because of its selective response to ethylene with relatively low cross-sensitivity toward carbon monoxide.

This sensor configuration was then exposed to water and phenanthrene and methylnaphthalene. This led to an increase of the cross-sensitivity of the device toward carbon monoxide making the device not suitable for the purposes of the present thesis. The approach to improve the sensor performance was to modify the reference electrode. Platinum, usually employed in literature as reference electrode, was exchanged for a mixed ionic-electronic conductor active to oxygen: $\mathrm{La}_{0.8} \mathrm{Sr}_{0.2} \mathrm{MnO}_{3}$ mixed with 8YSZ (LSM/8YSZ). Unfortunately, this increases the device activity toward carbon monoxide increasing its cross-sensitivity.

Several nanoparticles were added onto the working electrode to improve the catalytic activity and boost the electrochemical reaction of ethylene. Nickel, titanium and aluminum (the last two elements combined with nickel) provided the best performance: selectivity to ethylene with low cross-sensitivity toward carbon monoxide, water and phenanthrene. 
The effect of the electrolyte thickness was also checked in the range from 0.1 to $1.2 \mathrm{~mm}$. Although there was not a huge difference between them, the crosssensitivity toward carbon monoxide was slightly lower for the thinnest sensor. Other alternatives to 8YSZ electrolyte were tested at lower working temperatures $\left(400\right.$ to $\left.550^{\circ} \mathrm{C}\right)$ with the same electrodes materials: gadolinium-doped cerium oxide (CGO) and 10\% scandia-stabilized Zirconia (ScSZ). ScsZ-based device showed a good performance in dry conditions but the addition of water decreased its suitability. Once improved the catalytic activity of the working electrode, both devices showed a good performance at lower temperature in dry conditions for ethylene concentration above $100 \mathrm{ppm}$ but the best response was achieved at $550^{\circ} \mathrm{C}$. Both devices were selective to ethylene with low cross-sensitivity toward carbon monoxide, water and phenanthrene.

The effect of mixing the working electrode with an ionic conductor (8YSZ) was also tested in order to check if the good electrode performance was due to the material itself or the increase of the triple phase boundary where the reaction takes place by the addition of an ionic conductor. $\mathrm{La}_{0.87} \mathrm{Sr}_{0.13} \mathrm{CrO}_{3}$ (LSC) was selected because it showed an stable response. After mixing with $8 \mathrm{YSZ}$, the baresensor performance was similar to the bare LSC working electrode, although the ionic conductor could improve the electrode attachment and long-term stability. Finally, the best sensor configuration $\mathrm{Fe}_{0.7} \mathrm{Cr}_{1.3} \mathrm{O}_{3} / 8 \mathrm{YSZ} / / 8 \mathrm{YSZ} / / \mathrm{LSM} / 8 \mathrm{YSZ}$ (after infiltration of the working electrode with nickel) was exposed to nitrogen dioxide to check the cross-sensitivity. This is important as nitrogen dioxide is one of the most common gases in an exhaust gas. The sensor response was still selective to ethylene with a relatively low cross-sensitivity toward nitrogen dioxide and nitrogen dioxide plus water. The sensor mechanism could be explained by the mixed potential theory: when the sensor is exposed to a non-equilibrium system, the kinetics control the device and therefore, a voltage is generated between the controlling reactions in both electrodes. 


\section{Resumen}

En la presente tesis doctoral se han desarrollado dispositivos electroquímicos de estado sólido para la detección selectiva de hidrocarburos en los gases de escape de coches. Diversos materiales fueron empleados para ello. También se llevó a cabo la activación catalítica del electrodo de trabajo para mejorar la reacción electroquímica del analito objetivo.

El etileno fue seleccionado como el analito objetivo para cuantificar la cantidad total de hidrocarburos ya que es uno de los hidrocarburos más abundantes en un gas de escape. Pero el dispositivo no solo debe proporcionar una respuesta selectiva al etileno, sino que también debe tener una baja sensibilidad cruzada a otros compuestos también abundantes en un gas de escape como monóxido de carbono, agua, dióxido de nitrógeno, etc. El dispositivo consiste en un sensor potenciométrico de estado sólido en el que óxido de zirconio estabilizado con $8 \%$ de óxido de itrio (8YSZ) es empleado como electrolito. Dos electrodos son impresos en la superficie de cada cara.

Primero, diversos óxidos fueron empleados como electrodo de trabajo utilizando a su vez platino como electrodo de referencia a $550^{\circ} \mathrm{C}$. Muchos de los materiales fueron descartados por su falta de selectividad al etileno, su alta sensibilidad cruzada al monóxido de carbono o por su respuesta no estable. Finalmente, $\mathrm{Fe}_{0.7} \mathrm{Cr}_{1.3} \mathrm{O}_{3}$ mezclado con $8 \mathrm{YSZ}$ fue seleccionado como el material más prometedor dada su buena selectividad al etileno con baja sensibilidad cruzada al monóxido de carbono.

Esta configuración fue así expuesta a su vez tanto a agua como a fenantreno y metilnaftaleno. Esto produjo un aumento de la sensibilidad cruzada del dispositivo al monóxido de carbono, motivo por el que el sensor no sea adecuado para los objetivos de esta tesis. La estrategia adoptada consistió en actuar sobre el electrodo de referencia. El Platino, empleado habitualmente en la bibliografía como electrodo de referencia, fue cambiado por un conductor mixto iónicoelectrónico activo al oxigeno: $\mathrm{La}_{0.8} \mathrm{Sr}_{0.2} \mathrm{MnO}_{3}$ mezclado con $8 \mathrm{YSZ}$ (LSM/8YSZ). Desgraciadamente, esto provocó un aumento de la sensibilidad cruzada al monóxido de carbono.

Diversas nanopartículas fueron añadidas en el electrodo de trabajo para mejorar la actividad catalítica y aumentar la reacción electroquímica al etileno. Níquel, titanio y aluminio (especialmente la combinación de los dos últimos con níquel) dieron la mejor respuesta: el sensor era selectivo al etileno con baja sensibilidad cruzada al monóxido de carbono, agua y fenantreno. 
El efecto del espesor del electrolito en la respuesta del sensor también fue evaluado en un rango de $0.1 \mathrm{a} 1.2 \mathrm{~mm}$. Aunque no había una gran diferencia en la respuesta, la sensibilidad cruzada al monóxido de carbono era menor en el caso del dispositivo más fino. Otras alternativas al $8 Y S Z$ como electrolito también fueron evaluadas para trabajar a menores temperaturas $\left(400\right.$ a $\left.550^{\circ} \mathrm{C}\right)$ : oxido de cerio dopado con gadolinio (CGO) y óxido de zirconio estabilizado con un $10 \%$ de óxido de escandio (ScSZ). El dispositivo basado en ScSZ mostró un buen comportamiento a etileno a bajas temperaturas y en condiciones secas pero la adición de agua provocaba un aumento de la sensibilidad cruzada al monóxido de carbono. Una vez infiltrado el electrodo de trabajo con níquel, ambos dispositivos mostraron un buen comportamiento a bajas temperaturas en condiciones secas para concentraciones de etileno inferiores a $100 \mathrm{ppm}$, aunque la mejor respuesta fue obtenida a $550^{\circ} \mathrm{C}$. Ambos dispositivos mostraron una respuesta selectiva al etileno con baja sensibilidad cruzada al monóxido de carbono, agua y fenantreno.

Se estudió también el efecto de mezclar el electrodo de trabajo con un conductor iónico (8YSZ) para observar si la respuesta obtenida era debida al material mismo o por el incremento del punto triple de contacto (TPB), donde la reacción tiene lugar al añadir un conductor iónico. $\mathrm{La}_{0.87} \mathrm{Sr}_{0.13} \mathrm{CrO}_{3}$ (LSC) fue seleccionado porque mostró una respuesta estable. Una vez mezclado con $8 Y S Z$, la respuesta fue similar a la obtenida para el electrodo que solo contenía LSC, aunque la adición del conductor iónico puede mejorar la adherencia al electrolito y la estabilidad a largo plazo.

Finalmente, se comprobó la sensibilidad cruzada al dióxido de nitrógeno de la mejor configuración probada, $\mathrm{Fe}_{0.7} \mathrm{Cr}_{1.3} \mathrm{O}_{3} / 8 \mathrm{YSZ} / / 8 \mathrm{YSZ} / / \mathrm{LSM} / 8 \mathrm{YSZ}$, (después de infiltrar con níquel el electrodo de trabajo). Esto es importante ya que el dióxido de nitrógeno es uno de los elementos más comunes en un gas de escape de un coche. El sensor proporcionó una respuesta selectiva al etileno con una relativamente baja sensibilidad cruzada al dióxido de nitrógeno, solo o con agua. El mecanismo del sensor puede ser explicado por la teoría del potencial mixto: cuando el sensor se expone a una atmósfera con gases que no están en equilibrio, las cinéticas controlan el dispositivo y, por tanto, el voltaje generado se establece entre las reacciones cinéticamente favorecidas en cada electrodo. 


\section{Resum}

En la present tesi doctoral s'han desenvolupat dispositius electroquímics d'estat sòlid per a la detecció selectiva d' hidrocarburs als gasos d'escapament dels automòbils. Diversos materials van ser empleats per a tal fi. També es va dur a terme l'activació catalítica de l'elèctrode de treball per a millorar la reacció electroquímica al anàlit objectiu.

L' etilè va ser seleccionat com anàlit objectiu per a quantificar la quantitat total d' hidrocarburs, ja que és un dels hidrocarburs més abundants en un gas d'escapament. Però el dispositiu no ha de ser tan sols selectiu a l'etilè, sinó que també deu proporcionar una baixa sensibilitat creuada a altres elements força abundants en un gas d'escapament com són el monòxid de carboni, l'aigua, el diòxid de nitrogen, etc. Així, el dispositiu consisteix en un sensor potenciomètric d'estat sòlid en el que l'òxid de zirconi estabilitzat amb un $8 \%$ d'òxid d'itri (8YSZ) és empleat como a electròlit. Els elèctrodes van impresos a cadascuna de les superfícies del dispositiu.

Primer, diversos òxids es van emprar com a elèctrode de treball fent servir platí com elèctrode de referència a $550^{\circ} \mathrm{C}$. Molts dels materials van ser descartats per motiu de la seva manca de selectivitat al etilè, la seva alta sensibilitat creuada al monòxid de carboni o perquè la resposta no era estable. Finalment, el $\mathrm{Fe}_{0.7} \mathrm{Cr}_{1.3} \mathrm{O}_{3}$ mesclat amb $8 \mathrm{YSZ}$ va ser seleccionat com el material més prometedor atès a la selectivitat a l'etilè i la baixa sensibilitat creuada al monòxid de carboni.

Aquesta configuració és doncs exposada tant a l'aigua com al fenantrè i al metilnaftalè. Això va produir un increment de la sensibilitat creuada al monòxid de carboni, fent que el dispositiu no resulti idoni per als objectius de la present tesi. Es va adoptar com a estratègia modificar l'elèctrode de referència. Platí, empleat sovintment com a elèctrode de referència a la bibliografia, va ser canviat per un conductor mixt iònic-electrònic actiu a l'oxigen: $\mathrm{La}_{0.8} \mathrm{Sr}_{0.2} \mathrm{MnO}_{3}$ mesclat amb 8YSZ (LSM/8YSZ). Malauradament, això va provocar l'augment de la sensibilitat creuada al monòxid de carboni.

Diverses nanopartícules van ser afegides al elèctrode de treball per tal de millorar la seva activitat catalítica i així augmentar la reacció electroquímica de l'etilè. Níquel, titani i alumini (especialment la combinació dels dos darrers amb níquel) van donar la millor resposta: el sensor era selectiu a l'etilè amb una baixa sensibilitat creuada al monòxid de carboni, l'aigua i al fenantrè. 
L'efecte del espessor del electròlit a la resposta del sensor també va ser avaluada en un rang de 0.1 a $1.2 \mathrm{~mm}$. Malgrat que no hi ha una gran diferència en la resposta, la sensibilitat creuada al monòxid de carboni és menor en el cas del dispositiu més prim. Altres alternatives al 8YSZ com a electròlit van ser també avaluades per tal de treballar a temperatures menors $\left(400\right.$ a $\left.550^{\circ} \mathrm{C}\right)$ : òxid de ceri dopat amb gadolini (CGO) i òxid de zirconi estabilitzat amb un $10 \%$ d'òxid d'escandi (ScSZ).

El dispositiu basat en ScSZ va mostrar un bon comportament a l'etilè a baixes temperatures en condiciones seques, però la adició d'aigua provocava un augment de la sensibilitat creuada al monòxid de carboni. Una vegada que l'elèctrode de treball es infiltrat amb níquel, ambdós dispositius mostraren un bon comportament a baixes temperatures en condicions seques per a concentracions d'etilè menors de $100 \mathrm{ppm}$, encara que la millor resposta fou obtinguda a $550^{\circ} \mathrm{C}$. La resposta era selectiva a l'etilè amb una baixa sensibilitat creuada al monòxid de carboni, l'aigua i el fenantrè.

Es va comprovar també l'efecte de mesclar l'elèctrode de treball amb un conductor iònic (8YSZ) per esbrinar si la resposta obtinguda és deguda al material mateix o és deguda a l' increment del punt de triple contacte (TPB), on la reacció té lloc, al afegir un conductor iònic. $\mathrm{La}_{0.87} \mathrm{Sr}_{0.13} \mathrm{CrO}_{3}$ (LSC) va ser seleccionat perquè va mostrar una resposta estable anteriorment. Una vegada mesclat amb el 8YSZ, la resposta obtinguda va ser semblant a la resposta del LSC tot sol, no obstant això, la adició del conductor iònic pot millorar la adherència al electròlit i la estabilitat a llarg terme.

Finalment, es va comprovar la sensibilitat creuada al diòxid de nitrogen de la millor configuració emprada, $\mathrm{Fe}_{0.7} \mathrm{Cr}_{1.3} \mathrm{O}_{3} / 8 \mathrm{YSZ} / / 8 \mathrm{YSZ} / / \mathrm{LSM} / 8 \mathrm{YSZ}$, (una vegada infiltrat amb níquel l'elèctrode de treball). Això es força important ja que el diòxid de nitrogen és un dels compostos més abundants als gasos d'escapament. El sensor va proporcionar una resposta selectiva a l'etilè amb una relativament baixa sensibilitat creuada al diòxid de nitrogen, a més d'aquest conjuntament amb aigua. El mecanisme del sensor pot ser explicat per la teoria del potencial mixt: si el sensor es troba en una atmòsfera on els gasos no estan en equilibri, les cinètiques controlen el dispositiu i el voltatge generat s'estableix entre les dos reaccions cinèticament més afavorides en cada elèctrode. 


\section{Context and objectives of the Thesis}

Car exhaust gas emissions consists essentially of nitrogen, carbon monoxide, water, oxygen and a small fraction of $\mathrm{CO}, \mathrm{HCs}, \mathrm{NO}, \mathrm{PM}$, etc. Although the release of these pollutants into the environment is small for a simple car, a large amount of cars (i.e. as in cities) has a direct impact in human health and is a serious concern for health agencies of the European union as well as the United States of America. Most of these compounds are related with breath diseases or are cancerogenic and/or mutagenic. Long term exposure to exhaust gases is related with a risk of developing lung cancer. Moreover, these compounds can have a lethal effect on persons with previous breathing problems. For this reason, from the early 90 s both European and North American agencies have restricted the emission of these pollutants into the environment. The restrictions are becoming more and more stringent over the years just as the available technology allows to detect lesser concentration of the pollutants or to reduce the emission. Thus, the development of the Diesel Oxidation Catalyst, Diesel Particles Filter or the Selective Catalytic Reduction have considerably reduced the amount of pollutants in the exhaust gas. Nevertheless, as far as human health is involved, a further decrease of these compounds is required.

Miniaturized sensors for in-situ measurements at high temperature environments are required in order to achieve the restriction limits imposed by law. While $\mathrm{CO}$ sensors are widely known and they are reliable, $\mathrm{NO}_{\mathrm{x}}$ sensors are not fully reliable yet. Volkswagen emission scandal broke that most of the current cars are not able to achieve the legislation limits. Further developments should be performed.

In the case of hydrocarbons, currently there is no commercial sensor available to accomplish the legislation yet. The total amount of hydrocarbons is measured by combustion with no discrimination of the kind of HCs. Most hydrocarbons and mainly the polycyclic aromatic hydrocarbons are cancerogenic or mutagenic. Thus, there is an urge to develop a sensor capable to detect such compounds and it could lead to further restriction in future legislations.

The present PhD Thesis is focused on the development of a potentiometric sensor selective to hydrocarbons. Ethylene has been selected as the target gas because it is one of the major hydrocarbons in a car exhaust gas. The detection of this element could be used to quantify the total amount of HCs. However, other hydrocarbons as well as carbon monoxide, which is eliminated in a similar way, should be considered in the sensor performance as it can have a cross sensitivity toward these elements. 
For this aim, a solid-state based ionic device is employed because of the high temperature and harsh environment. Several materials with a promising catalytic activity are used as both working and reference electrode under an atmosphere imitating exhaust gas conditions. Besides the study of these materials, the influence of temperature, electrolyte thickness and catalytic activity are studied as well. The specific objectives of this Thesis are:

- Selection of the most promising materials as working electrode for ethylene detection

- Alternatives to the usual platinum used in literature as reference electrode to more active materials to oxygen reduction

- Optimization of the sensor response to achieve a selective response to ethylene with low cross-sensitivity toward carbon monoxide and other pollutants.

- Selection of the best elements for the catalytic activation of electrodes Study of the influence of the electrolyte thickness on the sensor response

- Evaluation of the possible use of alternative materials to 8YSZ which may allow lower working temperature 
Chapter 1

Introduction 



\section{Introduction}

\subsection{Sensor devices}

Sensor devices able to detect hydrocarbons or carbon monoxide in conditions, such as diesel exhaust gas, must face rough conditions in terms of temperature and contamination. The exhaust gas can achieve temperatures up to $900^{\circ} \mathrm{C}$ before the diesel catalyst oxidation. Furthermore, there are several noncombusted components like polycyclic aromatic hydrocarbons, carbon monoxide, nitrogen oxides, formaldehyde, etc. that can affect the sensor signal. Thus, sensors must be tough and stable enough to work under these conditions. Solid state devices are the most suitable option as they consist of a tough and dense ceramic solid electrolyte that provides good properties to work properly inside a diesel engine.

In this thesis, ethylene is selected as the target gas to detect hydrocarbons in a diesel exhaust gas. However, as aforementioned the sensor response must have a low cross sensitivity towards other gases in an exhaust gas. Thus, the best kind of sensor to ensure this aim as well as the most promising materials have to be evaluated in order to select the most promising configuration.

Any chemical sensor must fulfill some characteristics in order to provide a good performance. The following are the characteristics employed to characterize our devices [1-4]:

- Selectivity: is defined as the ability of the sensor to response to the analyte. The sensor should be selective to the analyte.

- Sensitivity: is defined as the relation between a physical/chemical input and an output electrical signal. The change in response with an increase of the concentration of the analyte should be as large as possible.

- Cross sensitivity: is defined as the interference in the sensor signal to the analyte due to other compounds.

- Response time: is defined as the response time of the sensor. Usually $t_{90}$ is employed, that means the time necessary to reach a $90 \%$ of the final response. A superb response time should be less than 10 seconds while an acceptable response time should be less than 30 seconds. 
Several chemical sensors are suitable for the detection of pollutants in gas streams and can be divided into the following options:

- Electrochemical sensors: These sensors consist of an electrolyte that contains electroactive species and two electrodes (working and reference electrode) on each face of the electrolyte where the reactions take place [5]. These sensors can be divided into:

- Potentiometric sensor: In this kind of sensors the measurement is made under zero current condition. Thus, the difference in voltage between both electrodes is recorded when the sensor is exposed to the target gas [6-14]. Simplicity, familiarity and cost make them one the best options.

- Amperometric sensor: This sensor is similar to potentiometric sensors but in this case a constant voltage is applied recording the current generated [15-19]. When the voltage is applied, electroactive species in the electrolyte are active and reactions take place in both electrodes. Therefore, velocity of slow electrochemical reactions could be increased.

- Impedancemetric sensor: This employs AC measurements at a specified range of frequencies. The design of the sensor is similar to both potentiometric and amperometric sensors, but instead of measuring voltage or current, a sinusoidal voltage is applied and the resulting current is measured. This sensor generates significant information about the processes taking place in the sensor. It can allow to understand the mechanism and detect selectively the target gas [20-26]. It can provide a huge amount of information however, the main drawback is that this is a technique usually hard to interpret, and more expensive than other alternatives.

- Optical sensors: In this kind of sensors electromagnetic radiation is passed through the exhaust gas. Interaction of this radiation with the analytes will change some optical parameters that could be related to the concentration of the analyte [27-33]. Unfortunately, this kind of sensors are either too expensive to be used in a car or are not adequate in terms of size.

The main focus of this thesis are the potentiometric sensors as these sensors are the most promising option to work in harsh conditions like exhaust gases and they are economically more viable than impedancemetric and optical sensors. However, impedancemetric measurements were carried out in this thesis for a better understanding of the potentiometric sensors employed. 


\subsection{Potentiometric sensors}

This kind of sensor is the most suitable option in terms of feasibility, simplicity and cost, and it is usually found in literature because of its toughness and high temperature resistance. They can work in a wider range of temperatures between $450-900^{\circ} \mathrm{C}$. In addition, there is another advantage: both electrodes can be exposed to the same atmosphere. Thus, there is no need to seal the reference electrode to expose it to a different atmosphere rich in oxygen.

A solid state ionic-based device is employed to meet the toughness requirements. Working and reference electrodes are on top of each face and they should be selective to the target gas and oxygen respectively.

\subsubsection{Sensor mechanism: the vacant mechanism}

The performance of the electrolyte is stablished by the mechanism and kinetics of the ionic conductor lattice and the oxygen from the environment. The charge transfer between oxygen and the electrolyte takes place in the triple phase boundary. This is the point where electrolyte, electrode and gas contact. In solidstate ionic conductors, the charge transfer is effectuated by ionic oxygen. Ionic conduction in solids is carried out by the movement of oxygen ions through the crystal lattice and this is possible because of the existence of some point defects in the lattice. Thus, the movement of these oxygen ions from the reference electrode to the working electrode takes place via interstitial sites or by hopping from vacancy to vacancy in the lattice or by a mixture of both phenomena [34].

According to this, only the existence of these defect points in the solid ionic conductor allows the ionic conductivity and therefore the sensing purposes. There are three different ways of creating this kind of defects in the ionic conductor: thermal excitation, change in the stoichiometry and doping with aliovalent cations whose charge-state is relative to the ion their substitute.

\section{Defect theory}

We have two kinds of defects: intrinsic and extrinsic. The intrinsic defect is inherent to the equilibrium state of the crystal. The thermal excitement of the material can produce Schottky or Frenkel defects moving the smaller ion from the lattice to an interstitial site (figure 1.1). Frenkel defects consist of a lattice vacancy and an interstitial defect, since the ion is displaced from its lattice position to an interstitial site creating a defect at the new location and a vacancy defect on its original position. Schottky defects are lattice vacancies which provide available vacancies for the ions to move through. The temperature should be high enough 
to achieve the equilibrium concentration of defects in appropriate times. However, there is a set of conservation rules that must be satisfied: the conservation of mass, charge, structure and electronic states.

a)

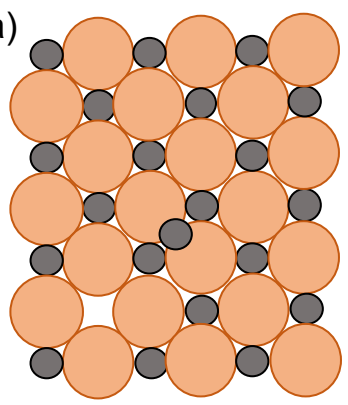

b)

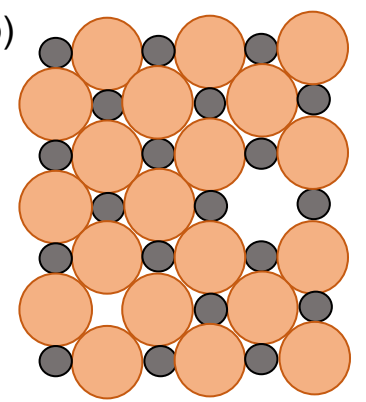

Figure 1.1 Scheme of defects in a molecule. a) Frenkel defect with one cation missing. b) Schottky defect with a pair of ions missing

The thermal excitation of electrons from the chemical bond to higher energy states causes the intrinsic electronic disorder. In a stoichiometric oxide material, the ground state corresponds to a nominally filled valence and a nominally empty conduction band. This excitation process of the electron allows it going across the band gap to the conduction band where it can move freely through the empty states. Nevertheless, this also leaves an empty electronic state at the top of the valence band that also allows charge transport. Adjacent electrons can move into this hole or empty state. Thus, after successive electron movements, the hole can move laterally in the opposite direction of the electrons in the conduction band acting as a particle with positive charge and mass.

The electronic conduction in most oxides is less uninhibited than holes and it takes place by the hopping mechanism: the electrons move by discrete jumps between localized states. An increase in temperature increases the jump, and therefore the electronic mobility.

An excess of holes or electrons on the localized centers can distort the lattice and produce a polarization of the surroundings ions, leading to self-trapping (small polaron). In this small polarons, the polarization cloud must travel with the carrier. On the other hand, large polarons have weaker bindings and longer distance distortions, and therefore the polarization is less significant.

Ionic defects due to extrinsic disorder involve the presence of an impurity ion that is dissolved into the lattice [35]. This is introduced when a change in the stoichiometry of the material modifies the composition, as it introduces either 
oxygen vacancies or interstitial oxygen in the structure. The substitution of the main ion by an isovalent impurity does not require extrinsic defects for charge compensation. But the substitution of the host by an aliovalent introduces changes in the structure and therefore oxygen vacancies and/or interstitial oxygen to maintain the charge neutrality of the crystal. The vacancies should appear from one of the solid-state sublattices. The two atoms should have a small difference of atomic radii and electronegativity and the number of valence electron should be similar. There are two kinds of extrinsic ionic defect: donor impurities (positively charged) providing either cation vacancies or anion interstitials; and acceptor impurities (negatively charged) providing cation interstitials or anion vacancies. Usually only one of them takes place.

The interaction of the doped-crystal with the ambient should be taken into account as a thermodynamic equilibrium will be achieved by electronic compensation introducing the extrinsic electronic disorder. Interaction between atmosphere and the doped-crystal imply either a gain or loss of the non-metallic constituent until the ionic defects introduced by the impurity have been replaced by electrons or holes of equivalent charge. Subsequently, the material is not stoichiometric anymore leading to intrinsic non-stoichiometric disorder.

Then, in reduction atmospheres the oxide material reacts with the atmosphere losing oxygen while in oxidizing atmospheres the oxide materials react with the atmosphere incorporating oxygen to the lattice. When adding an acceptor impurity, oxygen will enter in the lattice by taking two electrons from the valence band and leaving two compensating holes as overall result. While adding donor impurities has the effect of electrons leaving after the loss of the oxygen excess relative to the host lattice.

Below there is a summary if the defect reaction compensation of donor and acceptor.

\section{$\underline{\text { Donor }}$}

$D_{M}^{x} \leftrightarrow D_{M}^{\cdot}+e^{\prime}$

$K_{D}(T)\left[D_{M}^{x}\right]=\left[D_{M}\right] \cdot n$

A donor impurity with a positive charge $\left(D_{M}^{-}\right)$is compensated by an electron (e') 
$\underline{\text { Acceptor }}$

$$
\begin{aligned}
& A_{M}^{x} \leftrightarrow A_{M}^{\prime}+h \\
& K_{A}(T)\left[A_{M}^{x}\right]=\left[A_{M}^{\prime}\right] \cdot p
\end{aligned}
$$

An acceptor impurity with a negative charge $\left(A_{M}^{\prime}\right)$ is compensated by an electron hole $\left(h^{\prime}\right)$.

\section{$\underline{\text { Reduction atmospheres }}$}

The exposure of the material to low oxygen partial pressures leads to the reduction of the material by the generation of oxygen vacancies that retain two electrons and release $\mathrm{O}_{2}$.

$O_{o}^{x} \leftrightarrow \frac{1}{2} O_{2}+V_{o}^{*}+2 e^{\prime}$

$K_{R}(T)=p O_{2}^{\frac{1}{2}}\left[V_{O}^{\prime \prime}\right] n^{2}$

\section{Frenkel equilibrium on the oxygen sublattice}

$O_{o}^{x} \leftrightarrow V_{o}^{\prime \prime}+O_{i}^{\prime \prime}$

$K_{F}(T)=\left[V_{O}^{\prime \prime}\right]\left[O_{i}^{\prime \prime}\right]$

The creation of an oxygen vacancy in the lattice is compensated by an interstitial oxygen $\left(O_{i}^{\prime \prime}\right)$.

\section{Electronic equilibrium}

$n i l \leftrightarrow e^{\prime}+h$

$K_{e}=n \cdot p$

In electronic equilibrium conditions, the electrons on the lattice are balanced by electron holes.

Finally, extrinsic nonstoichiometry happens when the aliovalent impurity content exceed the concentration of any resulting from intrinsic disorder. The predominant 
kind of carrier depends on changes of oxygen concentration or temperature. Thus, there are four defects regions: reduction, ionic compensation, electronic compensation and oxidation. There are some ways to know the functional dependences of some of the defects by experimental measurements e.g. the equilibrium electrical conductivity or diffusion constants as function of temperature or oxygen activity.

Kröger-Vink diagram is a defect-model which tries to fit the results into a consistent model. This model usually represents the concentration of defects as a function of oxygen pressure. Therefore, it allows identifying the dominant defect in our material in either oxidizing or reducing atmospheres. The relation between electrical conductivity and oxygen concentration or temperature indicates which defect is dominating [36]. In most materials, the predominant defect change as a function of the oxygen concentration as shown in figure 1.2, where three different regions can be appreciated (low, mid and high oxygen partial pressure). In each condition, there is a different predominant defect and the electroneutrality condition should be taken into account:

$$
2\left[V_{o}^{\prime \prime}\right]+p \leftrightarrow 2\left[O_{i}^{\prime \prime}\right]+n
$$

In the first region of low oxygen partial pressure (Region I), equation 1.11 can be approximated to:

$$
n=2\left[V_{o}^{*}\right]
$$

In the second region, there is less reduction conditions and the material is near to stoichiometry. Two limiting conditions appear: ionic Frenkel disorder and electron holes generation [37]. When $\mathrm{K}_{\mathrm{e}}>\mathrm{K}_{\mathrm{F}}$ the intrinsic ionization of electrons predominates and electrons and electron holes are independent of oxygen $(n=p)$. On the other hand, when $\mathrm{K}_{\mathrm{F}}>\mathrm{K}_{\mathrm{e}}$ the Frenkel disorder predominate and equation $\mathrm{x}$ can be simplified to $\left[V_{0}^{\prime \prime}\right]=\left[O_{i}^{\prime \prime}\right]$, being both independent of oxygen partial pressure. Finally, in the region of high oxygen partial pressure (region III), the interstitial oxygen is the predominant element and therefore equation 1.11 can be described as:

$$
p=2\left[O_{i}^{\prime \prime}\right]
$$

Equations 1.6, 1.8 and 1.10, along with the simplified equations described for each region, allows us to calculate the dependence of oxygen partial pressure in each region (table 1.1). 
According to table 1.1, in the region I electrons and oxygen vacancies are the dominant effects. However, the material shows an electronic conductivity because of the higher mobility of the electrons compared to oxygen vacancies. Thus, in reduction conditions the material has a n-type conductivity with a $\mathrm{pO}_{2}^{-1 / 6}$ dependence. In region II, where there are lesser reduction conditions, whether the oxygen defects concentration is independent of oxygen partial pressure, the electronic carriers has a dependence of $\mathrm{pO}_{2}^{1 / 4}$ for electrons and $p \mathrm{O}_{2}^{-1 / 4}$ for electron holes. On the other hand, when the electronic carriers are independent of the oxygen partial pressure, $\left[\mathrm{O}_{i}^{\prime \prime}\right]$ and $\left[\mathrm{V}_{O}^{\prime \prime}\right]$ have a $\mathrm{pO}_{2}^{1 / 2}$ and $\mathrm{pO}_{2}^{-1 / 2}$ dependence on oxygen partial pressure respectively. Finally, in region III electron holes and oxygen interstitial are the predominant defects. As in the region I, the electronic conductivity prevails over ionic because of the higher mobility of the electron holes. Thus, the material has a p-conductivity with a $\mathrm{pO}_{2}^{1 / 6}$ dependence.

Table 1.1 Region dependent equations for defect species concentration in Frenkel disorder oxides

\begin{tabular}{|c|c|c|c|c|}
\cline { 2 - 5 } \multicolumn{1}{c|}{} & Region I & \begin{tabular}{c} 
Region II \\
Reduction \\
compensation \\
\hline $\begin{array}{c}\text { Neutrality } \\
\text { equations }\end{array}$
\end{tabular} & $\begin{array}{c}\text { Region II } \\
\text { lonic } \\
\text { compensation }\end{array}$ & Region III \\
\hline $\mathbf{n}$ & $\left(2 K_{R}\right)^{1 / 3} p O_{2}^{-1 / 6}$ & $K_{e}^{1 / 2}$ & $K_{R}^{1 / 2} K_{F}^{-1 / 4} p O_{2}^{-1 / 4}$ & $\left(\frac{K_{R} K_{e}}{2 K_{F}}\right)^{1 / 3} p O_{2}^{-1 / 6}$ \\
\hline $\mathbf{p}$ & $K_{e}\left(2 K_{R}\right)^{-1 / 3} p O_{2}^{1 / 6}$ & $K_{e}^{1 / 2}$ & $K_{e}\left(\frac{K_{F}^{1 / 2}}{K_{R}}\right)^{1 / 2} p O_{2}^{1 / 4}$ & $\left(\frac{2 K_{F} K_{e}^{2}}{K_{R}}\right)^{1 / 3} p O_{2}^{1 / 6}$ \\
\hline$\left[\boldsymbol{V}_{\boldsymbol{o}}\right]$ & $\frac{\left(2 K_{R}\right)^{1 / 3}}{2} p O_{2}^{-1 / 6}$ & $\frac{K_{R}}{K_{e}} p O_{2}^{-1 / 2}$ & $\left.K_{i}^{\prime \prime}\right]$ & $n=\left[O_{i}^{\prime \prime}\right]$ \\
\hline$\left[\boldsymbol{O}_{\boldsymbol{i}}^{\prime \prime}\right]$ & $2 K_{F}\left(2 K_{R}\right)^{-1 / 3} p O_{2}^{1 / 6}$ & $\frac{K_{F} K_{e}}{K_{R}} p O_{2}^{1 / 2}$ & $K_{F}^{1 / 2}$ & $K_{R}^{1 / 3}\left(\frac{2 K_{F}}{K_{e}}\right)^{2 / 3} p O_{2}^{-1 / 6}$ \\
\hline
\end{tabular}



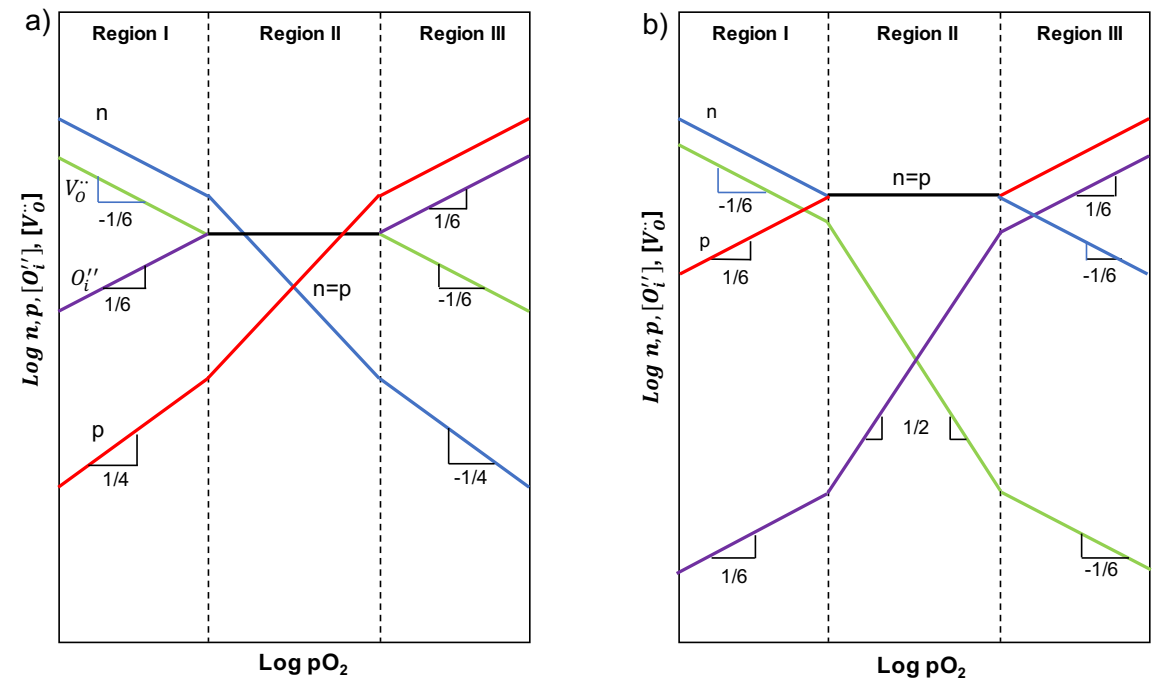

Figure 1.2 Concentration of ionic defects vs $\mathrm{pO}_{2}$ when: a) Oxygen Frenkel defects dominates $\left(K_{F}>K_{e}\right)$, b) intrinsinc ionization dominates $\left(K_{e}>K_{F}\right)$

Therefore, the conductivity will be total contribution of all charge carriers (ionic, electronic and holes) (eq. 1.14).

$$
\sigma_{T}=\sigma_{i}+\sigma_{n}+\sigma_{p}(1.14)
$$

\subsubsection{Electrochemical reactions}

\section{Nernstian behavior}

The Nernstian behavior is observed in equilibrium sensors, where all the electrons are produced in an oxidation reaction and are consumed by a reduction reaction (oxidation and reduction reaction are the same but in opposite directions). The generation of a voltage in the cell is due to movement of the oxygen ions through the solid electrolyte from the reference electrode to the working electrode. At a high temperature, there is a thermodynamic equilibrium between the gaseous oxygen, the oxygen ions and the electrons in the electrode.

In an Oxygen sensor, which is well known, the following equilibrium will be achieved in each electrode:

$$
O_{2}(\text { gas })+V_{\ddot{0}}+4 e^{-} \leftrightarrow 2 O^{2-}(1.15)
$$


Where $V_{o ̈}$ is a positive charged oxygen vacancy. Electronic charge transfer will occur between the electrode and the electrolyte as oxygen is incorporated or extracted from the lattice. When working and reference electrode are exposed to different partial pressure of oxygen, there is a transfer of oxygen from the side with high oxygen partial pressure to the side with lower oxygen partial pressure following the Nernst equation (eq. 1.16) [38-41].

$$
E=\frac{R T}{2 n F} \ln \frac{\left(p_{O_{2}}\right)_{e q}}{\left(p_{O_{2}}\right)_{r e f}}
$$

Where $\mathrm{F}$ is the Faraday constant, $\mathrm{n}$ is the number of electrons, $\mathrm{R}$ the gas constant, $\mathrm{T}$ the absolute temperature, and $\left(\mathrm{p}_{\mathrm{O} 2}\right)_{\text {ref }}$ is the oxygen partial pressure at the reference electrode while $\left(\mathrm{p}_{\mathrm{O} 2}\right)_{\mathrm{eq}}$ is the oxygen partial pressure at the working electrode.

However, this is a simple case where the sensor is only exposed to oxygen. In real situations, there are more gases than oxygen. Thus, several reactions apart from equation 1.15 take place at the working electrode.

$$
\begin{array}{r}
\mathrm{C}_{2} \mathrm{H}_{4}+6 \mathrm{O}^{-2} \leftrightarrow 2 \mathrm{CO}_{2}+2 \mathrm{H}_{2} \mathrm{O}+12 e^{-} \\
\mathrm{CO}+\mathrm{O}^{-2} \leftrightarrow \mathrm{CO}_{2}+2 e^{-} \quad(1.18) \\
\mathrm{NO}+\mathrm{O}^{-2} \leftrightarrow \mathrm{NO}_{2}+2 e^{-}(1.19)
\end{array}
$$

In atmospheres like diesel exhaust gases or industrial gas steam, there is a nonequilibrium mixture of gases. A combination of all those reactions will provide the apparent potential of the working electrode.

Thus, an equilibrium must be achieved in the working electrode controlled by the kinetics. If the electrode has not enough catalytic activity towards the target gas or the temperature is too low, there is a deviation from the ideal behaviour (Nernst equation) and therefore a mixed potential is stablished as the measured voltage does not obey the Nernstian equation. 


\section{Non-Nernstian behavior}

When a sensor with different working and reference electrodes is exposed to a non-equilibrium gas, the presence of at least two independent non-equilibrium gases starts a competitive oxidation and reduction reactions at the same electrode. A potential value between the Nernstian values of the individual processes is established at the working and reference electrode. The difference between both electrodes potential gives the voltage of the cell. This is called mixed potential, as the system reaches a saturation where the potential of each electrochemical reaction is the same $[34,38,42,43]$. Kinetics should be taken into account as the fastest reaction will control the mixed potential established.

In this kind of sensor there should be an asymmetry between both electrodes. Thus, the reference electrode should have higher catalytic activity towards oxygen while the working electrode should have a higher catalytic activity towards the analyte or target gas. This is the reason why both electrodes can be exposed to the same atmosphere, simplifying the design of the sensor.

Thus, the sensor operation follows the following steps:

1. The oxygen molecule in the atmosphere is transported from the gas to the reference electrode surface.

2. Dissociation: Oxygen molecule adsorbs to the electrode because of the catalytic activity of the reference electrode.

3. Ionic transport: Oxygen ions diffuse through the crystal lattice by hopping from vacancy to vacancy in the lattice. Electrons go through the electrolyte in the opposite direction to maintain the electrical neutrality.

4. The analyte in the atmosphere is also transported from the gas but to the working electrode surface.

5. The analyte is oxidized in the point where analyte, working electrode and oxygen ions from the solid electrolyte meet together. Electrons are liberated in this step.

As can be observed in eq. 1.15, electrons are needed for this reaction to take place. Hence, electrodes should have electronic conductivity as well as catalytic activity to the target gas. One way of achieving this, and improving the device performance at the same time, is to mix an electronic and an ionic material. This increases the triple phase boundary (TPB), this is the point where the gas meets both the ionic and electronic conductor. Thus, enlarging this TPB area can improve the performance 


\subsection{Materials and State of the art}

The state of the art is checked for each part of the sensor and the most employed materials in literature will be explained for both electrolyte and electrodes. This is a key factor to establish the most promising kind of materials in function of their role in the sensor. This will allow to select as starting materials similar compounds appropriate for the purpose this Thesis.

\subsubsection{Electrolyte}

Fully dense ionic conductors are employed as electrolyte. Materials presenting fluorite structure are used because of their high ionic mobility at medium-high temperatures. In this structure, the cations fit into a facecentered cubic unit cell while the oxygen ions (anions) occupy all the tetrahedral sites as can be observed in figure 1.3. There is a large number of octahedral interstitials voids that lead to rapid ion diffusion [44]. The presence of aliovalent dopants adds extrinsic defects to the structures i.e. it will provide oxygen vacancies allowing the ionic diffusion. In this thesis, yttrium-doped zirconia, Scandia-doped zirconia and gadolinium-doped ceria were employed.

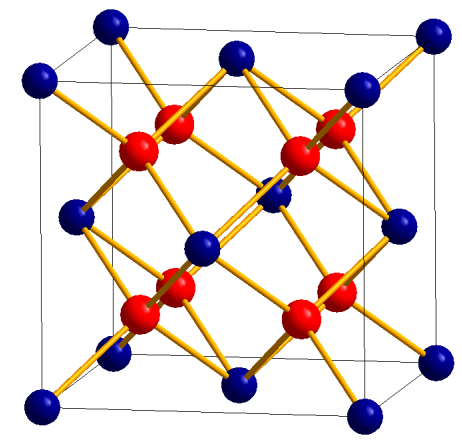

Figure 1.3 Face-centered cubic structure where the cations occupy the face-centered positions and the corners of the unite cell while the anions occupy the tetrahedral sites.

\subsubsection{Electrodes}

\section{Reference electrode}

In this electrode takes place the electrochemical reduction of oxygen (eq. 1.15). Not only catalytic activity towards oxygen is required but also a high electronic conductivity, so the electron can reach the oxygen. If the reference electrode has also ionic conductivity, the TPBs can be enlarged as explained later. The materials employed as reference electrode must not react with the 
electrolyte and moreover, they should have a similar thermal expansion coefficient to avoid cracks of detachment of the layer.

In literature, platinum is usually employed as reference electrode because of its high catalytic activity to oxygen reduction $[3,45,46]$. Nevertheless, platinum not only shows good catalytic activity to oxygen but to other materials. Thus, this can affect the sensor response as a mixed potential can be generated with oxygen and other species.

To avoid this situation, a different approach will be carried on. The key point will be the use of materials with a good catalytic activity to oxygen avoiding the cross sensitivity to other elements. Thus, materials usually employed as cathodes in solix oxide fuel cells (SOFC's) will be employed as reference electrode. The mixed electronic and ionic conductivity at mid-high temperatures of Perovksites and spinels, among other oxides employed in SOFC's, make them a promising candidate as electrode [47-50]. Perovskites has a general formula $\mathrm{ABO}_{3}$ with $\mathrm{B}$ cation in sixfold coordination and surrounded by an octahedron of oxygen ions, while the A cations are in the 12-fold cubo-octahedral positions as can be observed in figure 1.4 .

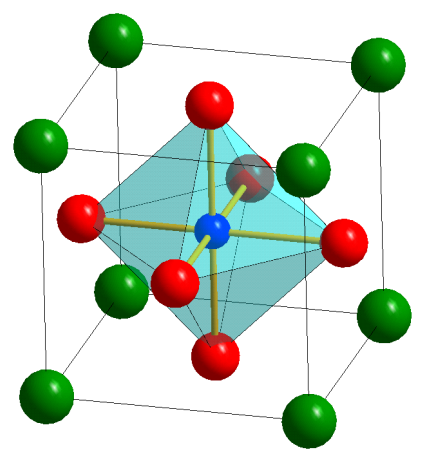

Figure 1.4 Perovskite unit cell whit $A$ cation in green, $B$ cations in blue and oxygen ions surrounding $B$ cations in red.

Spinel has a general formula $\mathrm{AB}_{2} \mathrm{O}_{4}$. In the normal spinel structure, the $\mathrm{A}$ cations fill $1 / 8$ of the tetrahedral sites while the $B$ cations fill half of the octahedral sites.

\section{Working electrodes}

This electrode will host the electrochemical oxidation of ethylene as indicated in equation 1.17. As in the reference electrode, the reaction will take place at the point where the gas meets the ionic and electronic conductor. 
Materials employed as working electrode must have a high catalytic activity to promote chemisorption and dissociation of ethylene/HCs at the surface [51-53]. Electrical conductivity is required to ensure the collection of the signal for its treatment. Again, like for the reference electrode, materials should have compatibility with the electrolyte and a similar thermal coefficient expansion to avoid cracks or delamination of the layer and the blockage of ions or electrons due to secondary phases.

Several materials have been tested for hydrocarbons, carbon monoxide, nitrogen oxides, etc. In the case of hydrocarbons detection, several oxides such as $\mathrm{Nb}_{2} \mathrm{O}_{5}$ [54], $\mathrm{In}_{2} \mathrm{O}_{3}$ [55], $\mathrm{NiO}$ [56], $\mathrm{CdO}$ [57], $\mathrm{TiO}_{2}$ [58], etc [59-64] have been employed as working electrodes. Moreover, gold -and even platinum- has been also employed as working electrode. Other structures such as spinels $\left(\mathrm{ZnCr}_{2} \mathrm{O}_{4}\right.$ [65] and $\mathrm{ZnCo}_{2} \mathrm{O}_{4}$ among others $\left.[66,67]\right)$ and perovskites $\left(\mathrm{La}_{0.9} \mathrm{Sr}_{0.1} \mathrm{CrO}_{3}[8,68,69]\right.$, $\mathrm{LaFeO}_{3}[70], \mathrm{NdFeO}_{3}[71,72]$ and $\left.\mathrm{SmFeO}_{3}[70]\right)$ are also reported for their use in the detection of hydrocarbons because of their electronic conductivity and their catalytic activity towards propylene and/or methane. In literature, the majority of works use planar sensor and there are two basic electrode configurations (figure 1.5): either two-sided devices where the electrodes are placed one in the top face and the second one in the back face of the electrolyte or both of them are placed in the same side facing each other. The geometries of the electrodes can be either rectangular or circular-shaped.

a)

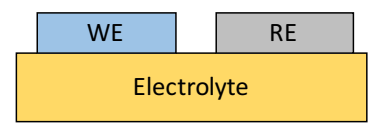

b)

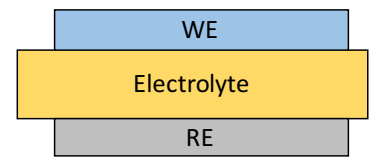

Figure 1.5 Usual sensor geometries employed in the literature: a) both electrodes are in the same side facing each other and b)two-sided configuration where each electrode is placed on one side

Many of these devices has been tested to detect selectively propylene as it is one of the easiest hydrocarbons to detect. The main drawback is that it could have a high cross sensitivity to other hydrocarbons. Moreover, in this thesis ethylene will be employed as target gas and reference to the total amount of hydrocarbons in the system, as it is one of the most common gases in an exhaust gas. Thus, in this thesis similar oxides as well as perovskites and spinels will be tested as their catalytic and electronic activity seems to be adequate for the detection of hydrocarbons. The aim will be to find one material that shows good properties for ethylene detection. As in the case of the reference electrode, the addition of ionic 
conductivity will enlarge the TPB's area increasing therefore the sensor performance[53].

\subsection{Electrochemical activation of oxygen}

The sensor performance depends on the configuration of the electrodes. Thus, the configuration of the electrode i.e. electronic conductor, ionic conductor, mixed ionic and electronic conductor, will provide a different performance of the sensor as shown in figure 1.6. Details of each configuration mechanism are explained below.

- Electronic conductor: When the electrode material has only predominately electronic conductivity the reaction takes place only at the interface electrodeelectrolyte when the gas reaches this point. This is the aforementioned triple phase boundary (TPB). The following mechanism occurs:

1. Oxygen diffusion.

2. Oxygen is adsorbed in the surface of the electrode and diffused to the TPB.

3. In the TPB takes place the charge transfer reaction. The ionic oxygen goes through the electrolyte.

- Electronic and ionic conductor: an improvement of the device performance could be achieved mixing a predominantly electronic conductor with a predominantly ionic conductor. This configuration allows the enlargement of the TPB surface along the electrode improving considerably the device performance. The mechanism is explained below:

1. Oxygen gas diffusion.

2. Oxygen is adsorbed on the surface of the electrode and it is diffused to the TPB. It should be taken into account that, as has been said, in this configuration the TPB area is larger than in the previous case.

3. In the TPB takes place the charge transfer reaction. The ionic oxygen goes through the ionic conductor to the electrolyte.

4. The oxygen ions incorporate into the electrolyte.

- Mixed ionic-electronic conductor: This configuration employs materials that have electronic as well as ionic conductivity by themselves. the electronic or the ionic conductivity of the material by design can be increased by the addition of aliovalent dopants. The mechanism is as follows:

1. Oxygen gas diffusion.

2. Oxygen is adsorbed on the surface of the electrode.

3. There is an exchange reaction between the oxygen on the surface and the oxygen vacancies or interstitials. 
4. The oxygen is diffused through the electrode to the electrolyte.

5. The oxygen ions incorporate into the electrolyte.

In the working electrode, the behavior is similar. The target gas is oxidized in the triple phase boundary employing the ionic oxygen from the electrolye.
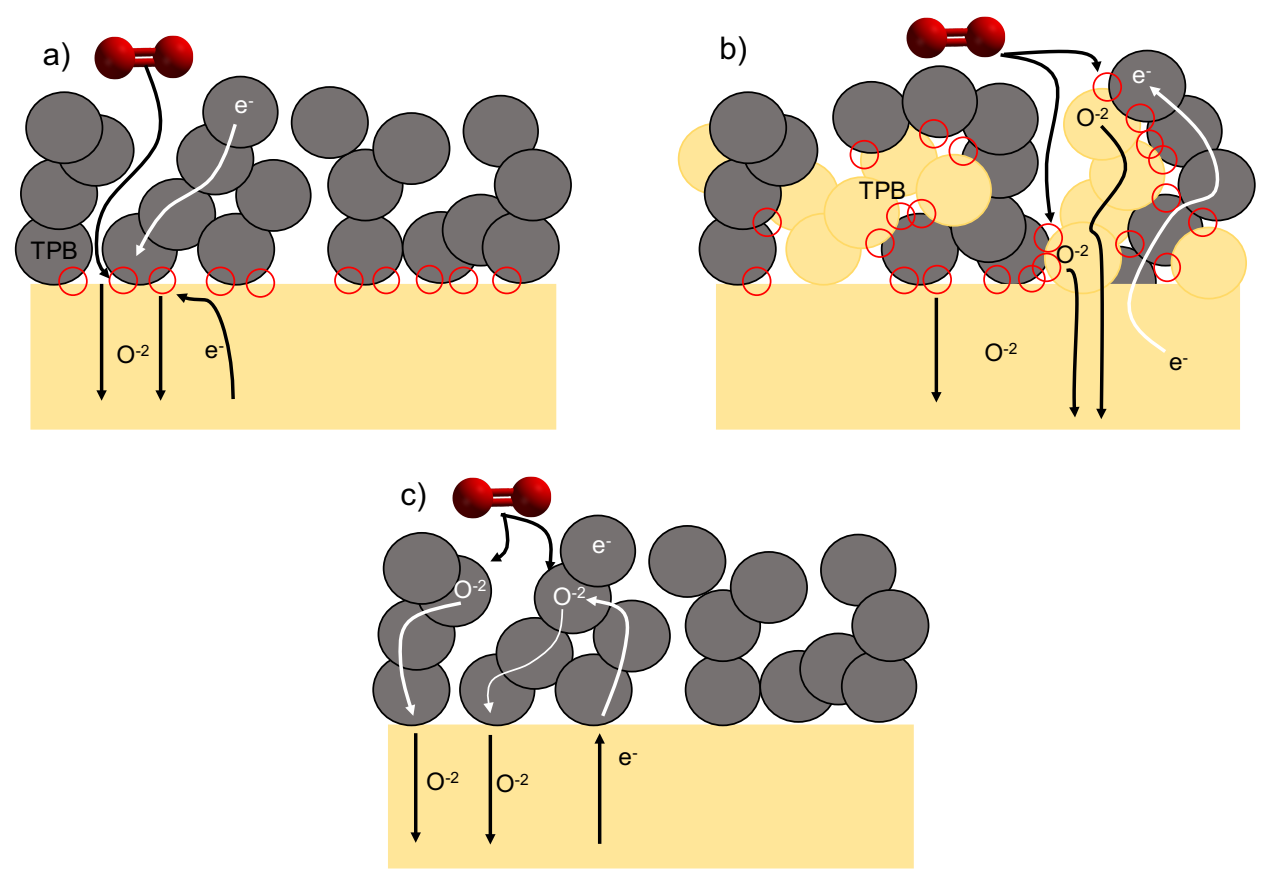

Figure 1.6 Sensor mechanism at the reference electrode for several electrode configurations: a) pure electronic electrode, b) ionic and electronic conductivity and c) mixed ionic-electronic conductivity. A similar mechanism is employed in the working electrode where the target gas is oxidized and provides the electrons employed in the reference electrode.

\subsection{Applications}

\subsubsection{Monitoring of gases}

\section{Environment monitoring}

Electrochemistry can play a key role in the protection of the environment. Electrochemical sensors and detectors are promising for in-situ measurements or monitoring of pollutants. Moreover, there are studies that link human health with urban air pollution [73,74]. 
Pollutants are emitted into the atmosphere from both natural and human made sources. While natural pollutants cannot be controlled, human made emission can be limited. This man-made emission has considerably increased since the industrial revolution. The usage of fossil resources and the development and growth of manufacture and chemicals have helped on the development of the humanity but also have had a negative effect on the environment and health. Pollutants in air are not only inhaled by humans but also they can be uptaken by plants and animals and be incorporated into the food chain or even in water. Recognizably, this also influences ecosystems like fauna and flora which are affected as well.

Air pollutants such as $\mathrm{NO}_{x}, \mathrm{CO}, \mathrm{HCs}, \mathrm{SO}_{2}, \mathrm{PM}$ and $\mathrm{O}_{3}$ are known or suspected to cause cancer or lung function. A high release rate of these elements in the air affects the quality of life and increases the mortality rate specially in those with respiratory or cardiovascular problems.

As far as risk control is concerned, a no risk-situation is not a realistic scenario, but a minimization of this risk is the objective of health care organizations and administrations in terms of air quality management.

In the last decades, most European countries and the U.S.A. have made big efforts to reduce air contamination and succeed in reducing them significantly. However, further restrictions must be applied e.g. NOx or PM as new studies reveal how they affect the human health even at low concentrations.

Air pollution can be caused by local sources e.g. traffic, heating, local industry or by transport of the pollutant from a medium-long distance [75]. Therefore, the complexity to detect the source of the air contamination and its similarity across the European countries, require supranational actions. Both the UE and the U.S.A. (Federal agency: United States Environmental Protection Agency) have legislation about health and environment [76].

\subsubsection{Monitoring of diesel exhaust gases}

Vehicles engines convert the chemical energy contained in diesel fuel into mechanical power. In the case of diesel cars, fuel is injected under pressure into the engine cylinder where it is mixed with air and combustion occurs. The exhaust gases that are discharged from the engine contain several constituents that are harmful to human health and to the environment. 
Although emissions from a car are relatively small, the emissions from large amounts of cars are a serious problem. This makes car exhaust gases one of the main contributors to air contamination. Cars exhaust gases are discharged into the atmosphere through the exhaust system and it contains mainly $\mathrm{CO}_{2}$ and water with a small concentration of harmful pollutants. In the case of a diesel car, this system will consist of:

- Muffler: noise attenuation

- Diesel Oxidation Catalyst (DOC): This element promotes the oxidation of the un-burned components from the engine. Thus, the DOC converts the un-burned $\mathrm{CO}$ and $\mathrm{HCs}$ into water and $\mathrm{CO}_{2}$. Usually consist of Aluminum oxide recovered with platinum and palladium.

- Diesel Particle Filter (DPF): it captures the particulate matters to prevent them to be discharged into the environment.

- Selective Catalytic Reduction (SCR): $\mathrm{NO}_{x}$ are selectively reduced in this element into nitrogen compounds e.g. ammonia or urea. Another alternative are the $\mathrm{NO}_{x}$ adsorbers, where the $\mathrm{NO}_{x}$ is kept on the catalyst washcoat during lean exhaust conditions and released during short period of rich air-fuel ratio operation. The $\mathrm{NO}_{x}$ is then catalytically reduced to nitrogen.

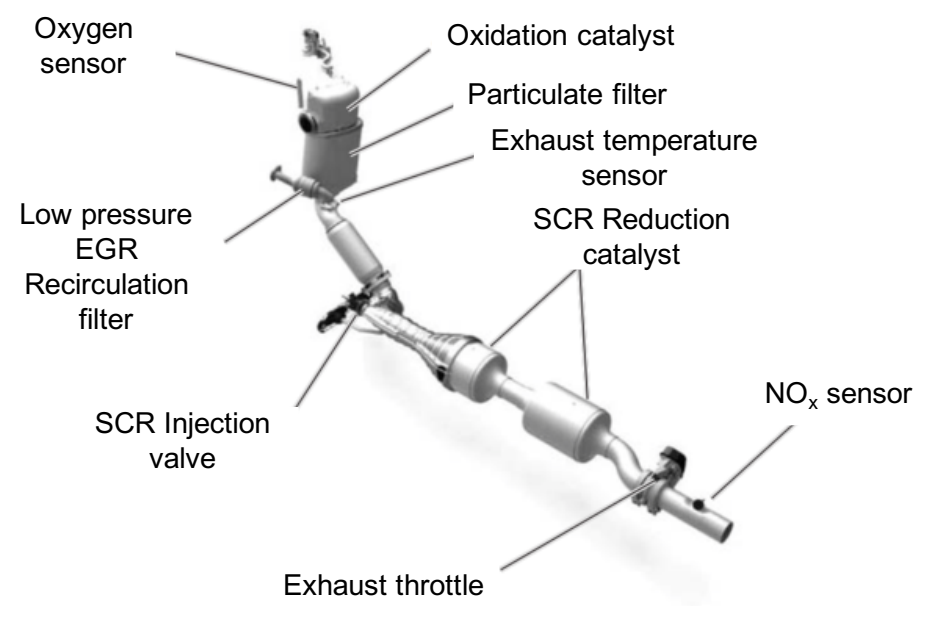

Figure 1.7 Diesel exhaust system. The system consists of a diesel oxidation catalyst for the un-burned gases, a diesel particle filter for removing particulate matters and selective catalytic reduction to reduce $\mathrm{NO}_{x}$ to nitrogen (source: Volkswagen)

The principal pollutants in petrol and diesel cars are carbon monoxide, nitrogen oxides, hydrocarbons and particulate matters. In general terms, long term 
exposure to exhaust gases has been reported to be associated with a higher risk of developing lung cancer [77]. Below are described the effects of these contaminants on human health [78]:

- Nitrogen oxides $\left(\mathrm{NO}_{\mathbf{x}}\right)$ : Both $\mathrm{NO}$ and $\mathrm{NO}_{2}$ are present in diesel exhaust gases, although $\mathrm{NO}$ tends to be oxidized to $\mathrm{NO}_{2} . \mathrm{NO}_{2}$ has a negative impact on human health, especially for those with respiratory illness or breathing difficulties. A long-term exposure can affect the lung function and increase allergenic response in sensitive people. In addition, $\mathrm{NO}_{\mathrm{x}}$ contributes to smog and ozone formation.

- Hydrocarbons (HCs): they contribute to the formation of ozone that can cause damage to the respiratory system. Besides, most of them are carcinogenic or indirect greenhouse gases.

- Carbon monoxide (CO): Carbon monoxide substitutes oxygen in blood and reduces the ability of red blood cells to carry oxygen. Then, there is a reduction of available oxygen in key organs. Long term exposure to high concentrations has a lethal effect while a low concentration still supposes a health risk for those with heart diseases.

- Particulate matter (PM): These small particles are related with respiratory and cardiovascular problems. People with respiratory disorders are specially affected.

The composition of the exhaust gas depends on the manufacturer, car model and the fuel employed. Figure 1.8 shows a typical diesel exhaust gas composition, where the pollutants are less than $1 \%$ of the total gas [79]. In diesel cars, the main contributors are $\mathrm{NO}_{x}$ and $\mathrm{PM}$ as their engines are lean combustion engines that also release although in a lower extent $\mathrm{CO}$ and $\mathrm{HCs}$. Both $\mathrm{CO}$ and $\mathrm{HCs}$ are the product of unburned fuels. Irregular operation like a change in speed, untidy injection or even nozzle cavity volumes, and injector needle bounce can lead to situations where part of the fuel remains unburned.

Nevertheless, hydrocarbons are especially tricky as they consist of several species and the ratio between light-heavy hydrocarbons may vary. In the present work, the focus is placed on hydrocarbons, as the aim of the work is the development of a device able to detect certain hydrocarbons because of the nonexistent devices for this application nowadays.

One of the main hydrocarbons in diesel exhaust gases is ethylene as shown in Table 1.2 [80] and figure 1.9 [81] from a Mercedes-Benz 1.7L turbocharged engine and on-road emissions measured in Caldecott tunnel in the San Francisco Bay, respectively. This high concentration can be related to the fact that ethylene 
could be a product of the oxidation of heavier hydrocarbons. Thus, there is a high concentration at the exhaust gas as it cannot be oxidized neither in the DOC nor in the high temperature gas leaving the engine with oxygen.

Polycyclic aromatic hydrocarbons (PAHs) are also of great interest because of their known carcinogenic and mutagenic effects $[81,82]$. Among them, there are some of special interest such as those listed in table 1.4 that have been listed by EPA as priority pollutants [83].

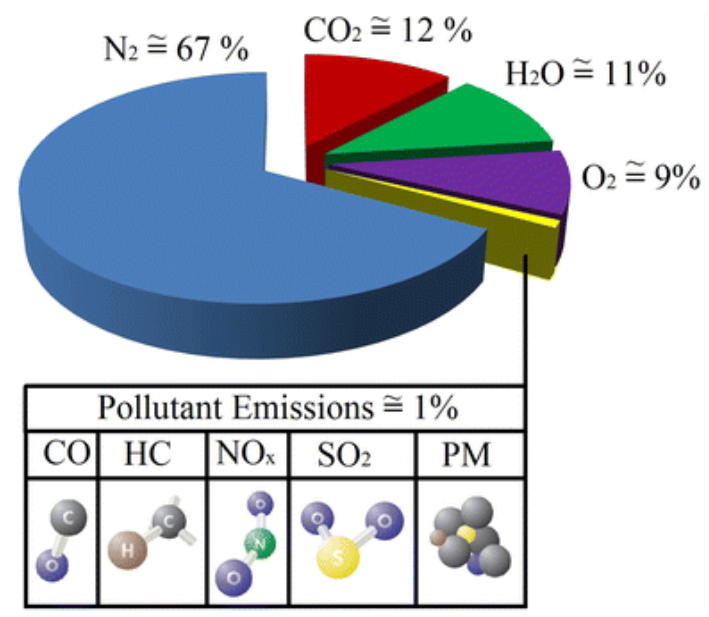

Figure 1.8 Diesel exhaust gas typical composition. Pollutants represents only a $1 \%$ of the total emissions. [79]

Table 1.2 Diesel exhaust composition for a Mercedes-Benz 1.7L turbocharged engine [80]

\begin{tabular}{|c|c|c|c|c|c|c|c|c|c|c|}
\hline \multicolumn{11}{|c|}{ Average concentrations over 10 regen cycles: rich for $3 \mathrm{sec}$. , lean for $60 \mathrm{sec}$. } \\
\hline \multicolumn{11}{|l|}{ FTIR data ppmC values } \\
\hline Post 80 Air:Fuel ratio sweep & Description & $\mathrm{CH}_{4}$ & $\mathrm{C}_{2} \mathrm{H}_{2}$ & $\mathrm{C}_{2} \mathrm{H}_{4}$ & $\mathrm{C}_{2} \mathrm{H}_{6}$ & $\mathrm{C}_{3} \mathrm{H}_{6}$ & $\mathrm{C}_{4} \mathrm{H}_{6}$ & $\mathrm{CH}_{2} \mathrm{O}$ & $\mathrm{C}_{2} \mathrm{H}_{4} \mathrm{O}$ & co \\
\hline Engine Out, 46 scans, 10 spectra, engine out lean & EO Lean & 2 & 4 & 16 & 0 & 4 & 3 & 13 & 7 & 190 \\
\hline Engine Out, 46 scans, 10 spectra, engine $14.3: 1 \mathrm{w} /$ cell scan & $14.25: 1$ & 53 & 137 & 100 & 13 & 40 & 16 & 37 & 22 & 1071 \\
\hline Engine Out, 46 scans, 10 spectra, engine $14: 1$ w/ cell scan & $14: 1$ & 53 & 138 & 102 & 14 & 44 & 17 & 40 & 24 & 1064 \\
\hline Engine Out, 46 scans, 10 spectra, engine $13.5 / 1 \mathrm{w} /$ cell scan & 13.5:1 & 55 & 147 & 108 & 16 & 54 & 21 & 43 & 34 & 1119 \\
\hline Engine Out, 46 scans, 10 spectra, engine $13: 1$ w/ cell scan & 13:1 & 45 & 140 & 111 & 13 & 67 & 27 & 38 & 61 & 1078 \\
\hline \multicolumn{11}{|l|}{ DEM Air:fuel ratio sweep } \\
\hline Engine Out, 46 scans, 10 spectra, engine out lean & EO Lean & 2 & 4 & 16 & 0 & 4 & 1 & 13 & 4 & 189.7 \\
\hline Engine Out, 46 scans, 10 spectra, engine $14.25: 1$ w/ cell scan & $14.25: 1$ & 32 & 48 & 41 & 0 & 10 & 1 & 10 & 6 & 1172 \\
\hline Engine Out, 46 scans, 10 spectra, engine $14: 1$ w/ cell scan & $14: 1$ & 40 & 60 & 43 & 0 & 11 & 2 & 16 & 6 & 1279 \\
\hline Engine Out, 46 scans, 10 spectra, engine $13.5 / 1$ w/ cell scan & 13.5:1 & 48 & 74 & 46 & 0 & 11 & 1 & 18 & 5 & 1402 \\
\hline Engine Out, 46 scans, 10 spectra, engine $13: 1$ w/ cell scan & 13:1 & 53 & 83 & 48 & 0 & 11 & 2 & 21 & 5 & 1446 \\
\hline Engine Out, 46 scans, 10 spectra, engine $12.1: 1$ w/ cell scan & $12: 1$ & 77 & 126 & 62 & 0 & 12 & 2 & 27 & 5 & 1712 \\
\hline
\end{tabular}



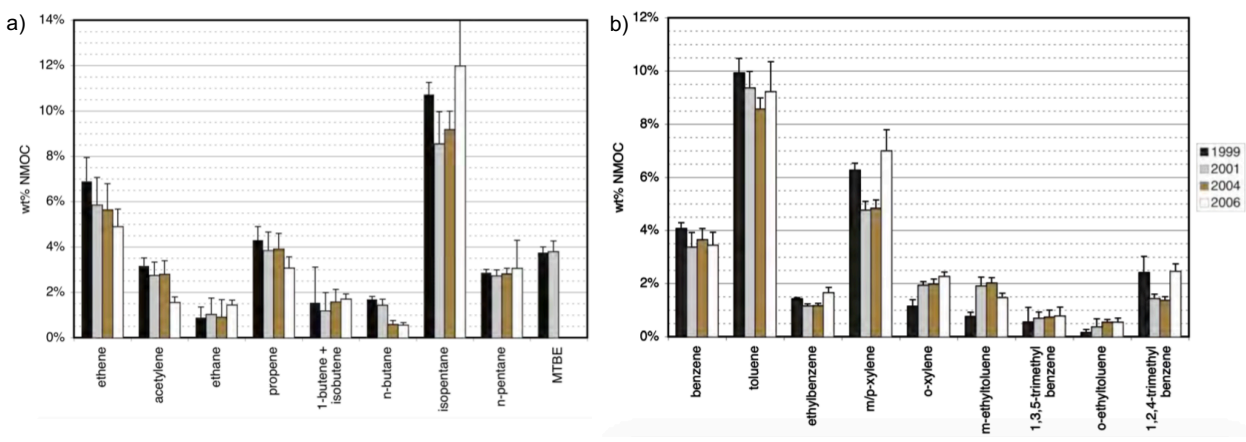

Figure 1.9 On-road hydrocarbon emissions measured in Caldecott tunnel in the San Francisco Bay during 2006 [81]

Table 1.3 Table of polycyclic aromatic hydrocarbons listed by EPA as priority pollutants [83]

\begin{tabular}{|c|c|c|c|c|c|}
\hline Compound & Number of rings & Molecular mass & Compound & Number of rings & Molcular mass \\
\hline Naphthalene & 2 & 128 & Benzo[a]anthracene & 4 & 228 \\
\hline Acenaphthylene & 2 & 152 & Chrysene & 4 & 228 \\
\hline Acenaphthene & 2 & 154 & Benzo[b]fluoranthene & 4 & 252 \\
\hline Flourene & 2 & 166 & Benzo[k]fluorantene & 4 & 252 \\
\hline Phenanthrene & 3 & 178 & Benzo[a]pyrene & 5 & 252 \\
\hline Anthracene & 3 & 178 & Dibenzo[a,h]anthracene & 5 & 278 \\
\hline Fluoranthene & 3 & 202 & Benzo[g,h,i]perylene & 5 & 276 \\
\hline Pyrene & 4 & 202 & Indeno[1,2,3-cd]pyrene & 5 & 276 \\
\hline
\end{tabular}

\section{European legislation}

European Union emissions regulations have as objective to harmonize rules on the construction of vehicles and reduce the pollutants discharged into the atmosphere and therefore, improving the air quality. Thus, the aim is to limit the exhaust gases emissions of elements such as nitrogen oxides, hydrocarbons or carbon monoxide.

First European regulation, EURO 1 [84], was implemented in 1992. This legislation made mandatory the catalytic converters in any car to be sold in European countries. This first legislation only limited the carbon monoxide, particulate matters, and the combination of hydrocarbon and nitrogen oxides. The limits were not as tight as nowadays, but this changed over the years as new legislations were approved with lower limits. In 2000, EURO 3 [85] was implemented and for the first time the emission limit of hydrocarbons and nitrogen 
oxides were split for petrol cars. The introduction of the diesel particles filters allowed to the drastic decrease of the emission limit of the particulate matters in the EURO 5 regulation [86](2009). Finally, the current EURO 6 was implemented in 2014 and it emphasized the reduction of $\mathrm{NO}_{x}[86,87]$.

Another interesting point implemented in EURO 6 is the requirement for unrestricted access to vehicle repair information and mainly to the on-boarddiagnostic (OBD). Thus, manufacturers must ensure an easy access to independent operators without discrimination in favour of official repair workshops [88].

Table 1.4 Evolution of the European gas exhaust emission limit over the years from EURO 1 to EURO 6 for petrol and diesel cars [89]

\begin{tabular}{|l|c|c|c|c|c|c|}
\cline { 2 - 7 } \multicolumn{1}{c|}{} & Emission limits for new vehicles with petrol engine \\
\cline { 2 - 7 } \multicolumn{1}{c|}{} & $\begin{array}{c}\text { Valid } \\
\text { from }\end{array}$ & $\begin{array}{c}\mathbf{C O} \\
(\mathbf{g} / \mathbf{k m})\end{array}$ & $\begin{array}{c}\mathbf{H C} \\
(\mathbf{g} / \mathbf{k m})\end{array}$ & $\begin{array}{c}\text { NO } \\
(\mathbf{g} / \mathbf{k m})\end{array}$ & $\begin{array}{c}\mathbf{H C}+\text { Nox } \\
(\mathbf{g} / \mathbf{k m})\end{array}$ & $\mathrm{PM}$ \\
\hline Euro I & $12 / 92$ & 2.72 & - & - & 0.97 & - \\
\hline Euro II & $01 / 97$ & 2.2 & - & - & 0.5 & - \\
\hline Euro III & $01 / 00$ & 2.3 & 0.2 & 0.15 & - & - \\
\hline Euro IV & $01 / 05$ & 1.0 & 0.1 & 0.08 & - & - \\
\hline Euro V & $09 / 09$ & 1.0 & 0.1 & 0.06 & - & 0.005 \\
\hline Euro VI & $08 / 14$ & 1.0 & 0.1 & 0.06 & - & 0.005 \\
\hline
\end{tabular}

\begin{tabular}{|l|c|c|c|c|c|c|}
\cline { 2 - 7 } \multicolumn{1}{c|}{} & Emission limits for new vehicles with diesel engine \\
\cline { 2 - 7 } \multicolumn{1}{c|}{} & $\begin{array}{c}\text { Valid } \\
\text { from }\end{array}$ & $\begin{array}{c}\mathbf{C O} \\
(\mathbf{g} / \mathbf{k m})\end{array}$ & $\begin{array}{c}\mathbf{H C} \\
(\mathbf{g} / \mathbf{k m})\end{array}$ & $\begin{array}{c}\text { NO } \\
(\mathbf{g} / \mathbf{k m})\end{array}$ & $\begin{array}{c}\mathbf{H C}+\text { Nox } \\
(\mathbf{g} / \mathbf{k m})\end{array}$ & $\mathbf{P M}$ \\
\hline Euro I & $01 / 92$ & 3.16 & - & - & 1.13 & 0.14 \\
\hline Euro II & $01 / 96$ & 1.00 & 0.15 & 0.55 & 0.70 & 0.08 \\
\hline Euro III & $01 / 00$ & 0.64 & 0.06 & 0.50 & 0.56 & 0.0 \\
\hline Euro IV & $01 / 05$ & 0.50 & 0.05 & 0.25 & 0.30 & - \\
\hline Euro V & $09 / 09$ & 0.50 & 0.05 & 0.18 & 0.23 & 0.005 \\
\hline Euro VI & $08 / 14$ & 0.50 & 0.09 & 0.08 & 0.17 & 0.005 \\
\hline
\end{tabular}

\section{United States of America legislation}

As in the European Union, the U.S.A. government created emission standards to reduce the emission of pollutants to the atmosphere. The United States Environmental Protection Agency (US EPA [90]) published the TIER 1 standards in 1991 [91]. Compared to EURO 1, this standard was more severe limiting the emission of $\mathrm{CO}, \mathrm{NMHC}, \mathrm{NO}_{x}$ and PM. In 2004 TIER 2 [92] was introduced. This regulation was more stringent in the emission limits (mainly for larger vehicles).

Apart from this federal legislation, the state of California promulgated its own legislation because they had preexisting standards before 1991 due to severe air 
pollution from cars [93]. California air resources board (CARB) adopted its first standards, the Low Emission Vehicle (LEV), in 1990 [94]. This standard run from 1994 to 2003 till the LEV II was adopted [95].

The LEV standards are more severe than the TIER and other states had the option to follow any of them. In 2009, 16 states had adopted the CARB standards and many manufactures tended to build to the CARB standards for the whole country.

Thus, EPA's is adapting their standards to the CARB, and their TIER 3 (from 2017 to 2025), adopted in 2014 [96], is very similar to the LEV III (from 2015 to 2025) adopted in 2012 [97].

Table 1.5 Gas exhaust emission limits for a) EPA's TIER 3 and b) CARB's LEV III [98]

b)

a)

\begin{tabular}{|c|c|c|c|c|}
\hline \multirow{2}{*}{ Bin } & NMOG+NO & $\mathbf{P M}$ & $\mathbf{C O}$ & $\mathbf{H C H O}$ \\
\cline { 2 - 5 } & $\mathbf{m g} / \mathbf{m i}$ & $\mathbf{m g} / \mathbf{m i}$ & $\mathbf{g} / \mathbf{m i}$ & $\mathbf{m g} / \mathbf{m i}$ \\
\hline Bin 160 & 160 & 3 & 4.2 & 4 \\
\hline Bin 125 & 125 & 3 & 2.1 & 4 \\
\hline Bin 70 & 70 & 3 & 1.7 & 4 \\
\hline Bin 50 & 50 & 3 & 1.7 & 4 \\
\hline Bin 30 & 30 & 3 & 1.0 & 4 \\
\hline Bin 20 & 20 & 3 & 1.0 & 4 \\
\hline Bin 0 & 0 & 0 & 0 & 0 \\
\hline
\end{tabular}

\begin{tabular}{|c|c|c|c|c|c|}
\hline Vehicle type & Emision Category & $\mathrm{NMOG}+\mathrm{NO}_{\mathrm{x}}$ & $\mathrm{Co}$ & $\mathrm{HCHO}$ & PM \\
\hline & & \begin{tabular}{|l|}
$\mathrm{g} / \mathrm{mi}$ \\
\end{tabular} & $\mathrm{g} / \mathrm{mi}$ & $\mathrm{mg} / \mathrm{mi}$ & $\mathrm{g} / \mathrm{mi}$ \\
\hline \multirow{6}{*}{$\begin{array}{c}\text { All PCs } \\
\text { LDTs } \leq 8500 \mathrm{lbsGVW} \\
\text { All MDPVs }\end{array}$} & LEV160 & 0.16 & 4.2 & 4 & 0.01 \\
\hline & ULEV125 & 0.125 & 2.1 & 4 & 0.01 \\
\hline & ULEV70 & 0.70 & 1.7 & 4 & 0.01 \\
\hline & ULEV50 & 0.50 & 1.7 & 4 & 0.01 \\
\hline & SULEV 30 & 0.03 & 1.0 & 4 & 0.01 \\
\hline & SULEV20 & 0.02 & 1.0 & 4 & 0.01 \\
\hline \multirow{6}{*}{$\begin{array}{l}\text { MDVs } 8501 \text { - } 10000 \text { lbs } \\
\text { GVW }\end{array}$} & LEV395 & 0.395 & 6.4 & 6 & 0.12 \\
\hline & ULEV 340 & 0.340 & 6.4 & 6 & 0.06 \\
\hline & ULEV 250 & 0.25 & 6.4 & 6 & 0.06 \\
\hline & ULEV200 & 0.20 & 4.2 & 6 & 0.06 \\
\hline & SULEVI170 & 0.17 & 4.2 & 6 & 0.06 \\
\hline & SULEVI150 & 0.15 & 3.2 & 6 & 0.06 \\
\hline \multirow{6}{*}{$\begin{array}{l}\text { MDVs } 10001-14000 \text { lbs } \\
\text { GVW }\end{array}$} & LEV630 & 0.63 & 7.3 & 6 & 0.12 \\
\hline & ULEV570 & 0.57 & 7.3 & 6 & 0.06 \\
\hline & ULEV400 & 0.40 & 7.3 & 6 & 0.06 \\
\hline & ULEV270 & 0.27 & 4.2 & 6 & 0.06 \\
\hline & SULEV230 & 0.23 & 4.2 & 6 & 0.06 \\
\hline & SULEV200 & 0.20 & 3.7 & 6 & 0.06 \\
\hline \multicolumn{6}{|c|}{$\begin{array}{l}\text { Abbreviations: } \\
\text { PC- Passenger car } \\
\text { LDT - Light duty truck } \\
\text { MDPV - medium-duty passanger vehicle } \\
\text { MDV - Medium-duty vehicle }\end{array}$} \\
\hline
\end{tabular}




\section{Gas sensing}

Apart from the oxygen lambda sensor, there are several sensing elements for $\mathrm{CO}$ and $\mathrm{NO}_{\mathrm{x}}$ detection. Unfortunately, the current $\mathrm{NO}_{\mathrm{x}}$ devices are not yet to be trusted for commercial purposes. Legislation limits are too low for the current state of the art sensors and they cannot provide a reliable response [87]. Volkswagen emissions scandal (or dieselgate) broke in September 2015 when the EPA accused Volkswagen group of violating the Clean Air Act. Cars were programmed to reduce its emissions when tested, but in real conditions they could release up to 40 times the tested $\mathrm{NO}_{x}$ value surpassing the legislated values. This scandal uncovered that most of the cars were not able to meet the legislation requirements. Further investigation should be done on this field to get reliable ways to reduce the emission limits.

In the case of hydrocarbons there is no commercial sensor for their detection at the time being. Therefore, there is an urgency to develop a device able to measure them, which will contribute to reduce their emissions. The strategy will be focused on one of the main elements and use it as a reference to control the total release to the atmosphere.

Regarding the hydrocarbons one of the main elements is ethylene as aforementioned. Thus, in this thesis the focus will be placed on this element as the target element in order to quantify and reduce the total amount of hydrocarbons in the exhaust gases. In addition, this will help to prevent or reduce exposure to priority PAHs listed in table 1.4. In addition, ethylene is not only one the major compounds in car exhaust gas but also exhibits the highest ozoneforming potential of all the major hydrocarbon emission sources [101-103].

The cross sensitivity of the sensor towards other hydrocarbons should be considered as it can add an additive response. Moreover, cross sensitivity towards other compounds such as $\mathrm{CO}$ should also be considered because they are present in relative high concentrations and the mechanism for their elimination is like for hydrocarbons.

\subsubsection{Other applications: Industrial gases monitoring}

Sensors cannot only be used for monitoring of air quality or pollutants but also for energy efficiency, emission control in combustion processes and control of both process and product quality.

In the industry, there is a continuous struggle for faster, more reliable and more stable sensors as well as low cost. Moreover, sensors related to monitoring and 
control of emissions in combustion processes are considered one of the Industries of the Future and they are expected to save up to 0.25 quadrillion BTU/year [99]. A good control of the emissions would lead to a better control of the process, lower emissions and efficient use of fuels. Then, a good control of $\mathrm{HCs}$ and $\mathrm{CO}$ is required in combustion activities such as glass making, gas appliances, wood burning, refinery, etc

The device could also be employed, among other sensors, for reducing emissions and reduce operative cost of fuel cells. Monitoring of hydrocarbon and ratio $\mathrm{CO} / \mathrm{H}_{2}$ can provide the efficiency of the reforming unit [100].

Finally, it can be used to prevent other types of problems like the sick building syndrome, as even at houses and apartments some toxic volatile compounds (as the aforementioned toluene, benzene and formaldehyde) may be emitted from various sources such as wallpapers, furniture and flooring [56]. Thus, in Japan it is mandatory in accordance with the New Building Law, the installation of indoors ventilators to remove these pollutants and the maximum concentration is regulated by the Japanese Ministry of Health, Labour and Welfare.

\subsection{References}

[1] K. Kalantar-zadeh, Sensors: an introductory course, Springer US, New York, pp. 196; 2013. doi:10.10.1007/978-1-4614-5052-8

[2] J. Janata, Principles of Chemical Sensors, Springer US, Boston, MA, pp. 373; 2009. doi:10.1007/b136378.

[3] C. Wang, X. Li, Y. Yuan, B. Wang, J. Huang, F. Xia, H. Zhang, J. Xiao, Effects of sintering temperature on sensing properties of $\mathrm{V} 2 \mathrm{O} 5$-WO 3 -TiO 2 electrode for potentiometric ammonia sensor, Sensors Actuators B. 241 (2017) 268-275. doi:10.1016/j.snb.2016.09.117.

[4] V.N. Mishra, R.P. Agarwal, Sensitivity, response and recovery time of $\mathrm{SnO} 2$ based thick-film sensor array for $\mathrm{H} 2, \mathrm{CO}, \mathrm{CH} 4$ and LPG, Microelectronics J. 29 (1998) 861-874. doi:10.1016/S0026-2692(98)00019-6

[5] T. Liu, X. Zhang, L. Yuan, J. Yu, A review of high-temperature electrochemical sensors based on stabilized zirconia, Solid State Ionics. 283 (2015) 91-102. doi:10.1016/j.ssi.2015.10.012.

[6] A. Volkov, E. Gorbova, A. Vylkov, D. Medvedev, A. Demin, P. Tsiakaras, Design and applications of potentiometric sensors based on proton-conducting ceramic materials. A brief review, Sensors Actuators B. Chem. 244 (2017) 10041015. doi:10.1016/j.snb.2017.01.097. 
[7] Y. Sadaoka, M. Mori, Detection of VOC in air with a planar-type potentiometric gas sensor based on YSZ with a Pt electrode modified with TiO 2, Sensors Actuators B. Chem. 248 (2017) 878-885. doi:10.1016/j.snb.2017.01.099.

[8] P.K. Sekhar, K. Subramaniyam, Electrical characterization of a mixed potential propylene sensor, Sensors Actuators B. Chem. 188 (2013) 367-371. doi:10.1016/j.snb.2013.07.003.

[9] Zosel, Ahlborn, Mueller, Westphal, Vashook, Guth, Selectivity of HCsensitive electrode materials for mixed potential gas sensors, Solid State lonics. 169 (2004) 115-119. doi:10.1016/S0167-2738(03)00082-1.

[10] L. Zhou, Q. Yuan, X. Li, J. Xu, F. Xia, J. Xiao, The effects of sintering temperature of ( $\mathrm{La} 0.8 \mathrm{Sr} 0.2$ ) 2 FeMnO $6-$ I on the NO 2 sensing property for YSZ-based potentiometric sensor, Sensors Actuators B. 206 (2015) 311-318. doi:10.1016/j.snb.2014.09.018.

[11] T. Ueda, H. Abe, K. Kamada, S.R. Bishop, H.L. Tuller, T. Hyodo, Y. Shimizu, Enhanced sensing response of solid-electrolyte gas sensors to toluene: Role of composite Au/metal oxide sensing electrode, Sensors Actuators B. Chem. 252 (2017) 268-276. doi:10.1016/j.snb.2017.05.172.

[12] Y. Fujio, T. Sato, N. Miura, Sensing performance of zirconia-based gas sensor using titania sensing-electrode added with palladium, Solid State lonics. 262 (2014) 266-269. doi:10.1016/j.ssi.2013.08.028.

[13] T. Ritter, G. Hagen, J. Kita, S. Wiegärtner, F. Schubert, R. Moos, Selfheated HTCC-based ceramic disc for mixed potential sensors and for direct conversion sensors for automotive catalysts, Sensors Actuators B. Chem. 248 (2017) 793-802. doi:10.1016/j.snb.2016.11.079.

[14] J.-P. Viricelle, P. Vernoux, J. Gao, I. Romanytsia, P. Breuil, C. Pijolat, ScienceDirect NO 2 -selective electrochemical sensors for Diesel exhausts, Procedia Eng. 168 (2016) 7-10. doi:10.1016/j.proeng.2016.11.112.

[15] N. Miura, G. Lu, M. Ono, N. Yamazoe, Selective detection of NO by using an amperometric sensor based on stabilized zirconia and oxide electrode, Solid State lonics. 117 (1999) 283-290. doi:10.1016/S0167-2738(98)00423-8

[16] K. Mahendraprabhu, P. Elumalai, Stabilized zirconia-based selective NO 2 sensor using sol-gel derived $\mathrm{Nb} 2 \mathrm{O} 5$ sensing-electrode, Sensors Actuators B. Chem. 238 (2017) 105-110. doi:10.1016/j.snb.2016.07.010.

[17] T. Ueda, V. V Plashnitsa, M. Nakatou, N. Miura, Zirconia-based amperometric sensor using $\mathrm{ZnO}$ sensing-electrode for selective detection of propene, (2006). doi:10.1016/j.elecom.2006.09.002. 
[18] C. Phawachalotorn, O. Sanguanruang, T. Ishihara, Highly selective amperometric sensors for carbon monoxide detection in exhaust gas, Sensors Actuators B. 161 (2011) 635-640. doi:10.1016/j.snb.2011.10.081.

[19] G. Fadeyev, A. Kalyakin, E. Gorbova, A. Brouzgou, A. Demin, A. Volkov, P. Tsiakaras, A simple and low-cost amperometric sensor for measuring $\mathrm{H} 2, \mathrm{CO}$, and CH4, Sensors Actuators B. Chem. 221 (2015) 879-883. doi:10.1016/j.snb.2015.07.034.

[20] Y. Shimizu, S. Yamamoto, S. Takase, A thick-film impedancemetric carbon monoxide sensor using layered perovskite-type cuprate, Sensors Actuators B. 249 (2017) 667-672. doi:10.1016/j.snb.2017.04.059.

[21] Y. Liu, J. Parisi, X. Sun, Y. Lei, Solid-state gas sensors for high temperature applications - a review. doi:10.1039/c3ta15008a.

[22] H. Ikeda, A. lio, S.A. Anggraini, N. Miura, Impedancemetric YSZ-based oxygen sensor using BaFeO 3 sensing-electrode, Sensors Actuators B. Chem. 243 (2017) 279-282. doi:10.1016/j.snb.2016.11.140.

[23] K. Cvejin, M. Sliwa, L. Manjakkal, J. Kulawik, G. Stojanoví, D. Szwagierczak, Impedancemetric NO sensor based on YSZ/perovskite neodymium cobaltite operating at high temperatures, Sensors Actuators B. Chem. 228 (2016) 612-624. doi:10.1016/j.snb.2016.01.071.

[24] K.-I. Shimizu, K. Kashiwagi, H. Nishiyama, S. Kakimoto, S. Sugaya, H. Yokoi, A. Satsuma, Impedancemetric gas sensor based on Pt and WO 3 coloaded TiO 2 and ZrO 2 as total $\mathrm{NO} \times$ sensing materials, Sensors Actuators B. 130 (2008) 707-712. doi:10.1016/j.snb.2007.10.032.

[25] H.-C. Cho, S. Takase, J.-H. Song, Y. Shimizu, Sensing behavior of solidstate impedancemetric NOx sensor using solid electrolyte transducer and oxide receptor, Sensors Actuators B. 187 (2013) 94-98. doi:10.1016/j.snb.2012.09.066.

[26] M. Stranzenbach, B. Saruhan, Equivalent circuit analysis on NO $x$ impedance-metric gas sensors, Sensors Actuators B. 137 (2009) 154-163. doi:10.1016/j.snb.2008.11.055.

[27] X. Liu, S. Cheng, H. Liu, S. Hu, D. Zhang, H. Ning, A survey on gas sensing technology., Sensors (Basel). $12 \quad$ (2012) 9635-65. doi:10.3390/s120709635.

[28] T. Martan, J. Aubrecht, O. Podraz, V. Matějec, I. Kašík, Detection of hydrocarbons using suspended core microstructured optical fiber, Sensors Actuators B. 202 (2014) 123-128. doi:10.1016/j.snb.2014.04.103.

[29] Y. Xiong, J. Tan, C. Wang, Y. Zhu, S. Fang, J. Wu, Q. Wang, M. Duan, A miniaturized oxygen sensor integrated on fiber surface based on evanescent- 
wave induced fluorescence quenching, J. Lumin. 179 (2016) 581-587. doi:10.1016/j.jumin.2016.08.005.

[30] A. Dutta, B. Deka, P.P. Sahu, Design and fabrication of silicon oxynitride based evanescent optical waveguide sensor for rapid detection of adulteration in petrol, Procedia Eng. 64 (2013) 195-204. doi:10.1016/j.proeng.2013.09.091.

[31] J. Mulrooney, J. Clifford, C. Fitzpatrick, E. Lewis, Detection of carbon dioxide emissions from a diesel engine using a mid-infrared optical fibre based sensor, Sensors Actuators A. 136 (2007) 104-110. doi:10.1016/j.sna.2006.11.016.

[32] S. Bagchi, R. Achla, S.K. Mondal, Electrospun polypyrrole-polyethylene oxide coated optical fiber sensor probe for detection of volatile compounds, Sensors Actuators B. 250 (2017) 52-60. doi:10.1016/j.snb.2017.04.146.

[33] A. Paliwal, A. Sharma, M. Tomar, V. Gupta, Carbon monoxide (CO) optical gas sensor based on ZnO thin films, Sensors Actuators B. 250 (2017) 679-685. doi:10.1016/j.snb.2017.05.064.

[34] S. Zhuiykov, Electrochemistry of zirconia gas sensors, CRC Press, 2008.

[35] Charged Semiconductor Defects, Springer London, London, 2009. doi:10.1007/978-1-84882-059-3.

[36] D.M. Smyth, The defect chemistry of metal oxides, Oxford University Press, Oxford, UK; PP304. 2000. doi:10.1007/978-1-84882-059-3

[37] H.L. Tuller, J. Schoonman, I. Riess, Oxygen ion and mixed conductors and their technological applications, Kluwer Academic, 2000.

[38] R.A. Mendybaev, J.R. Beckett, E. Stolper, L. Grossman, Measurement of oxygen fugacities under reducing conditions: Non-Nernstian behavior of $Y 203$ doped zirconia oxygen sensors, Geochimica et Cosmochimica Acta 62 (1998) 3131-3139. doi: http://10.1016/S0016-7037(98)00212-9

[39] R. Moos, K. Sahner, M. Fleischer, U. Guth, N. Barsan, U. Weimar, Solid State Gas Sensor Research in Germany-A Status Report. Sensors 9 (2009) 4323-4365. doi:10.3390/s90604323.

[40] R.P. O'Hayre, S.-W. Cha, W.G. Colella, F.B. Prinz, Fuel cell fundamentals $3^{\text {rd }}$ edition. Wiley, 2016, pp. 600.

[41] A.J. Bard, L.R. Faulkner, Electrochemical methods: fundamentals and applications, $2^{\text {nd }}$ edition, Wiley, 2001, pp. 864

[42] A. Angelo, B. Basile, S.P. Suzana, P. Nunes, Advanced membrane science and technology for sustainable energy and environmental applications, Woodhead Pub, Cambridge, UK, 2011, pp. 848. doi:10.1016/B978-1-84569-9697.50026-6 
[43] J.W. Fergus, Sensing mechanism of non-equilibrium solid-electrolytebased chemical sensors, J. Solid State Electrochem. 15 (2011) 971-984. doi:10.1007/s10008-010-1046-4.

[44] S.C. Singhal, K. Kendall, High-temperature solid oxide fuel cells: fundamentals, design, and applicatons, Elsevier Advanced Technology, 2003.

[45] P.K. Sekhar, J. Kysar, E.L. Brosha, C.R. Kreller, Development and testing of an electrochemical methane sensor, Sensors Actuators B. Chem. 228 (2016) 162-167. doi:10.1016/j.snb.2015.12.100.

[46] N. Miura, T. Sato, S.A. Anggraini, H. Ikeda, S. Zhuiykov, A review of mixed-potential type zirconia-based gas sensors, lonics (Kiel). 20 (2014) 901925. doi:10.1007/s11581-014-1140-1.

[47] G.-B. Jung, C.-T. Chang, C.-C. Yeh, X.-V. Nguyen, S.-H. Chan, C.-Y. Lin, J.-W. Yu, W.-T. Lee, S.-W. Chang, I.-C. Kao, Study of reversible solid oxide fuel cell with different oxygen electrode materials, Int. J. Hydrogen Energy. 41 (2016) 21802-21811. doi:10.1016/j.jhydene.2016.07.190.

[48] B.S. Prakash, S.S. Kumar, S.T. Aruna, Microstructure and performance of LSM/YSZ based solid oxide fuel cell cathodes fabricated from solution combustion co-synthesized powders and by solution precursor plasma spraying, Surf. Coat. Technol. 310 (2016) 25-32. doi:10.1016/j.surfcoat.2016.12.004.

[49] M. Park, H.Y. Jung, J.Y. Kim, H. Kim, K.J. Yoon, J.W. Son, J.H. Lee, B.K. Kim, H.W. Lee, Effects of mixing state of composite powders on sintering behavior of cathode for solid oxide fuel cells, Ceram. Int. 43 (2017) 11642-11647. doi:10.1016/j.ceramint.2017.05.347.

[50] S.-W. Baek, J. Jeong, H. Schlegl, A.K. Azad, D.S. Park, U.B. Baek, J.H. Kim, CERAMICS INTERNATIONAL Metal-supported SOFC with an aerosol deposited in-situ LSM and 8YSZ composite cathode, Ceram. Int. 42 (2015) 24022409. doi:10.1016/j.ceramint.2015.10.039.

[51] G.S. (Gennadiĭ S. Korotchenkov, Handbook of gas sensor materials: properties, advantages and shortcomings for applications. Volume 1, Conventional approaches, spRINGER, New York, USA, 2013, pp. 442. doi:10.1007/978-1-4614-7165-3

[52] B.M. Bhanage, M. Arai, Transformation and utilization of carbon dioxide, Springer, Berlin, Germany, 2014, pp. 388. doi:10.1007/978-3-642-44988-8

[53] X. Zhu, W. Yang, Mixed conducting ceramic membranes: fundamentals, materials and applications, Springer, Berlin, Germany, 2017, pp.367. doi:10.1007/978-3-662-53534-9

[54] L. Chevallier, E. Di Bartolomeo, M.L. Grilli, E. Traversa, High temperature detection of $\mathrm{CO} / \mathrm{HCs}$ gases by non-Nernstian planar sensors using $\mathrm{Nb} 2 \mathrm{O} 5$ 
$\begin{array}{lllll}\text { electrode, Sensors Actuators } & \text { B. } 130 \quad \text { (2008) 514-519. }\end{array}$ doi:10.1016/j.snb.2007.09.056.

[55] Y. Suetsugu, T. Sato, M. Breedon, N. Miura, C 3 H 6 sensing characteristics of rod-type yttria-stabilized zirconia-based sensor for ppb level environmental monitoring applications, Electrochim. Acta. 73 (2011) 118-122. doi:10.1016/j.electacta.2011.08.108.

[56] T. Sato, V. V. Plashnitsa, M. Utiyama, N. Miura, YSZ-based Sensor Using $\mathrm{NiO}$ Sensing Electrode for Detection of Volatile Organic Compounds in ppb Level, J. Electrochem. Soc. 158 (2011) J175. doi:10.1149/1.3573780.

[57] N. Miura, T. Shiraishi, K. Shimanoe, N. Yamazoe, Mixed-potential-type propylene sensor based on stabilized zirconia and oxide electrode, Electrochem. Commun. 2 (2000) 77-80. doi:10.1016/S1388-2481(99)00149-6

[58] Y. Fujio, T. Sato, N. Miura, Sensing performance of zirconia-based gas sensor using titania sensing-electrode added with palladium, Solid State Ionics. 262 (2014) 266-269. doi:10.1016/j.ssi.2013.08.028.

[59] B.C. Li Liu, Y. Zhang, G. Wang, S. Li, L. Wang, Y. Han, X. Jiang, A. Wei, High toluene sensing properties of NiOâ€"SnO2 composite nanofiber sensors operating at $330 \hat{A}^{\circ} \mathrm{C}$, Sensors Actuators B. Chem. 160 (2011) 448-454. doi:10.1016/j.snb.2011.08.007.

[60] S. Deng, X. Liu, N. Chen, D. Deng, X. Xiao, Y. Wang, A highly sensitive VOC gas sensor using p-type mesoporous Co 3 O 4 nanosheets prepared by a facile chemical coprecipitation method, Sensors Actuators B. Chem. 233 (2016) 615-623. doi:10.1016/j.snb.2016.04.138.

[61] R. Malik, V.K. Tomer, V. Chaudhary, M.S. Dahiya, S.P. Nehra, S. Duhan, K. Kailasam, A low temperature, highly sensitive and fast response toluene gas sensor based on $\mathrm{In}$ (III)-SnO 2 loaded cubic mesoporous graphitic carbon nitride, Sensors Actuators B. 255 (2018) 3564-3575. doi:10.1016/j.snb.2017.09.193.

[62] F. Li, C. Li, L. Zhu, W. Guo, L. Shen, S. Wen, S. Ruan, Enhanced toluene sensing performance of gold-functionalized WO $3 \cdot \mathrm{H} 2 \mathrm{O}$ nanosheets, Sensors Actuators B. 223 (2016) 761-767. doi:10.1016/j.snb.2015.10.005.

[63] M.H. Saberi, Y. Mortazavi, A.A. Khodadadi, Dual selective Pt/SnO 2 sensor to $\mathrm{CO}$ and propane in exhaust gases of gasoline engines using $\mathrm{Pt} / \mathrm{LaFeO}$ 3 filter, Sensors Actuators B. Chem. 206 (2015) 617-623. doi:10.1016/j.snb.2014.10.007.

[64] E.M. Preiß, T. Rogge, A. Krauß, H. Seidel, Tin oxide-based thin films prepared by pulsed laser deposition for gas sensing, Sensors Actuators B. Chem. 236 (2016) 865-873. doi:10.1016/j.snb.2016.02.105. 
[65] Y. Fujio, V. V Plashnitsa, P. Elumalai, N. Miura, Stabilization of sensing performance for mixed-potential-type zirconia-based hydrocarbon sensor, Talanta. 85 (2011) 575-581. doi:10.1016/j.talanta.2011.04.024.

[66] F. Sun, X. Li, L. Liu, J. Wang, Novel Zn-M-O (M=Sn, Co) sensing electrodes for selective mixed potential $\mathrm{CO} / \mathrm{C} 3 \mathrm{H} 8$ sensors, Sensors Actuators B. Chem. 184 (2013) 220-227. doi:10.1016/j.snb.2013.04.002.

[67] YSZ-based sensor using Cr-Fe-based spinel-oxide electrodes for selective detection of CO, Anal. Chim. Acta. 982 (2017) 176-184. doi:10.1016/J.ACA.2017.06.010.

[68] P. Kumar Sekhar, R. Mukundan, E. Brosha, F. Garzon, Effect of perovskite electrode composition on mixed potential sensor response, Sensors Actuators B. Chem. 183 (2013) 20-24. doi:10.1016/j.snb.2013.03.110.

[69] J. Zosel, R. Müller, V. Vashook, U. Guth, Response behavior of perovskites and Au/oxide composites as $\mathrm{HC}$-electrodes in different combustibles, Solid State lonics. 175 (2004) 531-533. doi:10.1016/j.ssi.2004.01.074.

[70] H. Truong Giang, H. Thai Duy, P. Quang Ngan, G. Hong Thai, D. Thi Anh Thu, D. Thi Thu, N. Ngoc Toan, Hydrocarbon gas sensing of nano-crystalline perovskite oxides $\mathrm{LnFeO} 3(\mathrm{Ln}=\mathrm{La}, \mathrm{Nd}$ and $\mathrm{Sm})$, Sensors Actuators B. Chem. 158 (2011) 246-251. doi:10.1016/j.snb.2011.06.013.

[71] T. Giang Ho, T. Duy Ha, Q. Ngan Pham, H. Thai Giang, T. Anh Thu Do, $\mathrm{N}$. Toan Nguyen, Nanosized perovskite oxide $\mathrm{NdFeO} 3$ as material for a carbonmonoxide catalytic gas sensor, Adv. Nat. Sci. Nanosci. Nanotechnol. 2 (2011) 15012-4. doi:10.1088/2043-6262/2/1/015012.

[72] Y. Wang, Y. Wang, W. Ren, P. Liu, H. Zhao, J. Chen, J. Deng, X. Xing, Improved conductivity of $\mathrm{NdFeO} 3$ through partial substitution of $\mathrm{Nd}$ by $\mathrm{Ca}$ : a theoretical study, Phys. Chem. Chem. Phys. Phys. Chem. Chem. Phys. 17 (2015) 29097-29102. doi:10.1039/c5cp03941j.

[73] The use of electrochemical sensors for monitoring urban air quality in lowcost, high-density networks, Atmos. Environ. 70 (2013) 186-203. doi:10.1016/J.ATMOSENV.2012.11.060.

[74] G. Hanrahan, D.G. Patil, J. Wang, Electrochemical sensors for environmental monitoring: design, development and applications. National Exposure Research Laboratory, U.S. Environtmental Protection Agency, pp.17. doi:10.1039/b403975k.

http://citeseerx.ist.psu.edu/viewdoc/download?doi=10.1.1.523.2540\&rep=rep1\&ty pe=pdf. Accessed November 20, 2017

[75] J.-O. Willums, New concepts in air pollution research: Interdisciplinary contributions by an international group of 20 young scientists,. Sprinegr, Basel; pp. 184. 1974. doi: 10.1007/978-3-0348-5779-6 
[76] WHO. Air Quality Guidelines for Europe 2nd ed. WHO Regional Publications, European Series No. 91 pp. 273. 2000; http://www.euro.who.int/_data/assets/pdf_file/0005/74732/E71922.pdf. Accessed November 20, 2017

[77] IARC Working Group on the Evaluation of Carcinogenic Risks to Humans. Meeting. 2012: Lyon France, 2014. International Agency for Research on Cancer. Diesel and gasoline engine exhausts and some nitroarenes. Volume 105. https://monographs.iarc.fr/ENG/Monographs/vol105/mono105.pdf. Accessed October 20, 2017.

[78] Vehicle Certification Agency. Cars and air pollution http://www.dft.gov.uk/vca/fcb/cars-and-air-pollution.asp. Accessed October 20, 2017.

[79] I.A. Reşitoğlu, K. Altinişik, A. Keskin, The pollutant emissions from dieselengine vehicles and exhaust aftertreatment systems, Clean Technol. Environ. Policy. 17 (2015) 15-27. doi:10.1007/s10098-014-0793-9.

[80] J.M. Storey, S.A. Lewis, B.H. West, S.P. Huff, C.S. Sluder, R.M. Wagner, N. Domingo, J. Thomas, M. Kass, Hydrocarbon species in the exhaust of diesel engines equipped with advanced emissions control devices Final Report CRC Project No. AVFL-10b-2 January 28, 2005, https://crcao.org/reports/recentstudies2005/AVFL-10b-

2\%20Final\%20Report\%20January\%2031\%202005.pdf. Accessed October 20, 2017.

[81] R.A. Harley, Report: On Road Measurement of Light Duty Gasoline and Heavy Duty Diesel Vehicle Emissions 2009. Department of Civil and Environmental Engineering, University of California at Berkeleyhttps://www.arb.ca.gov/research/seminars/harley3/harley3.pdf. Accessed October 20, 2017.

[82] C. Vieira De Souza, S.M. Corr, Polycyclic aromatic hydrocarbon emissions in diesel exhaust using gas chromatographyemass spectrometry with programmed temperature vaporization and large volume injection, (2015). doi:10.1016/j.atmosenv.2014.12.047.

[83] US EPA O. Initial List of Hazardous Air Pollutants with Modifications https://www.epa.gov/haps/initial-list-hazardous-air-pollutants-modifications.

Accessed October 20, 2017

[84] REGULATION (EC) No 70/220 OF THE EUROPEAN PARLIAMENT AND OF THE COUNCIL of 26 June 1991 on the approximation of the laws of the Member States relating to measures to be taken against air pollution by emissions from motor vehicles. EC OJ L 242, 30.8.1991, p. 1) http://eur- 
lex.europa.eu/legal-content/EN/TXT/PDF/?uri=CELEX:31991L0441\&from=EN Accessed November 27, 2017

[85] DIRECTIVE (EC) No 70/220 OF THE EUROPEAN PARLIAMENT AND OF THE COUNCIL of 13 October 1998 on the approximation of the laws of the Member States relating to measures to be taken against air pollution by emissions from motor vehicles and amending Council Directive 70/220/EEC. EC OJ L 350, 28.12.1998, p. 1)

http://eur-lex.europa.eu/resource.html?uri=cellar:9ee5d16b-1a4a-4a72-ac905e3a0bb1d745.0008.02/DOC_1\&format=PDF Accessed November 27, 2017

[86] REGULATION (EC) No 715/2007 OF THE EUROPEAN PARLIAMENT AND OF THE COUNCIL of 20 June 2007 on type approval of motor vehicles with respect to emissions from light passenger and commercial vehicles (Euro 5 and Euro 6) and on access to vehicle repair and maintenance information. EC OJ L $171,29.6 .2007$, p. 1)

http://eur-

lex.europa.eu/LexUriServ/LexUriServ.do?uri=OJ:L:2007:171:0001:0016:EN:PDF. Accessed November 28, 2017.

[87] M. Williams, R. Minjares, A technical summary of Euro 6/VI vehicle emission standards, 2016. http://www.theicct.org/sites/default/files/publications/ICCT_Euro6VI_briefing_jun2016.pdf (accessed October 12, 2017).

[88] he Introduction of Euro 5 and Euro 6 Emissions Regulations for Light Passenger and Commercial Vehicles 2015. http://www.rsa.ie/Documents/Vehicle\%20Std\%20Leg/Emissions\%20regs/Euro\%2 05\%20and\%20Euro\%206\%20Emissions\%20Reg\%20light\%20passengercommve hicles.pdf. Accessed 20 October 2017.

[89] EURO standards https://www.ngk.de/en/technology-in-detail/lambdasensors/basic-exhaust-principles/euro-standards/. Accessed November 28, 2017

[90] US EPA O. Regulations for Onroad Vehicles and Engines. https://www.epa.gov/regulations-emissions-vehicles-and-engines/regulationsonroad-vehicles-and-engines. Accessed November 20, 2017

[91] Environmental Protection Agency. 40 CFR Ch. I (7-1-01 Edition). Subpart A-General Provisions for Emission Regulations for 1977 and Later Model Year New Light-Duty Vehicles, Light-Duty Trucks and Heavy-Duty Engines, and for 1985 and Later Model Year New Gasoline Fueled, Natural GasFueled, Liquefied Petroleum Gas-Fueled and Methanol-Fueled Heavy-Duty Vehicles. . Authenticated US Government Information GPO, 42 FR 32907, June 28, 1977, 12-391. www.gpo.gov/fdsys/pkg/CFR-2001-title40-vol15/pdf/CFR-2001title40-vol15-part86-subpartA.pdf. Accessed 20 Octubre 2017 
[92] Environmental Protection Agency. 40 CFR Parts 80, 85, and 86. Control of Air Pollution From New Motor Vehicles: Tier 2 Motor Vehicle Emissions Standards and Gasoline Sulfur Control Requirements; Final Rule. Federal Register, February 10, 2000, Rules and Regulations, vol. 65, No. 28, 6698-6870. https://www.gpo.gov/fdsys/pkg/FR-2000-02-10/pdf/00-19.pdf. Accessed October 20, 2017

[93] Low Emission Vehicle (LEV) Program https://www.arb.ca.gov/msprog/levprog/levprog.htm\#background (accessed October 12, 2017).

[94] State of California. Air Resources Board. California exhaust emission standards and test procedures for 1988 and subsequent model passenger cars, light-duty trucks, and medium-duty vehicles. Adopted 20 May 1987 and amended 24 June 1996. 1-1 to 14-1. https://www.arb.ca.gov/msprog/levprog/ldvtps.pdf. Accessed October 20, 2017

[95] California Air Resources Board. LEV II and CAP 2000 amendments. Final Regulation Order Title 13, California Code of Regulations (CCR). Filed w/ Secretary of State 28 October 1999. Adopted 5 August 1999. 1-80. https://www.arb.ca.gov/regact/levii/oalfinal/finregor.pdf. Accessed October 20, 2017

[96] Environmental Protection Agency. 40 CFR Parts 79, 80, 85, et al. Control of Air Pollution From Motor Vehicles: Tier 3 Motor Vehicle Emission and Fuel Standards; Final Rule. Federal Register, April 28, 2014, Rules and Regulations, vol. 79, no. 81, 23414-23886. https://www.gpo.gov/fdsys/pkg/FR-2014-0428/pdf/2014-06954.pdf. Accessed October 20, 2017

[97] California Environmental Protection Agency. Air Resources Board. California 2015 and subsequent model criteria pollutant exhaust emission standards and test procedures and 2017 and subsequent model greenhouse gas exhaust emission standards and test procedures for passenger cars, light-duty trucks, and medium-duty vehicles. Adopted 22 March 2012. A-1 to II-36. https://www.arb.ca.gov/msprog/levprog/leviii/attacha3.pdf. Accessed October 20, 2017

[98] Emission Standards: USA: Cars and Light-Duty Trucks-Tier 3. https://www.dieselnet.com/standards/us/ld_t3.php (accessed November 22, 2017)

[99] F. Schubert, S. Wollenhaupt, J. Kita, G. Hagen, R. Moos, Platform to develop exhaust gas sensors manufactured by glass-solder-supported joining of sintered yttria-stabilized zirconia, J. Sensors Sens. Syst. 5 (2016) 25-32. doi:10.5194/jsss-5-25-2016. 
[100] S. Akbar, P. Dutta, C. Lee, High-Temperature Ceramic Gas Sensors: A Review, International Journal of Applied Ceramic Technology 3[4] 2006 302-311. doi: 10.1111/j.1744-7402.2006.02084.x

[101] M.T. McCulloch, N. Langford, G. Duxbury, Real-time trace-level detection of carbon dioxide and ethylene in car exhaust gases, Appl. Opt. 44 (2005) 2887. doi:10.1364/AO.44.002887.

[102] E. Grosjean, R.A. Rasmussen, D. Grosjean, Ambient levels of gas phase pollutants in Porto Alegre, Brazil, Atmos. Environ. 32 (1998) 3371-3379. doi:10.1016/S1352-2310(98)00007-7.

[103] S.G. Poulopoulos, D.P. Samaras, C.J. Philippopoulos, Regulated and unregulated emissions from an internal combustion engine operating on ethanolcontaining fuels, Atmos. Environ. 35 (2001) 4399-4406. doi:10.1016/S13522310(01)00248-5 

Chapter 2

Methodology 



\section{Methodology}

\subsection{Material synthesis}

Several methodologies have been applied to the preparation of the materials in function of the desirable characteristics for the powders and of the metal precursors nature. 8YSZ, ScSZ were available from commercial suppliers. CGO have been used from both a commercial supplier and by co-precipitation method. On the other hand, perovskites, spinels and mixture of oxides were obtained by a sol-gel route method. Finally, the catalyst to be infiltrated onto the porous substrates was introduced via precursors (nitrates mainly) dilution in ethanolwater.

\subsubsection{Co-precipitation}

One of the main advantages of this method is that it allows the synthesis of nanometric size powders. In this work this method, depicted in figure 2.1, has been used on the fabrication of gadolinium doped ceria electrolytes.

A clear solution of both commercial cerium and gadolinium nitrates (Sigma Aldrich) mixture is prepared in deionized water at $50{ }^{\circ} \mathrm{C}$. $\mathrm{A}(\mathrm{NH} 4)_{2} \mathrm{CO}_{3}$ solution is added to the nitrates mixture solution to get total precipitation and the final $\mathrm{NO}_{3}{ }^{-}$ $1 / \mathrm{CO}_{3}{ }^{-2}$ molar ratio is 0.75 . Then, the resultant precursor powders are dried at $100-150{ }^{\circ} \mathrm{C}$ after filtration and rinsing with water [1].

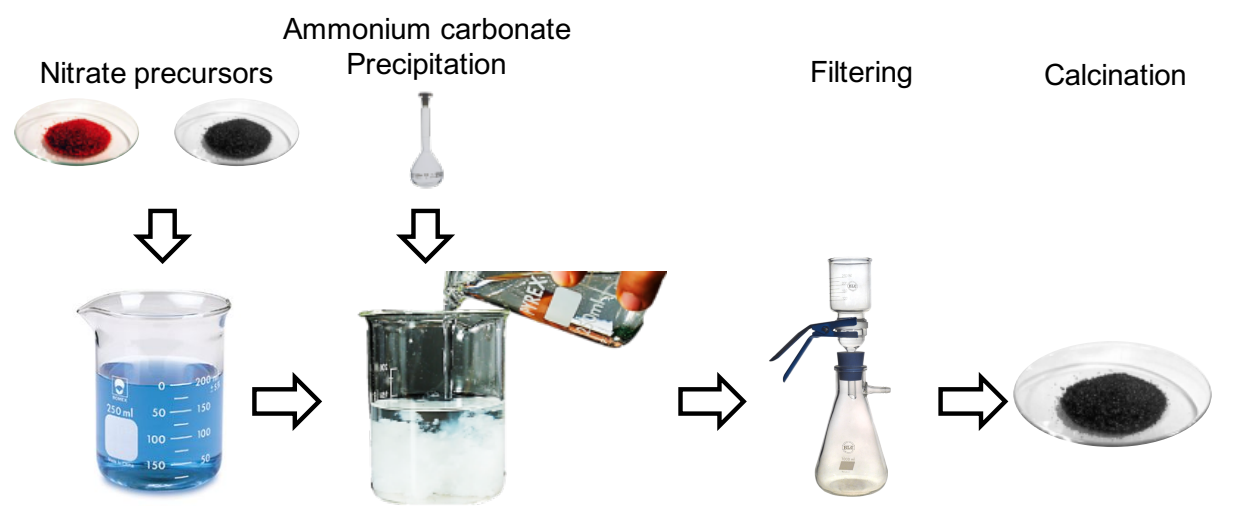

Figure 2.1 Scheme of the co-precipitation method for pure solid oxide formation 


\subsubsection{Sol-gel or Pechini Route}

The main advantage of this method is the homogeneity that can be achieved. This is possible because of getting carbonate-free, chemically homogeneous final oxide compounds that also have a high relative density and small size.

This technique involves the production of an amorphous-shape gel containing a metal complex. First, a homogeneous solution is obtained by mixing distilled water with transition metals as well as lanthanides nitrates employed as precursors $\left(\mathrm{Ce}\left(\mathrm{NO}_{3}\right)_{3} \cdot 6 \mathrm{H}_{2} \mathrm{O}\right.$ and $\mathrm{Fe}\left(\mathrm{NO}_{3}\right)_{3} \cdot 9 \mathrm{H}_{2} \mathrm{O}$ provided by Sigma Aldrich; $\mathrm{Ni}\left(\mathrm{NO}_{3}\right)_{3} \cdot 6 \mathrm{H}_{2} \mathrm{O}$ from $\left.\mathrm{ABCR}\right)$. Once the precursors powders are fully diluted, citric acid (Sigma Aldrich) are employed as chelating agent that prevents partial segregation of metal components [2]. Then, ethylene glycol was added to polymerize with the chelating agent and produce and organometallic polymer at $120^{\circ} \mathrm{C}$ (in a molar ratio 1:2:4 for nitrate solution, citric acid and ethylene glycol, respectively). Finally, the thermal decomposition of the precursors at $600{ }^{\circ} \mathrm{C}$ forms the desired structural phases (fluorite, perovskites, spinels, etc) [3,4].

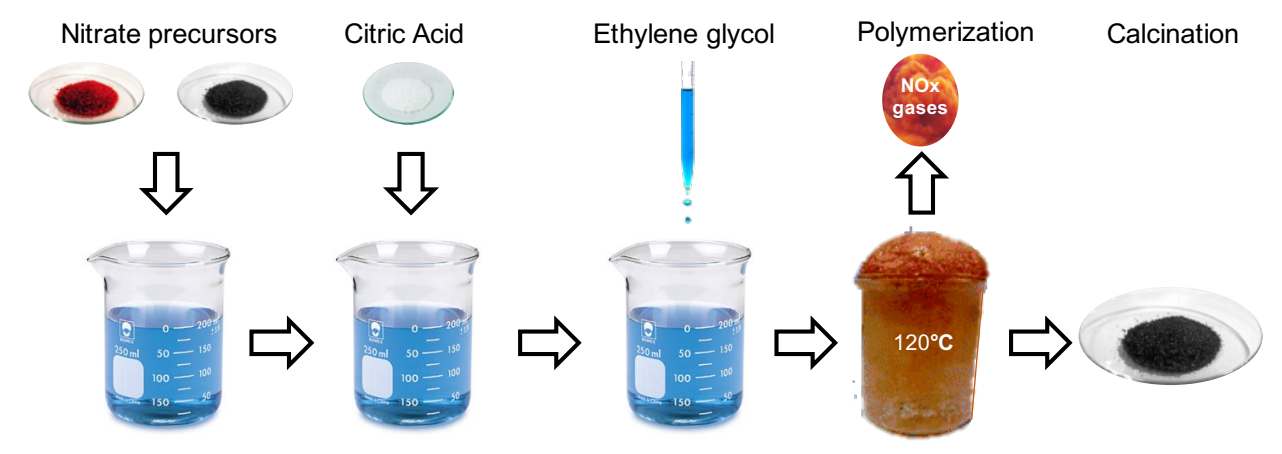

Figure 2.2 Scheme of the sol-gel or Pechini route for pure solid oxide formation

\subsection{Sample preparation}

\subsubsection{Electrolyte}

Solid electrolytes are obtained from the sintered powders through a procedure depicted in figure 2.3. Electrolytes consist of a flat disk with a diameter that depends on the configuration of the device as explained later. Homogeneity is achieved by ball-milling the powders with acetone and zirconia balls in a ratio 1:1:5 respectively for $24 \mathrm{~h}$. The final electrolyte consists of a flat disk with different diameter. Zirconia balls have $3 \mathrm{~mm}$ of diameter and the rotation goes up to 50 $\mathrm{rpm}$. This reduces and homogenize the particles size helping the sintering process. After the milling, the zirconia balls are pulled out and the powder dried. 
These powders are sieved through steel sieves to ensure a homogenous particles size distribution between 200 and $400 \mu \mathrm{m}$.

Here the process differs in function of the device configuration. The steps for both single and multi-device are explained below:

- Single device: A $26 \mathrm{~mm}$ diameter steel die is used to uniaxially press the material at $50 \mathrm{MPa}$ for 3 minutes. Afterwards, the green disk is sintered at high temperature in order to densify the electrolyte. The temperature and time of the process depend on the material, although usually is heated up to 1450 ${ }^{\circ} \mathrm{C}$ for $10 \mathrm{~h}$. In this case, the electrolyte has a diameter of $19 \mathrm{~mm}$ and a thickness between 500-900 $\mu \mathrm{m}$. The electrolyte disk-shape employed in the reactor for individual samples has to be polished till reduce the diameter to $15 \mathrm{~mm}$.

- Multi-device: This allow to use several channels. A $54 \mathrm{~mm}$ diameter steel die is used to uniaxially press the material at $100 \mathrm{MPa}$ for 1 minute. Afterwards, the green disk is sintered at an intermediate temperature in order to drill holes on the material to ensure wire connections later. After that, the material is sintered at high temperature $\left(1450^{\circ} \mathrm{C}\right.$ for $\left.10 \mathrm{~h}\right)$ to fully densify the electrolyte. In this case the electrolyte will have a diameter of $45 \mathrm{~mm}$ and a thickness between 100-1200 $\mu \mathrm{m}$.

For both configurations, the electrolyte faces are grinded with sandpaper to reach a homogeneous surface with no preferential paths.

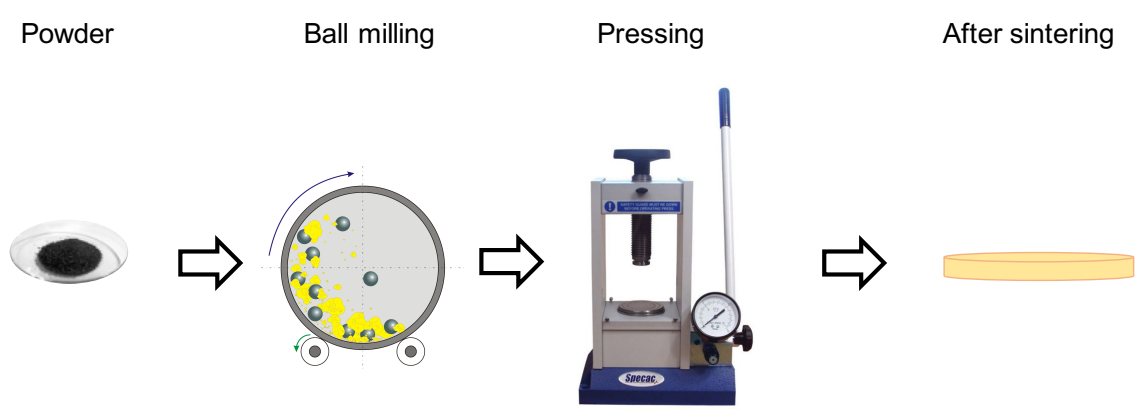

Figure 2.3 Methodology for the fabrication of solid disk-shape electrolytes 


\subsubsection{Electrode (catalytic layer) deposition}

Electrode porous layers with thicknesses within the range 15-30 $\mu \mathrm{m}$ were deposited on each face of the electrolyte. The electrodes layers are attached to the electrolyte by screen printing. This technique is low cost, simple and its reliability made it to be widely used to produce films in the range of 10-120 $\mu \mathrm{m}$.

In this method, a viscous ink containing the ceramic powder is applied to the electrolyte as depicted in figure 2.4. The ink consists of the ceramic powder mixed with an organic binder (ethyl cellulose) and a plasticizer (terpineol). The organic binder and the plasticizer help to get a fluid ink but with certain viscosity. These three elements are forced to pass through a three-roll mill to form a uniform slurry. This slurry is the ink that is employed to print over the electrolyte faces. In each step, the ink passes through a mesh, with different shapes, that provides a layer with a thickness of $15 \mu \mathrm{m}$. For thicker layers, the process has to be repeated after drying the previous layer at $70^{\circ} \mathrm{C}$ for $1 \mathrm{~h}$ or after completely dryness. Finally, the electrode is sintered at temperatures usually higher than $1000^{\circ} \mathrm{C}$.

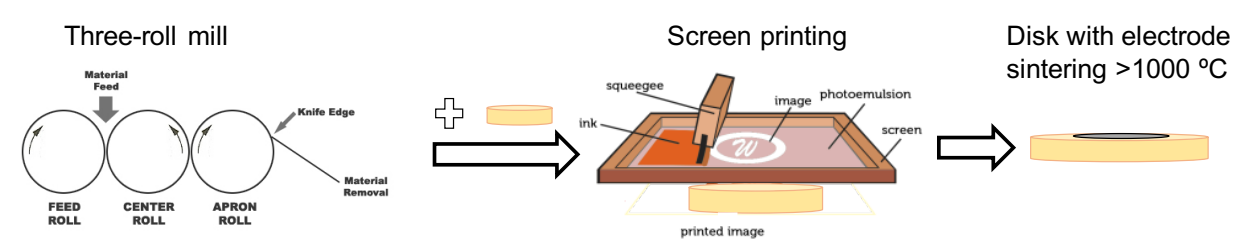

Figure 2.4 Methodology for the deposition of the catalytic layer over both faces of the electrolyte

In addition, a gold layer should be screen printed in top of non-electronic materials to ensure contact with the wires that goes to the measurement equipment. This layer will be dried and then sintered for $2 \mathrm{~h}$ at $800^{\circ} \mathrm{C}$.

In some cases, the electrodes were activated by infiltration of catalyst precursors (mostly nitrates) and subsequently calcined at $550{ }^{\circ} \mathrm{C}$ for $4 \mathrm{~h}$ in argon to remove the organics, and then at $550{ }^{\circ} \mathrm{C}$ as well for $2 \mathrm{~h}$ in a $5 \% \mathrm{H}_{2}$ in argon to reduce the catalyst. 


\subsection{Structural characterization}

\subsubsection{Scanning Electron Microscopy (SEM)}

Scanning electron microscopy (SEM) allows for high-resolution imaging of surfaces by using high-energy electrons (1-20KeV) generated by a heated tungsten filament. SEM has a magnification up to $10^{6}$ and great depth of field. For that purpose, an incident beam of monochromatic electrons causes a secondary emission across the sample surface, which is collected to form an image of the surface. The quality and contrast obtained in the image depends mainly on the conductivity and surface topography of the sample. Figure 2.5 shows a SEM column where there is an electron gun, two condenser lenses, an objective lens, an electron detection system, and a set of deflectors [5]. By detecting different emissions of the sample, it is possible to obtain diverse contrast images, i.e., backscattered electrons (BSE), Auger electrons (AES) and Energy dispersive $x$ ray spectroscopy (EDS). BSE causes different contrast subjected to the atomic number, $Z$, of the elements, so changes in composition can be distinguished; EDS is a qualitative and quantitative chemical microanalysis technique to characterize the elemental composition of the volume analysed. It is performed in conjunction with a SEM, but uses the X-rays that are emitted from the sample due to the electron beam. The combination of SEM with EDS allows the analysis of the sample morphology and the composition of the different phases that are present. The minimum detection limits are about 0.1 weight percent, depending on the element and matrix.

Conducting materials that allow the transport of the incident beam electrons do not need any handling of the sample. However, for poor conductors or insulators a conducting layer that does not modify the topography needs to be added. This is achieved by coating the sample under vacuum with Au or graphite (for EDS) using a sputter coater.

Two SEM devices were used on the characterizations, namely the Jeol JSM 6300 and Jeol JSM 5410, both with an acceleration voltage of $20 \mathrm{kV}$. The EDS microanalyses were carried out with a detector from Oxford Instruments. The Software INCAEnergy/Wave served for the interpretation of the X-ray patterns obtained. More recently, a ZEISS Ultra55 field emission SEM (FE-SEM) has been also used. 


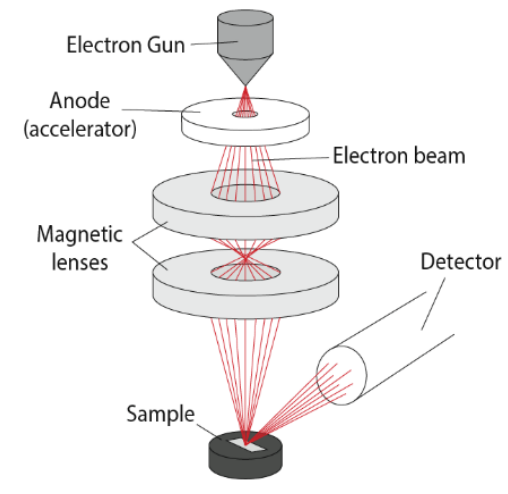

Figure 2.5 Schematic picture of SEM [6]

\subsubsection{Transmission Electron Microscopy (TEM)}

Transmission Electron Microscopy (TEM) utilizes energetic electrons to provide morphologic, compositional and crystallographic information on samples. The beam of electrons is transmitted through an ultra-thin specimen $(<200 \mathrm{~nm})$, interacting with it as the beam passes through. The electrons that are not absorbed by the sample are detected forming a two dimensions image, which is magnified and focused onto an imaging device (figure 2.6) $[7,8]$.

The TEM device employed for the experiments is a Philips CM10, which has allowed to check elements of particle sizes and morphologies of the nanoparticles. In addition, a transmission electron microscope FEI Tecnai F20 (with acceleration voltage of $200 \mathrm{kV}$ ) has been used.

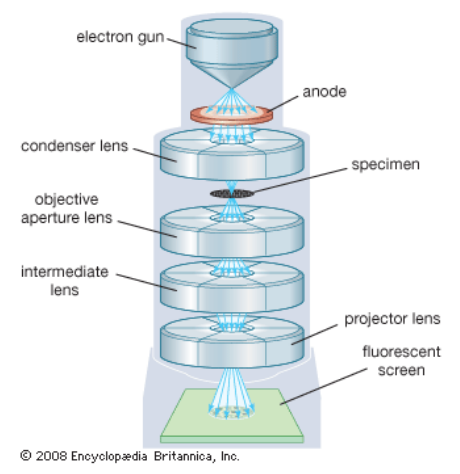

Figure 2.6 Schematic figure of TEM 


\subsubsection{X-Ray Diffraction}

In this thesis, very high temperatures $\left(>1000^{\circ} \mathrm{C}\right)$ have been used to produce metallic oxides and ensure the formation of crystalline compounds. Thus, they can be analysed by means of X-ray diffraction (XRD) technique [9].

Every crystalline substance has its own characteristic XRD pattern and therefore it can be used for its identification. XRD measurements are based on the physical principle that a monochromatic $X$-ray beam with a wavelength $\lambda$ comes into contact with the crystalline material at a particular angle. The diffraction is produced only when the distance travelled by the rays reflected from successive planes differs by a complete number of wavelengths and the detector records the intensity. As shown in Figure 2.7, the diffracted angle from the family of crystallographic planes $(h k l)$ has a value of $2 \lambda$, which is employed to determine the distance between layers of atoms in a sample using the Bragg's law:

$$
\lambda=2 \mathrm{~d} \cdot \sin \theta
$$

The angles of diffraction are characterized by peaks, whose height is function of the interaction of the X-ray with the crystal as well as the intensity of the source. The position of the peaks not only determines the crystalline substance but also provides information about the unit cell size and lattice parameters. Information about the crystallite size and microstrains can also be obtained through this technique.

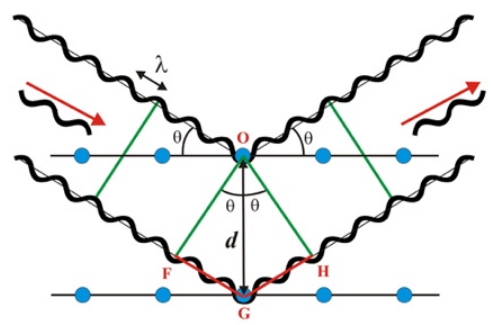

Figure 2.7 Schematic picture of Bragg's Law where diffraction of X-rays on a crystalline material can be observed [11]

Crystals have a regular and repetitive structure and the unit cell is the smallest repeating volume of the crystal and it is representative of the whole crystal. This unit cell is determined by three lattice constants $a, b, c$ (the basis vectors) and by three angles $\alpha, \beta, \gamma$ which separate the vectors: $\alpha$ separates $b$ and $c, \beta$ separates $a$ and $c$, and finally, $\mathrm{y}$ separates $\mathrm{a}$ and $\mathrm{b}$. The combination of these vectors and 
angles provides up to 14 structures, which are known as the fourteen Bravais lattices (figure 2.8) [10].

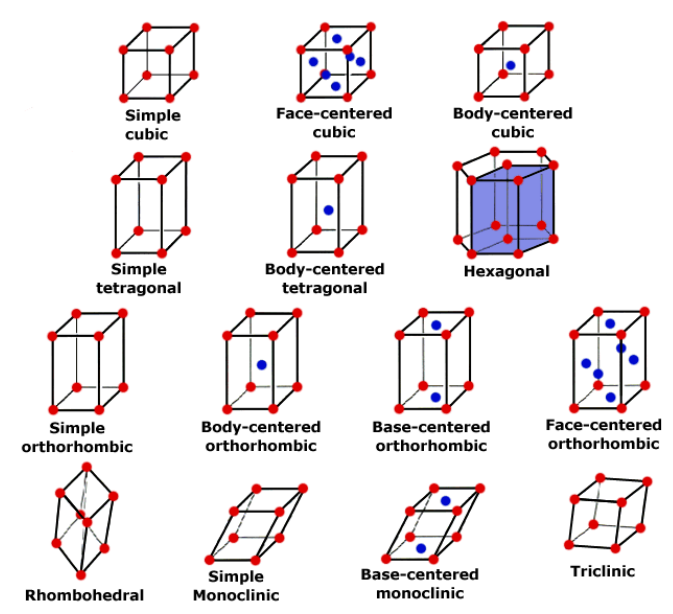

Figure 2.8 The fourteen Bravais lattices. Image extracted from [12]

Table 2.1 Bravais lattices parameters

\begin{tabular}{|ccc|}
\hline Crystal system & Edge lenght & Interaxial angle \\
\hline Triclinic & $\mathrm{a} \neq \mathrm{b} \neq \mathrm{c}$ & $\alpha \neq \beta \neq \gamma \neq 90^{\circ}$ \\
$\mathrm{a} \neq \mathrm{b} \neq \mathrm{c}$ & $\alpha=\gamma=90^{\circ} \neq \beta$ \\
Monoclinic & $\mathrm{a} \neq \mathrm{b} \neq \mathrm{c}$ & $\alpha=\beta=\gamma=90^{\circ}$ \\
Orthorhombic & $\mathrm{a}=\mathrm{b} \neq \mathrm{c}$ & $\alpha=\beta=\gamma=90^{\circ}$ \\
Tetragonal & $\mathrm{a}=\mathrm{b} \neq \mathrm{c}$ & $\alpha=\beta=90^{\circ}, \gamma=120^{\circ}$ \\
Hexagonal & $\mathrm{a}=\mathrm{b}=\mathrm{c}$ & $\alpha=\beta=\gamma \neq 90^{\circ}$ \\
Rhombohedral & $\mathrm{a}=\mathrm{b}=\mathrm{c}$ & $\alpha=\beta=\gamma=90^{\circ}$ \\
Cubic & & \\
\hline
\end{tabular}

A PANalytical Cubix fast diffractometer, using CuKa1 radiation $(\lambda=1.5406 \AA)$ and an $X^{\prime}$ Celerator detector in Bragg-Brentano geometry has been used for the identification of the crystalline phases. XRD patterns recorded in the $2 \lambda$ range from $10^{\circ}$ to $90^{\circ}$ were analyzed using X'Pert Highscore Plus software.

XRD has been employed in the present thesis for the determination of the phase purity of the synthesized compounds and discard the presence of impurities and secondary phases. as well as the study of the degradation of membranes after permeation tests. 


\subsubsection{Raman spectroscopy}

Information about the structure and properties of molecules forming ceramic materials can be obtained by using Raman spectroscopy. This information is obtained from the vibrational transitions of molecules. Raman vibrational bands are characterized by their frequency (energy), intensity, and band shape (environment of bonds). Depending on the masses of the atoms, their geometric arrangement and the strength of chemical bonds different frequencies will be obtained [13]. Therefore, observing anomalies in the position, intensity and shape of the bands it is possible to detect structural and compositional changes.

Raman spectra were measured with a Renishaw inVia Raman spectrometer equipped with a Leica DMLM microscope and a 514-nm $\mathrm{Ar}^{+}$ion laser as an excitation source. A x50 objective of 8-mm optical length was used to focus the depolarized laser beam on a spot of about $3 \mu \mathrm{m}$ in diameter. The Raman scattering was collected with a charged coupled device (CCD) array detector.

\subsubsection{X-Ray photoelectron Spectroscopy}

The X-ray photoelectron spectroscopy (XPS) technique analyses the surface chemistry of one compound. XPS method uses X-rays of energy $h v$ to eject electrons from inner-shell orbitals. Usually, the monochromatic sources of radiation are either $\mathrm{Al} \mathrm{Ka}(1486.6 \mathrm{eV})$ or $\mathrm{Mg} \mathrm{Ka}(1253.6 \mathrm{eV})$. The photon is absorbed by an atom in a molecule or solid, which leads to ionization and emission of a core (inner shell) electron. Then, the energy of electrons emitted by the material can be measured by using any appropriate electron energy analyser and thus, a photoelectron spectrum can be recorded following:

$E_{K}=h v+E_{b}+E_{W}(2.2)$

Where $E_{k}$ is the kinetic energy of the electrons, $h v$ is the energy of the photons, $E_{b}$ is the binding energy characteristic of each element, and $E_{w}$ is the work function of the spectrometer. The measurement generates a spectrum with some photoelectron peaks whose peak areas determine the composition of the materials surface. Both the shape of each peak and the binding energy can be slightly altered by the chemical state of the emitting atom and these abnormalities can be used to extract chemical bonding information. However, XPS is not sensitive to hydrogen or helium, and must be carried out in ultra-high vacuum conditions. [14]

Sintered pellets of the materials under study were quenched from high temperature in the desired atmosphere to air saturated liquid N2 to imitate the 
surface in working experimental conditions. Measurements were carried out on a SPECS spectrometer with a MCD-9 detector and using a non-monochromatic Al $\mathrm{K} X$-ray source. Spectra were recorded using analyzer pass energy of $30 \mathrm{~V}$, an Xray power of $100 \mathrm{~W}$ and under an operating pressure of 10-9 mbar. CASA software has been used to perform the spectra treatment. Binding energies (BE) were referenced to the $C 1 \mathrm{~s}$ peak at $284.5 \mathrm{eV}$. The energy regions of $\mathrm{O} 1 \mathrm{~s}$ and $\mathrm{C}$ $1 \mathrm{~s}$ transitions and the specific ones of the materials were recorded.

\subsection{Electrochemical characterization. Sensor performance}

\subsubsection{Open circuit voltage measurement}

Open circuit voltage measurements based on measuring the voltage for a zerocurrent applied were performed on the samples under different atmospheres and temperature.

In function of the sample, different set-ups were employed as discussed later.

\section{First reactor: Individual samples}

This methodology was followed for the first screening of the materials employed as working electrodes in chapter 3.

A gold layer is printed in top of the working electrode to ensure electrical contact between the current collector and the electrode. This can be skipped when platinum is employed as reference electrode because of its high electronical conductivity.

Two platinum current collectors are pressed onto both electrodes, and then the voltage gradient generated between both electrodes is recorded when no current is applied (employing a zero-current mode).

The measurements are carried out at $550^{\circ} \mathrm{C}$ and with a fix amount of $6 \%$ of oxygen. Several concentrations of ethylene and carbon monoxide are employed. The total flow is $550 \mathrm{ml} / \mathrm{min}$ and the gas flow is balanced with argon. Several sets of measurements were performed with different analytes concentrations:

- First set: Sensor performance was tested for both ethylene and carbon monoxide individually from $400 \mathrm{ppm}$ to 600,800 and $1000 \mathrm{ppm}$ in cycles of 20 minutes as indicated in figure 2.9. The same changes in 
concentration but with a background of $400 \mathrm{ppm}$ of the other analyte were performed for $\mathrm{Fe}_{2} \mathrm{NiO}_{4}$. In the case of $\mathrm{ZnCr}_{2} \mathrm{O}_{4}$ the sensor was also exposed to $400 \mathrm{ppm}$ of ethylene carbon monoxide and nitrogen dioxide.

- Second set: In this set of measurements the concentration range was decreased to 50-200 ppm. The response was checked for ethylene and carbon monoxide from $50 \mathrm{ppm}$ to 100,150 and $200 \mathrm{ppm}$ in cycles of 20 minutes. The cross-sensitivity was checked by three pulses of concentration from 50 to $200 \mathrm{ppm}$ of one analyte while the other remain fixed at $50 \mathrm{ppm}$.

- Third set: This final set is similar to the second set. First, concentration pulses of 20 minutes from 50 to 100, 150 and 200 ppm are performed for ethylene and carbon monoxide. But in this case the cross-sensitivity was checked by means of repeating the aforementioned concentration pulses for one analyte with $200 \mathrm{ppm}$ fixed of the other analyte as background. This third set was set as the standard method.

The acquisition of the voltage was performed by a Solartron 1470E. The equipment has two pairs of wires, one for current transport and another for voltage. Each pair is connected to platinum wires that are connected to the platinum current collectors, which in turn are connected to the electrodes. Thus, a zero-current was employed to record the voltage.

The output voltage is corrected in relation to the sensor response to the base gas. Thus, the voltage is calculated as a function of the sensor output to the neutral conditions $\left(6 \% \mathrm{O}_{2}\right.$ in $\left.\mathrm{Ar}\right)$ :

$$
\Delta V(m V)=V_{m}-V_{b}
$$

Where $V_{b}$ is the sensor response to $\mathrm{Ar}+6 \% \mathrm{O}_{2}$ and $\mathrm{V}_{\mathrm{m}}$ is the sensor response in sensing conditions. 


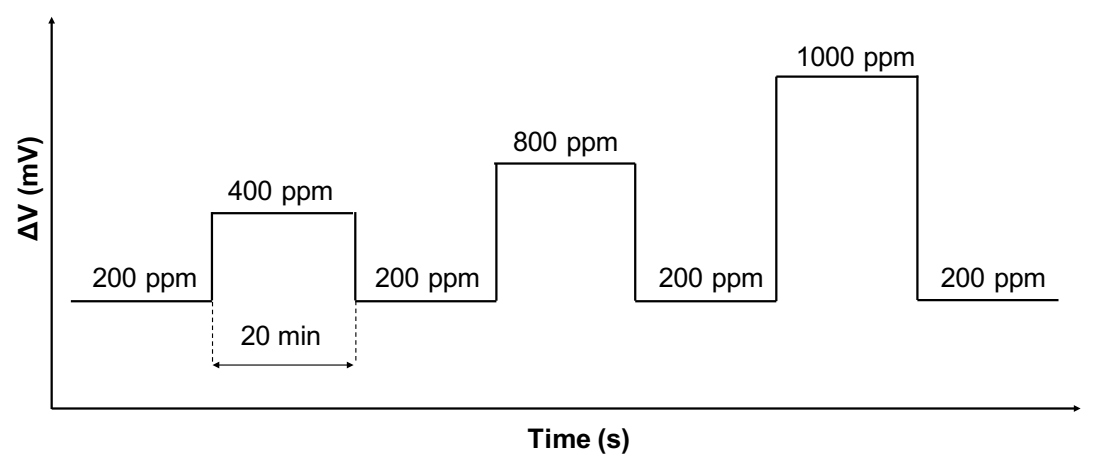

Figure 2.9 Methodology for individual sensors in the first reactor

\section{Second reactor: multi-sensor and individual samples}

Once the best materials are selected, a second reactor is designed to employ a multisensory device and work on the optimization of the device as it allows to measure up to 4 devices as shown in figure 2.10.

a)

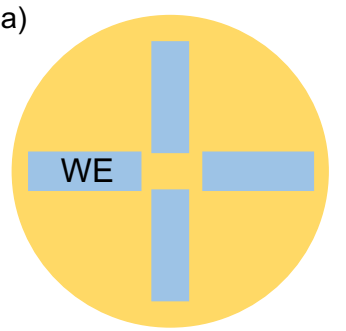

b)

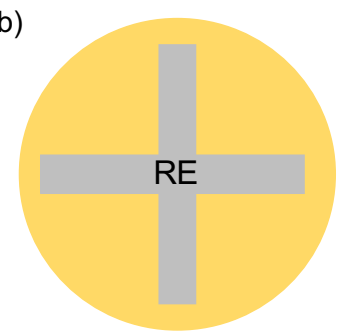

Figure 2.10 Multi-sensor device: a) Top face with four working electrodes on it and b) back face with one common reference electrode

A gold layer is printed in top of the working electrode to ensure electrical contact between the current collector and the electrode. In this reactor, the sensor has a hole for each electrode to ensure the electrical contact with the gold wires. Once the wire is passed through each hole and wrapped, silver paste is applied to ensure the contact between wire and electrode gold surface.

The measurements conditions are similar to the previous point. They are carried out at $550^{\circ} \mathrm{C}$ and with a fix $6 \%$ of oxygen. The measurements methodology for ethylene and carbon monoxide was the standard third set described in the previous point. The range of concentration is decreased to $50-200 \mathrm{ppm}$, which is within the car exhaust gas concentrations. 
Thus, sensor performance is tested for each gas individually from $50 \mathrm{ppm}$ to 100 , 150 and 200 ppm in cycles of 20 minutes as indicated in figure 2.11. Crosssensitivity is checked by repeating this concentration pulses with a fixed $200 \mathrm{ppm}$ of background of the other analyte. The total flow is $550 \mathrm{ml} / \mathrm{min}$ and the gas flow is balanced with argon.

The acquisition of the voltage was performed by a Keithley 3706 . The equipment is connected to a multiplexer that allows the measurement of four channels at the same time. Each channel consists of two wires: one is connected to the working electrode and the other one to the reference electrode.

As in the previous reactor, the output voltage is corrected in relation to the sensor response to the base gas as indicated in equation 2.3.

In chapter 5 a catalytic strategy was carried out in the working electrode to improve the sensor performance. Several devices were measured with different nanocatalyst added into the working electrode. If aspects such as the electrolyte thickness or electrode geometry and thickness differs, it can generate divergences in the voltage recorded. Thus, in order to enable comparison between the different devices, a normalization of the data is performed. Each device is normalized to its maximum response in the range $0-100$. This enable the comparison of the sensor trend when exposed to different conditions.

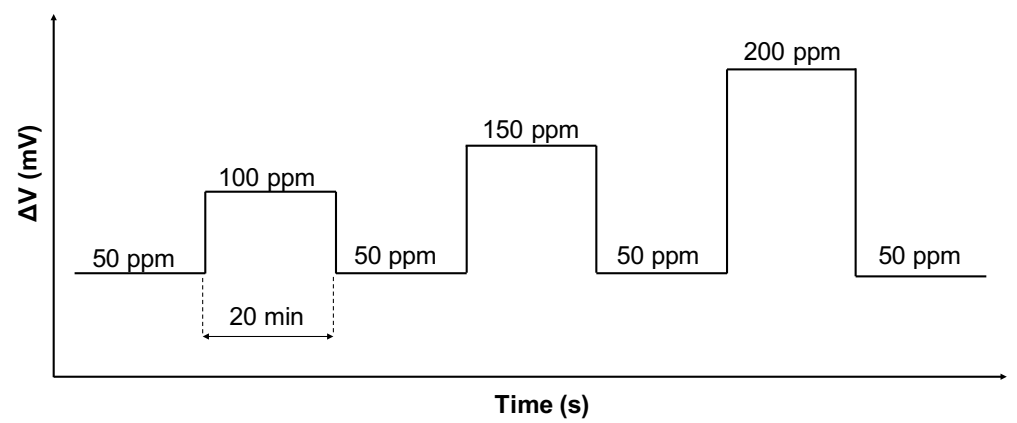

Figure 2.11 Methodology for multisensory and individual sensors in the second reactor

\subsubsection{Electrochemical Impedance Spectroscopy (EIS)}

The electrochemical impedance spectroscopy is a powerful technique that can give information about the processes that take place in the device, and moreover, determine which one is limiting the performance of the sensor. These processes can be either within the material (grain and grain boundary diffusion) or with 
process that takes place in the electrode or in the interface electrode-electrolyte (gas diffusion, mass and charge exchange reactions, adsorption, etc).

In EIS a small sinusoidal current or voltage is passed through the sample and the phase shift and amplitude (i.e. the real and imaginary parts) of the resulting voltage/current are measured [15]. In these measurements, the dependence of the frequency is not negligible, and analogous to Ohm's Law, the following equation applies:

$$
E=I \cdot Z
$$

Moreover, the voltage excitation signal can be expressed as function of time:

$$
E_{t}=E_{0} \sin (\omega t) \quad(2.5)
$$

Where $E_{t}$ is the voltage at $t$ time, $E_{0}$ is the amplitude of the signal and $\omega$ is the radial frequency. In a linear system, the current response signal $\left(I_{t}\right)$ is shifted in phase $\varphi$ with different amplitude $\left(\mathrm{I}_{0}\right)$ :

$$
I_{t}=I_{0} \sin (\omega t+\varphi) \quad(2.6)
$$

According to equations $2.4,2.5$ and 2.6 , the impedance can be expressed as:

$$
Z=\frac{E_{0} \sin (\omega t)}{I_{0} \sin (\omega t+\varphi)}=Z_{0} \frac{\sin (\omega t)}{\sin (\omega t+\varphi)}
$$

Finally, the impedance can also be expressed as a complex function with a real and imaginary part:

$$
Z(\omega)=Z_{0} \exp (i \varphi)=Z_{0} \cdot \exp [\cos (\varphi)+i \cdot \sin (\varphi)]
$$

Usually, EIS data analysis is made by plotting the results and fitting them to an electrical equivalent circuit that allows a physical interpretation of the data. The graphic representation of the imaginary part on the $y$-axis and the real part on the $\mathrm{x}$-axis gives a Nyquist plot and the spectras show usually a semicircle shape as indicated in figure 2.12. In this type of graphic, the intercept at high frequencies with the real axis is the pure ohmic resistance of the cell $\left(R_{0}\right)$. On the other hand, the intercept at the lower frequency in the real axis represents the differential resistance. The difference between the differential resistance and the ohmic resistance is the polarization resistance $\left(R_{p}\right)$ of the cell which is the sum of each single polarisation resistance caused by the loss mechanisms inside the cell. 


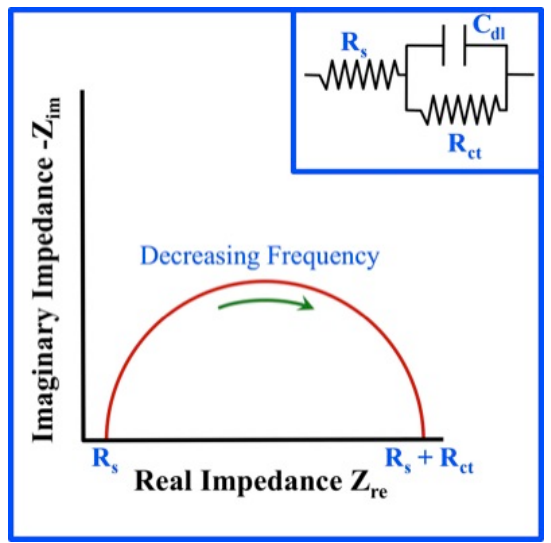

Figure 2.12 Impedance results as function of the imaginary and real impedance. Inset represents the equivalent electrical circuit that fits the EIS measurement response [16].

As said before, each process takes place at different frequencies. Thus, almost instantaneous electron or electron holes transport happens at high frequencies while other slower processes as the catalytic and the gas diffusion take place at lower frequencies. The equivalent electric circuits can explain which processes are taking place and which one is limiting the performance of the sensor.

The EIS measurement were performed in two-points configuration. Sensor output voltage to either $1000 \mathrm{ppm}$ or $200 \mathrm{ppm}$ of ethylene and carbon monoxide was employed as input signal, and a $10 \%$ of the sensor voltage as amplitude signal in the $1 \mathrm{E}-2$ to $1 \mathrm{E} 6 \mathrm{~Hz}$ frequency range. The response to the base gas $\left(\mathrm{Ar}+6 \% \mathrm{O}_{2}\right)$ was also evaluated.

The sinusoidal signal and the acquisition of the data were generated by a Solartron $1470 E$ and a 1455 A FRA module equipment in the first reactor. In the second reactor, the sinusoidal signal and the acquisition of the data were generated by an Autolab PGSTAT101 and a FRA32M module equipment.

Both machines have two pairs of wires, one for the current transport and the other one for the voltage. Each pair is connected to the wires that contact each one of the electrodes as shown in figure 2.13. 


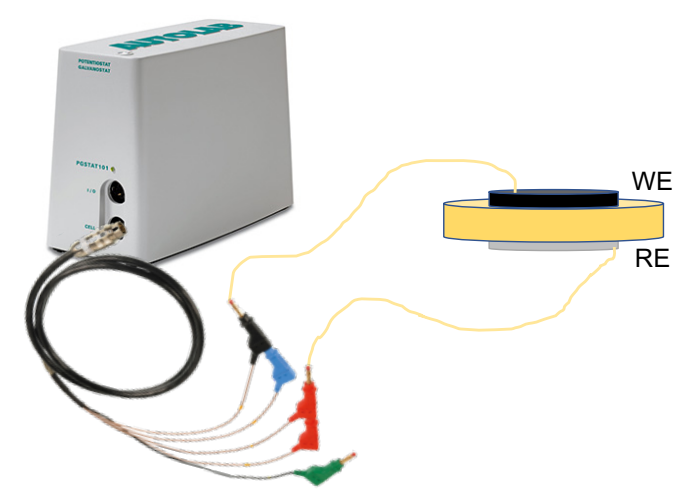

Figure 2.13 Scheme of the connection between the sensor and the Autolab PGSTAT101 and FRA32M module

\subsubsection{Experimental set-up and sensing}

\section{First reactor: Individual samples}

The first measurements were performed to check the suitability of the material for the ethylene sensing purpose. Thus, these materials screening were performed on a cylindrical two chambers quartz reactor as depicted in figure 2.14. The inner chamber has $16 \mathrm{~mm}$ diameter with a flat holed bottom that supports the device. Both electrodes are pressed by a Platinum mesh current collector that is connected to platinum wires that go through alumina tubes. The wires are plugged to the Solartron. The reactor is located inside a furnace that allows the heating of the sample to the desired temperature $\left(550^{\circ} \mathrm{C}\right)$, controlled by a thermocouple that was placed inside the chamber through the same alumina tube used by platinum wires.

Argon and oxygen gases were directly supplied from the pipeline distribution system available in the ITQ facilities. On the other hand, ethylene and carbon monoxide were fed from gas cylinders connected to the bench. The flow rate of all gas streams was controlled by mass flow controllers. The composition of the gas was checked by a gas chromatograph (micro-GC Varian CP-4900 equipped with Molsieve5A, PoraPlot-Q glass capillary and CP-Sil modules). 


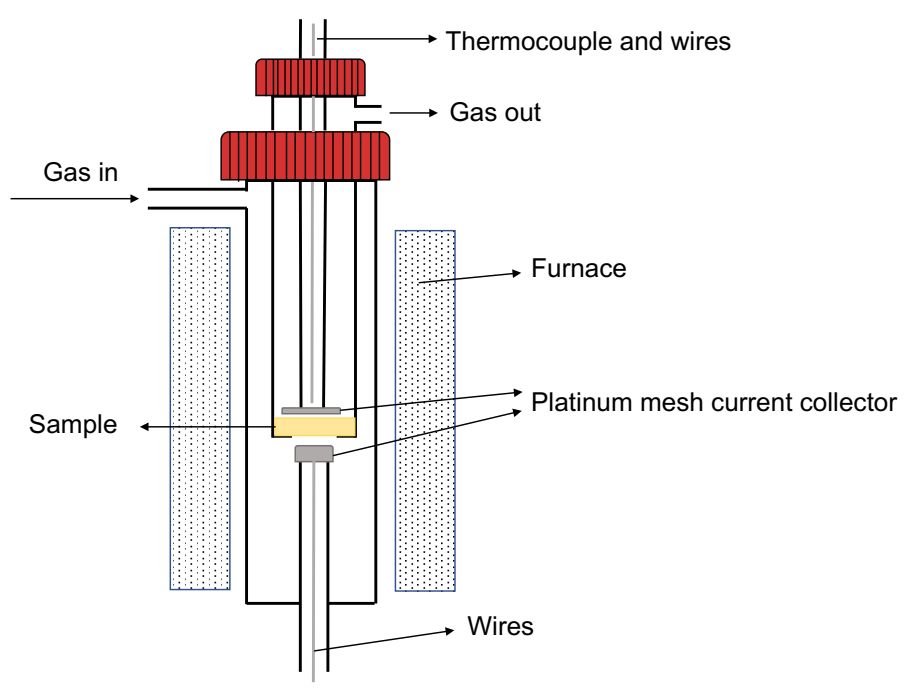

Figure 2.14 Schematic view of the first reactor for measurement of individual samples

\section{Second reactor: multi-sensor}

This reactor consists of a $70 \mathrm{~cm}$ cylindrical quartz tube with two lids. In one of these lids, two steel rods are employed to hold a ceramic holder where the samples are putted in (figure 2.15). Eight gold wires are passed through two alumina tubes (four wires in each tube) to contact the electrodes. These wires are plugged to the Keithley and the Autolab. A thermocouple to control the temperature in the sample area is also introduced.

Previously, the samples have been mechanized to make a hole that ensure the electrical contact with gold wires.

As in the previous reactor, Argon and oxygen gases were directly supplied from the pipeline distribution system available in the ITQ facilities. Ethylene and carbon monoxide were fed from gas cylinders connected to the bench. The flow rate of all gas streams was controlled by mass flow controllers $(550 \mathrm{ml} / \mathrm{min})$. 


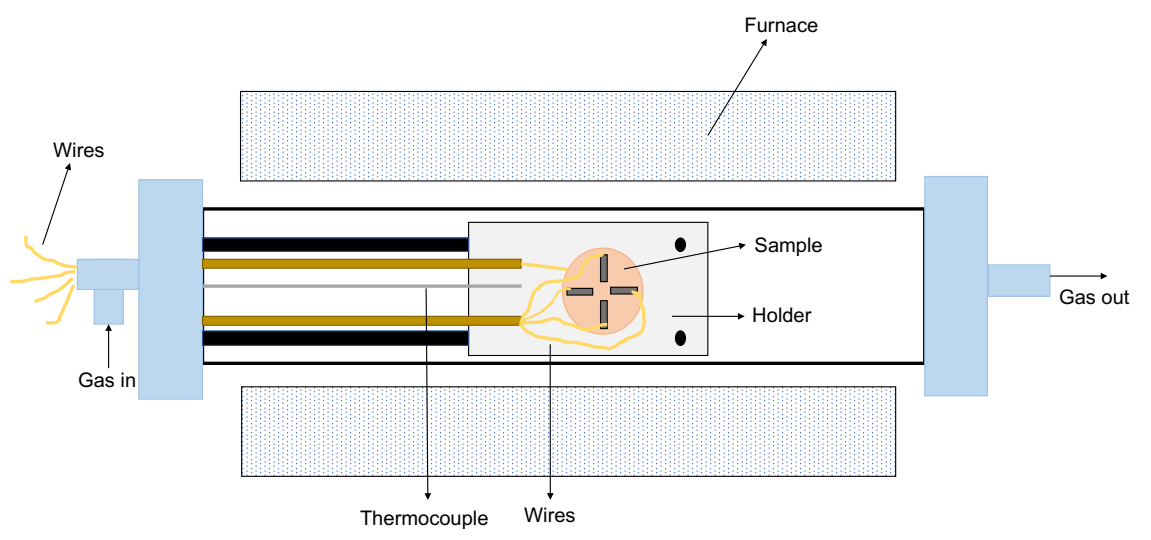

Figure 2.15 Schematic view of the reactor for multi-sensing. Four channels are available to measure four sensors at the same time

\subsection{References}

[1] S.-F. Wang, C.-T. Yeh, Y.-R. Wang, Y.-C. Wu, Characterization of samarium-doped ceria powders prepared by hydrothermal synthesis for use in solid state oxide fuel cells, Journal of Materials Research and Technology 2, Issue 2 (2013) 141-148. doi: http://10.1016/j.jmrt.2013.01.004

[2] M.P. Pechini, US Patent no 3330 697, in, 1967.

[3] R.M.A. Roque-Malherbe, The Physical Chemistry of Materials: Energy and Environmental Applications, CRC Press, 2009.

[4] S. Sakka, Handbook of sol-gel science and technology. 1. Sol-gel processing, Kluwer Academic Publishers, 2005.

[5] A. Khursheed, Scanning Electron Microscope Optics and Spectrometers, World Scientific, 2011.

[6] www.eng-atoms.msm.cam.ac.uk/RoyalSocDemos/SEM (accessed October 20, 2017)

[7] D.B. Williams, C.B. Carter, Transmission Electron Microscopy: A Textbook for Materials Science. Diffraction. II, Springer, 1996.

[8] E.N. Kaufmann, Characterization of Materials $2^{\text {nd }}$ ed, John Wiley \& Sons, 2002

[9] T. Ishihara, Perovskite Oxide for Solid Oxide Fuel Cells, Springer, US, 2009.

[10] W. Massa, Crystal Structure Determination, $2^{\text {nd }}$ ed., Springer, Berlin, 2004 
[11] www.xtal.iqfr.csic.es/Cristalografia/index-en.html (accessed October 20, 2017)

[12] www.seas.upenn.edu/ chem101/sschem/solidstatechem.html\#bravais (accessed October 20, 2017)

[13] P. Larkin, Infrared and Raman Spectroscopy, Elsevier, cop., Boston, 2011.

[14] H.R. Verma, Atomic and nuclear analytical methods: XRF, Mössbauer, XPS, NAA and Ion-Beam Spectroscopic Techniques, Springer, Berlin, 2006.

[15] R. Macdonald, Impedance Spectroscopy, J John Wiley \& Sons, 1987.

[16] www.gscsg.com/Electrochemical\%20Impedance\%20Spectroscopy.html 

Chapter 3

Study of working electrode materials for a selective $\mathrm{C}_{2} \mathrm{H}_{4}$ response 



\section{Study of working electrode materials for a selective $\mathrm{C}_{2} \mathrm{H}_{4}$ response}

\subsection{Introduction}

Potentiometric sensors are widely employed as exhaust gas sensors because of its toughness and stability under severe conditions of operation. The device must endure harsh conditions in terms of temperature and chemical stability. Ionic conductor materials such as zirconium oxide stabilized with yttrium (8YSZ) are commonly used as electrolyte because of its toughness. The device works as a solid-state electrochemical membrane, where oxygen is reduced on the reference electrode and oxygen ions from electrolyte are employed to oxidize the target gas on the working electrode. This explains the second main advantage of this kind of sensors, consisting in the possibility to expose both electrodes to the same environment. This characteristic makes the sensors suitable for automotive applications, e.g. detection of $\mathrm{CO}, \mathrm{NH}_{3}, \mathrm{NO}_{x}, \mathrm{CO}$, etc [1-3]. However, several reactions can take place at each electrode and an equilibrium will be achieved. Thus, the reaction with a faster reaction rate in each electrode is the one that will determine the electrochemical behaviour of the device. As can be derived from this, cross sensitivity should be avoided so that the working electrode must be selective to the target gas while the reference electrode should be catalytically active to oxygen. A proper selection of the materials for both electrodes is a key point for the sensor performance.

The device employed through this chapter consists of a solid 8YSZ membrane electrolyte [4-9], with a circular-shape working electrode in the top face and one circular-shape reference electrode in the back face, both of them screen-printed. The objective is to develop a device selective to ethylene with low crosssensitivity to carbon monoxide. The response is measured as a difference in voltage and it is measured when the sensor is exposed to different concentrations of ethylene and carbon monoxide, two of the most-abundant partially-oxidized compounds in diesel exhaust gas. A fixed $6 \%$ of oxygen is employed and finally, the flow is balanced with Argon to $550 \mathrm{ml} / \mathrm{min}$.

In the present chapter, several materials were screened for checking two issues: 1 ) the response to ethylene and 2) the cross-sensitivity toward carbon monoxide. Pervoskites, spinels and ceramic oxides are employed as working electrode to achieve a material with catalytic activity toward ethylene [5,10-17]. The material must show not only a high catalytic activity to ethylene but also a low crosssensitivity toward carbon monoxide and other pollutants. 


\subsection{Device structure and materials selection}

For this study, several materials were tested as working electrode employing a common device structure consisting of a solid 8YSZ electrolyte disk with platinum as reference electrode as depicted in figure 3.1. 8YSZ disks of $20 \mathrm{~mm}$ of diameter and $0.5 \mathrm{~mm}$ of thickness were produced as electrolytes as explained in section 2.2.1. The $8 \mathrm{YSZ}$ powder was pressed at $50 \mathrm{KN}$ and, after that, the green disk was sintered at $1350^{\circ} \mathrm{C}$ for $10 \mathrm{~h}$ in order to densify the disk. Working and reference electrodes were screen printed in each face respectively as a circular shape of $9 \mathrm{~mm}$ of diameter and sintered at $1150^{\circ} \mathrm{C}$ for $2 \mathrm{~h}$.

Gold porous layer is screen printed on top of the working electrode as a current collector to ensure electrical conductivity. This layer is sintered at $900^{\circ} \mathrm{C}$ for $2 \mathrm{~h}$.

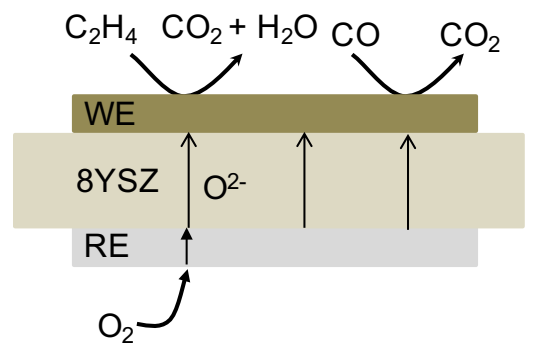

Figure 3.1 Scheme of the sensor device that consists of a dense 8YSZ electrolyte with several materials as working electrode (top face) and platinum as reference electrode (bottom face)

As working electrode, several perovskites, spinels and other oxides were studied employing a common platinum reference electrode as summarised in table 3.1. The objective is to get promising materials for selective hydrocarbon sensing. Materials were selected according to the literature because of its either good response to hydrocarbons or low response to carbon monoxide or because they were employed in fuel cells [5,10-17]. Platinum is usually employed as reference electrode do to its high catalytic activity[8,10,18-25]. 
Table 3.1 List of materials studied for the selective response of ethylene with platinum as reference electrode

\begin{tabular}{|c|c|}
\hline Material & Structure \\
\hline $\mathrm{La}_{0.87} \mathrm{Sr}_{0.13} \mathrm{CrO}_{3}$ & Perovskite \\
\hline $\mathrm{La}_{0.8} \mathrm{Sr}_{0.2} \mathrm{MnO}_{3}$ & Perovskite \\
\hline $\mathrm{Fe}_{0.7} \mathrm{Cr}_{1.3} \mathrm{O}_{3}$ & Metal oxide \\
\hline $\mathrm{ZnCr}_{2} \mathrm{O}_{4}$ & Spinel \\
\hline $\mathrm{FeNiO}$ & \\
\hline $\mathrm{NiO}+5 \%$ wt Au & Metal oxide \\
\hline
\end{tabular}

\subsection{Structural characterization}

Analysis of the XRD patterns of the different screened materials, as powders after calcination at $1300^{\circ} \mathrm{C}$, confirms that the desired phase is achieved for each material (figure 3.2). Diffraction peaks corresponding to any other oxide or any precursor are not observed, which in the case of both $\mathrm{La}_{0.87} \mathrm{Sr}_{0.13} \mathrm{CrO}_{3}$ (LSC) and $\mathrm{La}_{0.8} \mathrm{Sr}_{0.2} \mathrm{MnO}_{3}$ (LSM) indicate that the dopant is fully incorporated.

Figures 3.3 and 3.4 show the fracture cross section for each material employed as working electrode. As can be observed in figures $3.3 \mathrm{c}$ and $3.4 \mathrm{f}$, the common $8 Y S Z$ electrolyte shows a high density after sintering at $1350^{\circ} \mathrm{C}$ for $10 \mathrm{~h}$ despite some occlusive porosity. The thickness of the electrolyte is around $0.5 \mathrm{~mm}$ (figure 3.4f) and neither cracks nor pinholes can be observed. Figure $3.3 \mathrm{~d}$ shows the platinum at the bottom face. The layer is dense as well as homogeneous with a thickness of $7 \mu \mathrm{m}$. On the other hand, all working electrodes are porous layers with a thickness that varies between 10 and $30 \mu \mathrm{m}$ as a function of the material as can be observed in the SEM images shown in figures 3.3 and 3.4. This porous electrode ensures the gas exchange between the feed gas and the device in the triple phase boundary (TPB), the point where the gas meets the ionic conductor (electrolyte) and the electronic and catalytic active materials (WE). No reaction or interfaces between WE and electrolyte can be observed and all the electrodes are 
properly attached to the electrolyte with the exception of LSC and $\mathrm{Fe}_{0.7} \mathrm{Cr}_{1.3} \mathrm{O}_{3}$. LSC has no stability and it shows a detachment from the electrolyte after some tests performed at working conditions.

For $\mathrm{Fe}_{0.7} \mathrm{Cr}_{1.3} \mathrm{O}_{3}$ there are some variations: 1) a $1.1 \mathrm{~mm}$ thickness $8 \mathrm{YSZ}$ electrolyte disk is employed (figure 3.3c) as described in section 2.4.1. This is a bigger version of the device for multi-sensing purposes, and 2) it is mixed with $8 Y S Z$ to ensure attachment to the electrolyte as the electrode is not attached to the electrolyte after sintering. Figures $3.3 \mathrm{a}$ and $3.3 \mathrm{~b}$ show the porous microstructure of the layer with a homogeneous distribution of both grains. There is a difference in the grain size: $\mathrm{Fe}_{0.7} \mathrm{Cr}_{1.3} \mathrm{O}_{3}$ grains are bigger than $8 \mathrm{YSZ}$ although both of them are well distributed along the layer. In addition, no reaction neither between both phases nor on the grain boundaries can be observed. On top of the electrode, the porous gold layer employed as current collector can be observed.

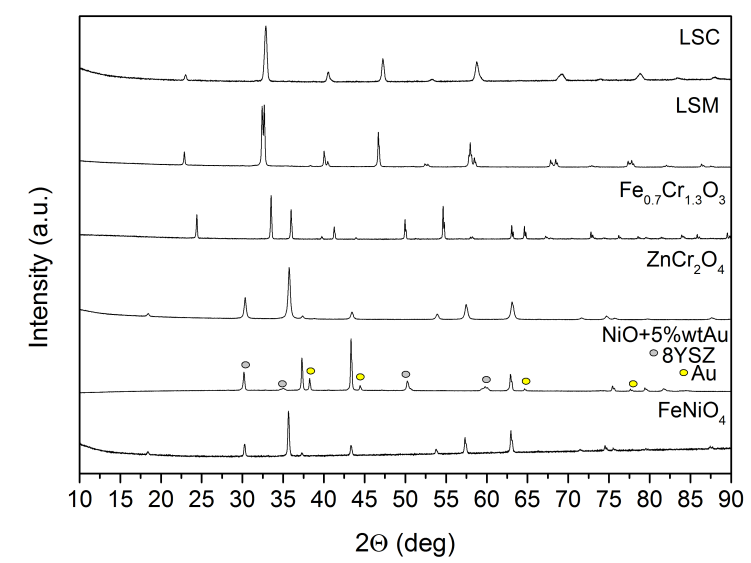

Figure 3.2X-Ray diffraction patterns of the materials studied at room temperature once they are synthesized 

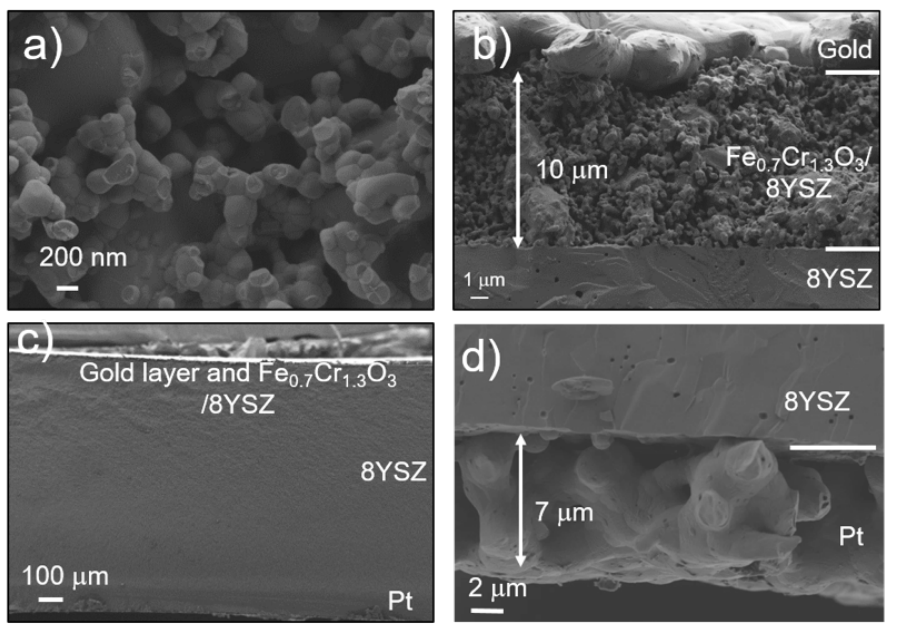

Figure 3.3 SEM image of the device cross-section corresponding to $\mathrm{Fe}_{0.7} \mathrm{Cr}_{1.3} \mathrm{O}_{3} / 8 \mathrm{YSZ}$ as WE and $\mathrm{Pt}$

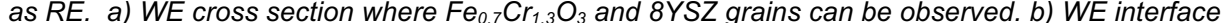
between $\mathrm{Fe}_{0.7} \mathrm{Cr}_{1.3} \mathrm{O}_{3}$ and $8 \mathrm{YSZ}$. c) Complete device with both electrodes and the $1.1 \mathrm{~mm}$-thick $8 \mathrm{YSZ}$ electrolyte. d) RE cross section where Pt layer and interface with 8YSZ can be observed.
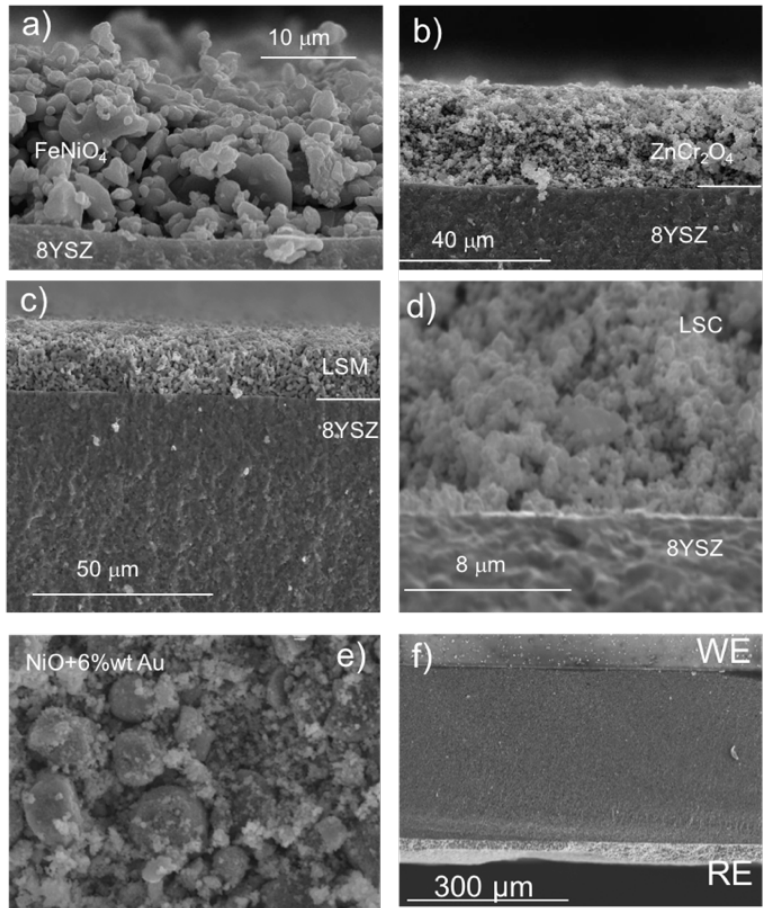

Figure 3.4 SEM image of the device cross-section corresponding to several materials employed as working electrode showing the interface between the working electrode and 8YSZ electrolyte for several materials: a) $\mathrm{FeNiO}_{4}$, b) $\mathrm{ZnCr}_{2} \mathrm{O} 4$, c) LSM, d) $\mathrm{LSC}$ and e) NiO+6\%wt Au surface view. 


\subsection{Electrochemical characterization}

When the sensor is exposed to oxidising and reducing agents, several reactions take place at the interface among electrodes, electrolyte and gas. Once the equilibrium is achieved, the reducing agents are oxidized in the working electrode (eq. 3.1 and 3.2) while in the reference electrode the oxygen is reduced it diffuses into the electrolyte (eq. 3.3). Not only electrochemical reaction but also the simultaneous heterogeneous catalytic conversion of the analytes with locallyadsorbed $\mathrm{O}_{2}$ can occur (eq. 3.4 and 3.5). This should be taken into account as this reaction can be more favoured or faster than the electrochemical reaction [26].

$$
\begin{gathered}
\mathrm{C}_{2} \mathrm{H}_{4}+6 \mathrm{O}^{2-} \rightarrow 2 \mathrm{CO}_{2}+2 \mathrm{H}_{2} \mathrm{O}+12 e^{-} \\
\mathrm{CO}+\mathrm{O}^{2-} \rightarrow \mathrm{CO}_{2}+2 e^{-}(3.2) \\
\frac{1}{2} \mathrm{O}_{2}+2 e^{-} \rightarrow \mathrm{O}^{2-}(3.3) \\
\mathrm{C}_{2} \mathrm{H}_{4}+3 \mathrm{O}_{2} \rightarrow 2 \mathrm{CO}_{2}+2 \mathrm{H}_{2} \mathrm{O}(3.4) \\
\mathrm{CO}+\frac{1}{2} \mathrm{O}_{2} \rightarrow \mathrm{CO}_{2}(3.5)
\end{gathered}
$$

\subsubsection{Potentiometric characterization}

In the first set of experiments, several materials listed in table 3.1 with structures such as pervoskites, spinels and other oxides, were studied employing platinum as reference electrode. The aim is to identify promising compounds for hydrocarbon sensing. Thus, high response to ethylene and a low response to carbon monoxide are required. The optimal device should have a high response to ethylene with a low response as well as cross-sensitivity to carbon monoxide, so the changes in concentration of carbon monoxide should not affect the sensor performance. In order to check this, the sensors were exposed to several concentrations of ethylene and carbon monoxide.

In this chapter platinum is assumed to be the reference electrode while working electrode is assumed to be each one of the materials employed. 


\section{First set of measurements}

The first material tested, $\mathrm{ZnCr}_{2} \mathrm{O}_{4}$, was exposed to $400,600,800$ and $1000 \mathrm{ppm}$ of ethylene and to $400 \mathrm{ppm}$ of carbon monoxide and nitrogen dioxide. The device was exposed to each concentration till stabilization as shown in figure 3.5. Figure $3.5 \mathrm{a}$ shows the sensor response to several concentrations of ethylene where a lineal response can be observed. On the other hand, sensor was exposed to 400 ppm of carbon monoxide and nitrogen dioxide till stabilization. Sensitivity to ethylene is higher when compared to carbon monoxide and nitrogen dioxide confirming that the material could be promising for ethylene detection.
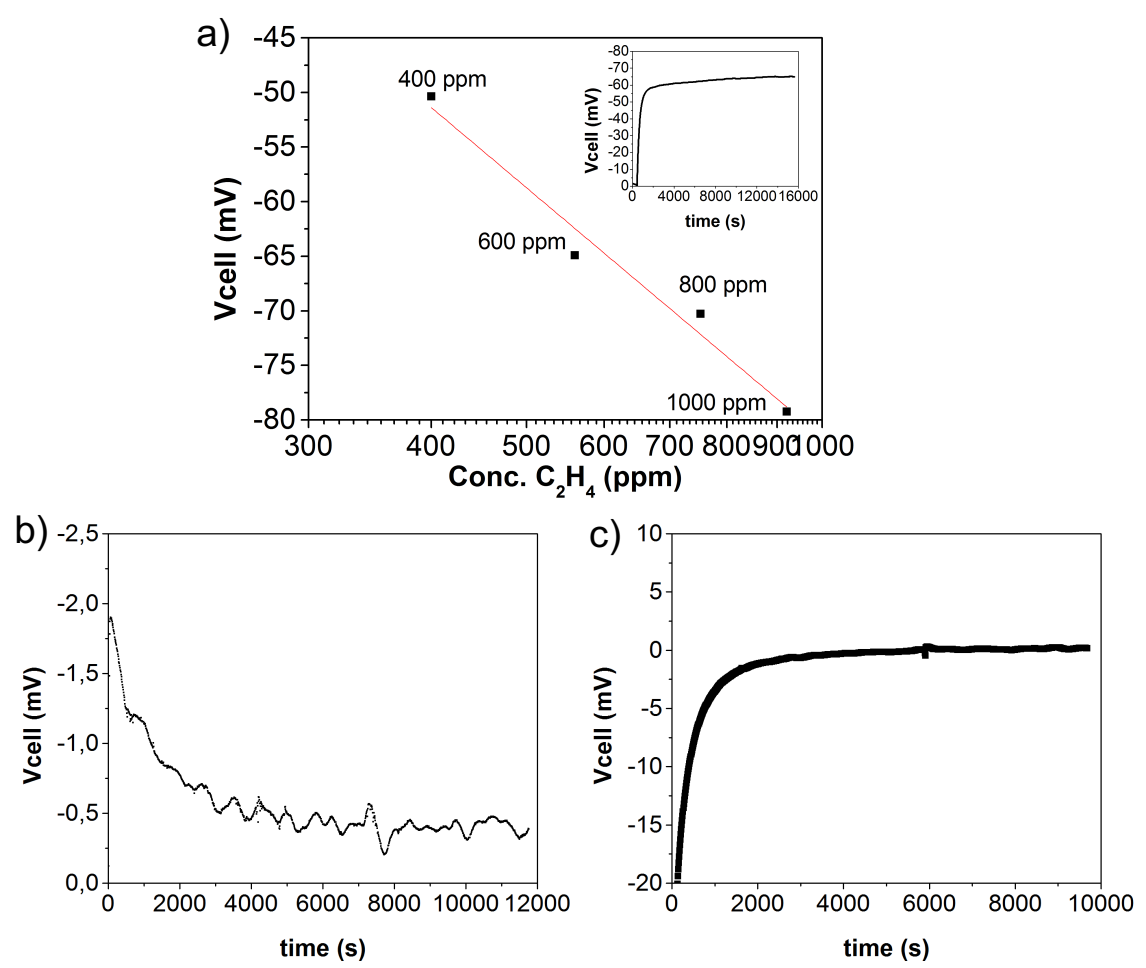

Figure 3.5 Device consisting of $\mathrm{ZnCr}_{2} \mathrm{O}_{4} / / Y 8 S Z / / P t$. Sensor response to: a) several concentrations of ethylene (400, 600, 800 and 1000 ppm) where a lineal response can be observed. B) 400 ppm of carbon monoxide. c) 400 ppm of nitrogen dioxide

The device employing $\mathrm{Fe}_{2} \mathrm{NiO}_{4}$ as WE was exposed to a different treatment. Four changes of concentration of 20 minutes from 400 to 800 ppm of ethylene were performed to check the response and reproducibility to ethylene (figure 3.6a). The procedure was performed from 400 to 1000 ppm (figure 3.6b). Additionally, the cross sensitivity was checked by means of exposing the sensor to the same 
changes of ethylene concentration but with $400 \mathrm{ppm}$ of carbon monoxide as background (figure $3.6 \mathrm{c}$ and d). Finally, the sensor response to $400 \mathrm{ppm}$ of carbon monoxide and nitrogen dioxide was measured till stabilization (figures $3.7 \mathrm{a}$ and $b$, respectively).

Sensor response to ethylene is reproducible although noisy. Figures $3.6 a$ and $b$ show that the change in response is noticeable from 400 to $800 \mathrm{ppm}$ but less pronounced when the change in response is from 800 to $1000 \mathrm{ppm}$. This indicates that the sensor is becoming saturated at high concentrations and is not suitable for hydrocarbon sensing at concentrations higher than $1000 \mathrm{ppm}$. Moreover, the addition of carbon monoxide background decreases the sensitivity of the sensor to ethylene. Despite the reproducibility not being affected, as seen in figure $3.6 \mathrm{c}$ (figure $3.6 \mathrm{~d}$ shows a noisier signal for the last two changes in concentration, probably due to a lack of good electrical contact with the recording system), the ethylene cross sensitivity toward carbon monoxide is not negligible.

Indeed, figure 3.7 a confirms the high sensitivity to carbon monoxide when compared to the response achieved for $400 \mathrm{ppm}$ of ethylene. On the other hand, nitrogen dioxide signal is not stable at all. As this material shows a better response to carbon monoxide rather than to ethylene, it is discarded for the present work. 

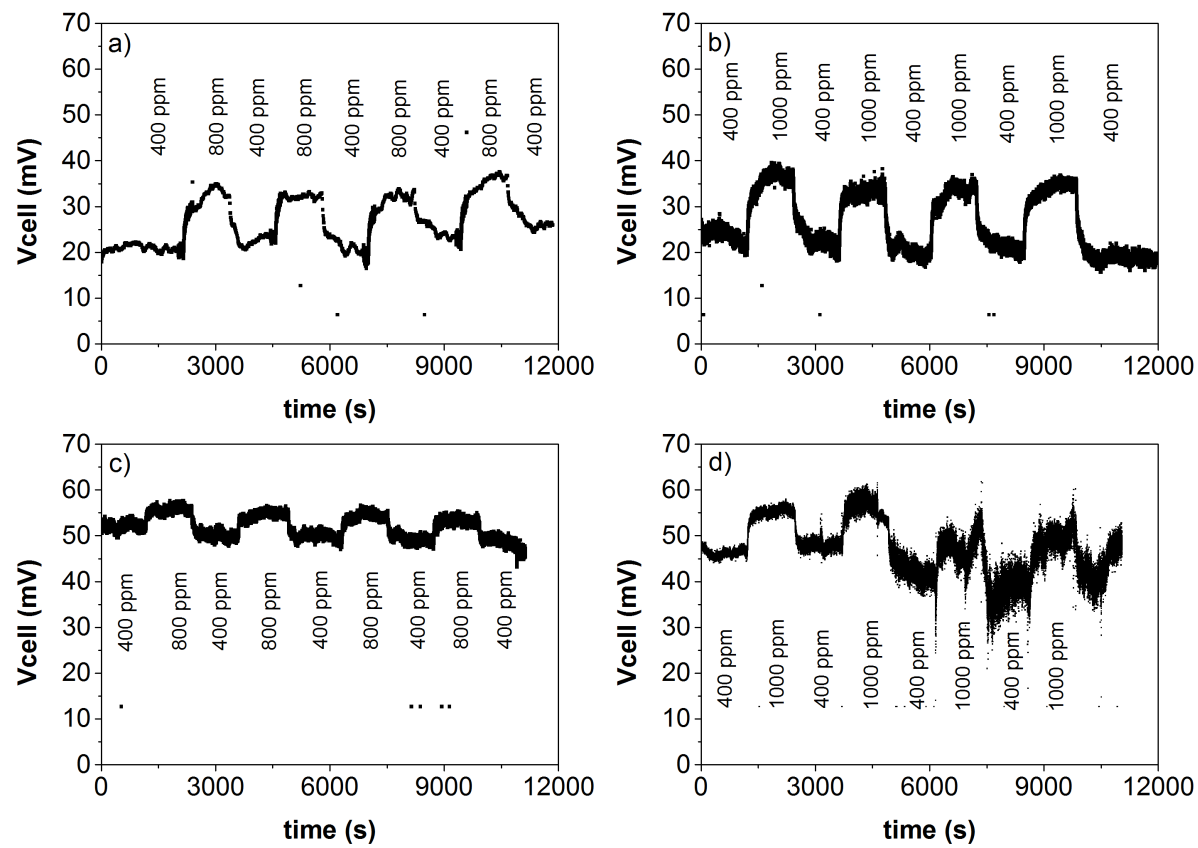

Figure 3.6 Sensor response for device consisting of $\mathrm{Fe}_{2} \mathrm{NiO}_{4} / / 8 \mathrm{YSZ} / / \mathrm{Pt}$. Changes in response with change in concentration from: a) 400 to 800 ppm of ethylene. b) 400 to 1000 ppm of ethylene. c) 400 to 800 ppm of ethylene with a background of 400 ppm of carbon monoxide. d) 400 to 1000 ppm of ethylene with a background of 400 ppm of carbon monoxide
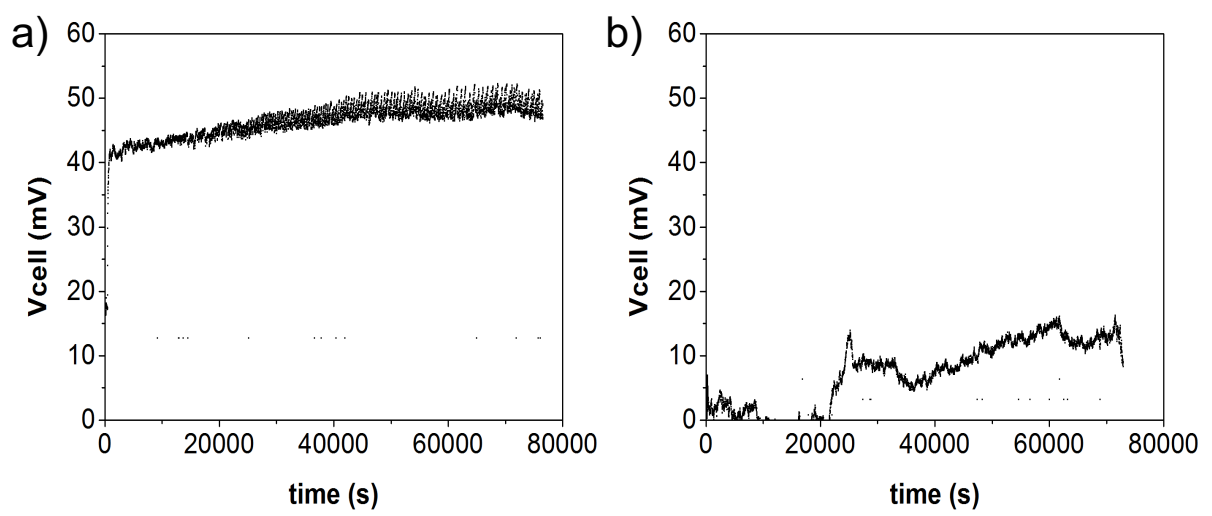

Figure 3.7 Sensor responses for device consisting of $\mathrm{Fe}_{2} \mathrm{NiO}_{4} / / 8 \mathrm{YSZ} / / \mathrm{Pt}$ to a) 400 ppm of carbon monoxide and b) 400 ppm of nitrogen dioxide 


\section{Second set of measurements}

From this point, the range of concentration is decreased from $400-1000 \mathrm{ppm}$ to $50-200 \mathrm{ppm}$ as it is more accurate for exhaust gas sensing. Besides, the methodology is also modified as explained in 2.4.1. First, changes in concentration for 20 minutes are performed from 50 to 100 , and 150 and $200 \mathrm{ppm}$ of ethylene and carbon monoxide, individually. And then, the cross-sensitivity is checked by performing three changes of concentration from 50 to $200 \mathrm{ppm}$ of one of the analytes for 20 minutes while the other analyte remains constant at 50 ppm.

$\mathrm{NiO}+5 \%$ wt $\mathrm{Au}$ as working electrode provides a reproducible response to ethylene and carbon monoxide according to figure $3.8 a$ and $b$, where the same sensor response is achieved in both cycles. The change in response with concentration is higher for the carbon monoxide exposure. Although the presence of a carbon monoxide background does not affect to the change in response with ethylene concentration (figure 3.8c), carbon monoxide has more influence on the sensor performance (figure 3.8d). It means that the carbon monoxide concentration has more control on the overall response. Moreover, the voltage generated indicates that the reaction is working the other way around: Platinum is acting as working electrode and eq. 3.1 and 3.2 are taking place at this electrode. Therefore, the oxide is working as the reference electrode and the reduction of the oxygen is taking place in this oxide. It should be taken into consideration that reactions described in eq. 3.1, 3.2 and 3.3 are taken place in both electrodes and an equilibrium is achieved, with the fastest reaction taking control over the electrode. Thus, the oxidation reaction of the analyte is probably more favoured in the platinum electrode than in the oxide. 

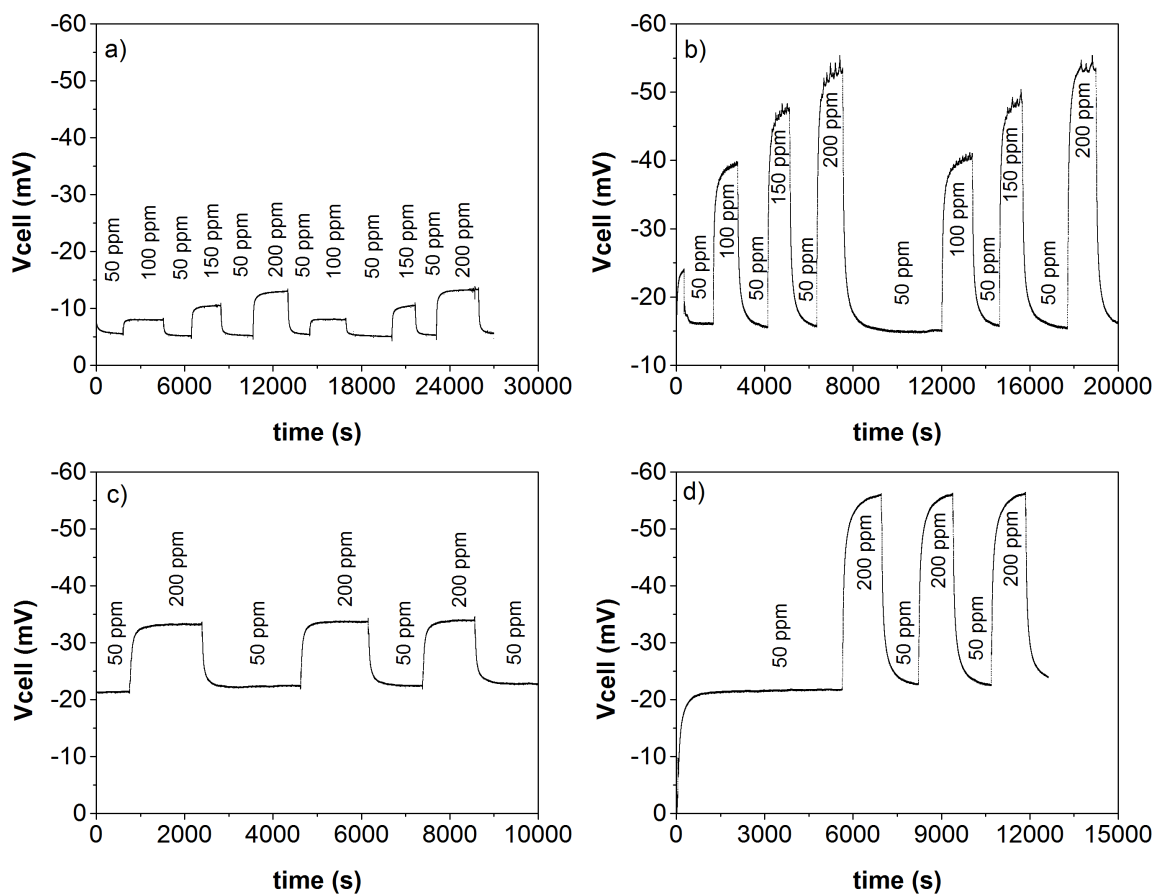

Figure 3.8 Sensor response for device consisting of NiO+5\%wt Au//8YSZ//Pt. Changes in response for 20 minutes with change in concentration from: a) 50 to 100, 150 and 200 ppm of ethylene. b) 50 to 100, 150 and 200 ppm of carbon monoxide. c) 50 to 200 ppm of ethylene with a background of 50 ppm of carbon monoxide. d) 50 to 200 ppm of carbon monoxide with a background of 50 ppm of ethylene

When LSC is employed as working electrode, the sensitivity to both ethylene and carbon monoxide are similar although a bit higher for carbon monoxide, as can be observed in figures $3.9 \mathrm{a}$ and $\mathrm{b}$. The responses are stable as well as reproducible for both analytes. When the influence of backgrounds on the sensor response is compared (figures $3.9 \mathrm{c}$ and $\mathrm{d}$ ), the sensor performance is analogous to the previous $\mathrm{NiO}$ case. The change in response from 50 to 200 ppm of ethylene is the same independently of the presence or not of a carbon monoxide background. The same can be observed for changes in carbon monoxide without ethylene and when ethylene background is added (figure 3.9d). In both cases the response is still stable and reproducible. However, there is a higher influence of carbon monoxide on the sensor performance, as the sensor gain is slightly higher than to ethylene. 
LSM provides a small sensitivity to ethylene as well as a low sensor gain with concentration (figures 3.10a and c). In addition, the response to ethylene shows a fluctuating pattern as well as a long time to stabilize. Thus, the device is not suitable for sensing purpose despite providing a small, noisy and unstable response to carbon monoxide (figures $3.10 \mathrm{~b}$ and $\mathrm{d}$ ) and a reproducible response to ethylene with carbon monoxide background.
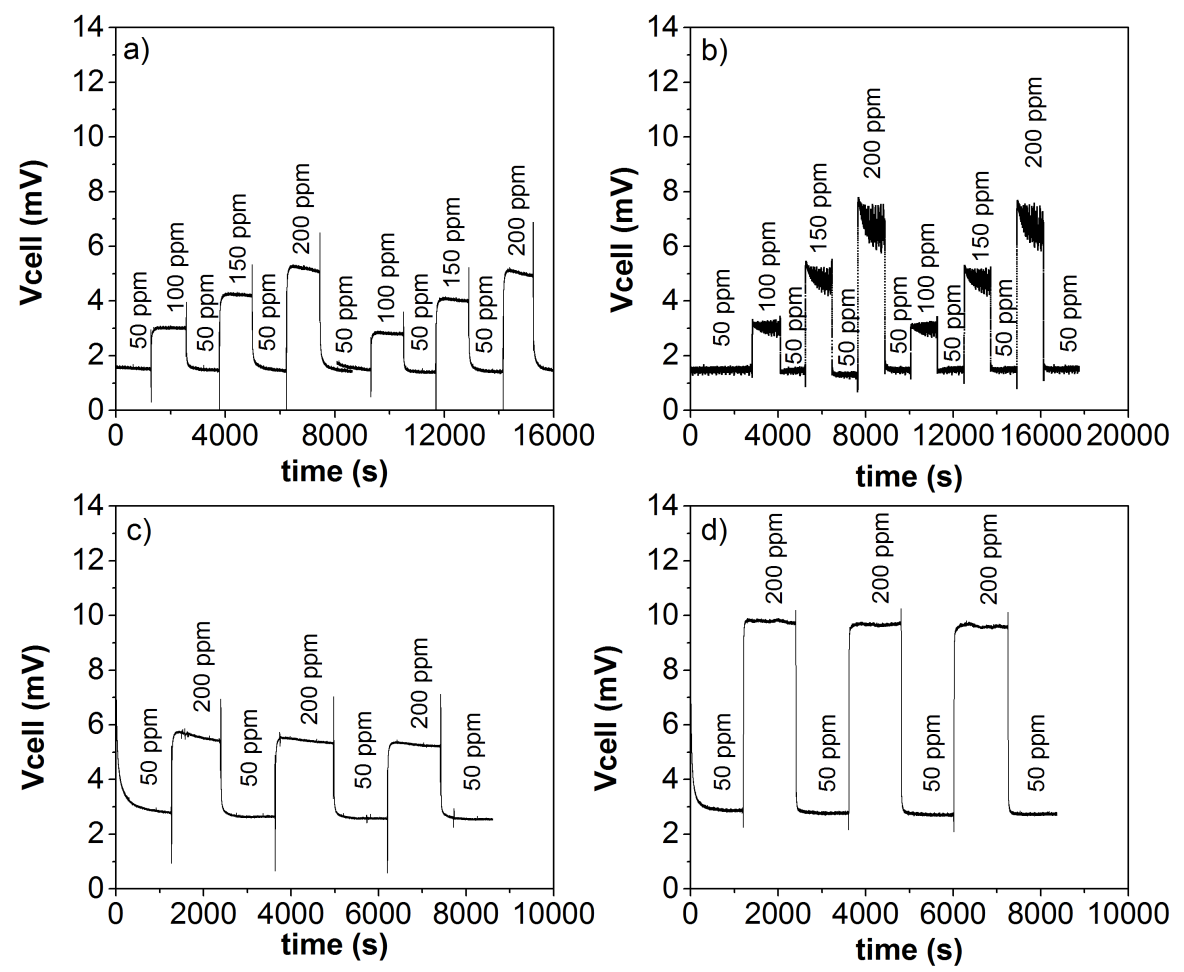

\footnotetext{
Figure 3.9 Sensor response for device consisting of LSC//8YSZ//Pt. Changes in response with change in concentration for 20 minutes from: a) 50 to 100, 150 and 200 ppm of ethylene, b) 50 to 100, 150 and $50 \mathrm{ppm}$ of carbon monoxide, c) 50 to $200 \mathrm{ppm}$ of ethylene with a background of $50 \mathrm{ppm}$ of carbon monoxide and d) 50 to $200 \mathrm{ppm}$ of carbon monoxide with a background of $50 \mathrm{ppm}$ of ethylene
} 

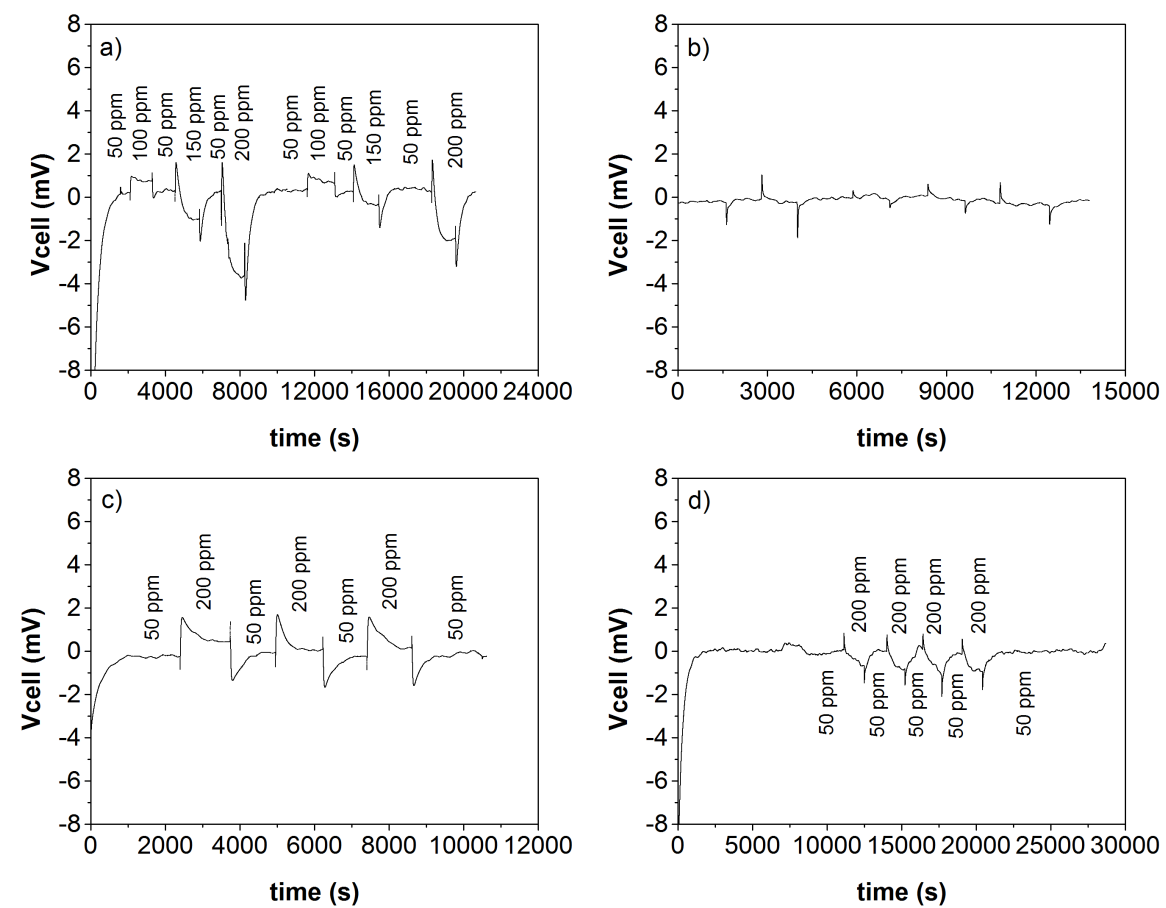

Figure 3.10 Sensor response for device consisting of LSM//8YSZ//Pt. Changes in response with change in concentration for 20 minutes from: a) 50 to 100,150 and 200 ppm of ethylene, b) 50 to 100 150 and $200 \mathrm{ppm}$ of carbon monoxide, c) 50 to $200 \mathrm{ppm}$ of ethylene with a background of $50 \mathrm{ppm}$ of carbon monoxide and d) 50 to 200 ppm of carbon monoxide with a background of $50 \mathrm{ppm}$ of ethylene. Most of the scenarios there is no stable response

\section{Third set of measurements}

Finally, in the case of the working electrode consisting of $\mathrm{Fe}_{0.7} \mathrm{Cr}_{1.3} \mathrm{O}_{3}$ mixed with $8 Y S Z$, the device was exposed to changes in concentration for 20 minutes from $50 \mathrm{ppm}$, used as base gas, to 100,150 and $200 \mathrm{ppm}$ as in the previous case. But now, the cross sensitivity is checked by means of repeating the same concentration changes described for one of the analytes while the other analyte remains fixed at $200 \mathrm{ppm}$.

This electrode material exhibits both selective response and a relatively high sensor gain to ethylene as can be observed in figure 3.11a. Furthermore, the material shows low cross-sensitivity towards carbon monoxide as no effect on the ethylene response can be observed when 200 ppm of carbon monoxide are added as background as shown in figure $3.11 \mathrm{~b}$. Additionally, the sensor response to ethylene is stable when changes in ethylene concentration are performed. On 
the other hand, figure $3.11 \mathrm{c}$ shows the small increase in response when the sensor is exposed to 50,100, 150 and $200 \mathrm{ppm}$ of carbon monoxide. The addition of $200 \mathrm{ppm}$ of ethylene as background leads to a flat response that is mainly due to ethylene (figure 3.11d). Thus, these results confirm the low cross-sensitivity of the device towards carbon monoxide and therefore, the device performance is promising for hydrocarbon sensing purposes. Regarding reproducibility, sensor response is reproducible for both analytes.

The device fulfils the aims expected for $\mathrm{HC}$ sensing purposes: high sensitivity to ethylene and low to carbon monoxide and a low cross-sensitivity of carbon monoxide over ethylene.
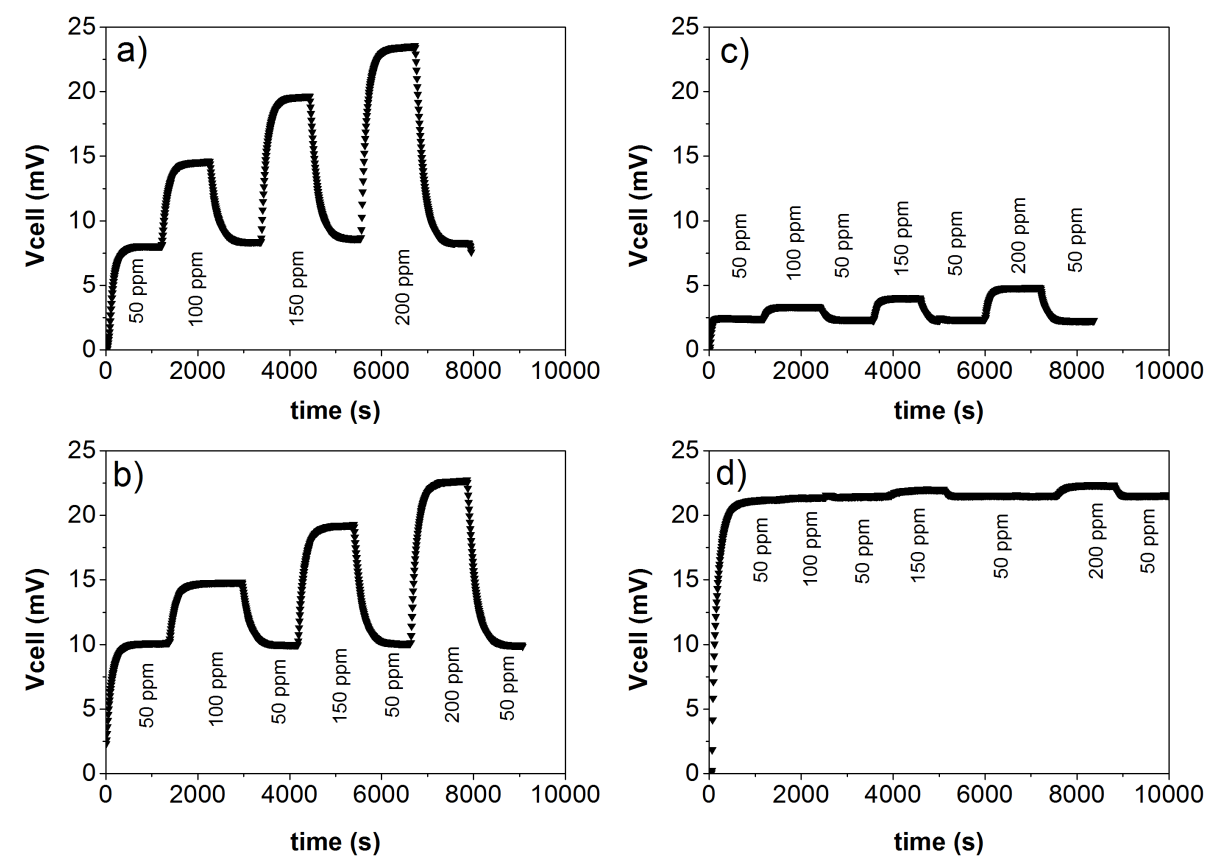

Figure 3.11 Sensor response for device consisting of $\mathrm{Fe}_{0.7} \mathrm{Cr}_{1.3} \mathrm{O}_{3} / 8 \mathrm{YSZ} / / 8 \mathrm{YSZ} / / \mathrm{Pt}$. Changes in response for changes in concentration of: a) 50 to 100, 150 and 200 ppm of ethylene, b) 50 to 100 , 150 and $200 \mathrm{ppm}$ of ethylene with a background of $200 \mathrm{ppm}$ of carbon monoxide. c) 50 to 100,150 and 200 ppm of carbon monoxide and d) 50 to 100, 150 and 200 ppm of carbon monoxide with a background of $200 \mathrm{ppm}$ of ethylene 


\subsubsection{Electrochemical Impedance Spectroscopy}

EIS results are depicted as Nyquist diagrams for $\mathrm{ZnCr}_{2} \mathrm{O}_{4}, \mathrm{LSM}, \mathrm{NiO}+6 \% \mathrm{wt} \mathrm{Au}$ and $\mathrm{Fe}_{2} \mathrm{NiO}_{4}$, and as a Bode and Nyquist diagram for $\mathrm{Fe}_{0.7} \mathrm{Cr}_{1.3} \mathrm{O}_{3}$ as shown in figures 3.12 and 3.13, respectively. In the case of $\mathrm{ZnCr}_{2} \mathrm{O}_{4}$, the EIS measurement was carried out at $400 \mathrm{ppm}$ of each analyte. The polarization resistance of ethylene and carbon monoxide are dissimilar as can be observed in figure 3.12a. This fact can explain the better response of the device to ethylene. EIS measurements for $\mathrm{Fe}_{2} \mathrm{NiO}_{4}$ were also carried out at $400 \mathrm{ppm}$ of ethylene and carbon monoxide. Unfortunately, figure $3.12 \mathrm{~b}$ shows a shift in the carbon monoxide response when compared to ethylene and, in addition, the response is noisy enough to make it hard to compare both materials. This shift corresponds to the electrolyte resistance or real resistance and could be due to some problems in the electrical connection between the electrode and the current collector or even the wires.

On the other hand, both LSM and $\mathrm{NiO}+6 \%$ wt Au were exposed to $200 \mathrm{ppm}$ of ethylene and carbon monoxide. As shown in figure 3.12b, LSM response provides an open arch and therefore a big resistance for both analytes that could be due to diffusion control. The negligible response provided by the device during the potentiometric characterization could be explained by this response. $\mathrm{NiO}$ also provides a noisy response at low frequencies that makes hard to compare both analytes as well as to get the polarization resistance; however, there is a difference in the response to analytes that could explain the difference in response obtained during the potentiometric characterization.

Figure 3.13 displays the Nyquist and Bode diagrams for $\mathrm{Fe}_{0.7} \mathrm{Cr}_{1.3} \mathrm{O}_{3}$. The shape of the semi-arch is similar for both analytes at high frequencies; therefore, the ionic mobility remains almost unaffected. However, at low frequencies there is a difference in the shape of the semi-arch as the ethylene arch is lower. Thus, this indicates that the sensor response depends on electrochemical reactions at the electrode itself or even at the interface between $\mathrm{Fe}_{0.7} \mathrm{Cr}_{1.3} \mathrm{O}_{3} / 8 \mathrm{YSZ} / / 8 \mathrm{YSZ}$ [27-31]. Thus, the better response to ethylene could be explained by this difference in the response. 

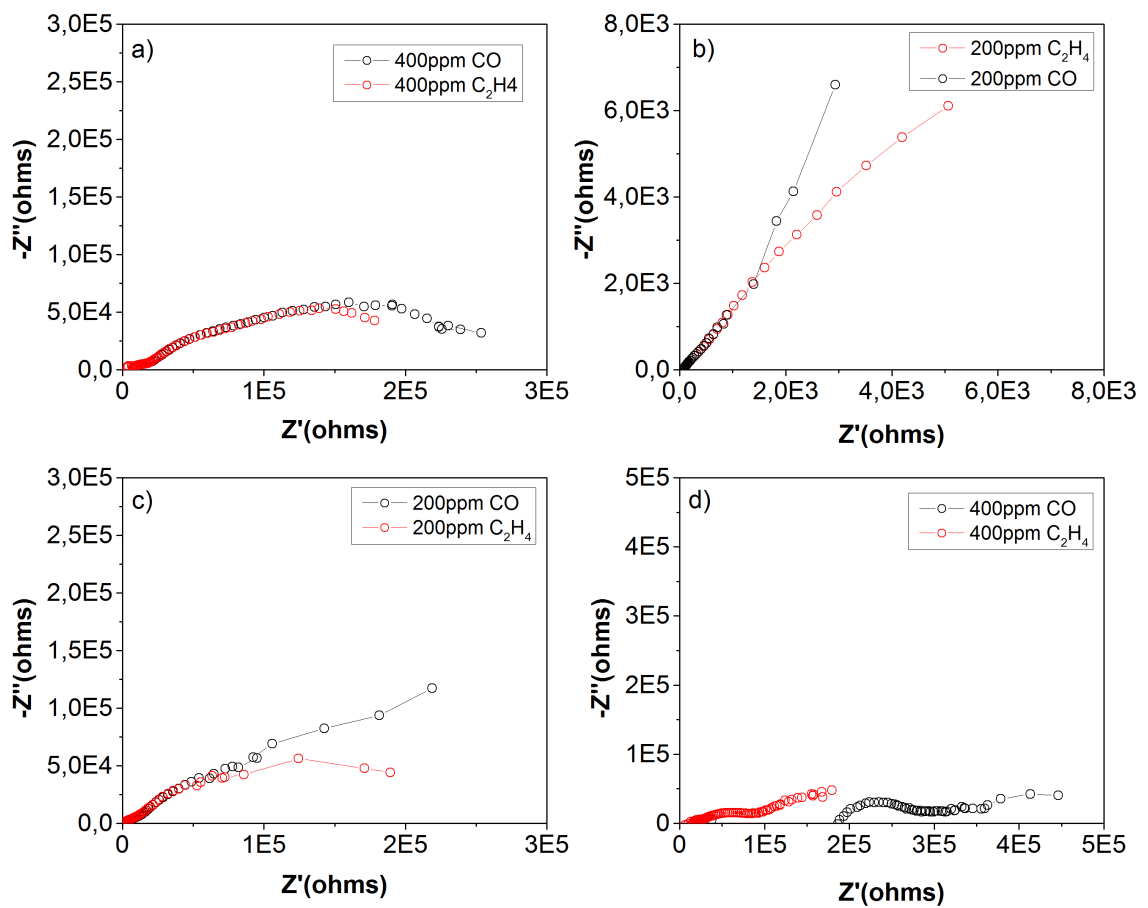

Figure 3.12 Impedance spectrometry study in $\mathrm{Ar}+6 \% \mathrm{O}_{2}$ and: a) $400 \mathrm{ppm}$ of carbon monoxide and 400 ppm of ethylene employing $\mathrm{ZnCr}_{2} \mathrm{O}_{4}$ as WE, b) 200 ppm of carbon monoxide and $200 \mathrm{ppm}$ of ethylene employing LSM as WE, c) 200 ppm of carbon monoxide and 200 ppm of ethylene employing $\mathrm{NiO}+6 \%$ wt $\mathrm{Au}$ as WE and d) $400 \mathrm{ppm}$ of carbon monoxide and $400 \mathrm{ppm}$ of ethylene employing $\mathrm{Fe}_{2} \mathrm{NiO}_{4}$ as WE
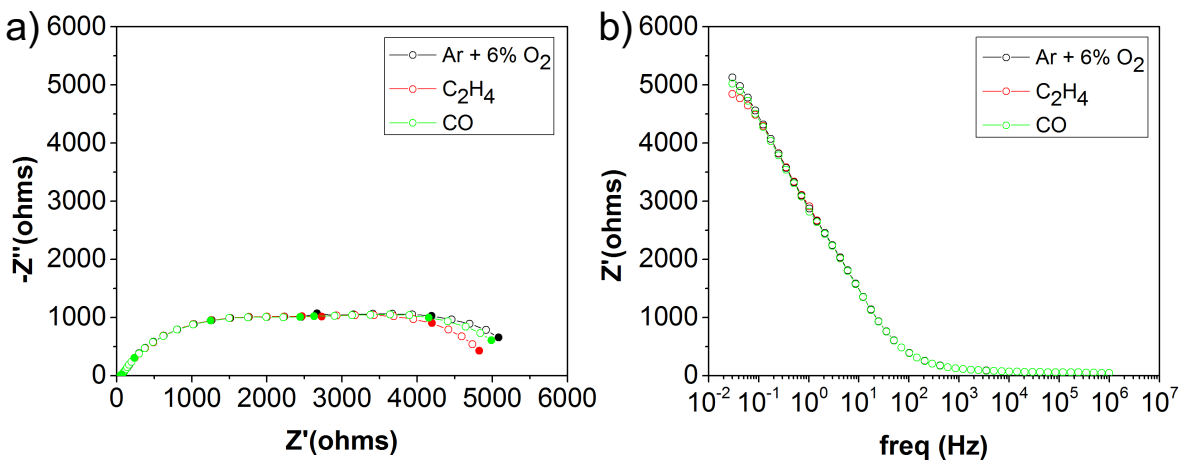

Figure 3.13 Impedance spectrometry study for $\mathrm{Ar}+6 \% \mathrm{O}_{2}, 200 \mathrm{ppm}$ of ethylene and $200 \mathrm{ppm}$ of carbon monoxide with $\mathrm{Fe}_{0.7} \mathrm{Cr}_{1.3} \mathrm{O}_{3} / 8 \mathrm{YSZ}$ as WE. a) Nyquist plot and b) bode plot 


\subsection{Device configuration: working electrode material selection}

After the electrochemical characterization, the main characteristics of each material are summarised in figure 3.14 and serve for the selection of the most promising materials for hydrocarbon detection. Several factors are depicted: sensor gain to ethylene and carbon monoxide as $\mathrm{mV} / \mathrm{ppm}$, response time, stability (Applying the following criteria: 100 for stable response and 0 for noisy response) and carbon monoxide cross sensitivity as a percentage defined as the sensitivity to carbon monoxide divided by the addition of the sensitivities to carbon monoxide and ethylene.

The main objective is to achieve a sensor response with: low cross sensitivity toward carbon monoxide, a high response to ethylene while the response to carbon monoxide remains as low as possible, a stable response and a fast response time. According to figure 3.14, there are three materials that show a high cross sensitivity to carbon monoxide: $\mathrm{NiO}+6 \%$ wt $\mathrm{Au}, \mathrm{Fe}_{2} \mathrm{NiO}_{4}$ and LSC. The good performance provided by the device with $\mathrm{NiO}+6 \%$ wt $\mathrm{Au}$ makes it more likely to be used as a carbon monoxide sensor device rather than for hydrocarbon sensing purposes. $\mathrm{Fe}_{2} \mathrm{NiO}_{4}$ exhibits the faster response but, unfortunately, there is also a high cross sensitivity toward carbon monoxide that makes it not useful for the present thesis purposes.

As a consequence, there are two promising materials for detecting hydrocarbons: $\mathrm{ZnCr}_{2} \mathrm{O}_{4}$ and $\mathrm{Fe}_{0.7} \mathrm{Cr}_{1.3} \mathrm{O}_{3}$. Despite its low cross sensitivity to carbon monoxide, $\mathrm{ZnCr}_{2} \mathrm{O}_{4}$ has two main disadvantages: its low response time (1200 seconds) and an ageing effect. In fact, it has been reported in literature the decrease of the sensor performance with time. Additionally, the sensor was tested again with the second methodology, in the range of concentrations between 50 and 200 ppm instead of 400 to $800 \mathrm{ppm}$, and the sensor output was much lower as well as noisier than in the first attempt as shown in figure 3.15 .

Thus, the most promising material for a selective detection of ethylene is $\mathrm{Fe}_{0.7} \mathrm{Cr}_{1.3} \mathrm{O}_{3} / 8 \mathrm{YSZ}$. This material provides a good sensitivity to ethylene with a stable response and a low cross sensitivity toward carbon monoxide and an acceptable response time into the bargain, although the response time should be decreased for real in-situ measurements. 


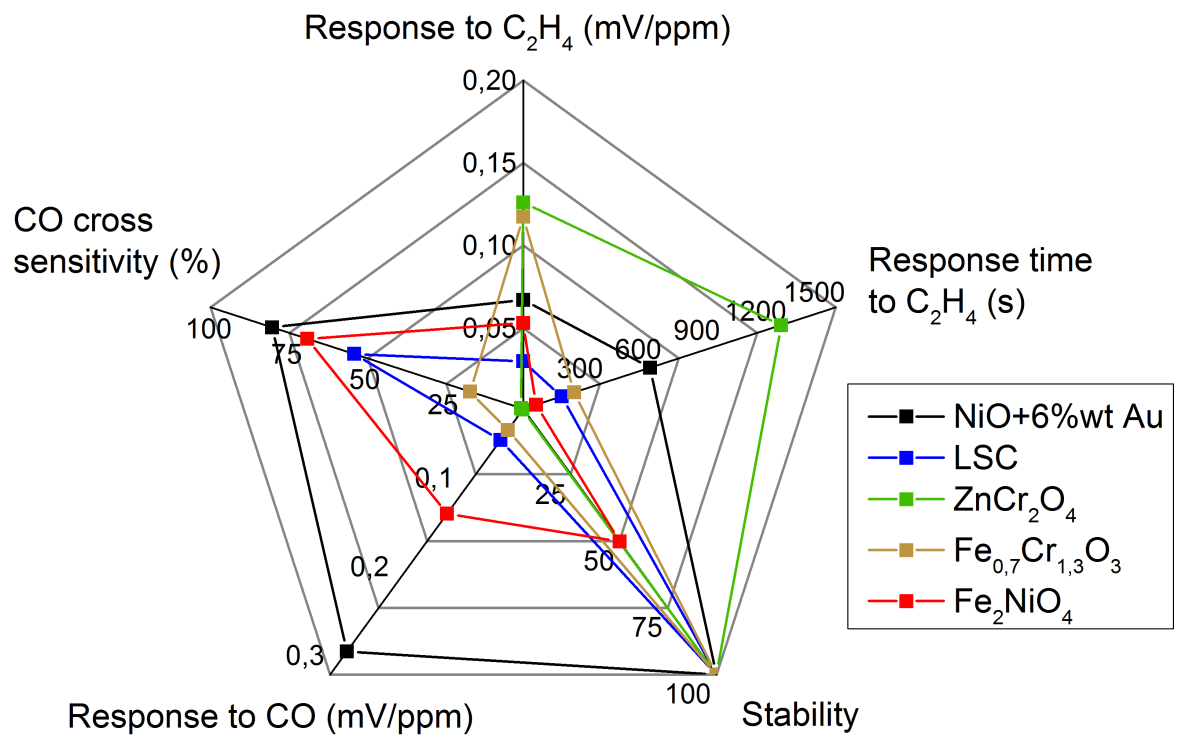

Figure 3.14 Radar chart with the main characteristics of the sensor output: sensitivity or sensor gain to ethylene defined as $\mathrm{mV} / \mathrm{ppm}$, response time, stability (Applying the following criteria: 100 for stable response and 0 for noisy response), Sensitivity or sensor gain to carbon monoxide defined as $\mathrm{mV} / \mathrm{ppm}$ and carbon monoxide cross sensitivity as a percentage defined as the sensitivity to carbon monoxide divided by the addition of the sensitivities to carbon monoxide and ethylene
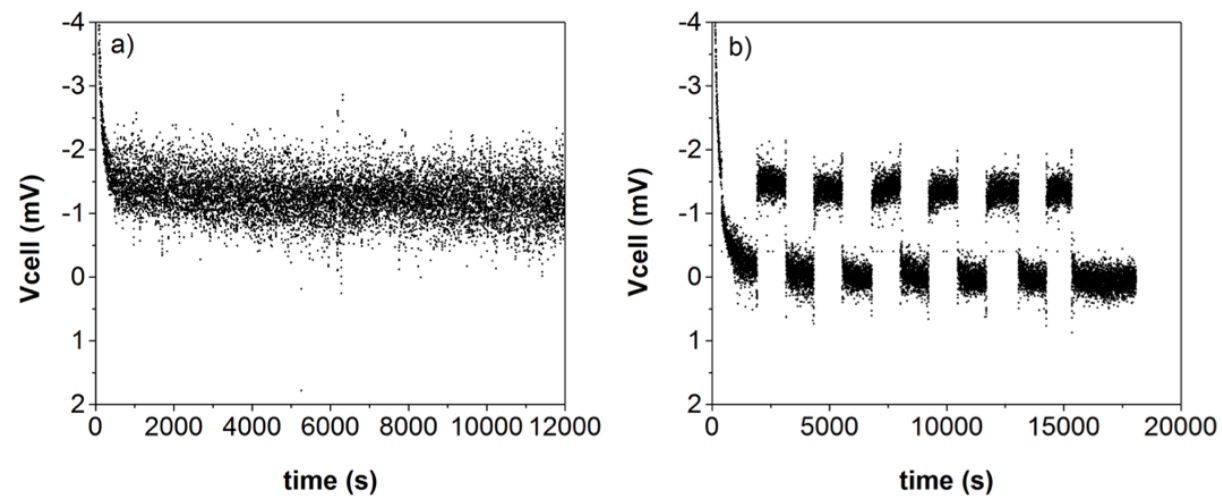

Figure 3.15 Sensor response of the device with configuration $\mathrm{ZnCr}_{2} \mathrm{O}_{4} / 8 \mathrm{YSZ} / \mathrm{Pt}$ for the second methodology. Sensor is exposed to: a) $50 \mathrm{ppm}$ of carbon monoxide and b) changes in concentration of ethylene from 50 to $200 \mathrm{ppm}$. 


\subsection{Conclusions}

Several materials were developed and tested through the present chapter. Aspects such as sensitivity to ethylene, carbon monoxide, cross sensitivity and stability were studied for each one of the assayed materials. Most of the materials do not show problems of compatibility with the 8YSZ electrolyte except for $\mathrm{Fe}_{0.7} \mathrm{Cr}_{1.3} \mathrm{O}_{3}$, that is detached when sintered. Thus, this material is mixed with $8 Y S Z$ to ensure the attachment to the electrolyte.

Materials such as $\mathrm{NiO}+6 \%$ wt $\mathrm{Au}$ and $\mathrm{Fe}_{2} \mathrm{NiO}_{4}$ showed a promising performance for carbon monoxide detection. NiO provides a high cross sensitivity to carbon monoxide making the device more suitable for carbon monoxide detection as it has a high sensor gain to carbon monoxide when compared to ethylene. The main drawback of this configuration is its lack of fast response. Conversely, $\mathrm{Fe}_{2} \mathrm{NiO}_{4}$ shows the fastest response and it also has a high cross sensitivity to carbon monoxide. Further experiments should be done to ensure the suitability of this sensor for carbon monoxide sensing. LSC configuration provides an unsatisfactory response for both analytes because it shows a similar sensitivity to both materials that makes the device unable to detect neither ethylene nor carbon monoxide selectively.

For ethylene detection, there are two promising materials: $\mathrm{ZnCr}_{2} \mathrm{O}_{4}$ and $\mathrm{Fe}_{0.7} \mathrm{Cr}_{1.3} \mathrm{O}_{3} . \quad \mathrm{ZnCr}_{2} \mathrm{O}_{4}$ provides a high sensitivity to ethylene with a low cross sensitivity to carbon monoxide. This makes the configuration ideal for ethylene detection but it has also two main drawbacks: the sensor response is too slow (the slowest material checked) and it has some long-term stability problems. Thus, the material finally selected as the working electrode for this thesis is $\mathrm{Fe}_{0.7} \mathrm{Cr}_{1.3} \mathrm{O}_{3}$ that provides a good sensitivity to ethylene with a low cross sensitivity to carbon monoxide as well, good stability and acceptable time response. However, the sensor time response should be improved in further studies to provide faster responses able to make the sensor suitable for in-situ measurements. In a real exhaust gas system, the sensor must provide real fast response with the changes of concentration to make it profitable.

\subsection{References}

[1] Guth U, Zosel J. Electrochemical solid electrolyte gas sensors Hydrocarbon and NOx analysis in exhaust gases. Ionics (Kiel) 2004;10:366-77.

[2] Fadeyev G, Kalakin a., Demin a., Volkov a., Brouzgou a., Tsiakaras P. Electrodes for solid electrolyte sensors for the measurement of $\mathrm{CO}$ and $\mathrm{H} 2$ content in air. Int J Hydrogen Energy 2013;38:13484-90. doi:10.1016/j.ijhydene.2013.07.094. 
[3] Yoo J, Chatterjee S, Wachsman ED. Sensing properties and selectivities of a WO3/YSZ/Pt potentiometric NOx sensor. Sensors Actuators, B Chem 2007;122:644-52. doi:10.1016/j.snb.2006.07.024.

[4] Plashnitsa $V$ V., Elumalai P, Fujio $Y$, Miura N. Zirconia-based electrochemical gas sensors using nano-structured sensing materials aiming at detection of automotive exhausts. Electrochim Acta 2009;54:6099-106. doi:10.1016/j.electacta.2008.12.040.

[5] Romanytsia I, Viricelle J-P, Vernoux P, Pijolat C. Application of advanced morphology $\mathrm{Au}-\mathrm{X}$ ( $\mathrm{X}=\mathrm{YSZ}, \mathrm{ZrO} 2$ ) composites as sensing electrode for solid state mixed-potential exhaust NOx sensor. Sensors Actuators B Chem 2015;207:3917. doi:10.1016/j.snb.2014.10.017.

[6] Miura N, Sato T, Anggraini SA, Ikeda H, Zhuiykov S. A review of mixedpotential type zirconia-based gas sensors. Ionics (Kiel) 2014;20:901-25. doi:10.1007/s11581-014-1140-1.

[7] lio A, Ikeda H, Anggraini SA, Miura N. Potentiometric YSZ-based oxygen sensor using BaFeO3 sensing-electrode. Electrochem Commun 2014;48:134-7. doi:10.1016/j.elecom.2014.09.004.

[8] Viricelle JP, Breuil P, Tournier G, Minot M, Pijolat C. Development of a YSZ based oxygen and hydrocarbon sensors for combustion control unit. Procedia Eng 2011;25:1089-92. doi:10.1016/j.proeng.2011.12.268.

[9] Mukundan R, Brosha EL, Garzon FH. Mixed Potential Hydrocarbon Sensors based on a YSZ Electrolyte and Oxide Electrodes. J Electrochem Soc 2003;150:H279. doi:10.1149/1.1621880.

[10] Brosha EL, Mukundan R, Brown DR, Garzon FH, Visser JH, Zanini M, et al. $\mathrm{CO} / \mathrm{HC}$ sensors based on thin films of $\mathrm{LaCoO} 3$ and $\mathrm{La0}$.8Sr0.2CoO3-?? metal oxides. Sensors Actuators, B Chem 2000;69:171-82. doi:10.1016/S09254005(00)00543-8.

[11] Chevallier L, Dibartolomeo E, Grilli M, Traversa E. High temperature detection of $\mathrm{CO} / \mathrm{HCs}$ gases by non-Nernstian planar sensors using $\mathrm{Nb2O} 5$ electrode. Sensors Actuators B Chem 2008;130:514-9. doi:10.1016/j.snb.2007.09.056.

[12] Yamaguchi M, Anggraini SA, Fujio $Y$, Sato $T$, Breedon M, Miura N. Stabilized zirconia-based sensor utilizing $\mathrm{SnO}$-based sensing electrode with an integrated $\mathrm{Cr} 2 \mathrm{O} 3$ catalyst layer for sensitive and selective detection of hydrogen. Int J Hydrogen Energy 2013;38:305-12. doi:10.1016/j.ijhydene.2012.10.049.

[13] MacAm ER, White BM, Blackburn BM, Di Bartolomeo E, Traversa E, Wachsman ED. La2CuO4 sensing electrode configuration influence on sensitivity and selectivity for a multifunctional potentiometric gas sensor. Sensors Actuators, B Chem 2011;160:957-63. doi:10.1016/j.snb.2011.09.012. 
[14] Fujio $Y$, Sato T, Miura N. Sensing performance of zirconia-based gas sensor using titania sensing-electrode added with palladium. Solid State Ionics 2014;262:266-9. doi:10.1016/j.ssi.2013.08.028.

[15] Mori M, Sadaoka Y, Nakagawa S, Kida M, Kojima T. Development of ethanol and toluene sensing devices with a planar-type structure based on YSZ and modified Pt electrodes. Sensors Actuators B Chem 2013;187:509-13. doi:10.1016/j.snb.2013.03.005.

[16] Zosel, Ahlborn, Mueller, Westphal, Vashook, Guth. Selectivity of HCsensitive electrode materials for mixed potential gas sensors. Solid State Ionics 2004;169:115-9. doi:10.1016/S0167-2738(03)00082-1.

[17] Elumalai $P$, Plashnitsa $\vee V$., Fujio $Y$, Miura N. Highly sensitive and selective stabilized zirconia-based mixed-potential-type propene sensor using $\mathrm{NiO} / \mathrm{Au}$ composite sensing-electrode. Sensors Actuators B Chem 2010;144:2159. doi:10.1016/j.snb.2009.10.063.

[18] Fergus JW. Sensing mechanism of non-equilibrium solid-electrolytebased chemical sensors. J Solid State Electrochem 2011;15:971-84. doi:10.1007/s10008-010-1046-4.

[19] Zosel, Westphal, Jakobs, Mueller, Guth. Au-oxide composites as HCsensitive electrode material for mixed potential gas sensors. Solid State lonics 2002;152-153:525-9. doi:10.1016/S0167-2738(02)00355-7.

[20] Jin $H$, Breedon $M$, Miura $N$. Sensing behavior of YSZ-based amperometric $\mathrm{NO}_{2}$ sensors consisting of $\mathrm{Mn}$-based reference-electrode and $\ln _{2} \mathrm{O}_{3}$ sensing-electrode. Talanta 2012;88:318-23. doi:10.1016/j.talanta.2011.10.047.

[21] Sekhar PK, Kysar J, Brosha EL, Kreller CR. Development and testing of an electrochemical methane sensor. Sensors Actuators B Chem 2016;228:162-7. doi:10.1016/j.snb.2015.12.100.

[22] Kumar Sekhar P, Mukundan R, Brosha E, Garzon F. Effect of perovskite electrode composition on mixed potential sensor response. Sensors Actuators B Chem 2013;183:20-4. doi:10.1016/j.snb.2013.03.110.

[23] Ueda T, Abe H, Kamada K, Bishop SR, Tuller HL, Hyodo T, et al. Enhanced sensing response of solid-electrolyte gas sensors to toluene: Role of composite Au/metal oxide sensing electrode. Sensors Actuators B Chem 2017;252:268-76. doi:10.1016/j.snb.2017.05.172.

[24] Chevallier L, Bartolomeo E Di, Grilli ML, Traversa E. High temperature detection of $\mathrm{CO} / \mathrm{HCs}$ gases by non-Nernstian planar sensors using $\mathrm{Nb} 2 \mathrm{O} 5$ electrode. Sensors Actuators B 2008;130:514-9. doi:10.1016/j.snb.2007.09.056. 
[25] Miura N, Lu G, Ono M, Yamazoe N. Selective detection of NO by using an amperometric sensor based on stabilized zirconia and oxide electrode. Solid State lonics 1999;117:283-90.

[26] Striker T, Ramaswamy V, Armstrong EN, Willson PD, Wachsman ED, Ruud JA. Effect of nanocomposite Au-YSZ electrodes on potentiometric sensor response to NOx and CO. Sensors Actuators B Chem 2013;181:312-8. doi:10.1016/j.snb.2013.02.039.

[27] Stranzenbach M, Saruhan B. Equivalent circuit analysis on NOx impedance-metric gas sensors. Sensors Actuators B Chem 2009;137:154-63. doi:10.1016/j.snb.2008.11.055.

[28] Hagen G, Dubbe A, Fischerauer G, Moos R. Thick-film impedance based hydrocarbon detection based on chromium(III) oxide/zeolite interfaces. Sensors Actuators B Chem 2006;118:73-7. doi:10.1016/j.snb.2006.04.005.

[29] Miura N, Nakatou M, Zhuiykov S. Impedancemetric gas sensor based on zirconia solid electrolyte and oxide sensing electrode for detecting total NOx at high temperature. Sensors Actuators B Chem 2003;93:221-8. doi:10.1016/S0925-4005(03)00196-5.

[30] Nakatou M, Miura N. Detection of propene by using new-type impedancemetric zirconia-based sensor attached with oxide sensing-electrode. Sensors Actuators B Chem 2006;120:57-62. doi:10.1016/j.snb.2006.01.044.

[31] Ikeda $\mathrm{H}$, lio A, Anggraini SA, Miura N. Impedancemetric YSZ-based oxygen sensor using BaFeO3 sensing-electrode. Sensors Actuators B Chem 2017;243:279-82. doi:10.1016/j.snb.2016.11.140. 
Chapter 4

\section{Water and polyaromatic hydrocarbons influence on sensor response. Reference Electrode improvement strategies}





\section{Water and polyaromatic hydrocarbons influence on sensor response. Reference Electrode improvement strategies}

\subsection{Introduction and motivation}

In the previous chapter, several materials were tested as working electrode to achieve a selective response to ethylene with low cross-sensitivity toward carbon monoxide. $\mathrm{Fe}_{0.7} \mathrm{Cr}_{1.3} \mathrm{O}_{3}$ was selected as the most promising working electrode material. In this chapter, the configuration $\mathrm{Fe}_{0.7} \mathrm{Cr}_{1.3} \mathrm{O}_{3} / 8 \mathrm{YSZ} / / 8 \mathrm{YSZ} / / \mathrm{Pt}$ is exposed to harsh conditions like in a car exhaust gas. Thus, the sensor is exposed to water and polyaromatic hydrocarbons (methylnaphthalene, phenanthrene and toluene).

The sensor was exposed to a $3 \%$ of water and the response to ethylene and carbon monoxide were recorded employing the procedure described in chapter 3 for $\mathrm{Fe}_{0.7} \mathrm{Cr}_{1.3} \mathrm{O}_{3} / 8 \mathrm{YSZ} / / 8 \mathrm{YSZ} / / \mathrm{Pt}$ configuration to measure the sensor response to both analytes. The addition of water increases the sensor response to both analytes and decreases the selectivity to ethylene. Thus, the addition of water leads to a lack of selective sensor response to ethylene making the sensor configuration not suitable for sensing purposes in car exhaust gases.

Same procedure was done to check the influence in the sensor response when $0,16 \mathrm{ppm}$ of phenanthrene are added. In this case, when the sensor is exposed to only one of the analytes, the sensor response is still slightly better to ethylene. However, when background gases are added, the response becomes similar as the cross sensitivity to carbon monoxide increases and therefore, the sensor is not selective to ethylene anymore.

The sensor was also exposed to changes in concentration of methylnaphthalene and toluene to study the performance of the device in atmospheres where both $\mathrm{PAHs}$ are present. In both cases the sensor response to the polyaromatics are high enough to consider the sensor not selective to ethylene as there is a high cross sensitivity toward these elements. Another aspect to take into account when working with this kind of elements is the formation of coke that can affect the sensor response. The sensor response changes when ethylene is measured again in dry conditions. Raman spectroscopy is performed to check the formation of coke after exposing the sensor to phenanthrene, methylnaphthalene and toluene. Although there are some peaks in the carbon region and fluorescence, that may indicate that there are complex organic molecules adsorbed on the 
electrode surface, no carbon fingerprint is observed clearly to the limit of the Raman technique.

In summary, a change in the sensor configuration is required to improve the performance under harsh conditions. The strategy employed to improve the sensor performance is to act over the reference electrode. It should be taken into account that the aim of the reference electrode is to be active to oxygen to promote the oxygen reduction. Thus, materials with a high ionic conductivity should be considered [1-3].

Then, to avoid cross sensitivity towards other elements because of the high catalytic activity of platinum, in this chapter an electronic conductor such as LSM is selected as reference electrode [4-7]. Unfortunately, the expected change in response is not fulfilled. The response is similar to both analytes with no selective response to either ethylene or carbon monoxide.

\subsection{Water and polyaromatic hydrocarbons influence on sensor response}

\subsubsection{Electrochemical characterization}

The Device with the configuration selected in the previous chapter, $\mathrm{Fe}_{0.7} \mathrm{Cr}_{1.3} \mathrm{O}_{3} / 8 \mathrm{YSZ} / / \mathrm{Pt}$, is tested under harsh conditions like in a car exhaust gas. This means that the device must be selective to ethylene even in the presence of elements such as water or polyaromatic hydrocarbons (PAHs). In an exhaust gas this kind of elements can be found and the cross-sensitivity towards them must be checked to ensure the selectivity to ethylene.

First, the influence of water is evaluated. The gas flow is passed through a water column at room temperature, feeding the system with $550 \mathrm{ml} / \mathrm{min}$ with a $3 \% \mathrm{vol}$ of $\mathrm{H}_{2} \mathrm{O}$. The procedure to check the sensor response is as aforementioned on the previous chapter for the same configuration, and described in section 2.4.1. Thus, once the water is added, changes in concentration of ethylene or carbon monoxide are performed from 50 to 100,150 and 200 ppm. Cross sensitivity is checked by means of performing changes in concentration from 50 to 100,150 and $200 \mathrm{ppm}$ of one of the analytes while the other analyte remains constant at $200 \mathrm{ppm}$

According to figure 4.1, the addition of water decreases the selectivity of the device to ethylene. Similar response to ethylene (figure 4.1a) and carbon monoxide (figure 4.1c) is achieved. Conversely to what happened in dry conditions (figure 3.11 ), the response to ethylene, individually as well as with 
carbon monoxide background (figure $4.1 \mathrm{a}$ and $\mathrm{b}$ ), increases but becomes similar to the respective carbon monoxide responses (figure $4.1 \mathrm{c}$ and $\mathrm{d}$ ). In particular, the addition of water increases the signal to ethylene either individually or with carbon monoxide background, remaining the sensor gain (slope) constant as shown in figure 4.2a. While the sensor gain to carbon monoxide increases from a flat response to a response similar to the one achieved with ethylene as observed in figure $4.2 \mathrm{~b}$.
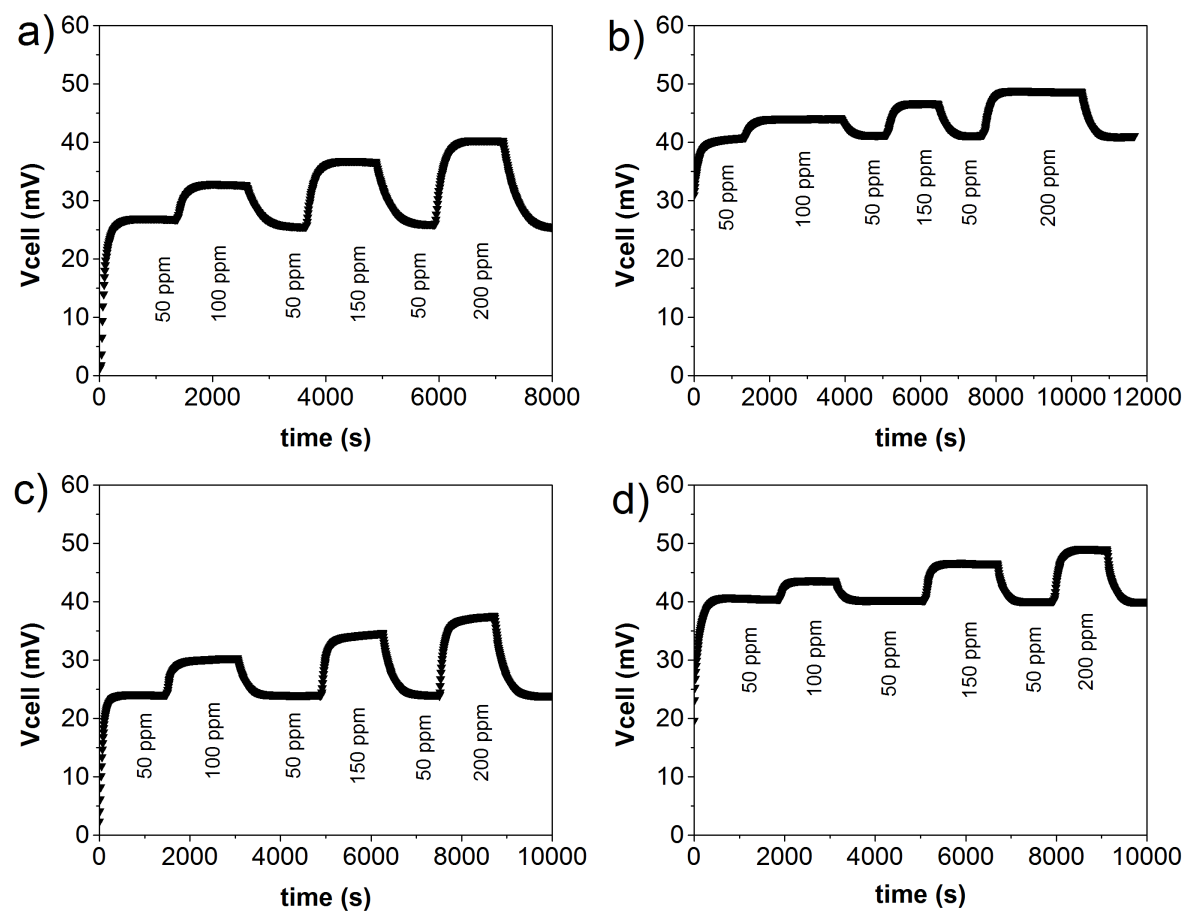

Figure 4.1 Response curves for changes in concentration in wet conditions (3\% of water) of: a) ethylene, b) ethylene with 200 ppm of carbon monoxide background, c) carbon monoxide and d) carbon monoxide with 200 ppm of ethylene background. Each change in concentration has 20 minutes of duration and it goes from 50 to 100,150 and $200 \mathrm{ppm}$. The sensor consists of $\mathrm{Fe}_{0.7} \mathrm{Cr}_{1.3} \mathrm{O}_{3} / 8 \mathrm{YSZ} / / 8 \mathrm{YSZ} / / \mathrm{Pt}$ and the working temperature is $550^{\circ} \mathrm{C}$ with $6 \%$ of oxygen and $3 \%$ of water 

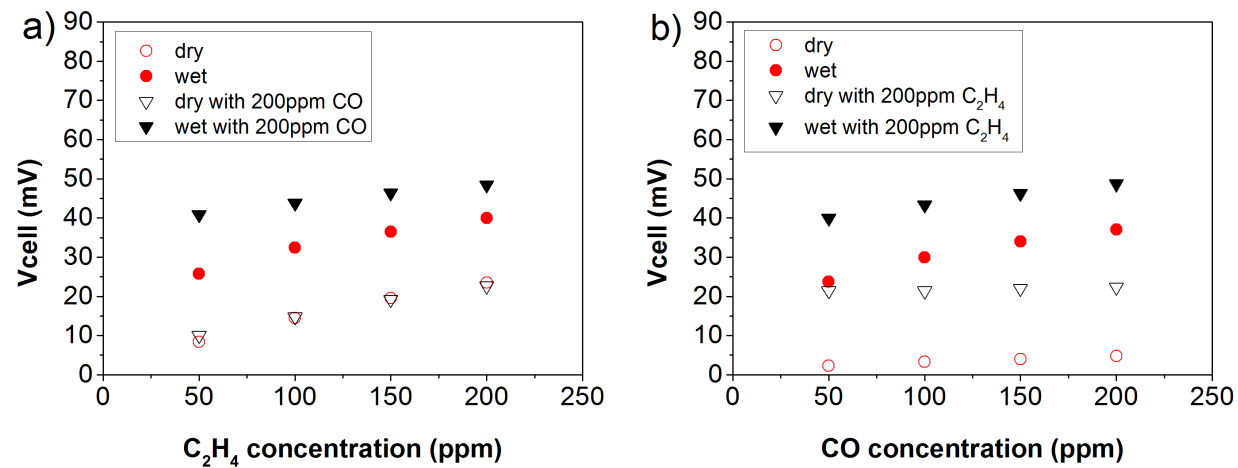

Figure 4.2 Sensor response (Vcell) as a function of analyte concentration for: a) ethylene and b) carbon monoxide. The effect of the background of the second analyte (200 ppm) and water (3\%) is also shown. Each point corresponds to the mean of the respective 20 minutes change in response

In figure 4.3, the sensor performance under wet conditions is summarized and can be clearly observed how the sensor response is not selective to ethylene as the sensor gain is similar to both ethylene and carbon monoxide. This may be caused by two effects: 1) Water could be promoting the carbon monoxide conversion by removing coke from the electrode surface or avoiding its formation or providing more ions that shift the equilibrium achieved in dry conditions[8], 2) water could be enabling the formation of $\mathrm{H}_{2}$ on both electrode surfaces via the water gas-shift reaction (eq. 4.1). The electrochemical oxidation of the locally-built $\mathrm{H}_{2}$ on the electrodes would be kinetically more favored than carbon monoxide oxidation and this may have an impact in the sensor response [9].

$$
\mathrm{H}_{2} \mathrm{O}+\mathrm{CO} \rightarrow \mathrm{CO}_{2}+\mathrm{H}_{2}
$$




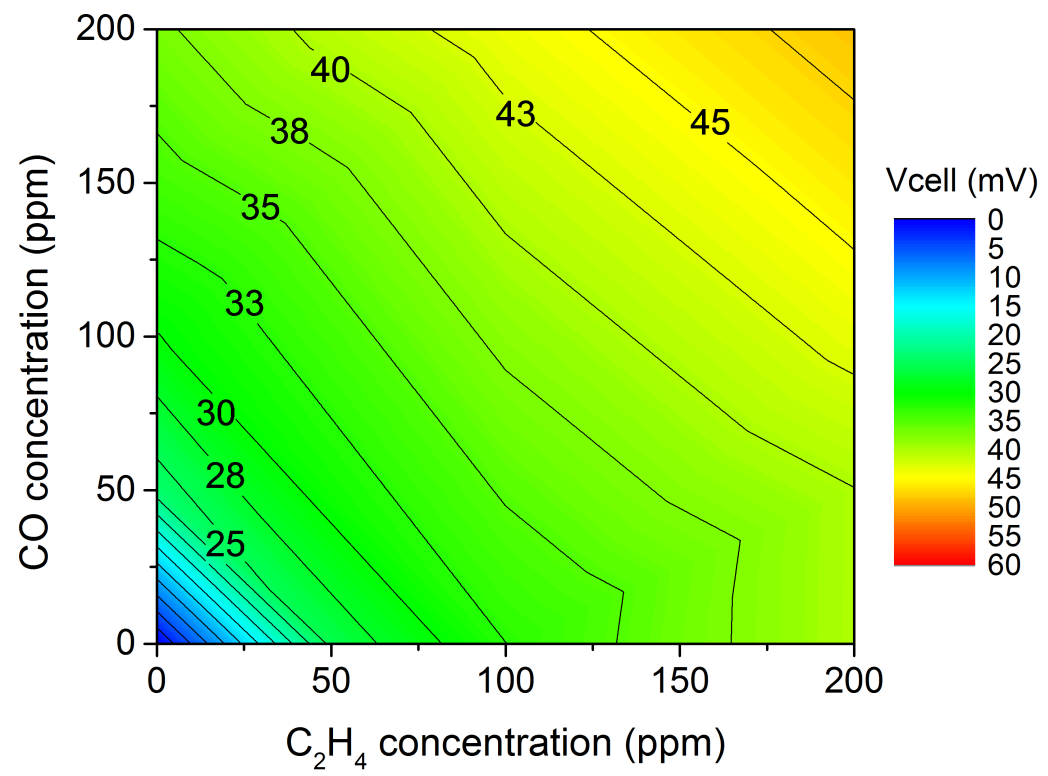

Figure 4.3 Contour plot displaying the sensor response (Vcell) as a function of the analytes concentration when a $3 \%$ of water is added to sensor configuration $\mathrm{Fe}_{0.7} \mathrm{Cr}_{1.3} \mathrm{O}_{3} / 8 \mathrm{YSZ} / / 8 \mathrm{YSZ} / / \mathrm{Pt}$

Additionally, an electrochemical impedance spectroscopy (EIS) is performed in wet conditions to check the response to both analytes. The measurements are performed from $0.03 \mathrm{~Hz}$ to $1 \mathrm{MHz}$ and it is done for the base gas, argon $+6 \% \mathrm{O}_{2}$, and for $200 \mathrm{ppm}$ of ethylene and carbon monoxide. Figure 4.4 shows how the addition of water only have some minor effects on the impedance at low frequencies. The rest of the spectrum remains practically unaffected for both analytes. Interfacial resistance for ethylene remains practically constant while for carbon monoxide there is a decrease in the interfacial resistance and it becomes similar to ethylene. This indicates that the carbon monoxide reaction is ameliorated on the electrode surface thanks to the water presence, and this can explain the worsening of the device response to ethylene. 

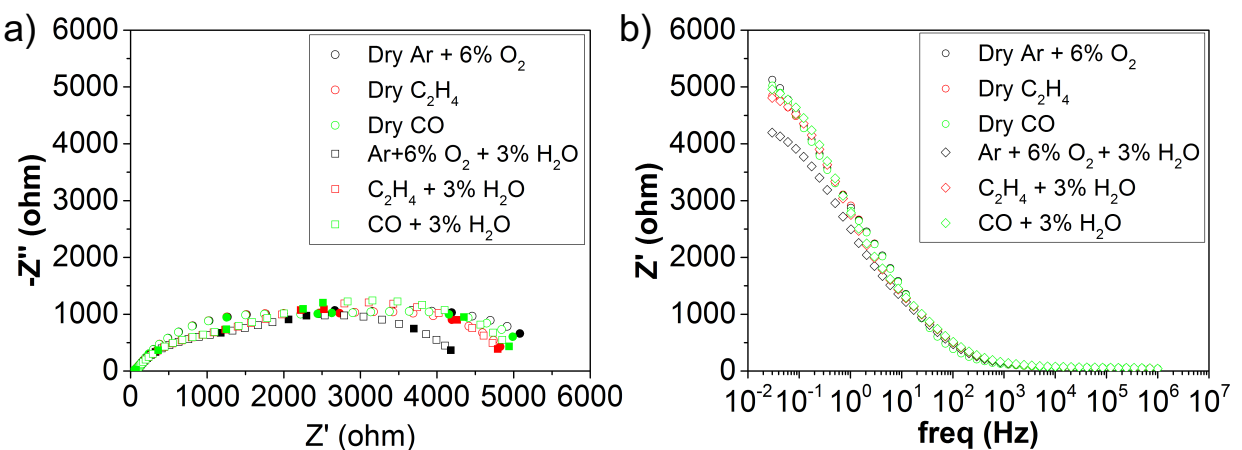

Figure 4.4 Impedance spectrometry study in dry and wet conditions for $\mathrm{Ar}+6 \% \mathrm{O}_{2}$ base gas, 200 ppm of ethylene and 200 ppm of carbon monoxide. a) Nyquist plot with water effect and b) bode plot with water effect

In addition, as aforementioned, the sensor is exposed to several polyaromatic hydrocarbons to check the response to ethylene under such harsh conditions. Other hydrocarbons can have a relatively high cross-sensitivity and consequently, affect to the sensor performance.

The total gas flow was passed through each polyaromatic hydrocarbon at room temperature to get the respective concentration provided by its vapor partial pressure. In a car, a great variety of PAHs are produced because of the unburned fuel and therefore, there is a wide selection of polyaromatic hydrocarbons that could be selected. Toluene was selected as one of the most common polyaromatic hydrocarbons as well as because of its toxicity, although the concentration provided by its vapor pressure $(28947.37 \mathrm{ppm})$ is much larger than the concentration present in a car exhaust gas as seen in chapter 1 . This is the main problem of the vast majority of the polyaromatic hydrocarbons; at room temperature their vapor pressure provide concentrations that are far away of a car exhaust gas range. There are two alternatives: 1) the first alternative was to change the conditions (temperature) of the total gas flow passed through the PAHs to get the concentration desired. But for most of the PAHs it could be tricky to change the temperature to get a concentration inside the range of concentrations in a car exhaust gas and, in addition, to keep the conditions through the whole set-up to avoid condensation. 2) The second alternative was to look for other PAHs that can provide lower concentrations at room temperature much closer to the ones in a car exhaust gas.

After considering the viability of both approaches, the second approach was selected in this thesis. Thus, two PAHs that provide an appropriate concentration inside the desired range were selected: phenanthrene and methylnaphthalene. 
First, the sensor was exposed to phenanthrene. The total gas flow was passed through phenanthrene at room conditions providing a concentration of $0.16 \mathrm{ppm}$ of the PAH. Once the phenanthrene is added, the same methodology exposed for water was followed. Figure 4.5 shows that the response to ethylene remains almost unaffected but there is a change in the sensor sensitivity to ethylene when carbon monoxide is added as background. This is confirmed by the response to carbon monoxide as shown in figure $4.5 \mathrm{c}$, where an increase in the sensor response to carbon monoxide can be observed when phenanthrene is added when compared to dry conditions (figure 4.2). In addition, when $200 \mathrm{ppm}$ of carbon monoxide are added as a background to the phenanthrene, the sensor gain becomes similar to both analytes as can be seen by comparing figures $4.5 \mathrm{~b}$ and $d$, although is still better to ethylene. This indicates that the addition of just $0.16 \mathrm{ppm}$ of phenanthrene in the atmosphere causes an increase in the cross sensitivity to carbon monoxide.

Figures $4.6 \mathrm{a}$ and $\mathrm{b}$ show the sensor response to changes in concentration of methylnaphthalene and toluene, respectively. The sensor response is recorded in dry conditions and then the total gas flow is passed through the PAHs twice in each case. Each change in concentration of PAH lasts for 20 minutes. The sensor gain is much larger than to ethylene, carbon monoxide or phenanthrene, as shown in table 4.1. Both PAHs show a high cross sensitivity toward $\mathrm{CO}$ and $\mathrm{C}_{2} \mathrm{H}_{4}$, superimposing its signal over both carbon monoxide and ethylene responses. After exposing the sensor to these hydrocarbons, the response changes when measured again in dry conditions without hydrocarbons. Figure 4.7 shows an increase in the ethylene response after exposing it to the PAHs even after the sensor calcination at $600^{\circ} \mathrm{C}$ with air. Chromium iron oxide structure provides Lewis acidic sites with a significant activity to aromatics [10]. One explanation to this change in response may be that iron oxide is more affected by ageing as well as coke formation leading to a reduction of its catalytic activity [11].

As far as it should be considered that the concentration of toluene is much larger than in an real car exhaust gas, both phenanthrene and methylnaphthalene are inside the range of concentration of an exhaust gas. Thus, the sensor response must be improved to reduce the cross sensitivity for both PAHs, and provide a proper ethylene-selective response in harsh conditions like in an exhaust gas. 

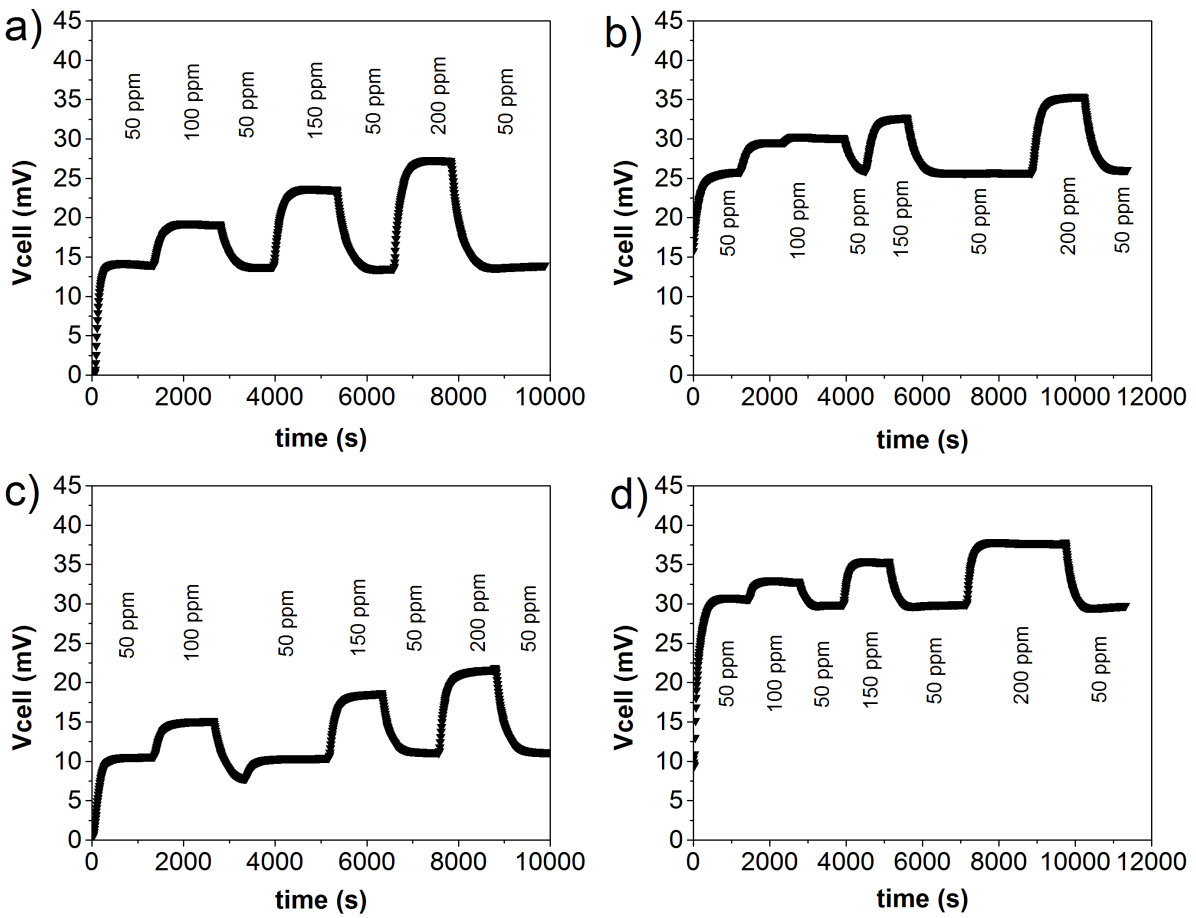

Figure 4.5 Response curves with a fixed concentration of $0.16 \mathrm{ppm}$ of phenanthrene for changes in concentration) of: a) ethylene, b) ethylene with 200 ppm of carbon monoxide background, c) carbon monoxide and d) carbon monoxide with 200 ppm of ethylene background. Each change in concentration has 20 minutes of duration and it goes from 50 to 100, 150 and $200 \mathrm{ppm}$. The sensor consists of $\mathrm{Fe}_{0.7} \mathrm{Cr}_{1.3} \mathrm{O}_{3} / 8 \mathrm{YSZ} / / 8 \mathrm{YSZ} / / \mathrm{Pt}$ and the working temperature is $550^{\circ} \mathrm{C}$ with $6 \%$ of oxygen and 0.16 ppm of phenenthrene
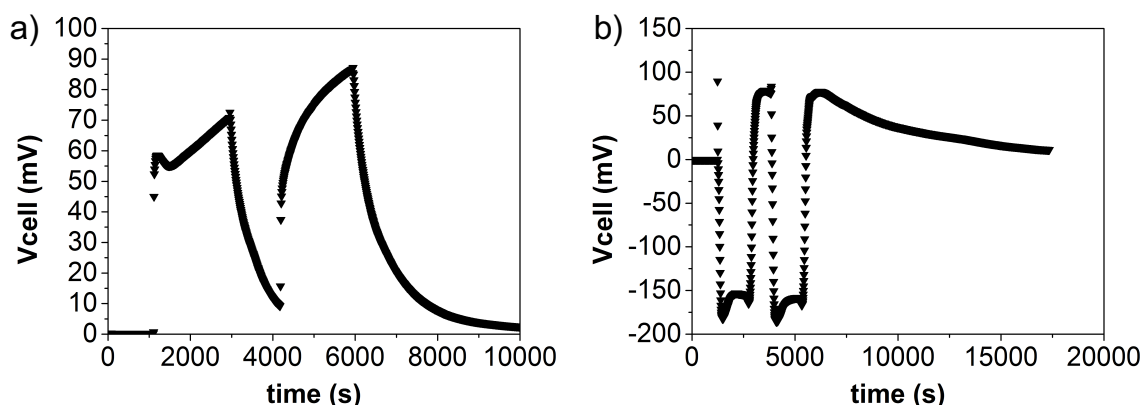

Figure 4.6 Sensor response curves for two changes of 20 minutes adding: a) methylnaphthalene (88.16 ppm) and b) toluene (28947.37). The sensor consists of $\mathrm{Fe}_{0.7} \mathrm{Cr}_{1.3} \mathrm{O}_{3} / 8 \mathrm{YSZ} / / 8 \mathrm{YSZ} / / \mathrm{Pt}$ working at $550^{\circ} \mathrm{C}$ and a $6 \%$ of oxygen 
Tabla 4.1 Sensor response as voltage $(\mathrm{mV})$ and sensor gain $(\mathrm{mV} / \mathrm{ppm})$ to several conditions: toluene, methylnaphthalene, phenanthrene, ethylene and carbon monoxide

\begin{tabular}{|c|c|c|c|}
\hline Element & Vcell (mV) & Concentration (ppm) & Sensor gain (mV/ppm) \\
\hline $\mathrm{C}_{7} \mathrm{H}_{8}$ & 119.16 & 28947.37 & 0.004 \\
\hline $\mathrm{C}_{11} \mathrm{H}_{10}$ & -158.75 & 88.16 & -1.80 \\
\hline $\mathrm{C}_{14} \mathrm{H}_{10}$ & 0.23 & 0.16 & 1.44 \\
\hline $\mathrm{C}_{2} \mathrm{H}_{4}$ & 23.49 & 200 & 0.12 \\
\hline $\mathrm{CO}$ & 4.82 & 200 & 0.02 \\
\hline
\end{tabular}

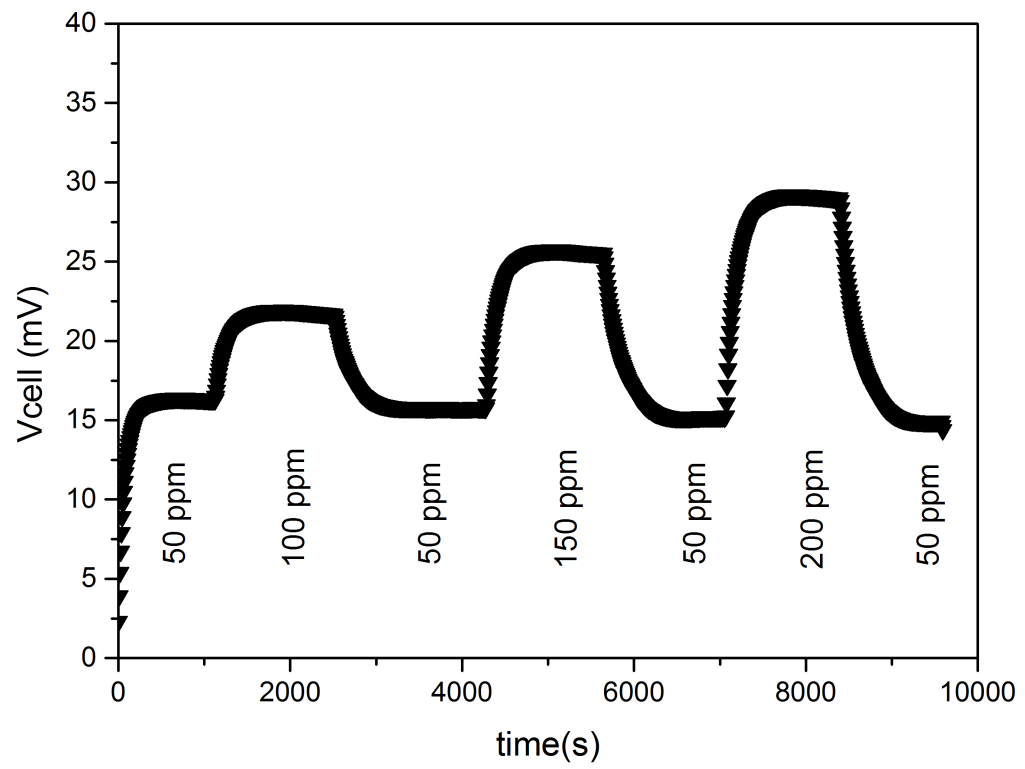

Figure 4.7 Response curves for changes in concentration of ethylene in dry conditions after the exposure of the sensor to polyaromatic hydrocarbons. Each change in concentration has 20 minutes of duration and it goes from 50 to 100, 150 and 200 ppm. The sensor consists of

$\mathrm{Fe}_{0.7} \mathrm{Cr}_{1.3} \mathrm{O}_{3} / 8 \mathrm{YSZ} / / 8 \mathrm{YSZ} / / \mathrm{Pt}$ and the working temperature is $550^{\circ} \mathrm{C}$ with $6 \%$ of oxygen without water and/or PAHs 


\subsubsection{Raman spectroscopy}

Raman spectroscopy analyses were performed over the $\mathrm{Fe}_{0.7} \mathrm{Cr}_{1.3} \mathrm{O}_{3} / 8 \mathrm{YSZ}$ working electrode layer with the gold collector on top after and before exposing the sensor to the different tests to check the coke formation. Figure 4.8 shows the Raman spectra at $785 \mathrm{~nm}$ before and after the tests. In both samples peaks corresponding to the spinel phase can be observed at band values of 533 and $682 \mathrm{~cm}^{-1}$ [12-14]. A common $\mathrm{Fe}_{3} \mathrm{O}_{4}$ peak can be also observed at the band value $1341 \mathrm{~cm}^{-1}[12]$.The Raman spectra after exposing the sensor to PAHs, show more peaks in the region from 1200 to $1600 \mathrm{~cm}^{-1}$. In this region, amorphous carbon (both 1340-1400 $\mathrm{cm}^{-1}$ and $1540-1600 \mathrm{~cm}^{-1}$ region peaks [15]) and carbon nanotubes $\left(1562 \mathrm{~cm}^{-1}[16]\right)$ are expected. Not only there are peaks in this carbon regions but also there is more fluorescence in the tested sample. This may indicate the presence of complex organic molecules adsorbed on the electrode surface. However, despite these considerations, no carbon fingerprint is observed by means of the Raman spectroscopy to the limit of this technique. However, coke deposition can be observed by SEM on top of the electrode after exposing the sensor to aromatics, although snapshots of coke are not easy to acquire and pictures are not shown because of the poor quality (blur and burnt).

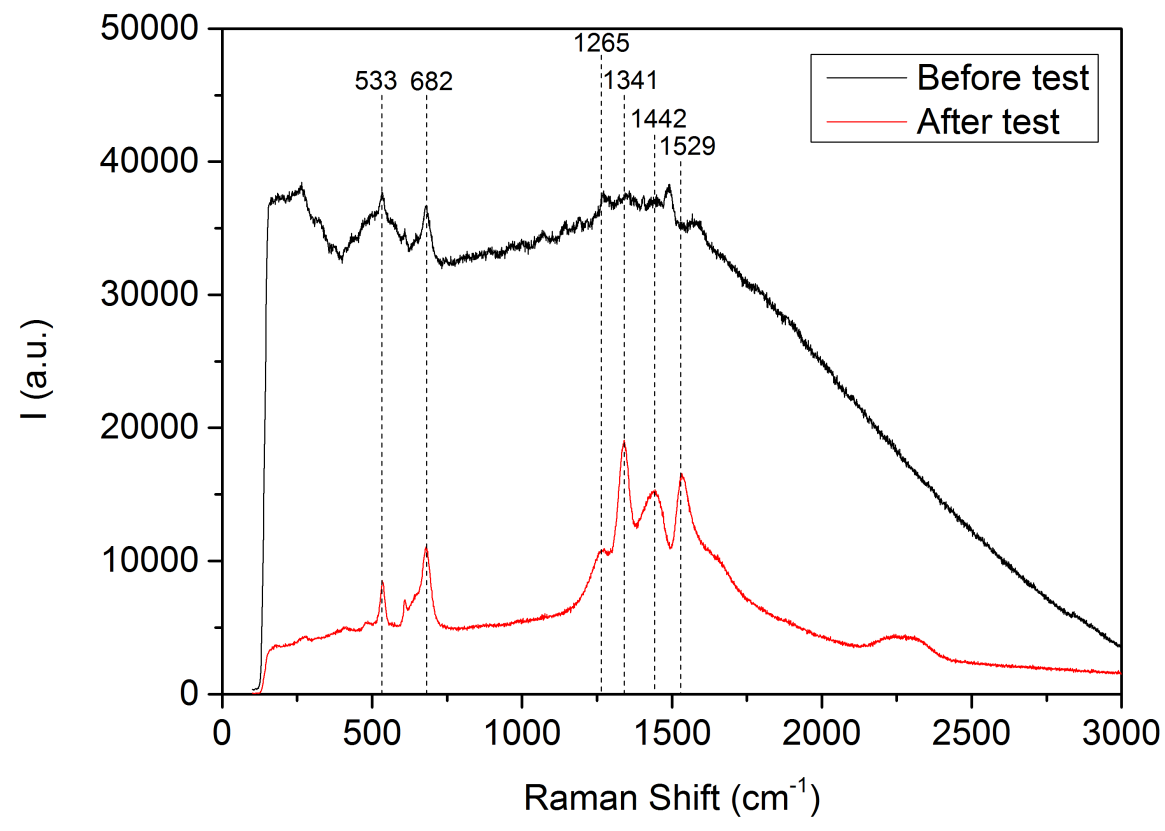

Figure 4.8 Raman spectra of the $\mathrm{Fe}_{0.7} \mathrm{Cr}_{1.3} \mathrm{O}_{3} / 8 \mathrm{YSZ}$ working electrode with gold layer as current collector before and after being exposed to polyaromatic hydrocarbons 


\subsection{Reference electrode improvement strategies}

The sensor configuration $\mathrm{Fe}_{0.7} \mathrm{Cr}_{1.3} \mathrm{O}_{3} / 8 \mathrm{YSZ} / / 8 \mathrm{YSZ} / / \mathrm{Pt}$ has proved to be not adequate for ethylene sensing purposes in conditions like an exhaust gas. As seen in section 4.2, in wet conditions or when PAHs are added, the sensor failed to provide a selective response to ethylene as the cross-sensitivity to carbon monoxide rises. Thus, the sensor configuration must be improved. The approach taken in this thesis is to act over the reference electrode. According to the theory, in the reference electrode the oxygen reduction should be favored, thus activity to oxygen in this electrode must be optimized. Materials with a high catalytic activity to oxygen reduction, or with more active area, should be considered to substitute the platinum. This is also a chance to reduce the cost of the device as platinum is an expensive material.

As this kind of potentiometric sensors shared a similar theoretical fundamentals with fuel cells, similar materials can be used. For instance, reference electrode in the present sensor has the same role than the cathode in a fuel cell, i.e. electrons are employed to reduce oxygen and get oxygen ions that go through the electrolyte to the anode (or could be the working electrode in the potentiometric sensor) [17-20]. Several materials are employed in the literature with good results, e.g. lanthanum magnetite materials doped with rare earth elements as $\mathrm{Sr}$, Co or Ce (LSM, LSC, LSCF, LCM, LNF, LBC, LNO), gadolinium materials (GSC, GSM), praseodymium materials (PCM, PSM, PBC), strontium materials (SSC, NSC, BSCCu) and yttria materials (YSCF, YCCF, YBCu) $[21,22,31-36,23-30]$. Materials must be good electrical conductor, must be chemically compatible with the electrolyte and thermally stable. In addition, it should have certain ionic conductivity to improve the performance of the cathode.

In this work, $\mathrm{La}_{0.8} \mathrm{Sr}_{0.2} \mathrm{MnO}_{3}$ is selected due to its good performance in fuel cells as cathode and its good compatibility with 8YSZ. In order to increase its ionic conductivity and improve its performance it is mixed 1:1 in volume with 8YSZ. Thus, LSM provides the electrical conductivity while the 8YSZ provides the ionic conductivity, enlarging the triple phase boundary area.

\subsubsection{Structural characterization}

The desired LSM phase is confirmed by an XRD analysis of the synthesized powder as shown in figure 4.9. Diffraction peaks corresponding to any other oxide or precursor are not observed. Figure 4.10 confirms that the electrode is porous to favor the reaction taking place in the triple phase boundary and at the interface. 
There is a good distribution of both elements and the grain size is similar for both of them. Neither reaction interfaces nor impurities are detected between the electrode and the electrolyte.

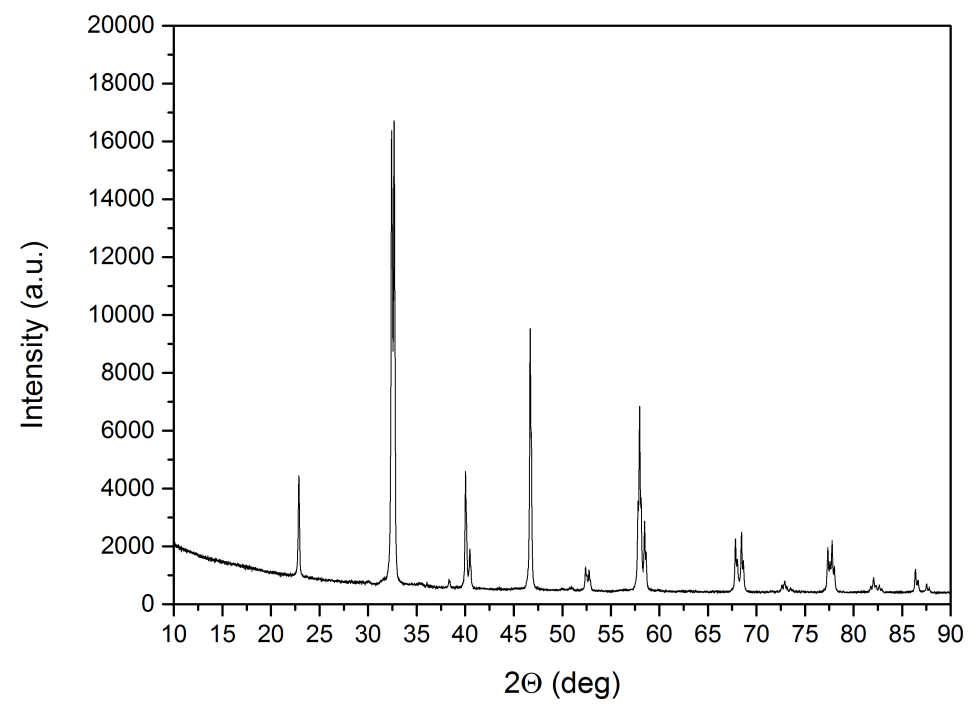

Figure $4.9 X$-ray diffraction patter of LSM used as reference electrode at room temperature once it is synthesized

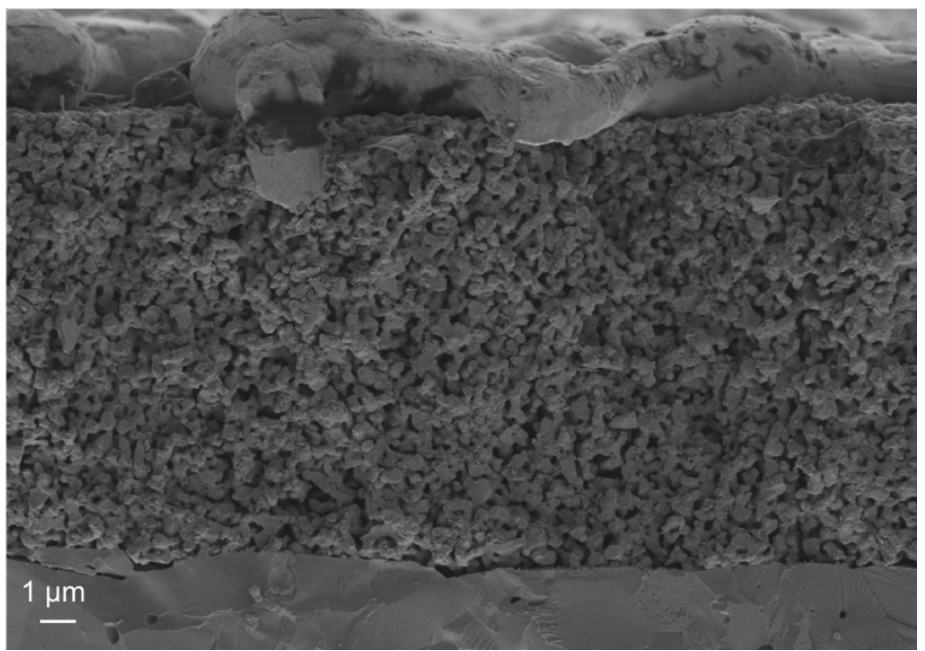

Figure 4.10 SEM image of the reference electrode cross-section corresponding to LSM/8YSZ with gold layer current collector on top. A good attachment to the electrolyte can be observed as well as a good distribution of both grains. 


\subsubsection{Electrochemical characterization}

The new sensor configuration, $\mathrm{Fe}_{0.7} \mathrm{Cr}_{1.3} \mathrm{O}_{3} / 8 \mathrm{YSZ} / / 8 \mathrm{YSZ} / / \mathrm{LSM} / 8 \mathrm{YSZ}$ (WE//8YSZ//Pt), is exposed to analytes following the procedure explained in chapter 2. Thus, the sensor is exposed to changes in concentration of ethylene and carbon monoxide in the range $50-200 \mathrm{ppm}$ individually as well as with a background of $200 \mathrm{ppm}$ of the other analyte.

In this scenario, when comparing figures $4.11 \mathrm{a}$ and $\mathrm{c}$, the sensor responses to ethylene and carbon monoxide are similar. It can be even noticed that the sensor gain to carbon monoxide is bigger than to ethylene. When 200 ppm of carbon monoxide are added as background, the sensor response to changes in ethylene concentration is negligible as can be observed in figure $4.11 \mathrm{~b}$. Therefore, the sensor response is being controlled by carbon monoxide concentration. Besides, sensor is responding to changes in carbon monoxide concentration when 200 ppm of ethylene are added as shown in figure $4.11 \mathrm{~d}$.

Unfortunately, this new sensor configuration leads to a sensor that lacks selectivity to ethylene oppositely to the response in dry conditions with $\mathrm{Pt}$ as reference electrode. Data collected is summarized in figure 4.12 as function of carbon monoxide and ethylene concentrations, and it can be clearly observed that the sensitivity to ethylene is not higher than carbon monoxide sensitivity. Fine-grained LSM/8YSZ electrodes exhibit significant activity towards oxygen gas reduction to produce $\mathrm{O}^{2-}$, and are the electrode of choice in conventional solid oxide fuel cells. In contrast, coarse Pt electrodes show limited activity. One possible explanation is that the change in the reference electrode activity is affecting to the equilibrium achieved in each electrode and is promoting the rate of carbon monoxide oxidation in the working electrode. Maybe platinum, employed as reference electrode in the previous device, was promoting the heterogeneous catalysis of carbon monoxide and avoiding or reducing its electrochemical reaction contribution. This could also explain why phenanthrene addition increases the cross-sensitivity toward carbon monoxide in the previous configuration. Maybe phenanthrene catalytic conversion with platinum is favored over carbon monoxide conversion and consequently there is more carbon monoxide to interact in the electrochemical reaction. 

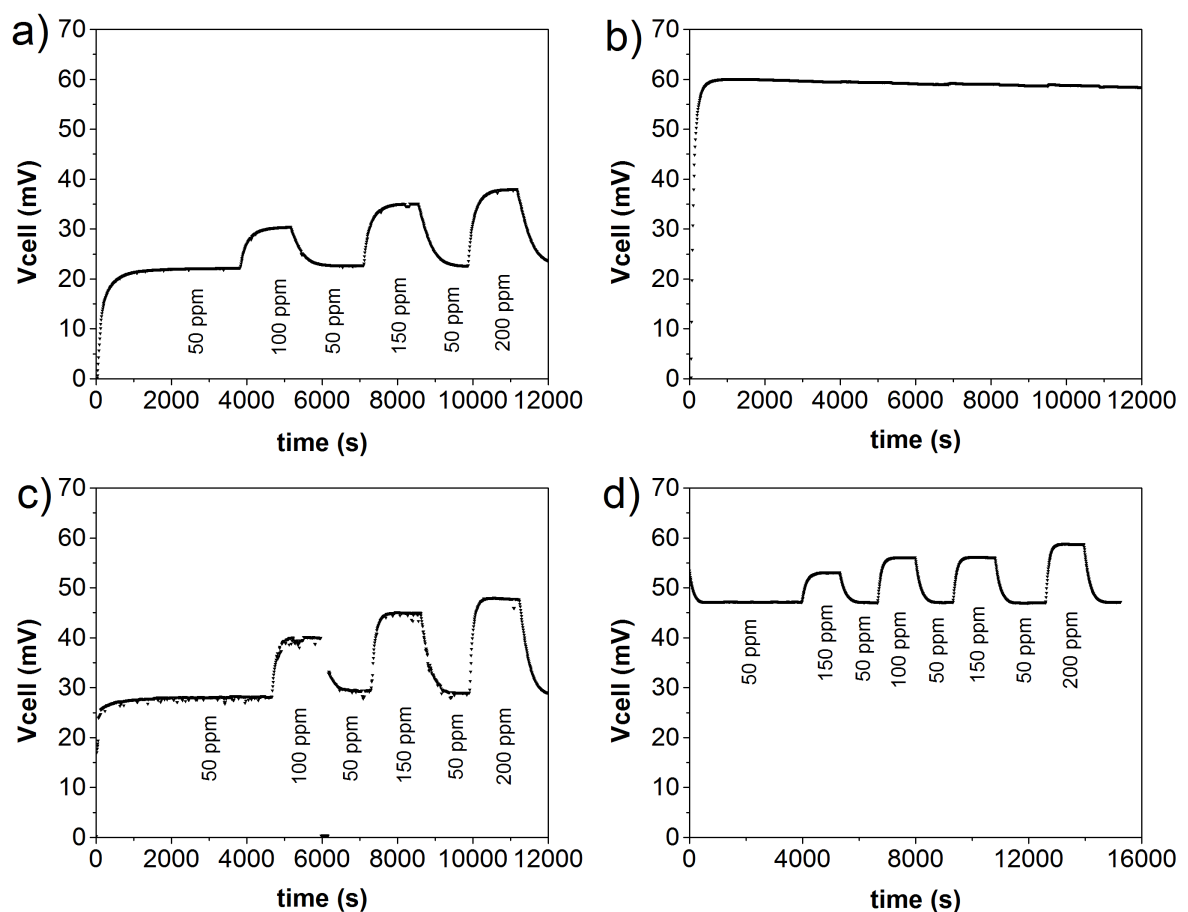

Figure 4.11 Response curves for the sensor configuration $\mathrm{Fe}_{0.7} \mathrm{Cr}_{1.3} \mathrm{O}_{3} / 8 \mathrm{YSZ} / / 8 \mathrm{YSZ} / / \mathrm{LSM} / 8 \mathrm{YSZ}$ for changes in concentration of: a) ethylene, b) ethylene with 200 ppm of carbon monoxide background, c) carbon monoxide and d) carbon monoxide with 200 ppm of ethylene background. Each change in concentration has 20 minutes of duration and it goes from 50 to 100,150 and 200 ppm. The tests are carried out at $550^{\circ} \mathrm{C}$ with $6 \%$ of oxygen.

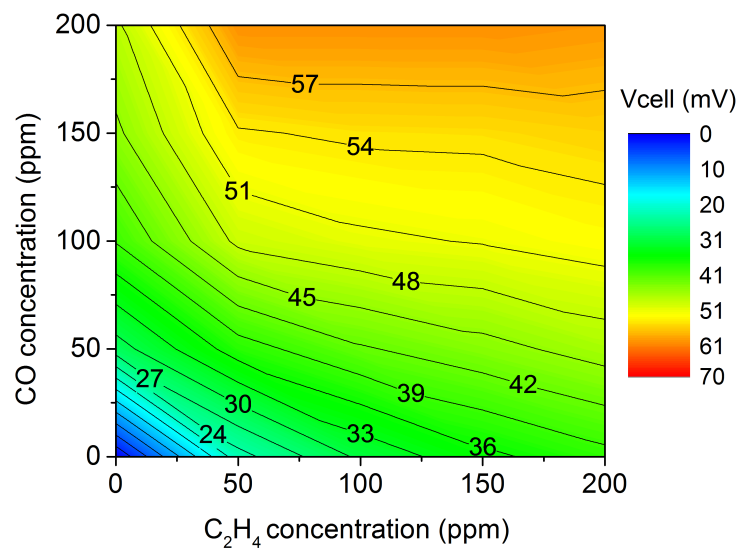

Figure 4.12 Contour plot displaying the sensor response (Vcell) as a function of the analytes concentration in dry conditions to sensor configuration $\mathrm{Fe}_{0.7} \mathrm{Cr}_{1.3} \mathrm{O}_{3} / 8 \mathrm{YSZ} / / 8 \mathrm{YSZ} / / \mathrm{LSM} / 8 \mathrm{YSZ}$ 
Additionally, an EIS analysis is performed to check the sensor performance. Figure 4.13 shows the Nyquist plots for base gas, 200 ppm of ethylene and 200 ppm of carbon monoxide. There is no difference in the shape of the semi-arcs at low frequencies when compared to the device employing Pt as RE (figure 3.13). This low frequencies region includes electrochemical reactions at the surface and catalytic activity. Thus, the fact that both analytes provide the same semi-arc can indicate that there is not selective response to any of them, being the reaction rates similar for both analytes.

LSM/8YSZ as reference electrode provides a cheaper version of the sensor with higher activity towards oxygen activation, but failed to provide a selective response to ethylene when tested. Mismatch between RE and WE reaction rates need for improvement of kinetics of WE. Further work it is needed to improve the sensor response and now it should be focused on the working electrode. The ethylene reaction rate must be improved over other analytes to ensure a proper sensor performance for ethylene sensing.

Thus, a careful design of the sensor (electrodes and electrolyte) is needed with a balanced reaction-rate in target reaction between both electrodes.

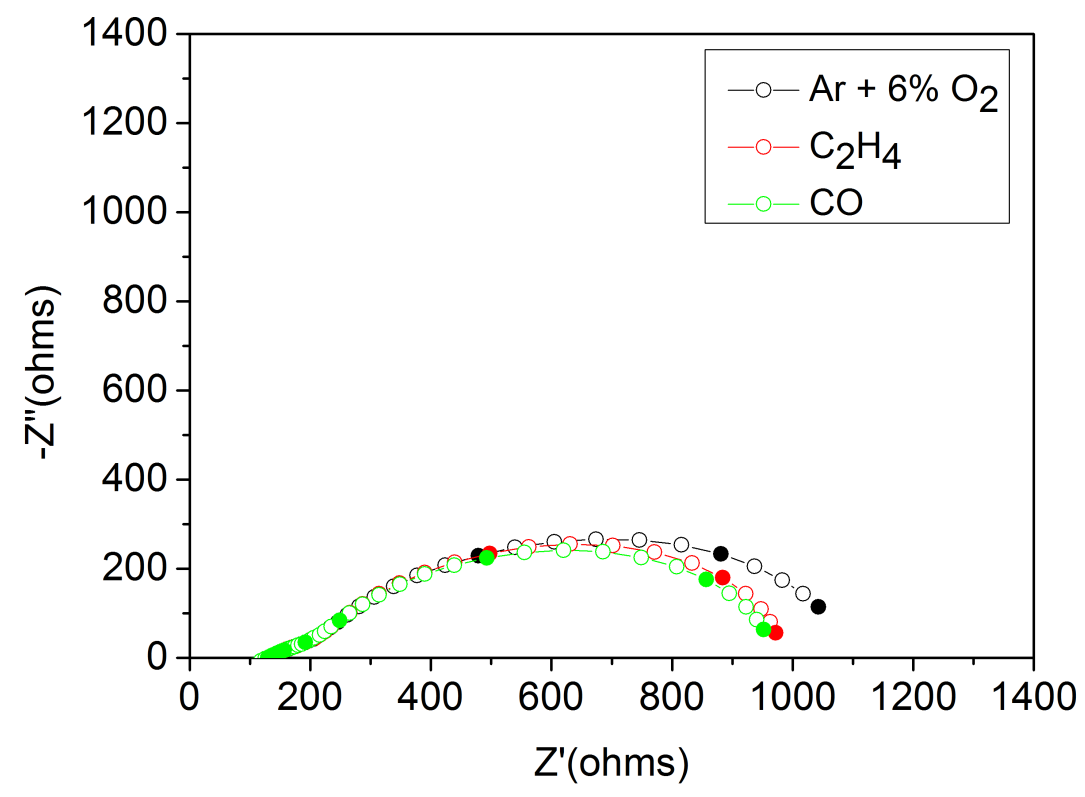

Figure 4.13 Impedance spectrometry study for the sensor configuration

$\mathrm{Fe}_{0.7} \mathrm{Cr}_{1.3} \mathrm{O}_{3} / 8 \mathrm{YSZ} / / 8 \mathrm{YSZ} / / \mathrm{LSM} / 8 \mathrm{YSZ}$. Nyquist plot for $\mathrm{Ar}+6 \%$ of $\mathrm{O}_{2}$ base gas, $200 \mathrm{ppm}$ of ethylene and 200 ppm of carbon monoxide is depicted 


\subsection{Conclusions}

The sensor configuration $\mathrm{Fe}_{0.7} \mathrm{Cr}_{1.3} \mathrm{O}_{3} / 8 \mathrm{YSZ} / / 8 \mathrm{YSZ} / / \mathrm{Pt}$ showed a good performance in dry conditions in the previous chapter and it is tested under harsh conditions like in a car exhaust gas i.e. with water, phenanthrene, methylnaphthalene and toluene. After exposing the sensor to water, the response is not selective to ethylene anymore. Sensor voltage output increases for both analytes but in the case of carbon monoxide also does the sensor gain. Both of them provide a similar sensor gain in wet conditions indicating that the crosssensitivity toward carbon monoxide has increased when compared to dry conditions.

The presence of hydrocarbons have a similar effect. The addition of $0.16 \mathrm{ppm}$ of phenanthrene provokes a reduction of the selectivity to ethylene as in the case of water. Although the sensor gain is slightly higher for ethylene, the crosssensitivity toward carbon monoxide is high enough to make the sensor not suitable for ethylene detection. On the other hand, the addition of $88.16 \mathrm{ppm}$ methylnaphthalene and $28947 \mathrm{ppm}$ of toluene distort the sensor response as they show a high cross sensitivity superimposing their signal to both ethylene and carbon monoxide responses.

The sensor response under harsh conditions like in a car exhaust gas makes the device not suitable for ethylene detection. The loss of selectivity to ethylene in wet conditions as well as in PAHs atmospheres makes it fundamental to improve the sensor configuration. The strategy followed is to act over the reference electrode by looking for an alternative material active to oxygen. Platinum not only is a good catalyst that can affect the final response because of the reactions taking place on its surface but it is also expensive. Since the reference electrode acts similarly to a cathode in a fuel cell, materials used usually as cathodes in fuel cells are considered. LSM/8YSZ is selected because of its good performance in literature for the oxygen reduction reaction as it provides electrical and ionic conductivity.

The change from Pt to LSM/8YSZ in the reference electrode does not improve the sensor performance as it provides a similar response to both carbon monoxide and ethylene. The equilibrium achieved increases the reaction rates for carbon monoxide on the working electrode leading to an increase on the sensor signal to carbon monoxide as well as the sensor gain. There is a mismatch between WE and RE reaction rates, and a careful design of the sensor must be done to balance the reaction-rate in the target reaction between both electrodes. Additionally, platinum could be promoting the catalytic reaction of carbon monoxide and then, there is less carbon monoxide to compete in the 
electrochemical reaction. This could also explain the increase in cross-sensitivity toward carbon monoxide when phenanthrene is added. Phenanthrene catalytic reaction with platinum could be more favored than carbon monoxide reaction and then there are more carbon monoxide able to compete in the electrochemical reaction.

Ethylene reaction kinetics must be improved in the working electrode and therefore. Thus, the current device employing LSM/8YSZ as RE is not selective to ethylene. Further optimization must be done focusing on the working electrode to improve the reaction rate to ethylene rather than to carbon monoxide, water or PAHs.

\subsection{References}

[1] R. Küngas, J.M. Vohs, R.J. Gorte, Effect of the lonic Conductivity of the Electrolyte in Composite SOFC Cathodes, J. Electrochem. Soc. 158 (2011) 743748. doi: 10.1149/1.3581109

[2] H. Kusaba, Y. Shibata, K. Sasaki, Y. Teraoka, Surface effect on oxygen permeation through dense membrane of mixed-conductive LSCF perovskite-type oxide, Solid State lonics. 177 (2006) 2249-2253. doi:10.1016/J.SSI.2006.05.038.

[3] Q. Jiang, K.J. Nordheden, S.M. Stagg-Williams, Oxygen permeation study and improvement of $\mathrm{Ba} 0.5 \mathrm{Sr} 0.5 \mathrm{Co} 0.8 \mathrm{Fe} 0.2 \mathrm{Ox}$ perovskite ceramic membranes, J. Memb. Sci. 369 (2011) 174-181. doi:10.1016/J.MEMSCI.2010.11.073.

[4] G.-B. Jung, C.-T. Chang, C.-C. Yeh, X.-V. Nguyen, S.-H. Chan, C.-Y. Lin, J.-W. Yu, W.-T. Lee, S.-W. Chang, I.-C. Kao, Study of reversible solid oxide fuel cell with different oxygen electrode materials, Int. J. Hydrogen Energy. 41 (2016) 21802-21811. doi:10.1016/j.ijhydene.2016.07.190.

[5] B.S. Prakash, S.S. Kumar, S.T. Aruna, Microstructure and performance of LSM/YSZ based solid oxide fuel cell cathodes fabricated from solution combustion co-synthesized powders and by solution precursor plasma spraying, Surf. Coat. Technol. 310 (2016) 25-32. doi:10.1016/j.surfcoat.2016.12.004.

[6] M. Park, H.Y. Jung, J.Y. Kim, H. Kim, K.J. Yoon, J.W. Son, J.H. Lee, B.K. Kim, H.W. Lee, Effects of mixing state of composite powders on sintering behavior of cathode for solid oxide fuel cells, Ceram. Int. 43 (2017) 11642-11647. doi:10.1016/j.ceramint.2017.05.347.

[7] S.-W. Baek, J. Jeong, H. Schlegl, A.K. Azad, D.S. Park, U.B. Baek, J.H. Kim, CERAMICS INTERNATIONAL Metal-supported SOFC with an aerosol deposited in-situ LSM and 8YSZ composite cathode, Ceram. Int. 42 (2015) 24022409. doi:10.1016/j.ceramint.2015.10.039. 
[8] N. Sakai, K. Yamaji, T. Horita, Y.P. Xiong, H. Kishimoto, M.E. Brito, H. Yokokawa, Effect of water on electrochemical oxygen reduction at the interface between fluorite-type oxide-ion conductors and various types of electrodes, Solid State lonics. 174 (2004) 103-109. doi:10.1016/j.ssi.2004.07.027.

[9] J. Vecchietti, A. Bonivardi, W. Xu, D. Stacchiola, J.J. Delgado, M. Calatayud, S.E. Collins, Understanding the Role of Oxygen Vacancies in the Water Gas Shift Reaction on Ceria-Supported Platinum Catalysts, (n.d.). doi:10.1021/cs500323u.

[10] B. Jäger, A. Wermann, P. Scholz, M. Müller, U. Reislöhner, A. Stolle, B. Ondruschka, Iron-containing defect-rich mixed metal oxides for Friedel-Crafts alkylation, Appl. Catal. A Gen. $443 \quad$ (2012) 87-95. doi:10.1016/j.apcata.2012.07.025.

[11] S.P. Ghorpade, V.S. Darshane, S.G. Dixit, Liquid-phase Friedel-Crafts alkylation using CuCr2-xFexO4 spinel catalysts, Appl. Catal. A Gen. 166 (1998) 135-142. doi:10.1016/S0926-860X(97)00266-4.

[12] B. Tian, J. Światowska, V. Maurice, S. Zanna, A. Seyeux, P. Marcus, Binary iron-chromium oxide as negative electrode for lithium-ion micro-batteries spectroscopic and microscopic characterization, Appl. Surf. Sci. 353 (2015) 1170-1178. doi:10.1016/J.APSUSC.2015.07.041.

[13] P.B. Samarasingha, N.H. Andersen, M.H. Sørby, S. Kumar, O. Nilsen, H. Fjellvåg, Neutron diffraction and Raman analysis of LiMn1.5Ni0.5O4 spinel type oxides for use as lithium ion battery cathode and their capacity enhancements, Solid State Ionics. 284 (2016) 28-36. doi:10.1016/J.SSI.2015.11.018.

[14] H.S. Jadhav, R.S. Kalubarme, A.H. Jadhav, J.G. Seo, Iron-nickel spinel oxide as an electrocatalyst for non-aqueous rechargeable lithium-oxygen batteries, (2016). doi:10.1016/j.jallcom.2016.01.131.

[15] M. Veres, M. Füle, S. Tóth, M. Koós, I. Pócsik, Surface enhanced Raman scattering (SERS) investigation of amorphous carbon, Diam. Relat. Mater. 13 (2004) 1412-1415. doi:10.1016/J.DIAMOND.2004.01.041.

[16] M.L. de la Chapelle, S. Lefrant, C. Journet, W. Maser, P. Bernier, A. Loiseau, Raman studies on single walled carbon nanotubes produced by the electric arc technique, Carbon N. Y. 36 (1998) 705-708. doi:10.1016/S00086223(98)00026-8.

[17] K. Huang, S.C. Singhal, Cathode-supported tubular solid oxide fuel cell technology: A critical review, J. Power Sources. 237 (2013) 84-97. doi:10.1016/J.JPOWSOUR.2013.03.001.

[18] Y. Li, R. Gemmen, X. Liu, Oxygen reduction and transportation mechanisms in solid oxide fuel cell cathodes, J. Power Sources. 195 (2010) 3345-3358. doi:10.1016/J.JPOWSOUR.2009.12.062. 
[19] F. Ramadhani, M.A. Hussain, H. Mokhlis, S. Hajimolana, Optimization strategies for Solid Oxide Fuel Cell (SOFC) application: A literature survey, Renew. Sustain. Energy Rev. $76 \quad$ (2017) 460-484. doi:10.1016/J.RSER.2017.03.052.

[20] K.-C. Chang, B. Ingram, J. llavsky, S. Lee, P. Fuoss, H. You, Synchrotron X-ray studies of model SOFC cathodes, part I: Thin film cathodes, Solid State Ionics. 311 (2017) 118-126. doi:10.1016/J.SSI.2017.10.005.

[21] A.M. Abdalla, S. Hossain, A.T. Azad, P.M.I. Petra, F. Begum, S.G. Eriksson, A.K. Azad, Nanomaterials for solid oxide fuel cells: A review, Renew. Sustain. Energy Rev. 82 (2018) 353-368. doi:10.1016/J.RSER.2017.09.046.

[22] S.-W. Baek, J. Jeong, H. Schlegl, A.K. Azad, D.S. Park, U.B. Baek, J.H. Kim, Metal-supported SOFC with an aerosol deposited in-situ LSM and 8YSZ composite cathode, Ceram. Int. $42 \quad$ (2016) 2402-2409. doi:10.1016/J.CERAMINT.2015.10.039.

[23] S.J. Lee, P. Muralidharan, S.H. Jo, D.K. Kim, Composite cathode for ITSOFC: Sr-doped lanthanum cuprate and Gd-doped ceria, Electrochem. Commun. 12 (2010) 808-811. doi:10.1016/J.ELECOM.2010.03.039.

[24] Y.T. Kim, N. Shikazono, Investigation of La0.6Sr0.4CoO3- $\delta$ $\mathrm{Gd} 0.1 \mathrm{Ce} 0.9 \mathrm{O} 2-\delta$ composite cathodes with different volume ratios by three dimensional reconstruction, Solid State lonics. 309 (2017) 77-85. doi:10.1016/J.SSI.2017.07.010.

[25] F. Zhao, R. Peng, C. Xia, LSC-based electrode with high durability for ITSOFCs, Fuel Cells Bull. 2008 (2008) 12-16. doi:10.1016/S1464-2859(08)701068.

[26] X. Song, S. Lee, Y. Chen, K. Gerdes, Electrochemically influenced cation

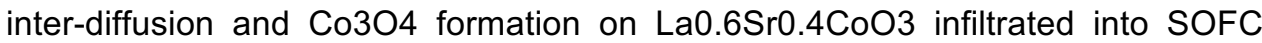
cathodes, Solid State Ionics. 278 (2015) 91-97. doi:10.1016/J.SSI.2015.05.026.

[27] M.M. Natile, G. Eger, P. Batocchi, F. Mauvy, A. Glisenti, Strontium and copper doped LaCoO3: New cathode materials for solid oxide fuel cells?, Int. J. Hydrogen Energy. 42 (2017) 1724-1735. doi:10.1016/J.IJHYDENE.2016.09.127.

[28] G.D. Han, K.C. Neoh, K. Bae, H.J. Choi, S.W. Park, J.-W. Son, J.H. Shim, Fabrication of lanthanum strontium cobalt ferrite (LSCF) cathodes for high performance solid oxide fuel cells using a low price commercial inkjet printer, J. Power Sources. 306 (2016) 503-509. doi:10.1016/J.JPOWSOUR.2015.12.067.

[29] Z. Zhu, Z. Wei, Y. Zhao, M. Chen, S. Wang, Properties characterization of tungsten doped strontium ferrites as cathode materials for intermediate temperature solid oxide fuel cells, Electrochim. Acta. 250 (2017) 203-211. doi:10.1016/J.ELECTACTA.2017.08.059. 
[30] H. Taguchi, R. Chiba, T. Komatsu, H. Orui, K. Watanabe, K. Hayashi, LNF SOFC cathodes with active layer using Pr6O11 or Pr-doped CeO2, J. Power Sources. 241 (2013) 768-775. doi:10.1016/J.JPOWSOUR.2013.04.141.

[31] L. Zhang, G. Yao, Z. Song, B. Niu, W. Long, L. Zhang, Y. shen, T. He, Effects of Pr-deficiency on thermal expansion and electrochemical properties in Pr1-xBaCo2O5+ס cathodes for IT-SOFCs, Electrochim. Acta. 212 (2016) 522534. doi:10.1016/J.ELECTACTA.2016.07.014.

[32] H. Li, L.-P. Sun, Q. Li, T. Xia, H. Zhao, L.-H. Huo, J.-M. Bassat, A. Rougier, S. Fourcade, J.-C. Grenier, Electrochemical performance of double perovskite Pr2NiMnO6 as a potential IT-SOFC cathode, Int. J. Hydrogen Energy. 40 (2015) 12761-12769. doi:10.1016/J.IJHYDENE.2015.07.133.

[33] C. Lenser, F. Gunkel, Y.J. Sohn, N.H. Menzler, Impact of defect chemistry on cathode performance: A case study of Pr-doped ceria, Solid State Ionics. 314 (2018) 204-211. doi:10.1016/J.SSI.2017.09.023.

[34] Y. Ji, H. Wang, H. Zhang, Gd0.8Sr0.2CoO3-ס-Sm0.1Ce0.901.95 composite cathode for intermediate temperature solid oxide fuel cells, Mater. Res. Bull. 85 (2017) 30-34. doi:10.1016/J.MATERRESBULL.2016.09.001.

[35] Y.-F. Bu, Q. Zhong, D.-D. Xu, X.-L. Zhao, W.-Y. Tan, Performance of Y0.9Sr0.1Cr0.9Fe0.1O3- $\delta$ as a sulfur-tolerant anode material for intermediate temperate solid oxide fuel cells, J. Power Sources. 250 (2014) 143-151. doi:10.1016/J.JPOWSOUR.2013.11.005.

[36] K.C. Wincewicz, J.S. Cooper, Taxonomies of SOFC material and manufacturing alternatives, J. Power Sources. 140 (2005) 280-296. doi:10.1016/J.JPOWSOUR.2004.08.032. 
Chapter 5

Optimization of $\mathrm{Fe}_{0.7} \mathrm{Cr}_{1.3} \mathrm{O}_{3}$ working electrode through surface activation by several compounds nanoparticles deposition 



\section{Optimization of $\mathrm{Fe}_{0.7} \mathrm{Cr}_{1.3} \mathrm{O}_{3}$ working electrode through surface activation by several compounds nanoparticles deposition}

\subsection{Introduction}

In the previous chapter, the change from $\mathrm{Fe}_{0.7} \mathrm{Cr}_{1.3} \mathrm{O}_{3} / 8 \mathrm{YSZ} / / 8 \mathrm{YSZ} / / \mathrm{Pt}$ to $\mathrm{Fe}_{0.7} \mathrm{Cr}_{1.3} \mathrm{O}_{3} / 8 \mathrm{YSZ} / / 8 \mathrm{YSZ} / / \mathrm{LSM} / 8 \mathrm{YSZ}$ leads to a sensor less sensitive to ethylene. As aforementioned, this new scenario produces a mismatch between RE and WE reaction rates and there is a need to improve the kinetics of the working electrode. Thus, a balanced reaction rate in target reaction between both electrodes is required. In this chapter, strategies for the surface activation of the working electrode will be carried out to improve the sensor response to ethylene while the carbon monoxide response remains negligible. The optimization of the working electrode will consist of the deposition of nanoparticles in the working electrode to improve or boost the electrochemical reaction of ethylene in this electrode.

Several elements such as $\mathrm{Ni}, \mathrm{Ru}, \mathrm{Ti}, \mathrm{Al}, \mathrm{Nb}, \mathrm{Ba}$ and $\mathrm{Pd}$ were employed as nanocatalysts. A complete electrochemical characterization was carried out after infiltration with each one of these elements. Channel infiltrated with nickel, titanium, ruthenium or aluminium shows an enhancement in their performance for ethylene detection. The functionalization of the working electrode surface provides a selective response to ethylene with low cross-sensitivity toward carbon monoxide. On the other hand, the channels infiltrated with niobium, palladium or barium despite showing an improvement of the signal, it is not enough to match the aims of the present work.

Moreover, a second infiltration with nickel was performed. The combination of both nanocatalysts ameliorates the sensor performance. Hence, channels infiltrated with $\mathrm{Nb}, \mathrm{Pd}$ or $\mathrm{Ba}$ show after infiltration with nickel a selective response to ethylene with relatively low cross-sensitivity to carbon monoxide in dry conditions. However, not only the sensor performances in wet conditions are poor but also their responses in dry conditions are below nickel, titanium or aluminium performance. Thus, these elements are not adequate for the sensing purposes in this work.

In contrast, the combination of nickel, titanium or aluminium with a second infiltration with nickel provides a device with a very good sensitivity to ethylene 
with low cross-sensitivity to carbon monoxide even in wet conditions. Thus, these configurations are promising for the purpose of this thesis as it allows to detect selectively ethylene even with the presence of carbon monoxide and water. Additionally, each channel is evaluated by means of an electrochemical impedance spectroscopy. These analysis backs the results obtained in the potentiometric characterization as it can be observed that after infiltration with each one of the elements considered as promising ( $\mathrm{Ni}, \mathrm{Ti}$ and $\mathrm{Al}$ ), the ethylene polarization resistance is lower than carbon monoxide resistance. This happens for channels infiltrated with the element itself as well as after the second nickel infiltration.

Consequently, the infiltration with nanocatalysts have proven to be able to modify the processes occurring at low frequencies related with catalytic reactions at the electrode surface. This helps to boost the electrochemical oxidation of ethylene becoming the main contributor in the overall reaction after achieving the equilibrium in the electrode. Thus, the mismatch in the reaction rates between working and reference electrode mentioned in the last chapter for the $\mathrm{Fe}_{0.7} \mathrm{Cr}_{1.3} \mathrm{O}_{3} / 8 \mathrm{YSZ} / / 8 \mathrm{YSZ} / / \mathrm{LSM} / 8 \mathrm{YSZ}$ configuration is solved.

\subsection{Selection of materials for surface activation}

Several candidates were considered for the optimization of the working electrode to improve its catalytic activity toward hydrocarbons. The porous electrode was infiltrated with both alkali earth metals and transition metals nanoparticles. The main aim is to spread nanoparticles on the electrode surface that boost the electrochemical reaction to the target analyte. As aforementioned, several reactions take place on the working electrode and an equilibrium is achieved. Thus, the nanoparticle must boost the electrochemical reaction of ethylene and have a low activity toward carbon monoxide and oxygen (and other pollutants) [17]. Therefore, the adsorption and dissociation of ethylene must be favoured while carbon monoxide adsorption should be low. In this work, several elements are employed because of their activity for oxidation of hydrocarbons/carbon monoxide (Elements used usually in catalytic processes): Al [8], Ti [2], Ni [9], Ru [10-12], Pd $[13,14], \mathrm{Nb}[15]$ and $\mathrm{Ba}$. These elements can possess a certain Lewis acidity or basicity (for the alkali elements) if there is the presence of a positive charge on the metal [13].

Infiltration is performed by dropping the precursor solution of each element in the range $0.1-1.5 \mathrm{M}$ on the surface of the calcinated electrode by capillarity. Thus, the solution drenches the porous electrode filling up all pores. After calcination, the nanoparticles are formed. Metal content is similar for each metal to enable comparison Two steps are followed during the calcination: firstly, the device is 
heated in argon at $550^{\circ} \mathrm{C}$ for 4 hours and secondly, the device is heated again at $550^{\circ} \mathrm{C}$ for 2 hours in $5 \%$ hydrogen. Each device will remain at working temperature for four weeks.

In this chapter, a multi-sensor as depicted in figure 5.1 is employed because it allows to work with four channels at the same time. Thereby, each channel is infiltrated with a different element.

a)
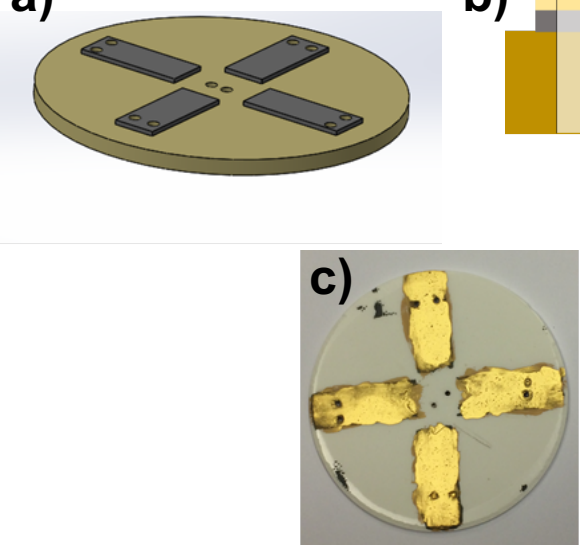

b)

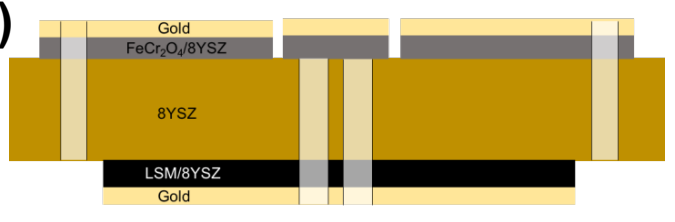

Figure 5.1 Design and pictures of the multi-device designed. a) The section shows the design of the multi-sensor with holes to attach the wires b) Cross section of the designed multi-sensor device. On top face, the working electrode $\left(\mathrm{Fe}_{0.7} \mathrm{Cr}_{1.3} \mathrm{O}_{3} / 8 \mathrm{YSZ}\right)$ with gold layers as current collector can be observed. On the other face, there is one common reference electrode (LSM/8YSZ) with a gold layer as current collector. c) $\mathrm{Fe}_{0.7} \mathrm{Cr}_{1.3} \mathrm{O}_{3} / 8 \mathrm{YSZ}$ channel with gold layer. d) Back face with LSM/8YSZ common reference electrode and gold layer.

\subsection{Electrochemical characterization}

First, the bare sensor response must be compared to be sure that each channel is providing a similar response to ethylene and carbon monoxide. As aforementioned in the methodology, the results are normalized to compare the trend of the channels to each other. Some differences in the value of the sensor response can appear because of the deviations in the manufacturing process: electrolyte thickness, electrodes geometry, thickness and position (WE electrode is covering the same area than RE relative to each other), gold current collector, etc.

The bare sensor response of several channels before being infiltrated with $\mathrm{Ni}, \mathrm{Ru}$, $\mathrm{Nb}, \mathrm{Ti}, \mathrm{Al}$ and $\mathrm{Ba}$ can be observed in Figure 5.2. The sensors are exposed to changes in concentration of ethylene and carbon monoxide in the range 50-200 
ppm at $550^{\circ} \mathrm{C}$ and with a $6 \%$ of oxygen, and each channel provides a similar performance. As seen in the previous chapter, the sensor response with the current configuration has no selectivity toward ethylene and it is almost the same for both ethylene and carbon monoxide. Once the reproducibility of the sensor is proved, each channel is infiltrated with different elements: $\mathrm{Ni}, \mathrm{Ru}, \mathrm{Ti}, \mathrm{Al}, \mathrm{Nb}, \mathrm{Ba}$ and $\mathrm{Pd}$. After performing the electrochemical characterization, the channels are infiltrated a second time with nickel as summarized in table 5.1.

a)
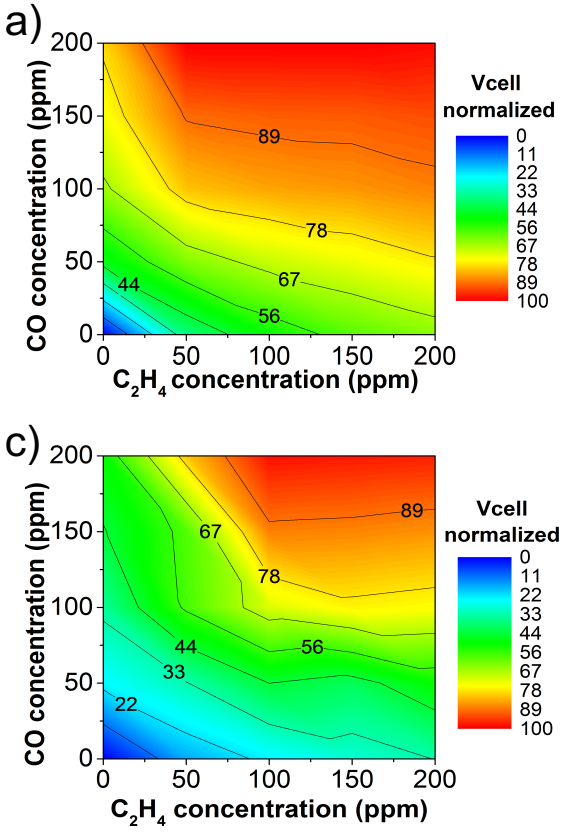

e)

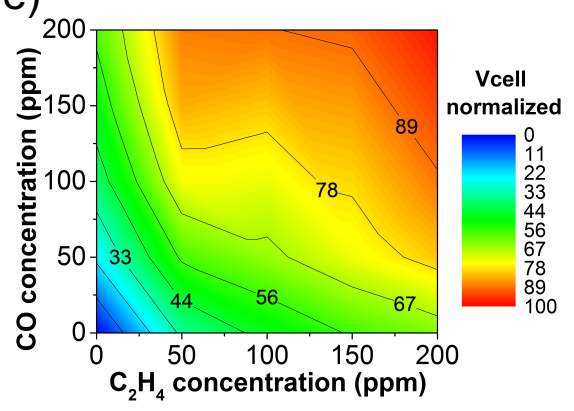

b)

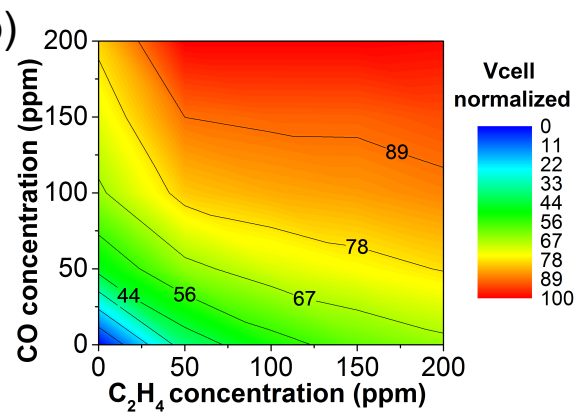

d)

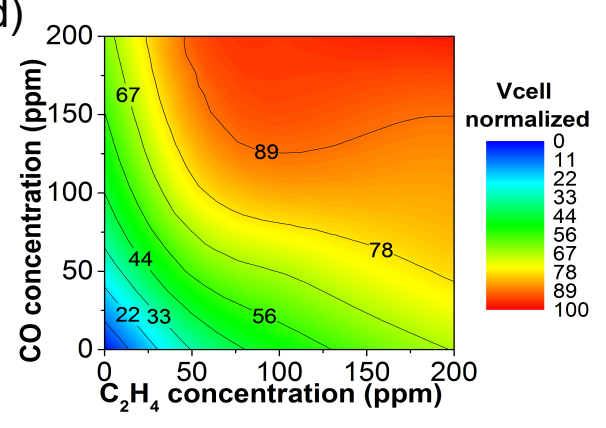

f)

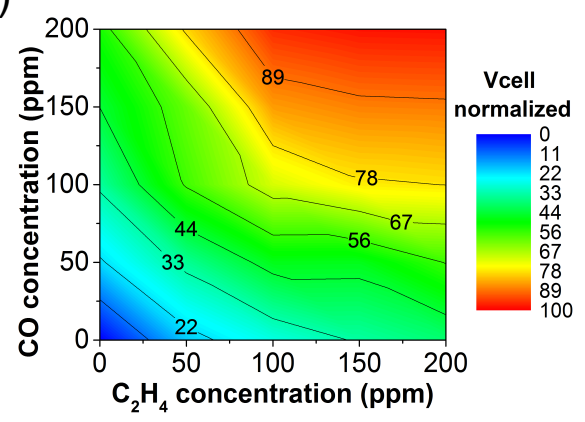

Figure 5.2 Bare sensor response of several channels to ethylene and carbon monoxide concentrations. Responses are normalized to compare among different channels and devices. 
Table 5.1 Infiltration carried out in each channel. A complete electrochemical characterization is performed after the first infiltration and then, another complete electrochemical characterization is carried out after the addition of the second infiltration.

\begin{tabular}{|c|c|c|c|c|c|c|c|}
\hline Channel & $\mathbf{1}$ & $\mathbf{2}$ & $\mathbf{3}$ & $\mathbf{4}$ & $\mathbf{5}$ & $\mathbf{6}$ & $\mathbf{7}$ \\
\hline $\begin{array}{c}\mathbf{1}^{\text {st }} \\
\text { element }\end{array}$ & $\mathrm{Ni}$ & $\mathrm{Ru}$ & $\mathrm{Nb}$ & $\mathrm{Ti}$ & $\mathrm{Al}$ & $\mathrm{Ba}$ & $\mathrm{Pd}$ \\
\hline $\begin{array}{c}\mathbf{2}^{\text {nd }} \\
\text { element }\end{array}$ & $\mathrm{Ni}$ & $\mathrm{Ru}$ & $\mathrm{Ni}$ & $\mathrm{Ni}$ & $\mathrm{Ni}$ & $\mathrm{Ni}$ & $\mathrm{Ni}$ \\
\hline
\end{tabular}

\subsubsection{Potentiometric Characterization}

\subsubsection{First batch: Ni and Ru infiltration}

\section{Nickel infiltration}

The infiltration of the working electrode with nickel $0.5 \mathrm{M}$ changes completely the performance of the device as shown in Figure 5.3a. The change in response to ethylene concentration is higher than to carbon monoxide. In addition, the effect of carbon monoxide on ethylene response is negligible, since an addition of 200 ppm of carbon monoxide as a background has a very low impact effect on the sensor response to ethylene. The response is mainly due to ethylene. Moreover, when there is background of $200 \mathrm{ppm}$ of ethylene, an increase in carbon monoxide concentration has no effect on the sensor response. Thus, the sensor response is selective to ethylene with a low cross-sensitivity to carbon monoxide.

A second infiltration with $\mathrm{Ni}$ improves even more the sensor performance. The selectivity to ethylene is higher than in the previous case and the overall response is more dependent on ethylene rather than carbon monoxide as depicted in Figure 5.3b. The change in response with carbon monoxide concentration is lower than when the channel is infiltrated once with $\mathrm{Ni}$. This indicates that the cross-sensitivity is even lower than in the previous case. The sensor response is not affected by the presence of carbon monoxide, and the device fulfils the aims of the present work at dry conditions.

In addition, the device is exposed to a wet atmosphere (3\% water) to check the response under wet conditions. Figure $5.3 \mathrm{c}$ shows a similar response to that 
observed in dry conditions. Although there is an increase in the influence of carbon monoxide concentration on the sensor response, the response to ethylene is still more significant and the cross-sensitivity to carbon monoxide remains low. Indeed, the sensor performance is similar to that in dry conditions. Thereby, nickel infiltration leads to a device able to measure selectively ethylene with low cross sensitivity to carbon monoxide in both dry and wet conditions.

Infiltration has boosted the electrochemical reaction in the working electrode to ethylene and it has solved the mismatch between RE and WE reactions rates that provided an unselective response in the previous chapter.

a)

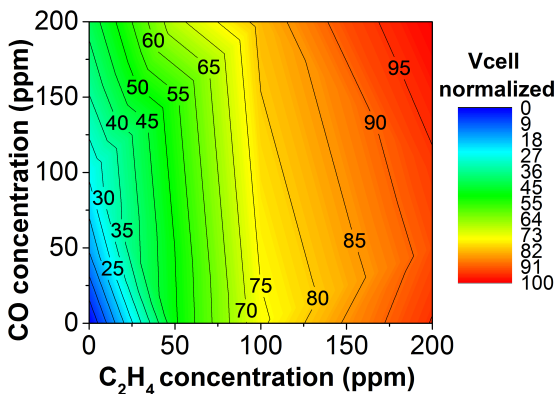

b)

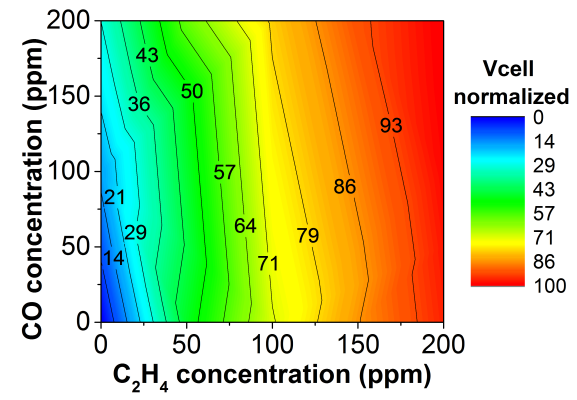

c)

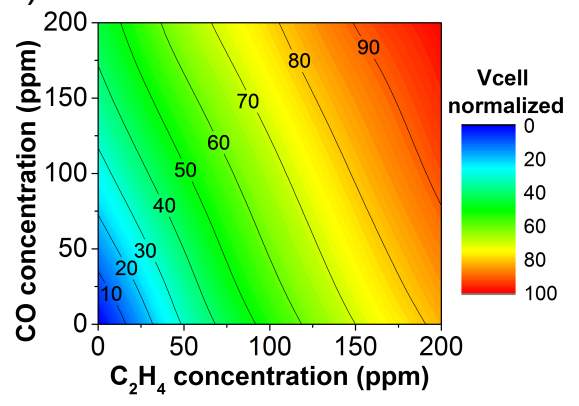

Figure 5.3 Sensor response after: a) First nickel infiltration in dry conditions. b) second nickel infiltration in dry conditions. c) Second nickel infiltration in wet conditions. 


\section{Ruthenium infiltration}

Ruthenium infiltration with a solution $0.13 \mathrm{M}$ provides a similar sensor response than nickel at dry conditions (figure 5.4). The channel response is also selective to ethylene although in this case the cross-sensitivity to carbon monoxide is higher. The sensor response to pure ethylene is higher than when a carbon monoxide background is added. In addition, the increase of the response with the ethylene concentration is lower than in the infiltration with $\mathrm{Ni}$. A second infiltration with ruthenium was performed but it took down the sensor signal. Probably this was due to a blockage of the electrode during the dropping of the solution and the later calcination.

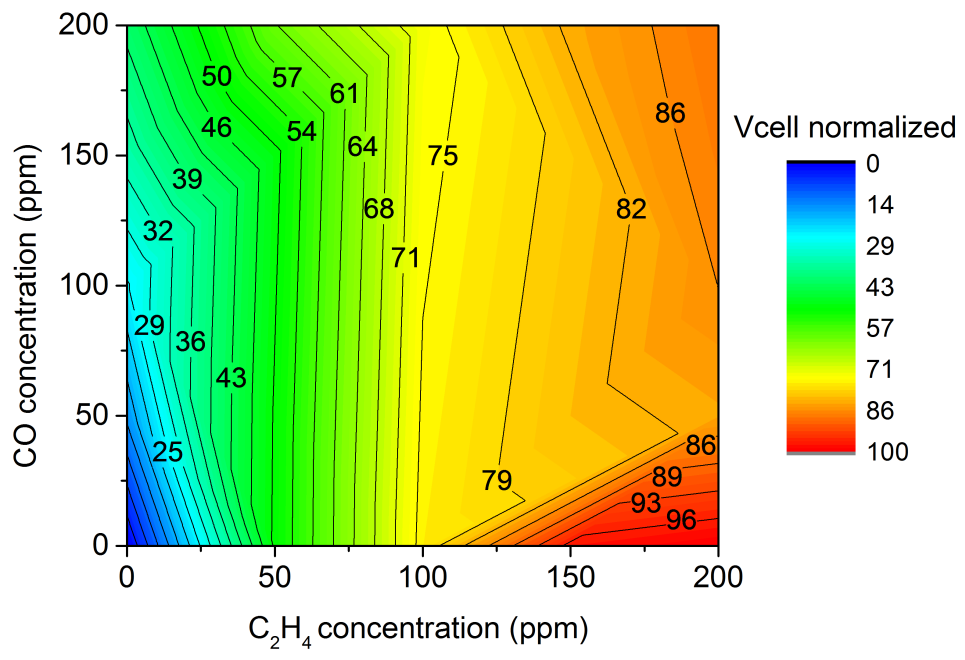

Figure 5.4 Sensor response after infiltration with ruthenium. 


\subsubsection{Second batch: Ti and Al infiltration}

\section{Titanium infiltration}

Infiltration with titanium provides a rise in the selectivity of the device toward ethylene as shown in Figure 5.5a. The sensor is now selective to ethylene with a low cross-sensitivity to carbon monoxide. When the sensor is exposed to pure gases, the sensor gain with concentration is lower for carbon monoxide when compared to ethylene. On the other hand, the addition of backgrounds of each gas provides a flat response to carbon monoxide. The response is mainly due to the $200 \mathrm{ppm}$ background of ethylene. Conversely, the sensitivity to ethylene is not a flat response, providing therefore a low cross-sensitivity to carbon monoxide.

A second infiltration with nickel is done to boost even more ethylene electrochemical reaction by combination of both nanocatalysts. The combination of both nanocatalyts increases even more the selectivity to ethylene and reduces cross-sensitivity to carbon monoxide as depicted in Figure 5.5b. The increase in response with carbon monoxide concentration is now negligible for both pure carbon monoxide and with ethylene background. On the other hand, the response to ethylene remains the same. Thus, this combination provides a better response as it reduces the cross-sensitivity to carbon monoxide.

Finally, the device is exposed to a wet atmosphere (3\% water) to ensure the sensor performance in wet conditions. Figure $5.5 \mathrm{c}$ shows the sensor performance under these conditions, where the sensor response is still selective to ethylene with a low cross-sensitivity to carbon monoxide. There is a slight increase of the cross-sensitivity to carbon monoxide compared to dry conditions but this increase is practically negligible as the sensor response is still dominated by changes in ethylene concentration. Combination of both nanocatalysts provides a lower cross-sensitivity toward carbon monoxide than in the case of nickel infiltration. Thus, this configuration lead to a sensor device selective to ethylene even in wet conditions. 
a)

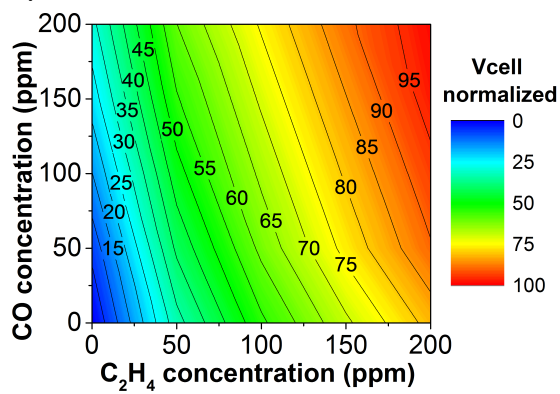

b)

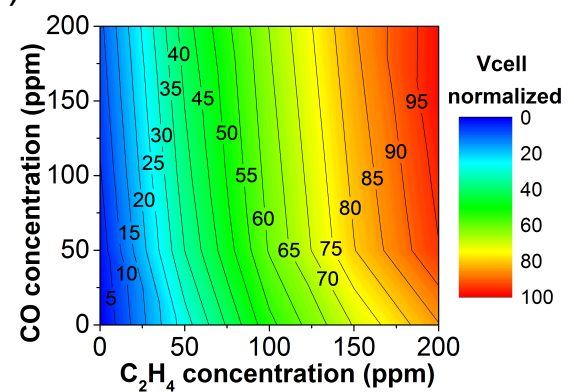

c)

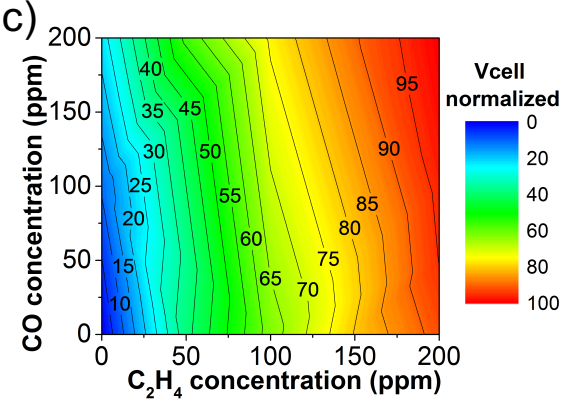

Figure 5.5 Sensor response after: a) First titanium infiltration in dry conditions. b) second infiltration with nickel in dry conditions. c) Second infiltration with nickel in wet conditions.

\section{Aluminium infiltration}

The infiltration of the device with aluminium $1.5 \mathrm{M}$ gives similar results as titanium infiltration (Figure 5.6a). The sensor performance has a response selective to ethylene because such response depends on the ethylene concentration for both pure ethylene and with carbon monoxide background. On the other hand, the change in response with carbon monoxide concentration is low and more depending on ethylene when this element is added as background. Thus, the device shows a selective response to ethylene with low cross-sensitivity to carbon monoxide.

As in the case of titanium, a second infiltration with nickel is performed. Combination of both nanocatalysts enhances the main characteristics of the sensor: selectivity to ethylene and low cross-sensitivity to carbon monoxide. The cross-sensitivity to carbon monoxide is even lower as can be observed in Figure $5.6 \mathrm{~b}$ and the sensor response is mainly dependent on ethylene concentration. As in the case of titanium, the addition of water ( $3 \%$ water) has practically no effect on the sensor response as shown in Figure 5.6c. There is a slight increase in the cross-sensitivity to carbon monoxide but the sensor response is still provided by 
ethylene. Therefore, it can be concluded that the sensor with aluminium plus nickel is a promising material for selective ethylene detection.

a)

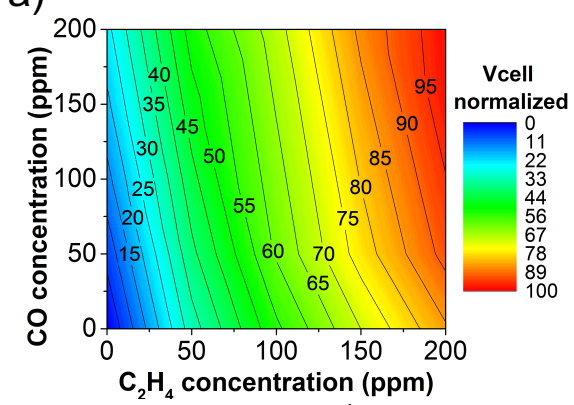

b)

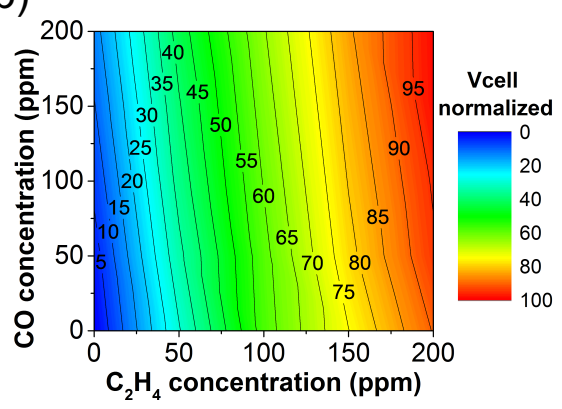

C)

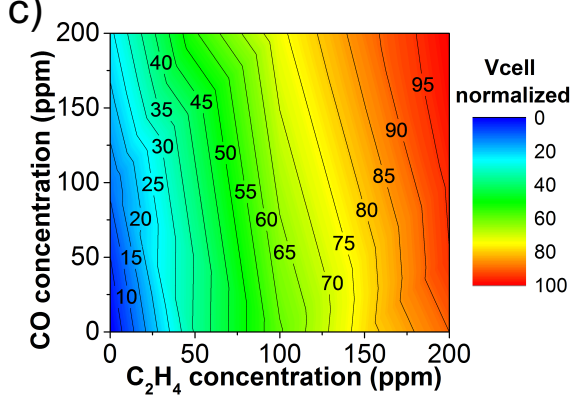

Figure 5.6 Sensor response after: a) First aluminium infiltration in dry conditions. b) second infiltration with nickel in dry conditions. c) Second infiltration with nickel in wet conditions.

\subsubsection{Third batch: Niobium, barium and palladium infiltration}

\section{$\mathrm{Nb}$ infiltration}

An infiltration with niobium $0.5 \mathrm{M}$ leads to a sensor that shows a selective response to ethylene but with a higher cross-sensitivity when compared with other infiltrated materials such as $\mathrm{Ti}, \mathrm{Ni}$ or Al. The increase in the cross sensitivity can be observed in Figure 5.7a. The change in concentration of carbon monoxide has now an effect on the sensor response.

When a second infiltration with nickel is done, the sensor performance is enhanced considerably. As shown in Figure $5.7 \mathrm{~b}$ the cross-sensitivity to carbon monoxide has decreased and now the change in response with carbon monoxide concentration is negligible. On the other hand, the response is dependent on the ethylene concentration. Thus, after the second infiltration the sensor performance 
is similar to previous infiltrations (figure $5.6 \mathrm{~b}$ and figure $5.5 \mathrm{~b}$ ) with a selective response to ethylene and low cross-sensitivity to carbon monoxide.

The sensor is also exposed to wet conditions ( $3 \%$ water) and as can be seen in Figure $5.7 \mathrm{c}$, the sensor performance is not appropriate. The cross-sensitivity to carbon monoxide increases with water addition, and the response of the sensor depends also on the changes in concentration of carbon monoxide. Thus, this configuration is not appropriate for a selective response to ethylene under wet conditions.

a)

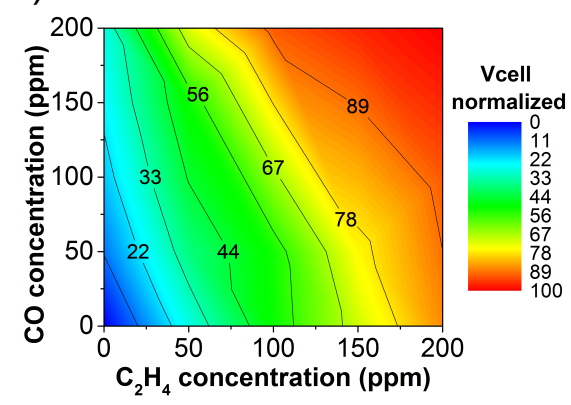

c) b)

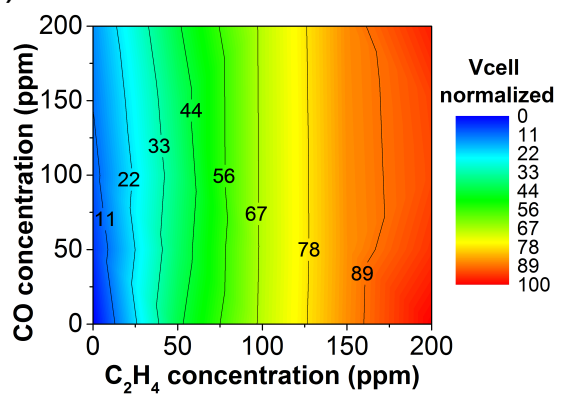

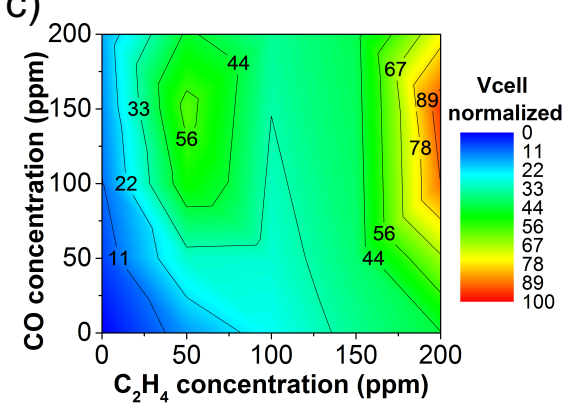

Figure 5.7 Sensor response after: a) First niobium infiltration in dry conditions. b) second infiltration with nickel in dry conditions. c) Second infiltration with nickel in wet conditions.

\section{Ba and Pd infiltration}

Infiltration with barium (Figure $5.8 \mathrm{a}$ ) $0.5 \mathrm{M}$ produces a sensor response with certain cross-sensitivity to carbon monoxide. Although the sensor output signal is low when compared to other devices infiltrated, the change in response with ethylene concentration is higher than the change in concentration with carbon monoxide concentration. Thus, this makes the sensor suitable for ethylene detection despite the low output. The sensor response is improved after a second infiltration with nickel (Figure 5.8b), but there is still present some cross-sensitivity 
to carbon monoxide. Despite providing a relatively good response to ethylene, the response is worst when compared to other elements studied in this chapter. Moreover, the addition of water gives an inaccurate response, unselective to ethylene probably due to a mismatch between reactions taking place in each electrode. Thus, the water effect makes the sensor not suitable for the sensing purposes of this work.

Finally, in the case of palladium (Figure 5.9) $0.5 \mathrm{M}$, the response after infiltration with palladium is not selective to ethylene as seen in Figure 5.9a. A second infiltration with nickel improves slightly the sensor response but there is still a high cross-sensitivity to carbon monoxide that makes it less profitable than other alternatives (Figure 5.9b). In addition, water has an effect on the sensor response, providing irregularities in the change of response with ethylene concentration (Figure 5.9c). There is no increase in the sensor response with an increase of the ethylene concentration. Thus, this configuration is not profitable for selective ethylene detection in exhaust gases.

a)

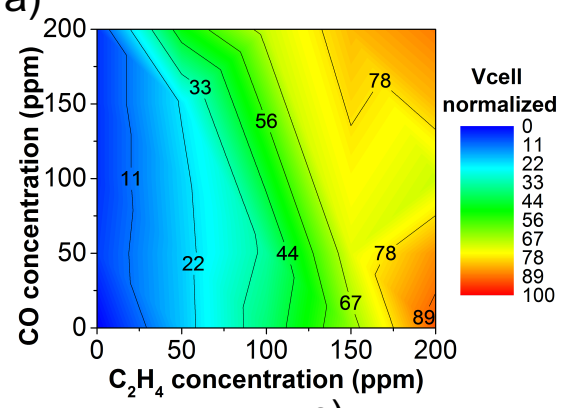

b)

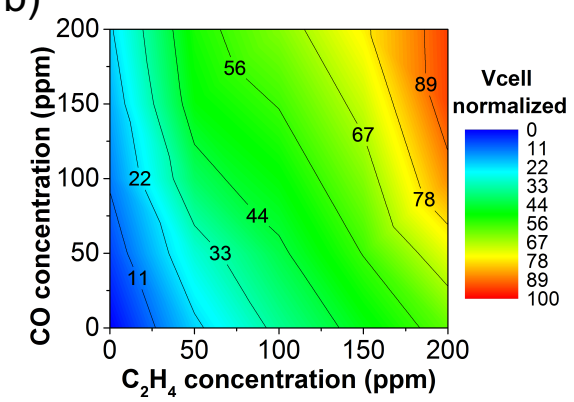

c)

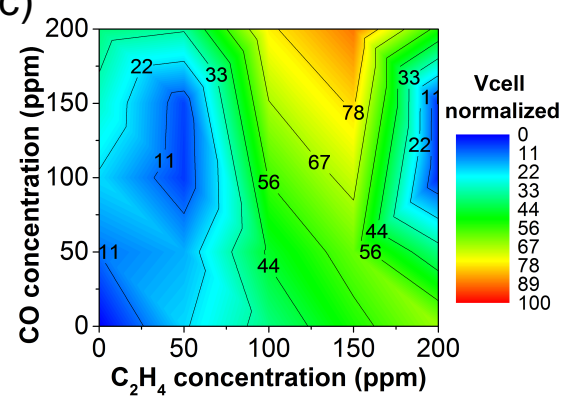

Figure 5.8 Sensor response after: a) First barium infiltration in dry conditions. b) second infiltration with nickel in dry conditions. c) Second infiltration with nickel in wet conditions. 
a)

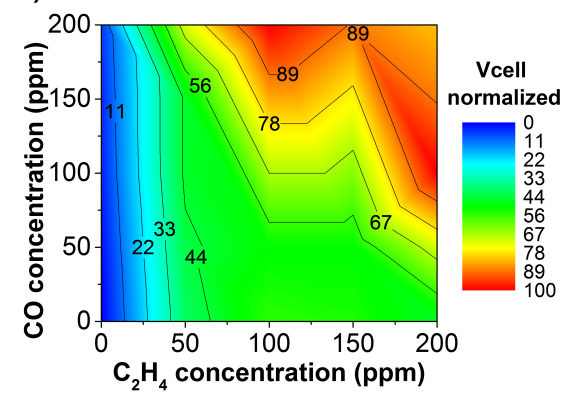

b)

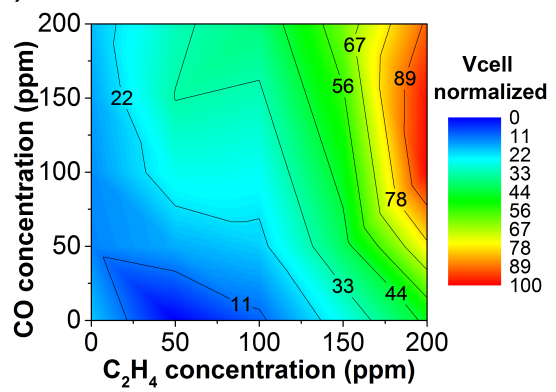

c) 200

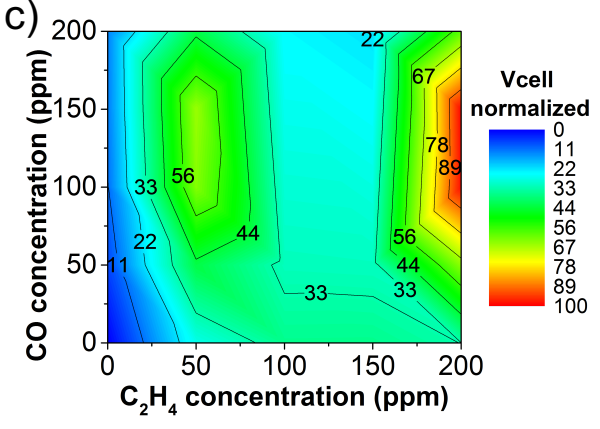

Figure 5.9 Sensor response after: a) First palladium infiltration in dry conditions. b) second infiltration with nickel in dry conditions. c) Second infiltration with nickel in wet conditions.

\subsubsection{Electrochemical impedance spectroscopy}

Additionally, electric impedance spectroscopy analysis is performed under 200 ppm of pure carbon monoxide and ethylene for the five elements that provides a better response: $\mathrm{Ni}, \mathrm{Al}, \mathrm{Ti}, \mathrm{Nb}$ and $\mathrm{Ru}$. The impedance analysis is done for the bare sensor, the sensor infiltrated with the first element and the sensor infiltrated additionally with nickel. Figures 5.10 to 5.14 depict the Nyquist and bode plots from $0.03 \mathrm{~Hz}$ to $1 \mathrm{MHz}$ for each scenario.

Infiltration with nickel, titanium and aluminium leads to a two-arcs contribution that can be fitted to an equivalent circuit consisting of two parallel combinations of resistance-constant phase elements circuits connected in series (figure 5.105.12). While the device infiltrated with niobium shows a three-arch contribution that can be fitted to an equivalent circuit consisting of three parallel combinations of resistance constant phase elements (figure 5.13). The shape of the arch at high frequencies is similar in all cases.

The first arch contribution $\left(C=10^{5}-10^{6} \mathrm{~F}\right.$ as shown in figures $5.15 \mathrm{~b}$ and $\left.5.15 \mathrm{~d}\right)$ at $550^{\circ} \mathrm{C}$ and employing $8 \mathrm{YSZ}$ as electrolyte can be attributed to the interface 
electrode-electrolyte. As can be observed in figures $5.15 a$ and $5.15 \mathrm{c}$, the $R_{\text {Interace }}$ remains constant when the sensor is exposed to ethylene and carbon monoxide for all elements: bare sensor as well as the device infiltrated with each material and after the second nickel infiltration. Therefore, the ionic mobility remains almost unaffected i.e. it is not altered by the infiltration of nanocatalysts.

On the other hand, the second arch contribution at low frequencies $\left(C=10^{3}-10^{4} \mathrm{~F}\right.$ as shown in figure $5.15 \mathrm{~b}$ and $\mathrm{d}$ ) is related with catalytic processes at the electrode surface and depends on each infiltration. Still, the bare sensor polarization resistance $(R p)$ for ethylene and carbon monoxide is practically the same as can be observed in figure 5.16. This is in agreement with the lack of selectivity obtained in the potentiometric characterization (this and the previous chapter). The sensor response is not selective to ethylene as it has a high crosssensitivity to carbon monoxide.

\section{Nickel infiltration}

In the case of nickel, the first infiltration with nickel has practically no effect on the response to ethylene whilst the carbon monoxide response increases heavily as can be observed in figures $5.10 \mathrm{a}$ and $5.10 \mathrm{~b}$. This proves that the addition of nanocatalyst can have an effect on the sensor response as there is a modification of the surface and catalytic processes occurring on the electrodes. Thus, this confirms that the ethylene electrochemical reaction can be boosted to improve the sensor performance as has been seen in the potentiometric characterization. Second infiltration with nickel reduces both ethylene and carbon monoxide contributions (Figures 5.10 and 5.15a and 5.15c). However, there is a difference in the polarization resistance between ethylene and carbon monoxide as shown in figure 5.16. This effect could be responsible for the selective sensor response to ethylene with a low cross-sensitivity toward carbon monoxide observed in the potentiometric measurements. 

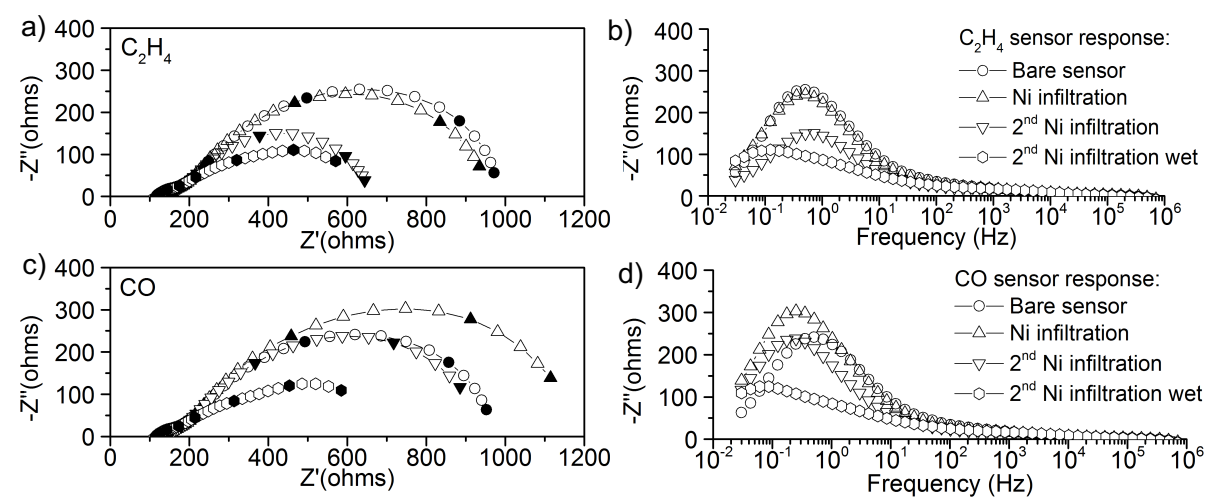

e)

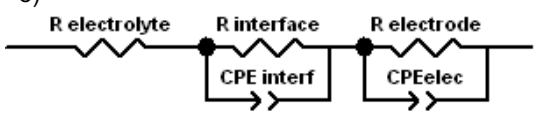

Figure 5.10 EIS results for nickel infiltration and additional infiltration with nickel at $550^{\circ} \mathrm{C}$. a) Nyquist plot and b) Bode plot for 200 ppm of ethylene. c) Nyquist plot and d) Bode plot for 200 ppm of carbon monoxide. e) Equivalent electrical circuit

\section{Titanium infiltration}

In the case of the infiltration with titanium, the second arch contribution at low frequencies increases for both gases (figure 5.11). The difference is that the increase is higher for carbon monoxide and therefore the polarization resistance is higher (figure 5.16). Despite this increase in both contributions, this difference can explain the better response of the sensor to ethylene. Moreover, the addition of nickel leads again to a reduction of both contributions although in the case of carbon monoxide it is a slight reduction (figures 5.11 and 5.15). Therefore, there is a gap between both contributions and this could be responsible for the good selectivity of the device to ethylene with low cross-sensitivity toward carbon monoxide observed during the potentiometric characterization (Figure 5.5).

Additionally, the electrochemical impedance spectroscopy was also performed under wet conditions ( $3 \%$ water) for both gases. The addition of water promotes a reduction of both contributions although, again, the decrease of ethylene contribution is higher (figure 5.11). Once again, this could be an explanation for the improvement of the sensor performance after the surface functionalization with nanocatalysts for the purposes of the present work: selective detection of ethylene with low cross sensitivity toward carbon monoxide and other elements. 

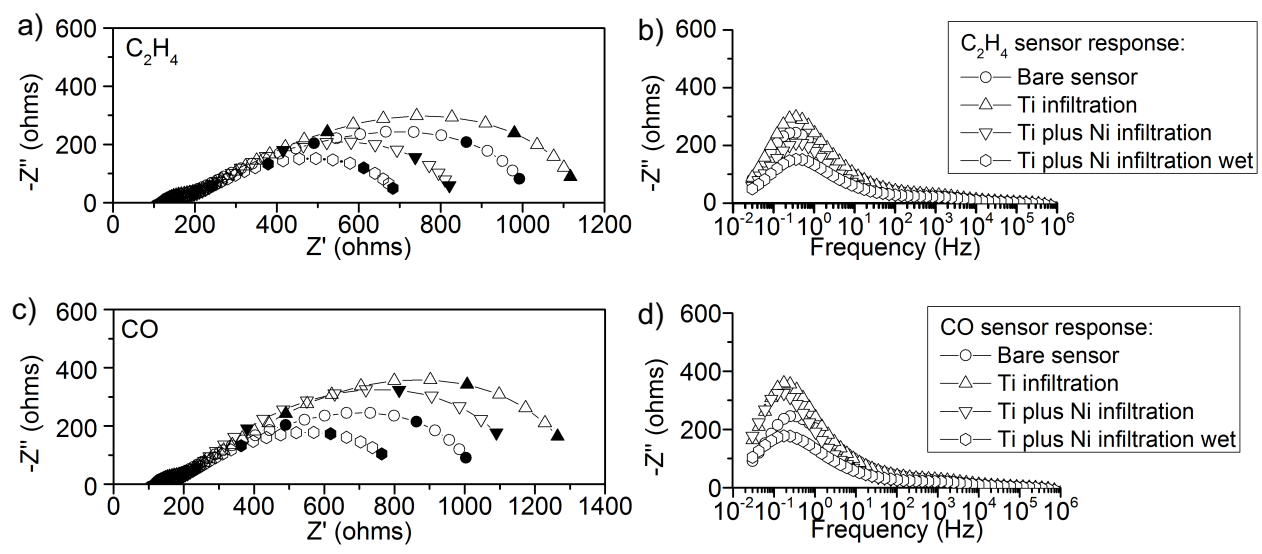

e)

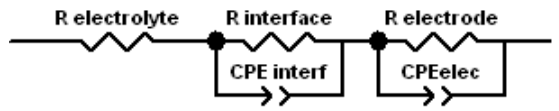

Figure $5.11 \mathrm{EIS}$ results for titanium infiltration and additional infiltration with nickel at $550^{\circ} \mathrm{C}$. a) Nyquist plot and b) Bode plot for 200 ppm of ethylene. c) Nyquist plot and d) Bode plot for 200 ppm of carbon monoxide. e) Equivalent electrical circuit

\section{Aluminium infiltration}

When the sensor is infiltrated with aluminium there is a decrease of the second arch contribution of ethylene and an increase of carbon monoxide contribution when compared to the bare sensor (figure 5.12). This is in agreement with the improvement of the sensor performance observed previously (Figure 5.6). Additionally, the infiltration of nickel emphasises the reported effect: the ethylene contribution is reduced even more whilst the carbon monoxide contribution increases. Thus, the polarization resistance (figure 5.16) is lower for ethylene, explaining the better performance of the device for selective detection of ethylene.

The addition of water leads to a reduction of both contributions as in the case of titanium, but the decrease of ethylene contribution is higher. Once again, this can explain the better response of the device to ethylene. 

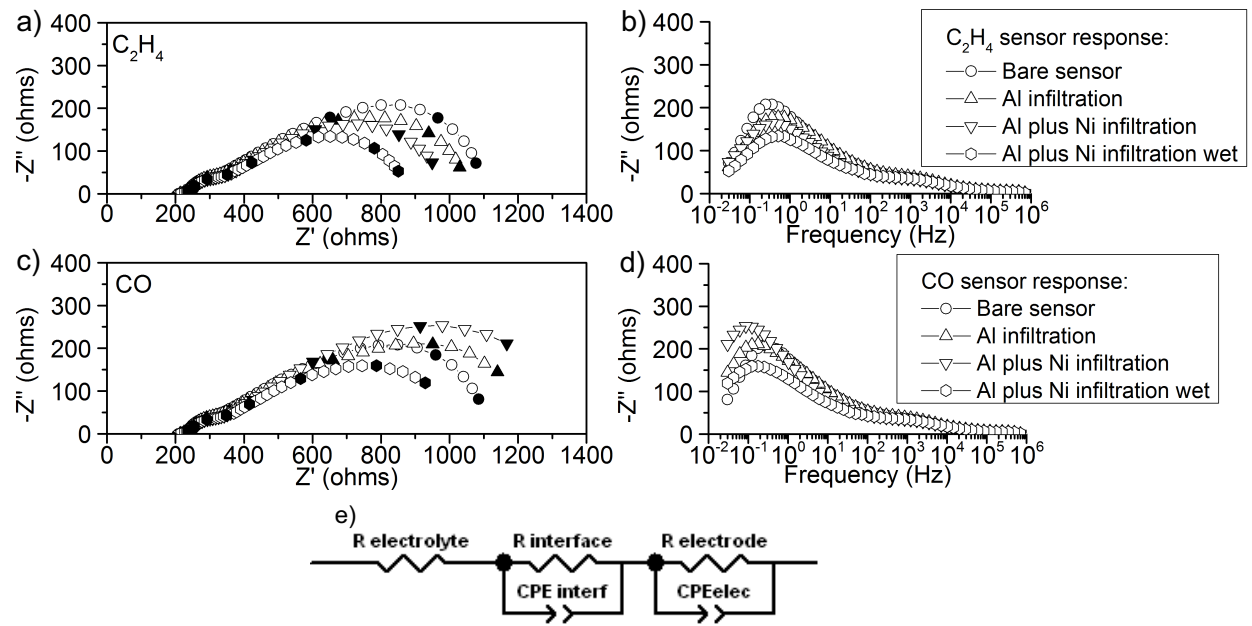

Figure $5.12 \mathrm{EIS}$ results for aluminium infiltration and additional infiltration with nickel at $550^{\circ} \mathrm{C}$. a) Nyquist plot and b) Bode plot for 200 ppm of ethylene. c) Nyquist plot and d) Bode plot for 200 ppm of carbon monoxide. e) Equivalent electrical circuit

\section{Niobium infiltration}

As aforementioned, when the channel is infiltrated with niobium the spectra can be fitted to an equivalent circuit consisting of three parallel combinations of resistance constant phase elements. In this case there are two contributions related with catalytic processes occurring on the electrode surface $\left(C=10^{3}-10^{4} \mathrm{~F}\right)$.

When the channel is only infiltrated with niobium the contribution of ethylene and carbon monoxide is similar. Even the polarization resistance of ethylene is slightly higher (figure 5.13 and 5.16). As seen previously, only infiltration with niobium was inadequate to provide a selective response to ethylene with low crosssensitivity to carbon monoxide (Figure 5.7a). A certain non-negligible crosssensitivity to carbon monoxide can be observed. However, a second infiltration with nickel makes almost constant the carbon monoxide contribution while the ethylene contribution is reduced notably (figure 5.13). In this case, the polarization resistance is much lower for ethylene rather than to carbon monoxide (figure 5.16). This can explain the improvement of the sensor performance after the infiltration with nickel during the potentiometric characterization: it provides a selective response to ethylene with low cross-sensitivity to carbon monoxide.

Addition of water (3\%) leads to an increase of the signal for both contributions and it becomes similar (figure 5.13). Thus, this can explain again the lack of 
sensitivity to ethylene observed in the potentiometric characterization shown in Figure 5.7c.
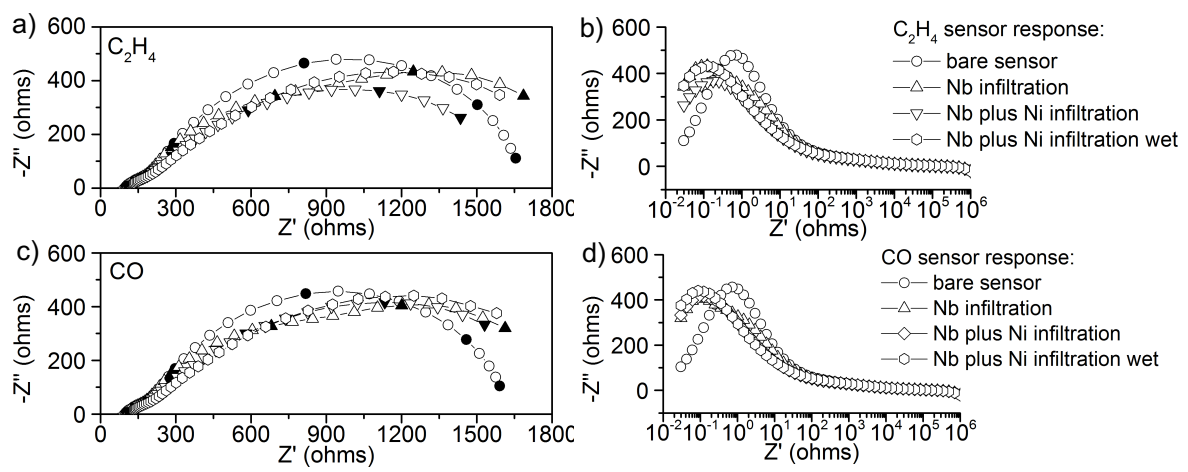

e)

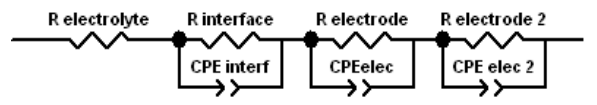

Figure 5.13 EIS results for niobium infiltration and additional infiltration with nickel at $550^{\circ} \mathrm{C}$. a) Nyquist plot and b) Bode plot for 200 ppm of ethylene. c) Nyquist plot and d) Bode plot for 200 ppm of carbon monoxide. e) Equivalent electrical circuit

\section{Ruthenium infiltration}

In the case of the infiltration with ruthenium, there were some problems to obtain clear and stable impedances to fit but it can be observed in Figure 5.14 that the contributions for both gases are similar although slightly higher for ethylene. Still, Figure 5.14 inset shows the response after infiltration with ruthenium where there is a considerable decrease of the ethylene contribution compared to carbon monoxide that can explain the improvement of the sensor for ethylene sensing purposes. Unfortunately, there was no possibility to measure the channel after a second infiltration with ruthenium. 


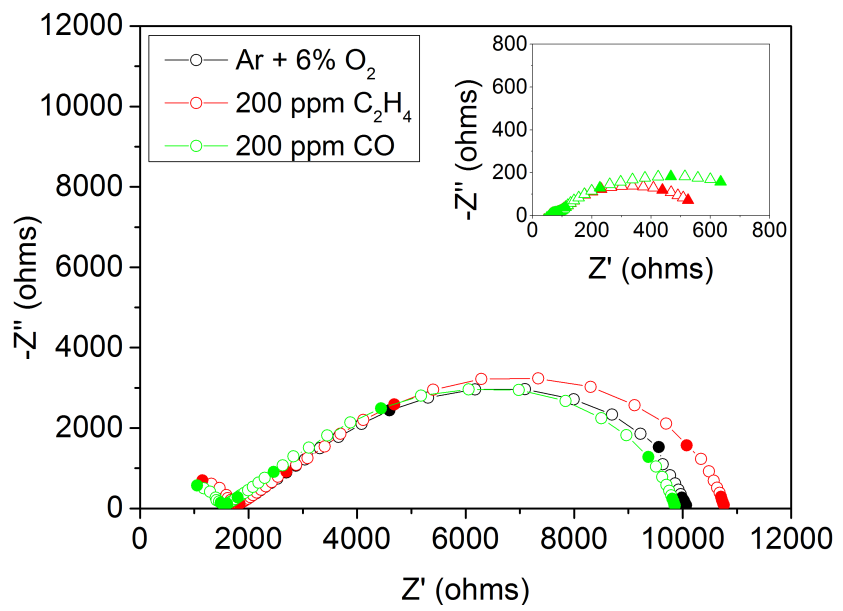

Figure 5.14 Nyquist plot for the bare channel before infiltrating with ruthenium at $550^{\circ} \mathrm{C}$. Inset can be observed the sensor response to $200 \mathrm{ppm}$ of ethylene and carbon monoxide after infiltrating with ruthenium at $550^{\circ} \mathrm{C}$
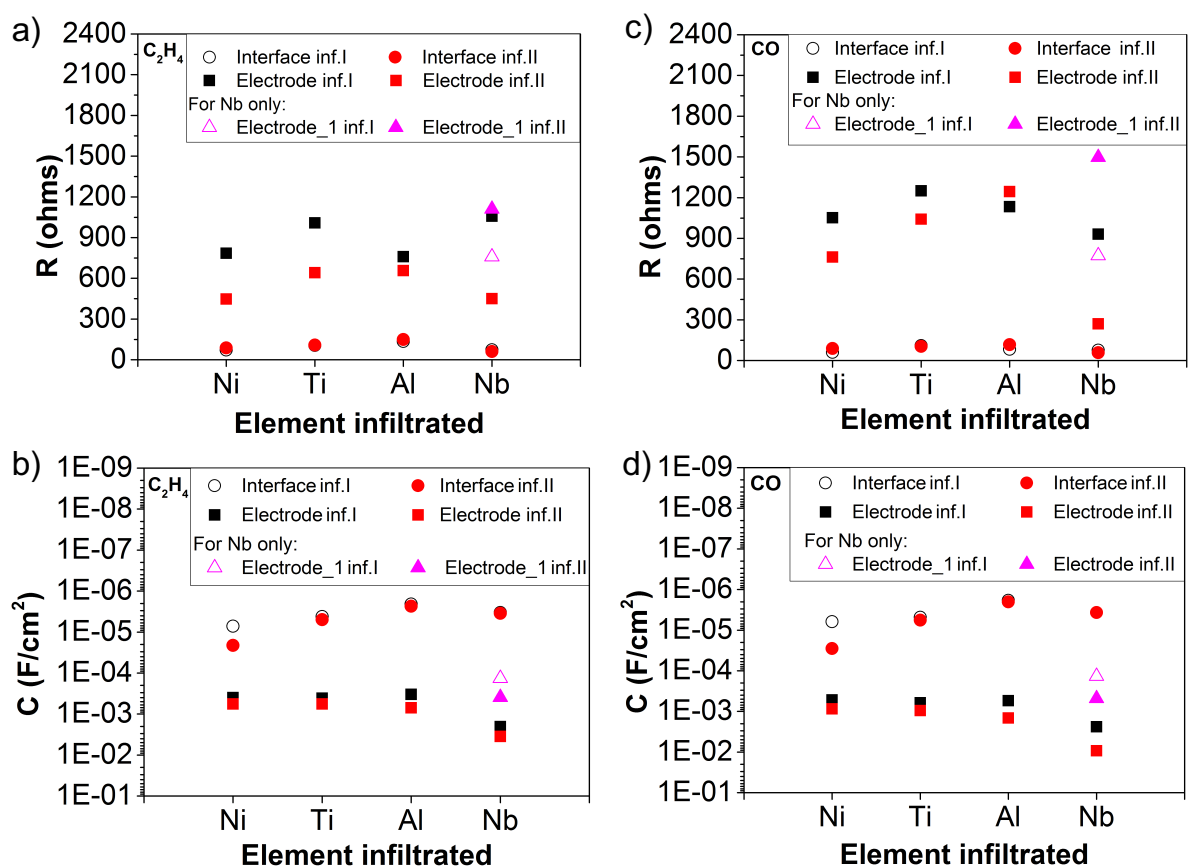

Figure 5.15 Equivalent electrical circuit fitting results for the first infiltration (inf. I) with each material and the second common infiltration with nickel (inf. II): a) Resistances for 200 ppm of ethylene b) Capacitance for 200 ppm of ethylene. c) Resistances for 200 ppm of carbon monoxide. d)

Capacitances for 200 ppm of carbon monoxide. In the case of nickel titanium and aluminium there are only two contributions $\left(R_{\text {interface }}\right.$ and $\left.R_{\text {electrode }}\right)$ while in the case of niobium there is an additional contribution related with electrode $\left(R_{\text {electrode_ } 1}\right)$ 


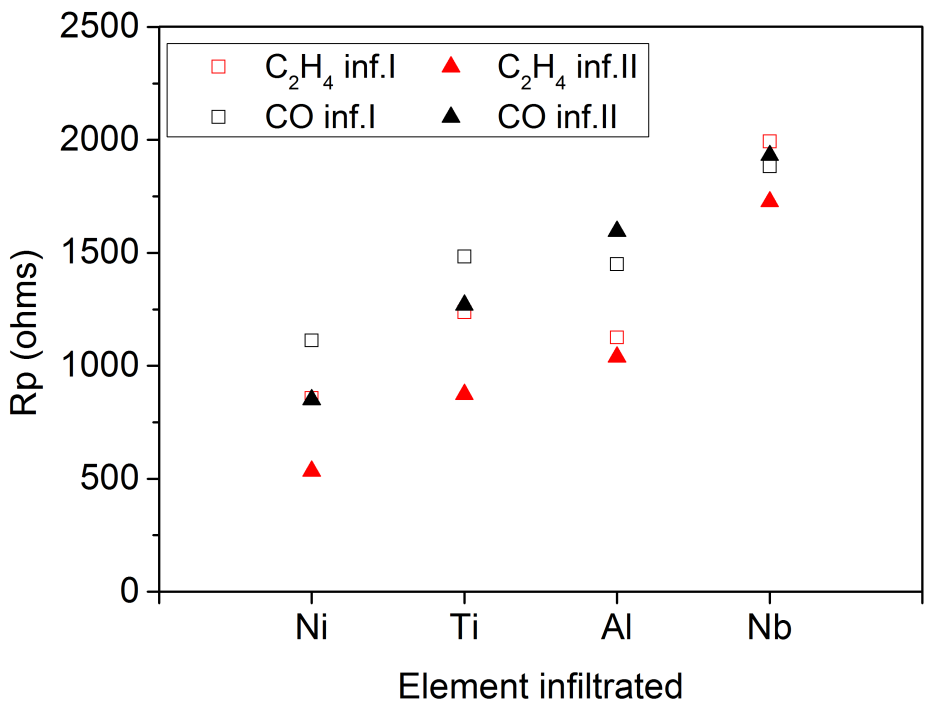

Figure 5.16 Polarization resistance to ethylene and carbon monoxide for first infiltration with each material (inf. I) as well as for the second common infiltration with nickel (inf. II)

Thus, the electrochemical impedance spectroscopy backs the results obtained during the potentiometric characterization. Infiltration with nanocatalysts leads to an improvement or boost of the ethylene electrochemical reaction. Some of the elements infiltrated are able to promote an improvement of the sensor performance by themselves i.e. $\mathrm{Ni}, \mathrm{Ti}, \mathrm{Al}$ while niobium needs the addition of a second nanocatalyst $(\mathrm{Ni})$ to achieve a selective sensor to ethylene.

In all cases, the combination of two nanocatalyts leads to a major improvement of the sensor performance. Although contribution to both ethylene and carbon monoxide are observed, the reduction of the polarization resistance is much higher for the ethylene. Therefore, it can be concluded that the addition of these nanocalysts has an effect on the sensor response improving the processes at low frequencies related with catalytic processes occurring at the electrode surface. One possible explanation could be that nanocatalyst are promoting gas-phase reaction of carbon monoxide and reducing its contribution in the electrochemical reaction $[16,17]$. Although part of the ethylene could be reacting by the gas-phase reaction as well it is still controlling the kinetics of the electrochemical reaction. In the case of niobium, the water addition could be promoting ethylene catalytic reaction and this reduce the device selectivity. 


\subsection{Structural characterization}

After test, the samples were characterized by Field Emission Scanning Electron Microscopy (FESEM) to check if the nanoparticles infiltrated were spread over the working electrode. Figure 5.17 shows the cross section of the complete working electrode (common for each case) and the cross section of the detailed electrode for each infiltration carried out. As aforementioned in chapter 3 , the distribution of $\mathrm{Fe}_{0.7} \mathrm{Cr}_{1.3} \mathrm{O}_{3}$ and $8 \mathrm{YSZ}$ is homogeneous although the grain size is different, $8 \mathrm{YSZ}$ grains are smaller. A detailed view of the electrode reveals that the nanoparticles are integrated into the electrode for each infiltration: small particles attached to both grains can be observed, increasing the active surface area. In the case of titanium, aluminium, niobium barium and palladium (Figure 5.17c, d, e, g and $h$ respectively) two different nanoparticles sizes can be observed. Comparison with the particles achieved for nickel infiltration in Figure 5.17b and an Energydispersive X-ray spectroscopy (EDX) analysis could indicate that the bigger nanoparticles are nickel, while the smaller ones should be the other infiltrated element. EDX failed to identify the mail element of this small nanoparticles to the limit of this technique. In the case of barium and palladium, the nanoparticles seem to be distributed in a lesser extent. This could explain the lesser activity of this material to ethylene when compared to the rest of infiltrations. However, the presence of nanoparticles is homogeneous and constant along the electrode. On the other hand, ruthenium distribution is poorer as the nanoparticles seems to be gathered at some points creating some aggregates although there is a good dispersion through the electrode. This can explain the poorer performance when compared to nickel at the same conditions. Therefore, nickel, titanium and aluminium better performance could be related to a better electrocatalytic properties of the material itself at the working atmosphere. 

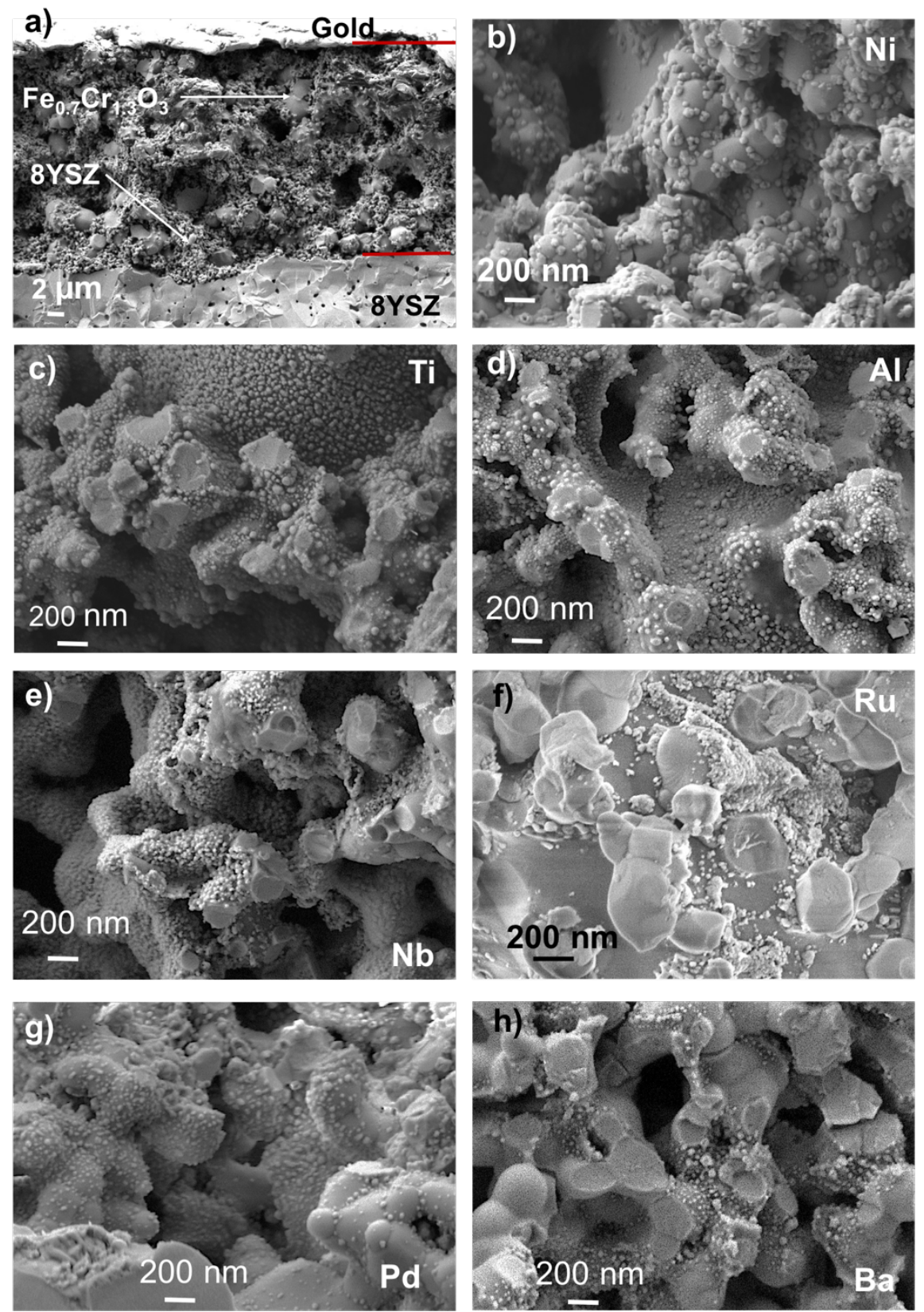

Figure 5.17 FESEM image of the working electrode (a) and images of the different working electrodes infiltrated with: b) nickel, c) titanium, d) aluminium, e) niobium, f) ruthenium, g) palladium and $h$ ) barium. In all cases the infiltrated nanoparticles can be observed 
Further studies were performed to confirm the oxidation state of nickel nanoparticles. Fresh powder is prepared, impregnated with nickel, calcined at 550 ${ }^{\circ} \mathrm{C}$, and finally reduced at $300^{\circ} \mathrm{C}$ in hydrogen. First, $\mathrm{H}$-atom chemisorption is done to check the adsorption of $\mathrm{H}_{2}$ on nickel. This analysis indicates that there is a metallic active surface area of $3,15 \cdot 10^{-2} \mathrm{~m}^{2} / \mathrm{g}$. In addition, XPS analysis of the working electrode after sensor testing as well as the fresh powder with nickel impregnated is performed. After the deconvolution of the Ni2p3/2 XPS spectra (Figure 5.18), three contributions related to metallic $\mathrm{Ni}$ and $\mathrm{Ni}$ oxides [18-21] can be observed. After potentiometric sensor characterization, nickel nanoparticles are partially oxidized, as the metallic nickel contribution is lesser than in the case of the $\mathrm{H}_{2}$-reduced sample. Note that the sensor electrode is not subjected to any reduction treatment in $\mathrm{H}_{2}$ prior to the potentiometric test in carbon monoxide/ethylene at $550^{\circ} \mathrm{C}$. These results combined with the $\mathrm{H}$-atom chemisorption and the potentiometric measurements confirm that metallic nickel is partially present in the working electrode.

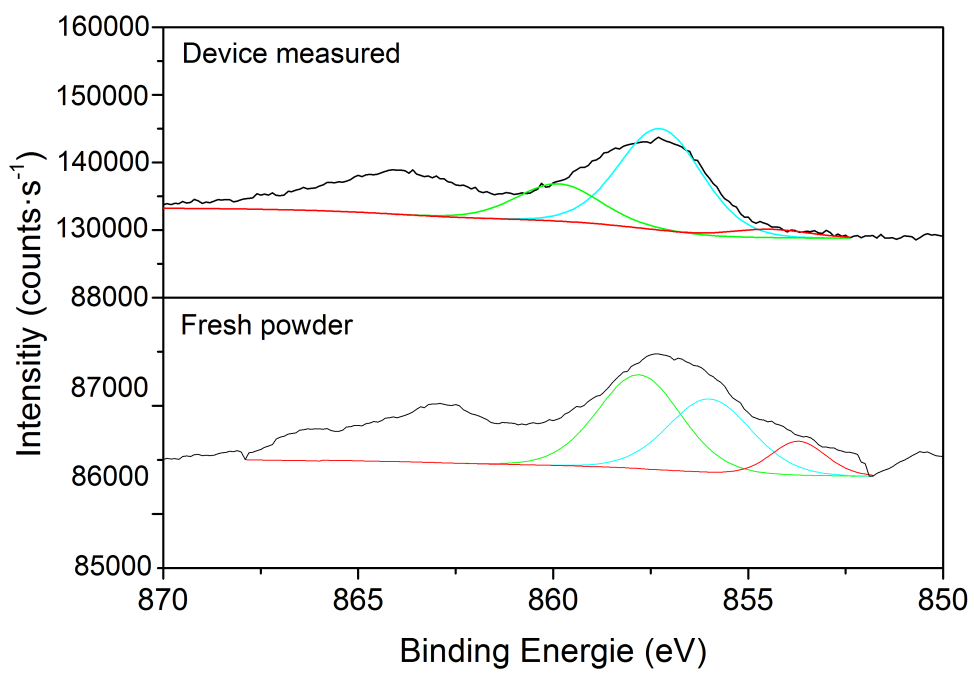

Figure 5.18 Ni2p3/2 XPS deconvoluted spectra for the working electrode of the device after potentiometric measurement (top) and for fresh powder impregnated with nickel (bottom). There are three contributions: $\mathrm{Ni}$ (red) and Ni oxides (cyan and green) 


\subsection{Conclusions}

In this chapter, several elements have been tested to functionalize the working electrode surface and improve the electrochemical reaction toward ethylene and solve the mismatch between working and reference electrodes caused by the $\mathrm{Fe}_{0.7} \mathrm{Cr}_{1.3} \mathrm{O}_{3} / 8 \mathrm{YSZ} / / 8 \mathrm{YSZ} / / \mathrm{LSM} / 8 \mathrm{YSZ}$ configuration. Thus, the elements have been infiltrated in the working electrode as nanoparticles able to improve the catalytic activity to ethylene.

Potentiometric characterization has shown that infiltration with nickel, ruthenium, titanium or aluminium leads to an improvement of the sensor performance. The response after the infiltration become selective to ethylene with a low crosssensitivity toward carbon monoxide in dry conditions. Moreover, a second infiltration with nickel not only largely improves the sensor performance at dry conditions but also proves to provide a device able to measure selectively ethylene under wet conditions. Nanocatalyst probably not only boost the electrochemical reaction to ethylene but also promotes the gas-phase reaction to carbon monoxide.

On the other hand, elements such as niobium, barium or palladium despite improving their signal, failed to prove an adequate improvement of the sensor for ethylene sensing purposes. However, a second infiltration with nickel increases their performance in dry conditions although the response is still poor at wet conditions. Therefore, these elements are discarded as potential materials for a selective detection of ethylene. Nevertheless, it should be considered that these elements (especially niobium) could show a good performance in combination with other elements not tested in this work.

This has been also confirmed by means of electrochemical impedance spectroscopy analyses. Resistance attributed to interface between electrolyte and electrode $\left(C=10^{5}-10^{6} \mathrm{~F}\right)$ is not affected by the infiltrations performed as expected. While the low frequency resistances associated to catalytic processes occurring in the electrode varies as a function of the infiltration performed. For $\mathrm{Ni}, \mathrm{Ti}$ and $\mathrm{Al}$ infiltrations, with and without the second nickel infiltration, the ethylene polarization resistance is lower than carbon monoxide resistance. Therefore, this difference explains the better response to ethylene and low cross-sensitivity to carbon monoxide. The presence of the nanoparticles along the electrode has been confirmed by means of FESEM. Promising infiltrating materials such as $\mathrm{Ni}$, $\mathrm{Ti}$ and $\mathrm{Al}$ are well distributed in both $\mathrm{Fe}_{0.7} \mathrm{Cr}_{1.3} \mathrm{O}_{3}$ and $8 \mathrm{YSZ}$ grains.

Consequently, the infiltration with nanocatalysts has proven to be able to modify the processes occurring at low frequencies related with catalytic reactions at the 
electrode surface and therefore, they boost the electrochemical reaction of ethylene becoming this reaction the main contributor in the overall reaction taking place at the electrode. This solves the mismatch in the reaction rates between working and reference electrodes for the bare sensor configuration $\left(\mathrm{Fe}_{0.7} \mathrm{Cr}_{1.3} \mathrm{O}_{3} / 8 \mathrm{YSZ} / / 8 \mathrm{YSZ} / / \mathrm{LSM} / 8 \mathrm{YSZ}\right)$. Thus, infiltration with nickel, titanium or aluminium plus a second infiltration with nickel is a promising methodology for selective detection of ethylene even in atmospheres containing carbon monoxide or water as happens in car exhaust gases. In addition, the device is exposed to working temperature for four weeks with no visible effects on the long-term.

\subsection{References}

[1] R.R. Ford, Carbon Monoxide Adsorption on the Transition Metals, Adv. Catal. 21 (1970) 51-150. doi:10.1016/S0360-0564(08)60564-7.

[2] M. Gajdo, A. Eichler, J. Hafner, CO adsorption on close-packed transition and noble metal surfaces: trends from ab initio calculations, J. Phys. Condens. Matter. 16 (2004) 1141-1164. doi:10.1088/0953-8984/16/8/001.

[3] S. Schnur, A. Groß, Strain and coordination effects in the adsorption properties of early transition metals: A density-functional theory study, Phys. Rev. B 81 (2010), 033402. doi:10.1103/PhysRevB.81.033402.

[4] M.D. Morse, M.E. Geusic, J.R. Heath, R.E. Smalley, Surface reactions of metal clusters. II. Reactivity surveys with $\mathrm{D}_{2}, \mathrm{~N}_{2}$, and CO, J. Chem. Phys. 83 (1985) 2293-2304. doi:10.1063/1.449321.

[5] C. Bernardon, M. Ben Osman, G. Laugel, P. Pale, Acidity versus metalinduced Lewis acidity in zeolites for Friedel-Crafts acylation, Comptes Rendus Chim. 20 (2017) 20-29. doi:10.1016/J.CRCI.2016.03.008.

[6] W.P. Krekelberg, J. Greeley, M. Mavrikakis, Atomic and Molecular Adsorption on $\operatorname{Ir}(111)$, J. Phys. Chem. B. 108 (2003) 987-994. doi:10.1021/jp035786c.

[7] R. Guilard, S. Brandes, C. Tardieux, A. Tabard, M. L'Her, C. Miry, P. Gouerec, Y. Knop, J.P. Collman, Synthesis and Characterization of Cofacial Metallodiporphyrins Involving Cobalt and Lewis Acid Metals: New Dinuclear Multielectron Redox Catalysts of Dioxygen Reduction, J. Am. Chem. Soc. 117 (1995) 11721-11729. doi:10.1021/ja00152a013.

[8] S. Tewari, A. Bhattacharjee, Structural, electrical and optical studies on spray-deposited aluminium-doped $\mathrm{ZnO}$ thin films, PRAMANA c Indian Acad. Sci. 76 (2011) 153-163. doi: 10.1007/s12043-011-0021-7

[9] J. Karczewski, B. Bochentyn, S. Molin, M. Gazda, P. Jasinski, B. Kusz, Solid oxide fuel cells with Ni-infiltrated perovskite anode, Solid State lonics. 221 (2012) 11-14. doi:10.1016/j.ssi.2012.06.002. 
[10] P.R. Makgwane, S.S. Ray, Nanosized ruthenium particles decorated carbon nanofibers as active catalysts for the oxidation of $p$-cymene by molecular oxygen, J. Mol. Catal. A Chem. 373 (2013) 1-11. doi:10.1016/j.molcata.2013.02.017.

[11] N.K. Monteiro, F.B. Noronha, L.O.O. da Costa, M. Linardi, F.C. Fonseca, A direct ethanol anode for solid oxide fuel cell based on a chromite-manganite with catalytic ruthenium nanoparticles, Int. J. Hydrogen Energy. 37 (2012) 98169829. doi: 10.1016/j.ijhydene.2012.03.157.

[12] R.S. Niranjan, S.R. Sainkar, K. Vijayamohanan, I.S. Mulla, Ruthenium: Tin oxide thin film as a highly selective hydrocarbon sensor, Sensors Actuators, B Chem. 82 (2002) 82-88. doi:10.1016/S0925-4005(01)00994-7.

[13] K. Pignat, J. Vallotto, F. Pinna, G. Strukul, Cationic Complexes of Palladium(II) and Platinum(II) as Lewis Acid Catalysts for the Diels-Alder Reaction, Organometallics. 19 (2000) 5160-6167. doi:10.1021/om0003943.

[14] E. Dilonardo, M. Penza, M. Alvisi, G. Cassano, C. Di Franco, F. Palmisano, L. Torsi, N. Cioffi, Sensitive detection of hydrocarbon gases using electrochemically Pd-modified $\mathrm{ZnO}$ chemiresistors., Beilstein J. Nanotechnol. 8 (2017) 82-90. doi:10.3762/bjnano.8.9.

[15] H. Ning, Z.-Q. Lan, J. Guo, M.-Q. Tan, Carbon-monoxide adsorption and dissociation on $\mathrm{Nb}(110)$ surface, Appl. Surf. Sci. 328 (2015) 641-648. doi:10.1016/j.apsusc.2014.12.088.

[16] T. Sato, M. Breedon, N. Miura, Reduction in Ethanol Interference of Zirconia-Based Sensor for Selective Detection of Volatile Organic Compounds, J. Electrochem. Soc. 160 (2013) B146-B151. doi:10.1149/2.007309jes.

[17] R. Wama, V. V. Plashnitsa, P. Elumalai, T. Kawaguchi, Y. Fujio, M. Utiyama, N. Miura, Improvement in Propene Sensing Characteristics by the Use of Additives to In[sub 2]O[sub 3] Sensing Electrode of Mixed-Potential-Type Zirconia Sensor, J. Electrochem. Soc. 156 (2009) J102. doi:10.1149/1.3090168.

[18] A.P. Grosvenor, M.C. Biesinger, R.S.C. Smart, N.S. Mclntyre, New interpretations of XPS spectra of nickel metal and oxides, Surf. Sci. 600 (2006) 1771-1779. doi:10.1016/j.susc.2006.01.041.

[19] P. Prieto, V. Nistor, K. Nouneh, M. Oyama, M. Abd-Lefdil, R. D?az, XPS study of silver, nickel and bimetallic silver?nickel nanoparticles prepared by seedmediated growth, Appl. Surf. Sci. 258 (2012) 8807-8813. doi:10.1016/j.apsusc.2012.05.095.

[20] C. Solís, S. Somacescu, E. Palafox, M. Balaguer, J.M. Serra, Particular transport properties of NiFe2O4 thin films at high temperatures, J. Phys. Chem. C. (2014). doi:10.1021/jp506938k. 
[21] H.A.E. Hagelin-Weaver, J.F. Weaver, G.B. Hoflund, G.N. Salaita, Electron energy loss spectroscopic investigation of $\mathrm{Ni}$ metal and $\mathrm{NiO}$ before and after surface reduction by $\mathrm{Ar}+$ bombardment, J. Electron Spectros. Relat. Phenomena. (2004). doi:10.1016/j.elspec.2003.10.002. 

Chapter 6

\section{Influence of 8YSZ electrolyte thickness on the sensor performance}





\section{Influence of 8YSZ electrolyte thickness on the sensor performance}

\subsection{Introduction}

In this chapter, the influence of the electrolyte thickness on the sensor performance is evaluated. For this purpose, several electrolytes with different thicknesses $(0.6,0.8$ and $1.2 \mathrm{~mm})$ are pressed and sintered and then, they are compared to a thin commercial electrolyte from Kerafol $(0.1 \mathrm{~mm})$. The methodology followed is similar to that in previous chapter.

As the configuration $\mathrm{Fe}_{0.7} \mathrm{Cr}_{1.3} \mathrm{O}_{3} / 8 \mathrm{YSZ} / / 8 \mathrm{YSZ} / / \mathrm{LSM} / 8 \mathrm{YSZ}$ shows a lack of selectivity to ethylene, in this chapter working electrodes of each device are infiltrated with nickel. Thus, only when the sensor response for every device is selective to ethylene, the effect of the thickness on the sensor performance can be studied.

Overall, as in the case of mixed ionic-electronic conductors membranes for oxygen permeation and solid oxides fuel cells, an improvement of the sensor performance is expected to happen when the electrolyte thickness is thinner as it reduces the ohmic losses $[1,2,11-17,3-10]$. Potentiometric and electrochemical impedance spectroscopy corroborates this expected influence: the thinnest electrolyte provides a better performance while the thicker electrolyte provides the poorest response. In between, the sensor performance remains almost constant. Thus, there are two critical conditions that improves or worsens the sensor performance and a region in between 0.6 and $1 \mathrm{~mm}$ where the sensor performance is independent on the electrolyte thickness.

This is reinforced by the electrochemical impedance spectroscopy results. The polarization resistance increases with the thickness. Moreover, the response for the thinner commercial electrolyte differs when compared to the other electrolytes pressed manually. Structural characterization by scanning electron microscopy confirms the thicknesses of each electrolyte and the proper incorporation of nickel into the working electrode. 


\subsection{Electrochemical characterization}

In this chapter, four different electrolytes thicknesses were employed. Dense $8 Y S Z$ (Tosoh) disks of $20 \mathrm{~mm}$ of diameter were obtained by uniaxially pressing at $50 \mathrm{KN}$ and calcination at $1000^{\circ} \mathrm{C}$ for four hours to drill holes to ensure contact between electrodes and wires and then, $1450^{\circ} \mathrm{C}$ for ten hours. Several quantities of powder were employed to prepare three disks with $0.6,0.8$ and $1.2 \mathrm{~mm}$ of thickness. The thinner electrolyte was a commercial dense disk from Kerafol with $15.5 \mathrm{~mm}$ of diameter and a thickness of $0.1 \mathrm{~mm}$. In this case, the holes were drilled directly. In all cases, electrodes were screen printed as described in chapter 2.

The aim of this chapter is to study the influence of the thickness on the sensor response. Thus, the four devices with different thicknesses $(0.1,0.6,0.8$ and 1.2 $\mathrm{mm}$ ) were exposed to several concentrations in the range $0-200 \mathrm{ppm}$ of ethylene and carbon monoxide individually as well as with a background of $200 \mathrm{ppm}$ of the other analyte.

\subsubsection{Potentiometric characterization}

As aforementioned in previous chapters, the $\mathrm{Fe}_{0.7} \mathrm{Cr}_{1.3} \mathrm{O}_{3} / 8 \mathrm{YSZ} / / 8 \mathrm{YSZ} / / \mathrm{LSM} / 8 \mathrm{YSZ}$ configuration leads to a device with a lack of selectivity to ethylene as can observed in Figure 6.1 to Figure 6.4a. The sensor performance in all devices is similar providing a sensor response not selective to ethylene and with high cross-sensitivity toward carbon monoxide as reported in previous chapters. Moreover, Figure 6.1 to Figure $6.4 \mathrm{~d}$ show how the addition of water leads to a poor performance as it increases the cross-sensitivity toward carbon monoxide. In the case of the thinner device, the sensor performance remains almost unaffected as shown in Figure 6.1d. Thus, an improvement of the electrocatalytic activity of the working electrode is needed as seen before. In this chapter, nickel is selected as the infiltrated element as it was one of the most promising elements to enhance the sensor performance as reported in chapter 5 .

Upon infiltration with nickel, selectivity to ethylene is increased and the crosssensitivity toward carbon monoxide reduced as reported in chapter 5 (Figure 6.1 to Figure $6.4 \mathrm{~b}$ ). Furthermore, the addition of $3 \%$ of water has no effect on the sensor response in terms of selectivity to ethylene and cross-sensitivity toward carbon monoxide as can be seen in Figure 6.1 to Figure 6.4e. According to the results obtained in chapter 5 , a second infiltration with nickel should improve the sensor performance. Figure 6.1 to Figure $6.4 \mathrm{c}$ confirm that the sensor performance is enhanced by a second nickel infiltration. This improvement can also be observed for wet conditions (Figure 6.1 to Figure 6.3f) and therefore, in all 
cases the response is selective to ethylene with a low cross-sensitivity toward carbon monoxide and water, regardless of the electrolyte thickness.
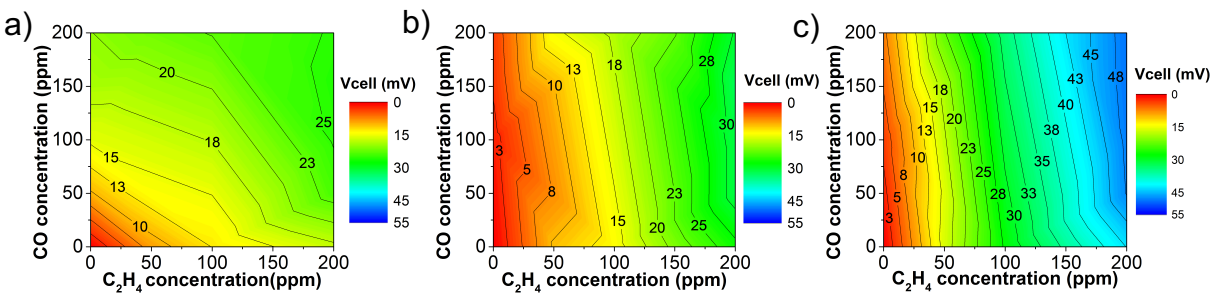

d)
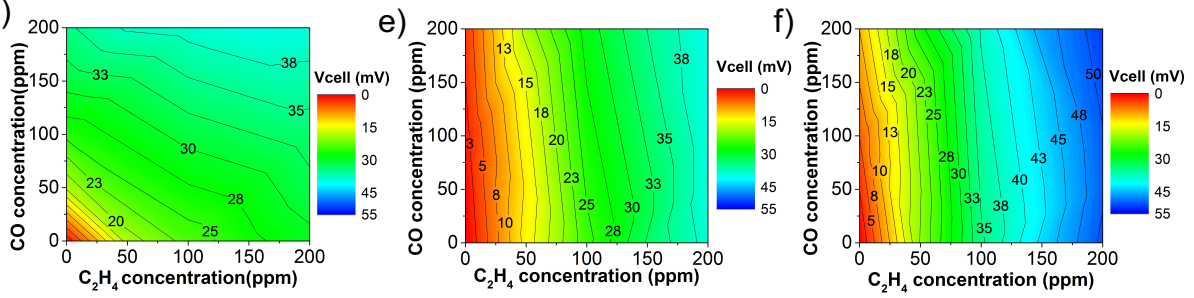

Figure $6.1 \mathrm{~V}_{\text {cell }}(\mathrm{mV})$ sensor response for the thinner device $(0.1 \mathrm{~mm})$ as a function of analytes concentration for: a) bare sensor in dry conditions, b) after nickel infiltration in dry conditions, c) after second nickel infiltration in dry conditions, d) bare sensor in wet conditions, e) after nickel infiltration in wet conditions, $f$ ) after second nickel infiltration in wet conditions

a)

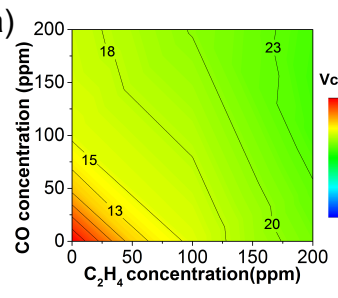

d)

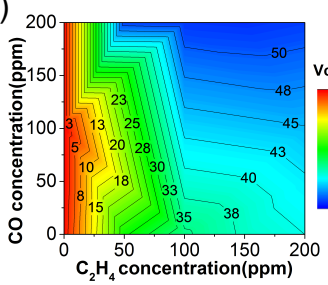

b)

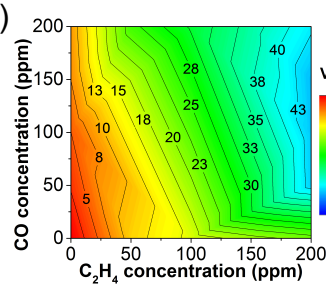

e)

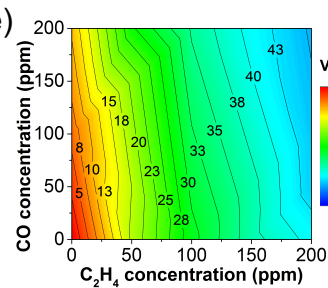

C)

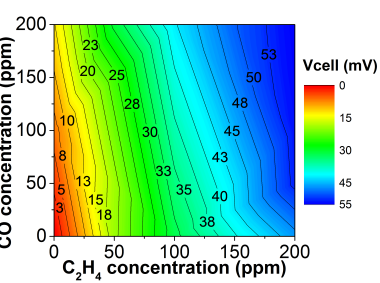

f)

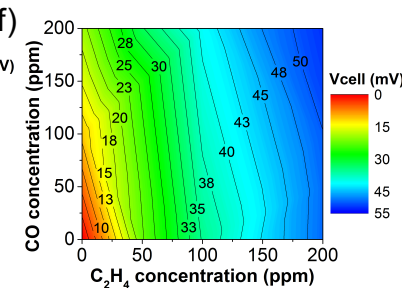

Figure 6.2 $\mathrm{V}_{\text {cell }}(\mathrm{mV})$ sensor response for the $0.6 \mathrm{~mm}$ thickness electrolyte device as a function of analytes concentration for: a) bare sensor in dry conditions, b) after nickel infiltration in dry conditions,

c) after second nickel infiltration in dry conditions, d) bare sensor in wet conditions, e) after nickel infiltration in wet conditions, f) after second nickel infiltration in wet conditions 
a)

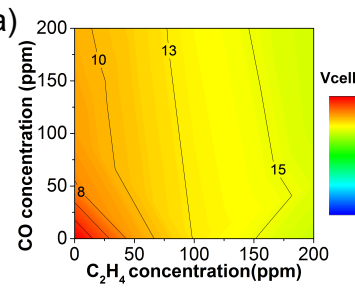

d)

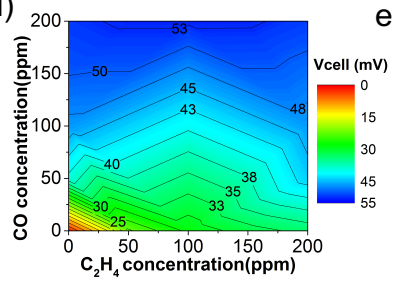

b)

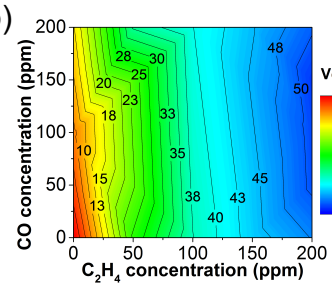

c) 200

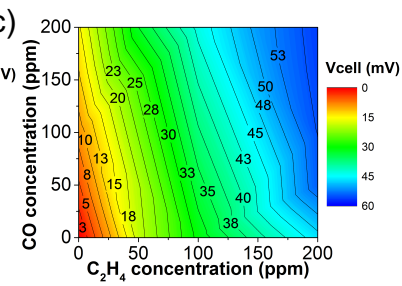

e)

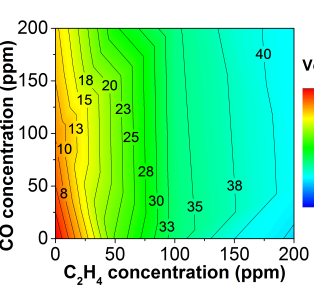

f)

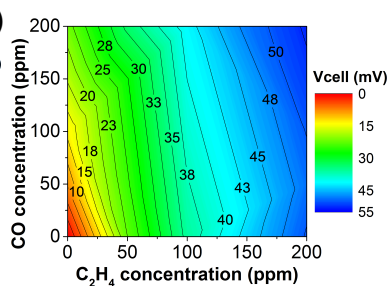

Figure $6.3 V_{\text {cell }}(\mathrm{mV})$ sensor response for the $0.8 \mathrm{~mm}$ thickness electrolyte device as a function of analytes concentration for: a) bare sensor in dry conditions, b) after nickel infiltration in dry conditions,

c) after second nickel infiltration in dry conditions, d) bare sensor in wet conditions, e) after nickel infiltration in wet conditions, f) after second nickel infiltration in wet conditions

a)

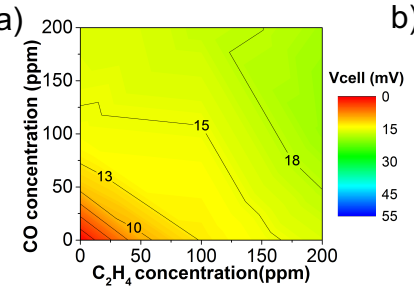

d)

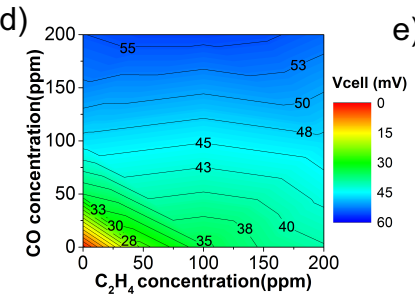

b)

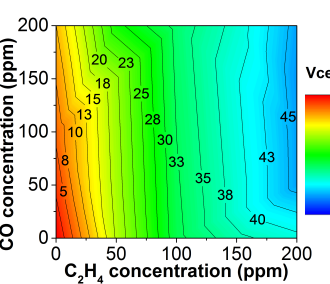

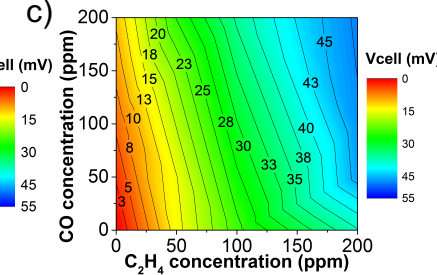

e)

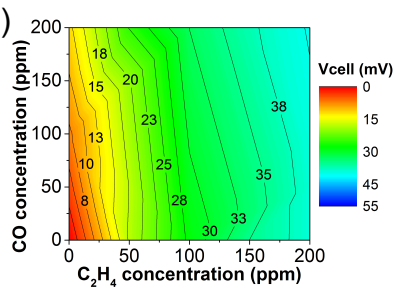

Figure $6.4 V_{\text {cell }}(\mathrm{mV})$ sensor response for the $1.2 \mathrm{~mm}$ thickness electrolyte device as a function of analytes concentration for: a) bare sensor in dry conditions, b) after nickel infiltration in dry conditions, c) after second nickel infiltration in dry conditions, d) bare sensor in wet conditions, e) after nickel infiltration in wet conditions

The sensor output is calculated as $\mathrm{mV} / \mathrm{ppm}$ in order to allow a comparison between different thicknesses. As the sensor response is lineal with the analyte concentration within the studied range, the sensor sensitivity is defined as $\mathrm{V}_{\text {cell }} /$ analyte concentration and calculated by means of a linear regression as can be observed in Figure 6.5 for the thinner device. 


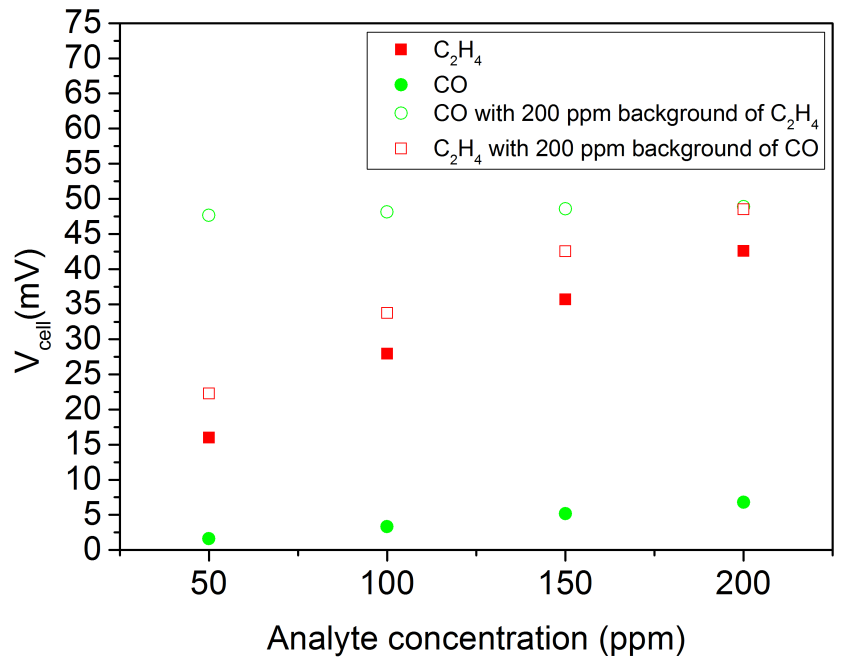

Figure 6.5 Example of $V_{\text {cell }}$ sensor response as a function of analyte concentration. This example corresponds to the thinner electrolyte, although the sensor performance is similar for all devices. Full red square indicates changes in concentration of ethylene while empty red squares indicates changes in concentration of ethylene with 200 ppm of carbon monoxide as background. On the other hand, full green dot indicates changes in concentration of carbon monoxide while green full dots indicates the changes in concentration of carbon monoxide with 200 ppm of ethylene as background

Figure 6.6 exhibits the influence of thickness on the sensor sensitivity in dry conditions (Figure $6.6 \mathrm{a}$ ) as well as when there is an addition of $3 \%$ of water (Figure 6.6b), $0.23 \mathrm{ppm}$ of phenanthrene (Figure 6.6c) and $88 \mathrm{ppm}$ of methylnaphthalene (Figure 6.6d). Polyaromatic compounds influence is a crucial factor of the sensor performance as they can offer a high cross sensitivity. In addition, they can be a potential match in atmospheres containing ethylene. Thus, same procedure explained in methodology is followed for ethylene and carbon monoxide but with a fixed background of each polyaromatic compound.

In dry conditions, the sensitivity of each sensor remains practically constant to ethylene even when 200 ppm of carbon monoxide is added as background. Only the thicker sensor shows a slight decrease of the sensitivity. Nevertheless, in the case of carbon monoxide there is an increase in sensitivity when the thickness is increased from 0.1 to $0.6 \mathrm{~mm}$. Then, the sensitivity remains almost constant in the range $0.6-1.2 \mathrm{~mm}$. The addition of $200 \mathrm{ppm}$ of ethylene as background keeps constant the carbon monoxide sensitivity for all devices, confirming that ethylene electrochemical reaction is controlling the working electrode. Thus, the cross- 
sensitivity toward carbon monoxide is lower for the thinnest device as it has the highest sensitivity to ethylene and the lowest sensitivity to carbon monoxide.

On the other hand, the addition of $3 \%$ of water shows a decrease of the ethylene sensitivity as the thickness of the electrolyte goes from 0.1 to $0.6 \mathrm{~mm}$ for both pure ethylene and when $200 \mathrm{ppm}$ of carbon monoxide is added as background. In the case of carbon monoxide, there is an increase of the sensitivity when the thickness increases from 0.1 to $0.6 \mathrm{~mm}$, although the increases are lower when there is a background of $200 \mathrm{ppm}$ of ethylene. For both analytes the sensitivity remains almost unaffected for thicknesses ranging between 0.6 and $1.2 \mathrm{~mm}$.

The addition of phenanthrene provides a similar trend than in dry conditions but, in this case, the decrease of ethylene sensitivity is higher when carbon monoxide background is added. This higher decrease of ethylene sensitivity plus the increase of carbon monoxide sensitivity (observed also in dry conditions) leads to a higher cross-sensitivity toward carbon monoxide for the thicker electrolyte when phenanthrene is added. On the other hand, the thinner device shows the lowest cross-sensitivity.

When methylnaphthalene is added, the ethylene sensitivity decreases as the thickness increase for both pure ethylene and ethylene with 200 ppm of carbon monoxide background. On the other hand, carbon monoxide sensitivity is only slightly affected and it decreases slightly. Thus, the cross-sensitivity towards carbon monoxide increases significantly when the thickness of the electrolyte is enlarged.

Thus, a critical thickness can be observed in terms of cross-sensitivity toward carbon monoxide. The thinner device $(0.1 \mathrm{~mm})$ offers the best response as it provides the lowest cross-sensitivity to carbon monoxide while the thicker device $(1.2 \mathrm{~mm})$ has the highest cross-sensitivity. In between, there is a region (0.6-0.8) where the sensor performance is independent on the electrolyte thickness and its response remains almost constant. Thus, it can be concluded that there is an influence of the electrolyte thickness on the sensor response. 
a)

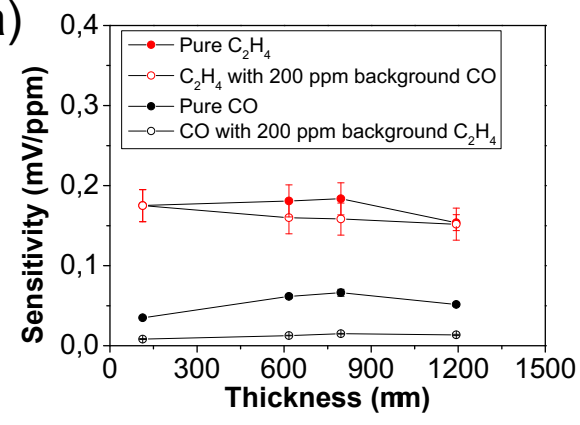

c)

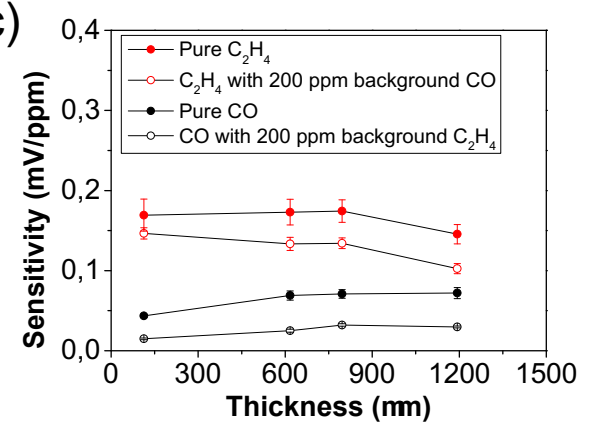

b)

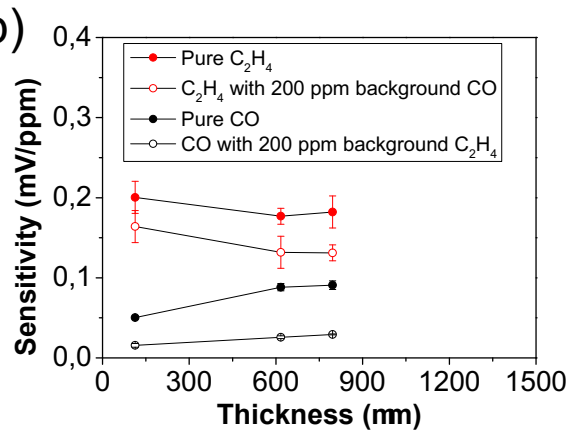

d)

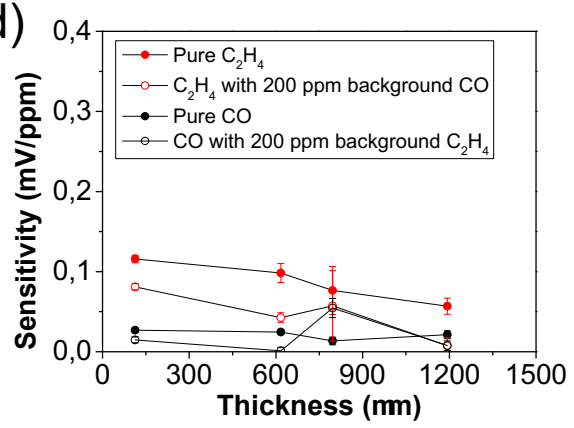

Figure 6.6 Sensor sensitivity as a function of the thickness of the electrolyte $(0.1,0.6,0.8$ and $1.2 \mathrm{~mm})$ for pure ethylene and carbon monoxide as well as response with a background of $200 \mathrm{ppm}$ of each analyte and background of phenantrene and methylnaphthalene. Sensitivity is represented for: a) dry conditions, b) wet conditions, c) phenanthrene presence $(0.23 \mathrm{ppm})$ and d) methylnaphthalene presence (88 ppm)

\subsubsection{Electrochemical Impedance Spectroscopy}

An electrochemical impedance spectroscopy of the system is performed to confirm the sensor performance aforementioned in the potentiometric characterization. After performing the surface activation with nickel nanoparticles, the sensor response is analysed when exposed to $200 \mathrm{ppm}$ of ethylene and carbon monoxide in dry conditions, wet conditions and in the presence of 0.23 ppm of phenanthrene and $88 \mathrm{ppm}$ of methylnaphthalene. Nyquist plots from 0.03 $\mathrm{Hz}$ to $1 \mathrm{MHz}$ for the four different $8 \mathrm{YSZ}$ thicknesses are depicted for dry and wet conditions in Figure 6.7 and for the case when phenanthrene and methylnaphthalene are added as background in Figure 6.9. In the case of dry and wet conditions, all devices responses can be fitted to an equivalent circuit consisting of two parallel combinations of resistance-constant phase element ( $R$ CPE) circuits connected in series. There are two arch contributions: the first one, corresponding to a capacitance between $10^{-5}-10^{-6} \mathrm{~F}$ can be attributed to the interface electrode-electrolyte as long as $8 \mathrm{YSZ}$ is employed as electrolyte at $550^{\circ} \mathrm{C}$ as working temperature. The second contribution belongs to capacitances 
between $10^{-2}-10^{-3} \mathrm{~F}$ and can be related to surface catalytic processes taking place at the electrode.
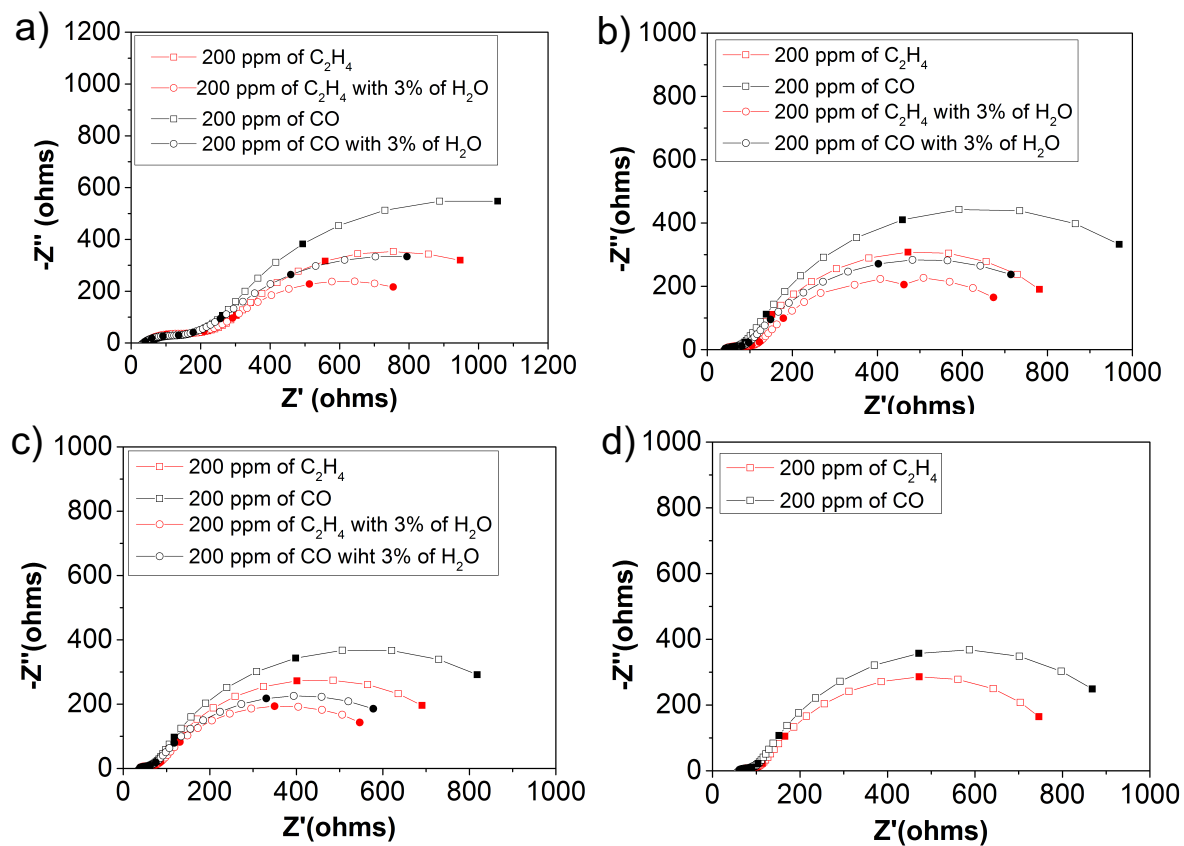

e)

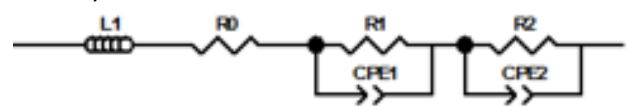

Figure 6.7 Electrochemical Impedance Spectroscopy study for the devices after the addition of nickel nanoparticles. Devices are exposed to $200 \mathrm{ppm}$ of ethylene and carbon monoxide in dry conditions as well as wet conditions. The EIS spectra is shown for each thickness: a) $0.1 \mathrm{~mm}, b) 0.6 \mathrm{~mm}, c) 0.8 \mathrm{~mm}$ and d) $1.2 \mathrm{~mm}$. The devices response can be fitted to an equivalent circuit consisting of two parallel combination of resistance-constant phase element (R-CPE) circuits connected in series as shown in e)

The thinnest sensor has a different behaviour because it has a slightly higher interface electrode-electrolyte contribution than the rest of the thicker sensors for both ethylene and carbon monoxide as can be observed in Figure 6.8b. Moreover, the contribution of the electrode is also higher than in the rest of thicker devices. This confirms that there is a difference in the surface and catalytic processes occurring on the electrode as the thickness of the electrolyte increases more than $0.1 \mathrm{~mm}$. Surprisingly, polarization resistance $(\mathrm{Rp})$ is higher for the thinnest sensor for both ethylene and carbon monoxide. Polarization resistance 
was expected to reduce its contribution when the thickness of the electrolyte decreases as there is lower ohmic losses. Howsoever, it seems to be related to the processes taking place at the electrode.

Concerning the analytes response, Figure 6.8d shows that ethylene electrode contribution is lower than carbon monoxide for each device. Water addition causes a decrease in the electrode contribution to both analytes when compared to dry conditions but there is still a difference between both of them, ethylene contribution is still lower. In the case of the interface electrode-electrolyte contribution, it remains almost equal when water is added. Thus, water has an effect on the reaction taking place at the electrode. The difference in the electrode resistance (and therefore the polarization resistance) between ethylene and carbon monoxide can explain the good performance of the device aforementioned and its low cross-sensitivity toward carbon monoxide.

The devices with an electrolyte thickness between 0.6 and $1.2 \mathrm{~mm}$ have a similar interface electrode-electrolyte contribution for both ethylene and carbon monoxide in dry and wet conditions. Therefore, this contribution is independent on the analyte and the electrolyte thickness when surpassed a critical thickness $(0.1$ $\mathrm{mm}$ ) as observed in Figure 6.8b. The electrode contribution, and therefore the polarization resistance, decreases in the range from 0.1 to $0.8 \mathrm{~mm}$ and then, they kept almost stable in the range from 0.8 to $1.2 \mathrm{~mm}$. However, the polarization resistance value is similar for each device in the range between 0.6 and $1.2 \mathrm{~mm}$. In wet conditions, the trend is similar for the range $0.1-0-8 \mathrm{~mm}$ but unfortunately the device with an electrolyte thickness of $1.2 \mathrm{~mm}$ could not be measured. This is in agreement with the potentiometric characterization performed previously (Figure 6.1 to Figure 6.4). Furthermore, the ethylene electrode contribution is lower than carbon monoxide contribution in both dry and wet conditions. Once more, this can be attributed to a difference in the catalytic processes occurring on the surface of the electrode and therefore, it can explain the selective response to ethylene with low cross-sensitivity toward carbon monoxide.

Although all devices provide an acceptable response for the aim of this work, it has been checked that there is an influence of the thickness of the electrolyte on the sensor response. Thus, the thinnest device provides the better performance despite offering the highest polarization resistance. This can be explained because not only the thinnest device provides the highest polarization resistance as absolute value, but it also provides the highest difference between ethylene and carbon monoxide polarization resistance. Consequently, the cross-sensitivity toward carbon monoxide is lower than in the case of the thicker sensors. 

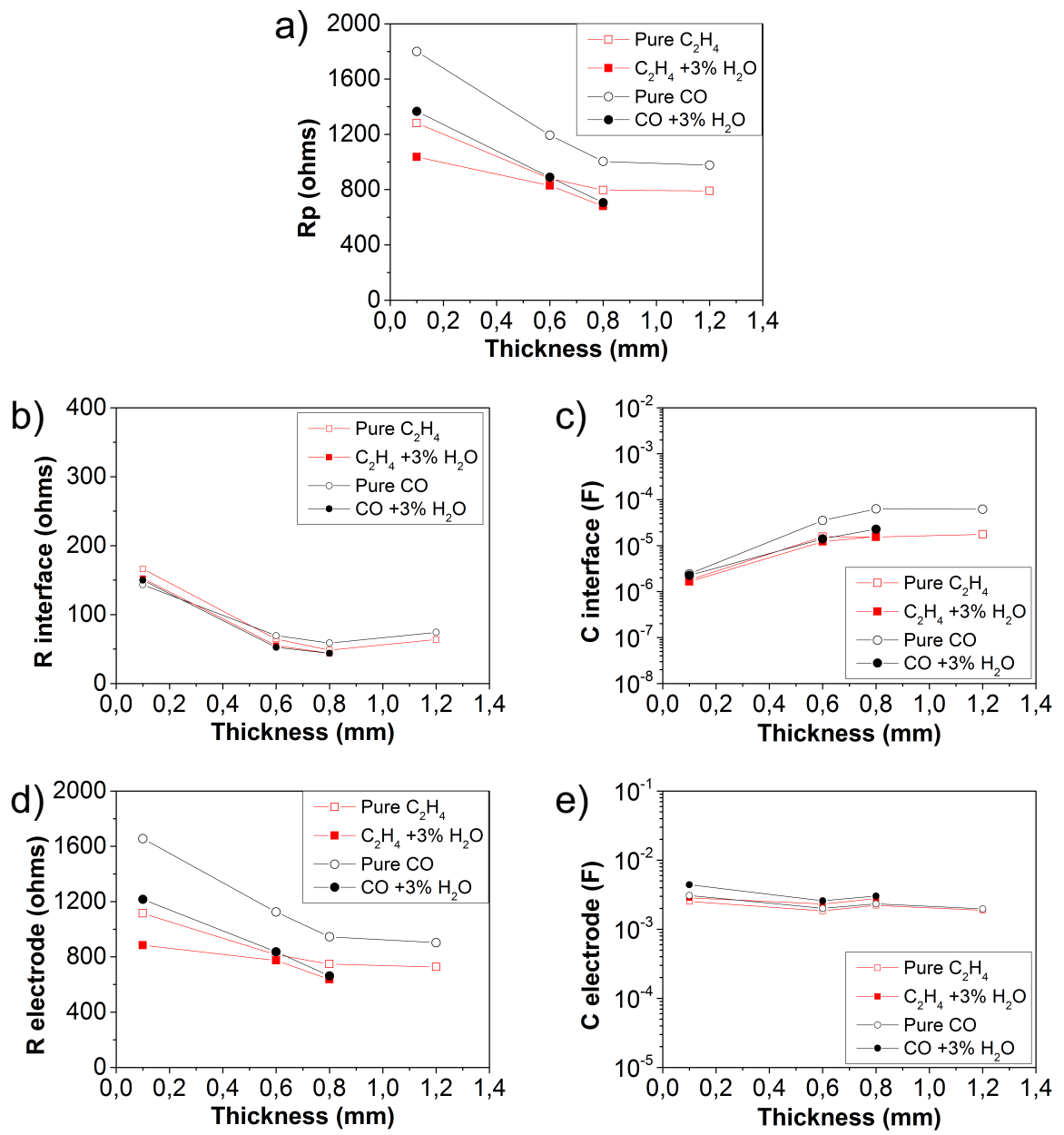

Figure 6.8 Equivalent electrical circuits fitting results as a function of thickness: a) Polarization resistance $(R p)$. b) resistance related to the contribution of the interface electrode-electrolyte. $c$ ) capacitance of the contribution related to the interface electrode-electrolyte. d) resistance related to the contribution of the catalytic processes occurring on the electrode. e) capacitance related to the contribution of the catalytic processes occurring on the electrode

Figure 6.9 shows the EIS spectra for each device to $200 \mathrm{ppm}$ of ethylene or carbon monoxide when either phenanthrene or methylnaphthalene are added. In all cases, the first arch contribution remains constant with the addition of the polyaromatic compounds. On the other hand, the addition of phenanthrene has an effect on the second arch contribution for all devices but the thinner one. Carbon monoxide EIS spectra remains almost unaffected but ethylene contribution is increased with the addition of the polyaromatic compound. In the case of the thinnest device, the addition of phenanthrene has practically no effect 
on the EIS spectra for ethylene. Thus, this is again in agreement with the low cross-sensitivity observed for the thinner device (Figure 6.6c). Otherwise, the addition of methylnaphthalene has an impact on the EIS spectra for both analytes. In this case, the difference in the arch contribution between ethylene and carbon monoxide is reduced as the thickness is increased. This is also in agreement with the potentiometric characterization performed where the sensitivity to ethylene is reduced and the cross-sensitivity toward carbon monoxide increased (Figure 6.6d).
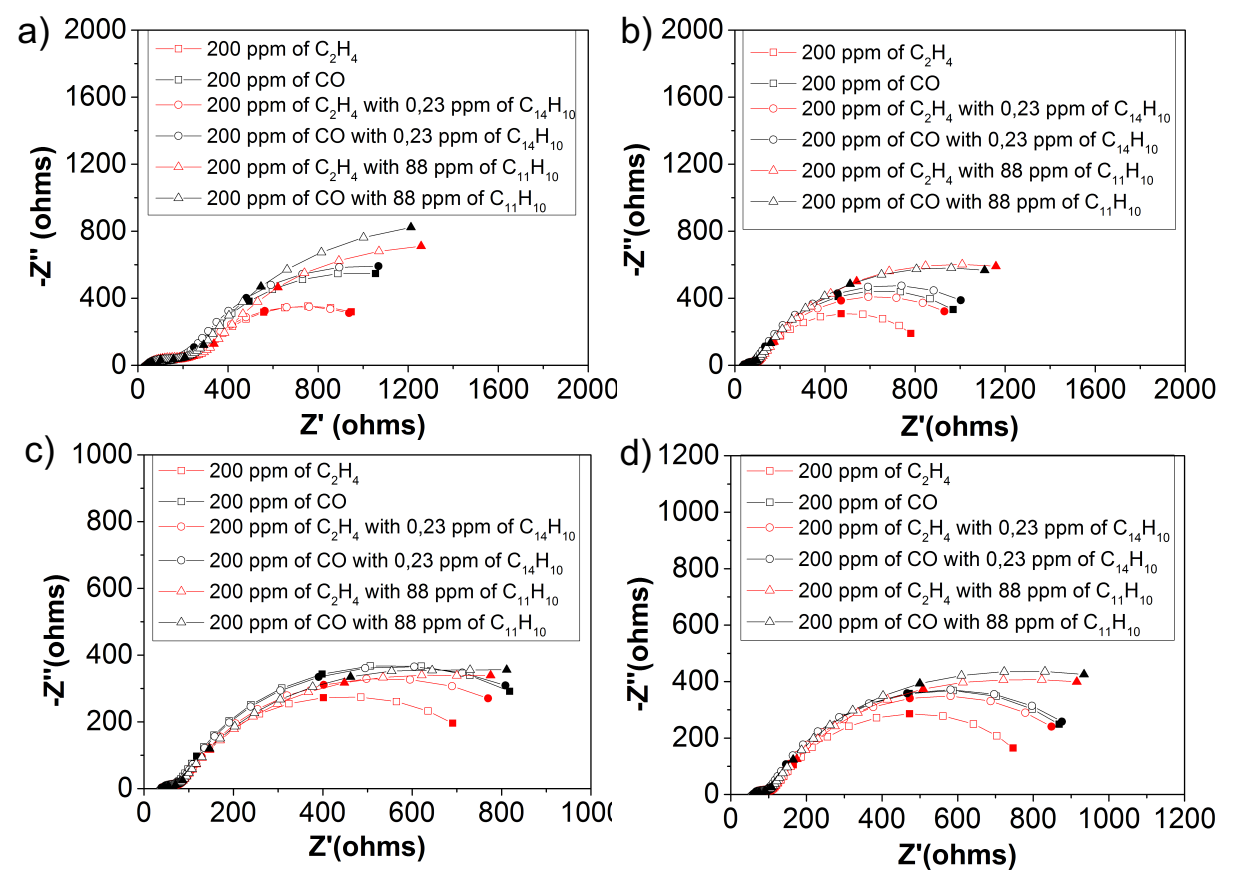

Figure 6.9 Electrochemical Impedance Spectrometry study for the devices after nickel infiltration on the working electrode when the sensor is exposed to 200 ppm of ethylene or carbon monoxide with a background of $0.23 \mathrm{ppm}$ of phenanthrene or $0.88 \mathrm{ppm}$ of methylnaphthalene. The EIS spectra is shown for each thickness: a) $0.1 \mathrm{~mm}$, b) $0.6 \mathrm{~mm}, 0.8 \mathrm{~mm}$ and d) $1.2 \mathrm{~mm}$ 


\subsection{Structural characterization}

FESEM analysis is carried out to check the structural and morphological characteristics of the devices. Figure 6.10 shows the fracture cross-section of the complete device for each thickness. Thus, the thickness of each electrode is confirmed to be $0.1,0.6,0.8$ and $1.2 \mathrm{~mm}$, respectively. Working electrode and reference electrode can be observed all along the surface with their respective gold current collector layer. In addition, Figure 6.11 reveals that electrolytes are fully dense for both commercial and prepared electrolytes.

A FESEM analysis of both working and reference electrodes of the thinner device is depicted in Figure 6.12 as an example. The structural characterization of both electrodes is common for each of the studied devices with different thickness. As seen in previous chapters, Figure $6.12 \mathrm{a}$ and $6.12 \mathrm{c}$ show porous electrodes and a homogeneous grain distribution of $8 \mathrm{YSZ}$ and $\mathrm{Fe}_{0.7} \mathrm{Cr}_{1.3} \mathrm{O}_{3}$ or LSM, respectively. Once again, there is a difference in the grain size between $\mathrm{Fe}_{0.7} \mathrm{Cr}_{1.3} \mathrm{O}_{3}$ and $8 \mathrm{YSZ}$ grains as $\mathrm{Fe}_{0.7} \mathrm{Cr}_{1.3} \mathrm{O}_{3}$ grains are bigger. A detailed view of the working electrode (Figure 6.12b) reveals the dispersion of nickel nanoparticles among the electrode. The nanocatalysts are present in both $\mathrm{Fe}_{0.7} \mathrm{Cr}_{1.3} \mathrm{O}_{3}$ and $8 \mathrm{YSZ}$ grains. On the other hand, Figure $6.12 \mathrm{~d}$ shows a detailed view of the reference electrode crosssection where a homogeneous distribution of LSM/8YSZ grains with no difference in the grain size can be observed. In addition, there is no presence of nickel nanoparticles among the electrode. Moreover, in both electrodes no reaction interfaces between electrode and electrolyte are detected. This is in agreement with the impedance spectroscopy analysis performed, where the resistance attributed to the interface was similar for all devices. 
a)

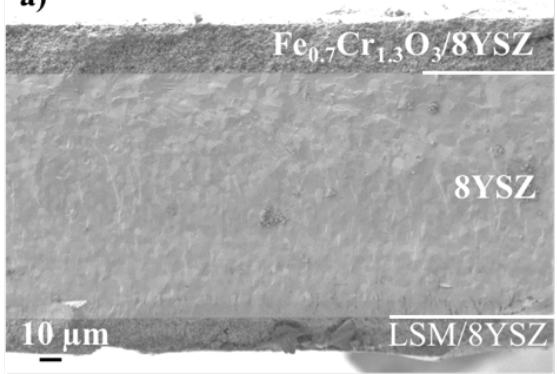

c) $\quad \mathrm{Fe}_{0.7} \mathrm{Cr}_{1.3} \mathrm{O}_{3} / 8 \mathrm{YSZ}$

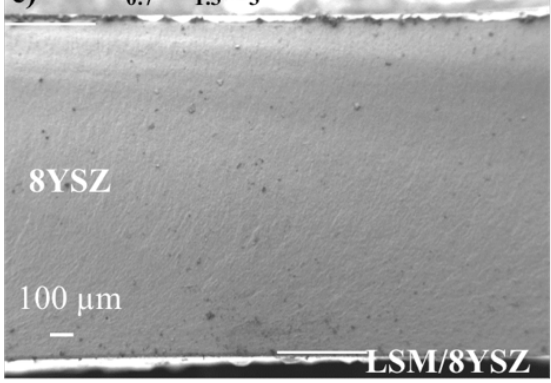

b) $\quad \mathrm{Fe}_{0.7} \mathrm{Cr}_{1.3} \mathrm{O}_{3} / 8 \mathrm{YSZ}$

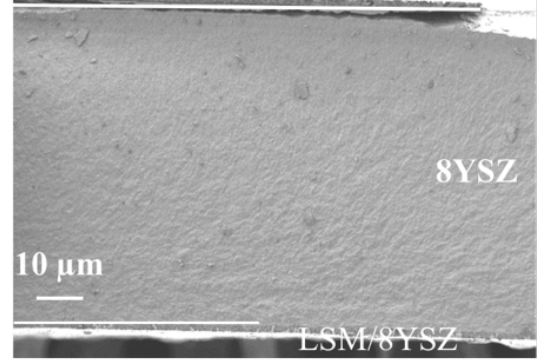

d) $\mathrm{Fe}_{0.7} \mathrm{Cr}_{1.3} \mathrm{O}_{3} / 8 \mathrm{YSZ}$

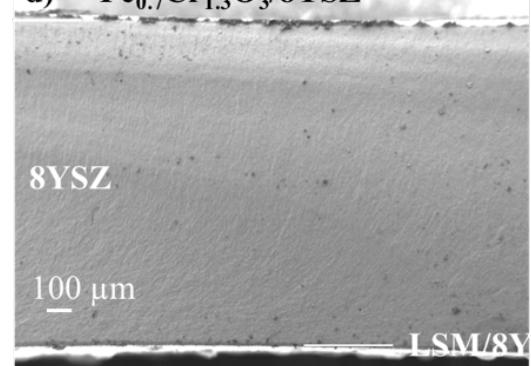

Figure 6.10 FESEM images of the fracture cross-section of the device for each electrolyte thickness: a) $0.1 \mathrm{~mm}$, b) $0.6 \mathrm{~mm}, \mathrm{c}) 0.8 \mathrm{~mm}$ and d) $1.2 \mathrm{~mm}$
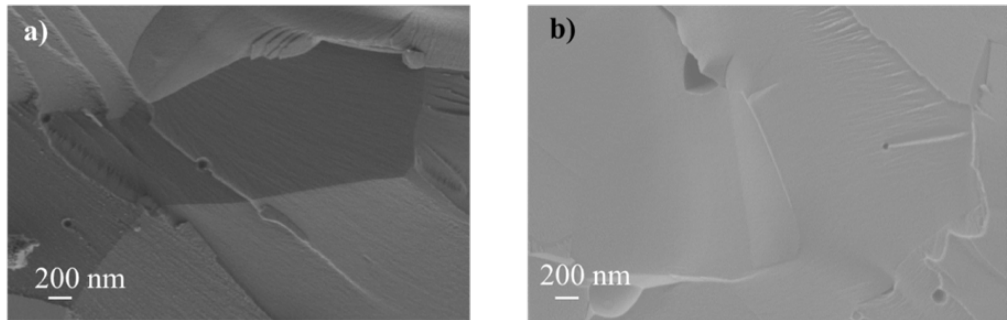

Figure 6.11 Detailed views of the fracture cross-section of the full dense electrolyte for commercial electrolyte from Kerafol (a) and one of the prepared electrolytes corresponding to the electrolyte with a thickness of $0.6 \mathrm{~mm}(\mathrm{~b})$. The rest of the prepared electrolytes has the same structural characteristics 

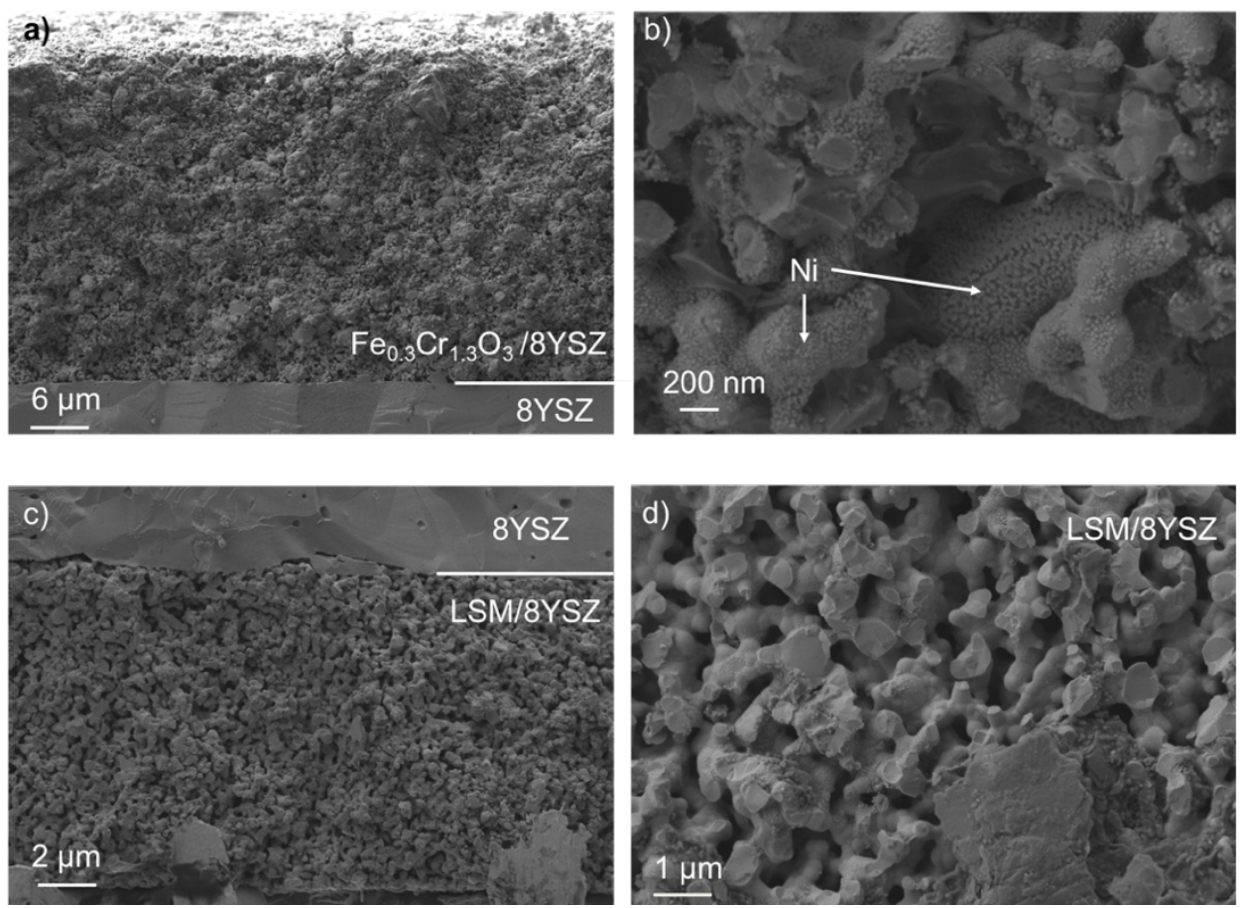

Figure 6.12 FESEM images of the fracture cross-section of: a) interface between working electrode and electrolyte, $b$ ) detailed view of the working electrode, $c$ ) interface between reference electrode and electrolyte and d) detailed view of the reference electrode. All images belong to the thinner device $(0.1 \mathrm{~mm})$ as an example. The rest of devices present similar electrodes structures

\subsection{Conclusions}

In this chapter, the influence of the electrolyte thickness on the sensor response has been evaluated. Different devices with different thickness are studied $(0.1$, $0.6,0.8$ and $1.2 \mathrm{~mm}$ ) exposing this devices to several concentrations of ethylene and carbon monoxide in dry and wet conditions as well as with a fixed concentration of phenanthrene $(0.23 \mathrm{ppm})$ and methylnaphthalene (88 ppm).

The potentiometric characterization reveals that in dry conditions, the ethylene sensitivity remains almost constant in the range between 0.1-0.8 mm, and it falls down when the electrolyte increases up to $1.2 \mathrm{~mm}$. When carbon monoxide is introduced as background, the ethylene sensitivity drops from $0.1 \mathrm{~mm}$ to $0.6 \mathrm{~mm}$, then it remains constant in the range $0.6-0.8 \mathrm{~mm}$ and decreases again when it goes from 0.8 to $1.2 \mathrm{~mm}$. Carbon monoxide sensitivity increases from 0.1 to 0.6 $\mathrm{mm}$, remains constant in the range between 0.6-0.8 $\mathrm{mm}$ and then increases again when the electrolyte thickness increases up to $1.2 \mathrm{~mm}$. The carbon 
monoxide sensitivity remains constant for all thicknesses when an ethylene background is added.

In wet conditions ( $3 \%$ of water) there is an overall slight increase of the sensor sensitivity for both analytes. The sensor performance trend is similar to the response in dry conditions but the decrease of ethylene sensitivity and the increase of carbon monoxide sensitivity are larger. In the range between 0.6-0.8 $\mathrm{mm}$ the sensitivity to both analytes remain almost constant.

The addition of a fixed phenanthrene background provides sensor performance similar to the performance observed in dry conditions for each electrolyte thickness. On the other hand, the addition of a fixed methylnaphthalene background decreases the sensitivity to both analytes as the electrolyte thickness is increased. The decrease is higher for ethylene sensitivity.

Then, the thinnest device provides the better performance as the cross-sensitivity toward carbon monoxide is the lowest while the thicker sensor provides the highest cross-sensitivity toward carbon monoxide.

These results are backed by an electrochemical impedance spectrometry. The devices response can be fitted to an equivalent circuit consisting of two parallel combinations of resistance-constant phase element (R-CPE) circuits connected in series. The first resistance attributed to the interface electrode-electrolyte remains constant for both analytes in dry and wet conditions for each device in the range between 0.6 to $1.2 \mathrm{~mm}$ although the resistance is slightly higher for the device with an electrolyte thickness of $0.1 \mathrm{~mm}$. Thus, this contribution is independent of the analyte and the electrolyte thickness when a critical thickness $(0.1 \mathrm{~mm})$ is surpassed.

On the other hand, the second resistance associated with the catalytic processes taking place at the electrode surface is different for each analyte and thickness. This indicates that there is a difference in the surface and catalytic processes occurring on the electrode. Unexpectedly, the electrode resistance and therefore the polarization resistance, decreases when the electrolyte thickness is increased. A lower polarization resistance was expected when reducing the thickness of the electrolyte as the ohmic losses are also decreased. However, despite this higher resistance, the difference in resistance between ethylene and carbon monoxide is also higher for the thinnest sensor. The trend is similar when the sensor is exposed to wet conditions. Consequently, this can explain the lower cross-sensitivity toward carbon monoxide of the thinner device. 
Hence, although there are slight differences in the sensor performance when the thickness is increased, there is an influence of the electrolyte thickness on the sensor performance. Thus, the lower is the electrolyte thickness, the lower is the cross-sensitivity toward carbon monoxide.

\subsection{References}

[1] C.-J. Li, C.-X. Li, Y.-Z. Xing, M. Gao, G.-J. Yang, Influence of YSZ electrolyte thickness on the characteristics of plasma-sprayed cermet supported tubular SOFC, Solid State lonics 177 (2006), 2065-2069). doi:10.1016/j.ssi.2006.03.004.

[2] T. Duangmanee, S. Wannakitti, R. Suwanwarangkul, S. Charojrochkul, Electrical Property of Thick Film Electrolyte for Solid Oxide Fuel Cell, J. Met. Mater. Miner. 18 (2008) 7-11.

[3] T. Van Gestel, D. Sebold, H.P. Buchkremer, Processing of 8YSZ and CGO thin film electrolyte layers for intermediate- and low-temperature SOFCs, J.
Eur.
Ceram.
Soc.
35
(2015)
1505-1515.

doi:10.1016/J.JEURCERAMSOC.2014.11.017.

[4] S.C. Singhal, K. Eguchi, ECS transactions 35, Solid Oxide Fuel Cells 12 (SOFC XII), The electrochemical society, Pennington, US .

[5] P.F. Haworth, S. Smart, J.M. Serra, J.C. Diniz Da Costa, Combined investigation of bulk diffusion and surface exchange parameters of silver catalyst coated yttrium-doped BSCF membranes, Phys. Chem. Chem. Phys. Phys. Chem. Chem. Phys. 14 (2012) 9104-9111. doi:10.1039/c2cp41226h.

[6] P. Haworth, S. Smart, J. Glasscock, J.C. Diniz da Costa, High performance yttrium-doped BSCF hollow fibre membranes, Sep. Purif. Technol. 94 (2012) 16-22. doi:10.1016/J.SEPPUR.2012.04.005.

[7] T. Schiestel, M. Kilgus, S. Peter, K.J. Caspary, H. Wang, J. Caro, Hollow fibre perovskite membranes for oxygen separation, J. Memb. Sci. 258 (2005) 1-4. doi:10.1016/J.MEMSCI.2005.03.035.

[8] H. Wang, C. Tablet, J. Caro, Oxygen production at low temperature using dense perovskite hollow fiber membranes, J. Memb. Sci. 322 (2008) 214-217. doi:10.1016/J.MEMSCI.2008.05.038.

[9] H. Kusaba, Y. Shibata, K. Sasaki, Y. Teraoka, Surface effect on oxygen permeation through dense membrane of mixed-conductive LSCF perovskite-type oxide, Solid State lonics. 177 (2006) 2249-2253. doi:10.1016/J.SSI.2006.05.038.

[10] A. Behrouzifar, A.A. Asadi, T. Mohammadi, A. Pak, Experimental investigation and mathematical modeling of oxygen permeation through dense 
Ba0.5Sr0.5Co0.8Fe0.2O3- $\delta$ (BSCF) perovskite-type ceramic membranes, Ceram. Int. 38 (2012) 4797-4811. doi:10.1016/J.CERAMINT.2012.02.068.

[11] A.A. Asadi, A. Behrouzifar, M. Iravaninia, T. Mohammadi, A. Pak, Preparation and Oxygen Permeation of La $0.6 \mathrm{Sr} 0.4$ Co $0.2 \mathrm{Fe} 0.8 \mathrm{O} 3-\delta$ (LSCF) Perovskite-Type Membranes: Experimental Study and Mathematical Modeling, Ind. Eng. Chem. Res. 51 (2012), 3069-3080. doi:10.1021/ie202434k.

[12] A.V. Kovalevsky, A.A. Yaremchenko, V.A. Kolotygin, A.L. Shaula, V.V. Kharton, F.M.M. Snijkers, A. Buekenhoudt, J.R. Frade, E.N. Naumovich, Processing and oxygen permeation studies of asymmetric multilayer Ba0.5Sr0.5Co0.8Fe0.2O3- $\delta$ membranes, J. Memb. Sci. 380 (2011) 68-80. doi:10.1016/J.MEMSCI.2011.06.034.

[13] Q. Jiang, K.J. Nordheden, S.M. Stagg-Williams, Oxygen permeation study and improvement of $\mathrm{Ba} 0.5 \mathrm{Sr} 0.5 \mathrm{Co} 0.8 \mathrm{Fe} 0.2 \mathrm{Ox}$ perovskite ceramic membranes, J. Memb. Sci. $369 \quad$ (2011) 174-181. doi:10.1016/J.MEMSCI.2010.11.073.

[14] P. Niehoff, S. Baumann, F. Schulze-Küppers, R.S. Bradley, I. Shapiro, W.A. Meulenberg, P.J. Withers, R. Vaßen, Oxygen transport through supported Ba0.5Sr0.5Co0.8Fe0.2O3-ס membranes, Sep. Purif. Technol. 121 (2014) 60-67. doi:10.1016/J.SEPPUR.2013.07.002.

[15] F. Schulze-Küppers, S. Baumann, W.A. Meulenberg, D. Stöver, H.-P. Buchkremer, Manufacturing and performance of advanced supported $\mathrm{Ba} 0.5 \mathrm{Sr} 0.5 \mathrm{Co0} .8 \mathrm{Fe} 0.2 \mathrm{O}-\delta$ (BSCF) oxygen transport membranes, J. Memb. Sci. 433 (2013) 121-125. doi:10.1016/J.MEMSCI.2013.01.028.

[16] A. Ghadimi, M.A. Alaee, A. Behrouzifar, A.A. Asadi, T. Mohammadi, Oxygen permeation of $\mathrm{BaxSr} 1-x \mathrm{Co} 0.8 \mathrm{Fe} 0.2 \mathrm{O} 3-\delta$ perovskite-type membrane: Experimental and modeling, Desalination. 270 (2011) 64-75. doi:10.1016/J.DESAL.2010.11.022.

[17] W.K. Hong, G.M. Choi, Oxygen permeation of BSCF membrane with varying thickness and surface coating, J. Memb. Sci. 346 (2010) 353-360. doi:10.1016/J.MEMSCI.2009.09.056. 

chapter 7

\section{Alternatives to 8YSZ as electrolyte: CGO and ScSZ}





\section{Alternatives to 8YSZ as electrolyte: CGO and ScSZ}

\subsection{Introduction}

In previous chapters, $\mathrm{Fe}_{0.7} \mathrm{Cr}_{1.3} \mathrm{O}_{3} / 8 \mathrm{YSZ} / / 8 \mathrm{YSZ} / / \mathrm{LSM} / 8 \mathrm{YSZ}$ was established as the standard sensor configuration that provides selective response to ethylene and low cross-sensitivity toward carbon monoxide after surface activation by nanocatalyst deposition on the working electrode. The current device detects selectively ethylene at $550^{\circ} \mathrm{C}$. This temperature is sufficient for sensing in environments like cars exhaust gases because the temperature is high and a heater can be attached to ensure that the sensor works at this temperature. Nevertheless, the possibility to detect this analyte at lower temperatures is interesting enough to study it further and look for alternatives to 8YSZ electrolyte. Moreover, this can make the sensor suitable for other sensing applications that require lower temperature.

Nowadays, 8YSZ is one of the most employed electrolyte in technologies such as SOFC because of its chemical stability [1-8]. One of the main challenges is to reduce the temperature to the intermediate and low temperature ranges. The problem with zirconium oxide is that it exhibits a limited oxygen conduction at lower temperatures and this limits its applications. There are two approaches: reduce the electrolyte thickness to reduce its contribution as much as possible as has been done in chapter 6 , and look for alternatives to 8YSZ with a higher conductivity at lower temperatures [9].

In this chapter, $\mathrm{Ce}_{0.8} \mathrm{Gd}_{0.2} \mathrm{O}_{2-\delta}(\mathrm{CGO})$ and zirconium oxide stabilized scandium (ScSZ; with $10 \%$ of $\mathrm{Sc}_{2} \mathrm{O}_{3}$ ) are employed as alternatives to $8 \mathrm{YSZ}$. These materials are selected because they can provide a good ionic conductivity at lower temperature than $8 Y S Z$ [3,9-21]. The devices are checked at 550, 500, 450 and $400^{\circ} \mathrm{C}$ to compare the response to $8 Y S Z$ at $550^{\circ} \mathrm{C}$ in order to analyse the influence of temperature in the performance of these materials. Then, a surface activation of the working electrode by nickel nanoparticles deposition will be carried on and the device checked again at $550,500,450$ and $400^{\circ} \mathrm{C}$.

As electrodes, $\mathrm{Fe}_{0.7} \mathrm{Cr}_{1.3} \mathrm{O}_{3}$ is selected as working electrode and LSM/8YSZ is selected as reference electrode. In the case of the device employing CGO as electrolyte, the working electrode is mixed with CGO to ensure a proper attachment to the electrolyte. The reference electrode is not changed to keep same configuration than in previous chapters. 
Thus, there are two configurations: 1) $\mathrm{Fe}_{0.7} \mathrm{Cr}_{1.3} \mathrm{O}_{3} / \mathrm{CGO} / / \mathrm{CGO} / / \mathrm{LSM} / 8 \mathrm{YSZ}$ and 2) $\mathrm{Fe}_{0.7} \mathrm{Cr}_{1.3} \mathrm{O}_{3} / 8 \mathrm{YSZ} / / \mathrm{ScSZ} / / \mathrm{LSM} / 8 \mathrm{YSZ}$.

\subsection{Electrochemical characterization}

The target of this chapter is to study the influence of temperature and evaluate the feasibility of employing ScSZ or CGO as alternatives to 8YSZ. Potentiometric measurements and impedance measurements are carried out for the bare sensor with these electrolytes at several temperatures $\left(550,500,450\right.$ and $\left.400^{\circ} \mathrm{C}\right)$ in dry conditions. The effect of water is also analysed. In addition, the working electrode of both sensors is infiltrated with nickel nanoparticles to improve the catalytic activity toward ethylene as shown in chapter 5 . The effect of temperature is analysed again and also the effect of water and polyaromatics (phenanthrene and methylnaphthalene).

\subsubsection{Bare sensor}

In first place, the sensor response of the devices employing CGO and ScSZ are checked at $550^{\circ} \mathrm{C}$ in dry conditions and compared to the device using $8 Y S Z$ as electrolyte (as employed in chapter 4). Figure $7.1 \mathrm{a}$ and $\mathrm{b}$ depicts the open circuit voltage of the devices employing CGO and ScSZ respectively. It can be noticed that the sensor response is noticeably lower than the sensor response shown in figure 4.12 for the device employing $8 \mathrm{YSZ}$ as electrolyte at $550^{\circ} \mathrm{C}$. Nevertheless, the performance of the sensor is similar: the response is not selective to ethylene and there is a considerable cross-sensitivity toward carbon monoxide although lesser than for the bare sensor employing 8YSZ.

a)

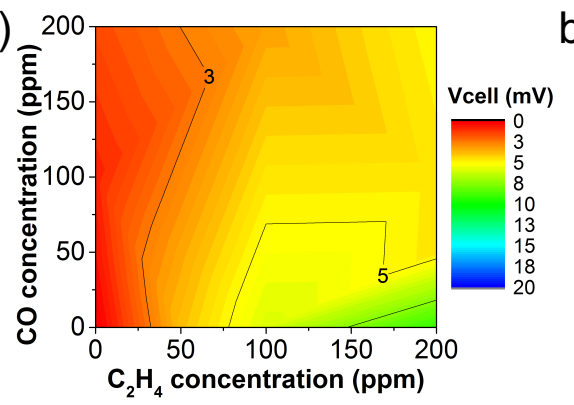

b)

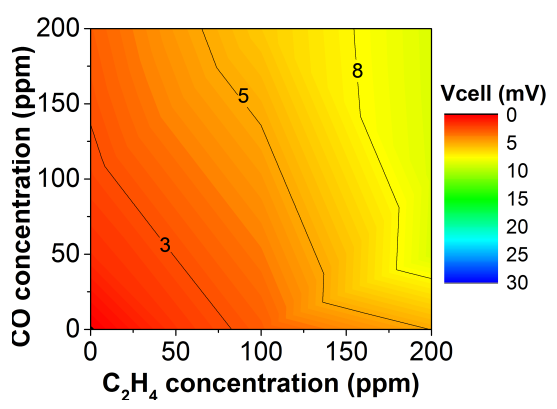

Figure $7.1 \mathrm{~V}_{\text {cell }}$ sensor response as a function of ethylene and carbon monoxide concentration at $550^{\circ} \mathrm{C}$ for devices employing as electrolyte: a) $\mathrm{CGO}$ and b) $\mathrm{ScSZ}$. $\mathrm{Fe}_{0.7} \mathrm{Cr}_{1.3} \mathrm{O}_{3} / 8 \mathrm{YSZ}$ is employed as working electrode and LSM/8YSZ as reference electrode 


\subsubsection{Influence of temperature}

Once the sensors responses are checked at $550^{\circ} \mathrm{C}$, the influence of lower temperatures is evaluated by exposing both devices at 500,450 and $400^{\circ} \mathrm{C}$. Figure 7.2 depicts the sensor performance as a function of the analyte concentration at each temperature for both devices employing CGO and ScSZ as electrolyte. In the case of CGO, there is an increase of the sensor response to both analytes as the temperature decreases (Figure 7.2a, Figure 7.2b and Figure 7.2c) [22]. Not only increases the overall response to both analytes but also the cross-sensitivity toward carbon monoxide. Then, the highest sensor response is obtained at $400^{\circ} \mathrm{C}$ as observed in Figure $7.2 \mathrm{c}$, but the sensor response is not selective to ethylene and the cross-sensitivity toward carbon monoxide is high enough to make it not suitable for the desired sensing purposes.

Conversely, for ScSZ the sensor response is similar to CGO in terms of output signal but, in this case, not only there is an increase in the output signal to both analytes but also the selectivity to ethylene. Moreover, the cross-sensitivity toward carbon monoxide at lower temperatures is lower than the one achieved at $550^{\circ} \mathrm{C}$ (Figure 7.2d, Figure 7.2e and Figure 7.2f). The best response in terms of signal value, selective to ethylene and cross-sensitivity toward carbon monoxide is reached at $400^{\circ} \mathrm{C}$. Unfortunately, at $400^{\circ} \mathrm{C}$ the sensor response time is high and the stabilization time large. This makes $450^{\circ} \mathrm{C}$ the most promising work temperature for a potentiometric sensor to ethylene. Although it is not the best response achieved, the sensor still provides a good performance in terms of stabilization, selectivity to ethylene and cross-sensitivity toward carbon monoxide. An analogous $8 Y S Z$-based device is also exposed to $450^{\circ} \mathrm{C}$ in order to check the sensor response of a device employing $8 Y S Z$ as electrolyte at lower temperatures. In Figure 7.3 it can be observed that, although the signal output is higher than the response achieved for ScSZ, the response in terms of selectivity to ethylene and cross-sensitivity toward carbon monoxide is poorer than for ScSZ.

Finally, the influence of water on the sensor response was checked as well. Figure $7.4 \mathrm{a}$ and $7.4 \mathrm{~b}$ depict the response of the sensor at $450^{\circ} \mathrm{C}$ as a function of the analytes for the devices employing CGO and ScSZ as electrolyte, respectively. Unfortunately, the addition of water increases both the signal output and the cross-sensitivity toward carbon monoxide and therefore, the sensor employing ScSZ is not suitable for ethylene detection in these conditions.

Thus, the change of the electrolyte from $8 Y S Z$ to ScSZ leads to a device able to detect selectively ethylene with a relatively low cross-sensitivity toward carbon monoxide when it works below $500^{\circ} \mathrm{C}$ in dry conditions. This is an advantage as it 
can detect ethylene at lower temperatures without requiring a catalytic activation of the working electrode. Unfortunately, when the sensor is exposed to water there is an increase of the cross-sensitivity toward carbon monoxide that makes it not suitable for sensing purposes. In the case of CGO, the cross-sensitivity toward carbon monoxide is too high for the desired purpose for both dry and wet conditions.

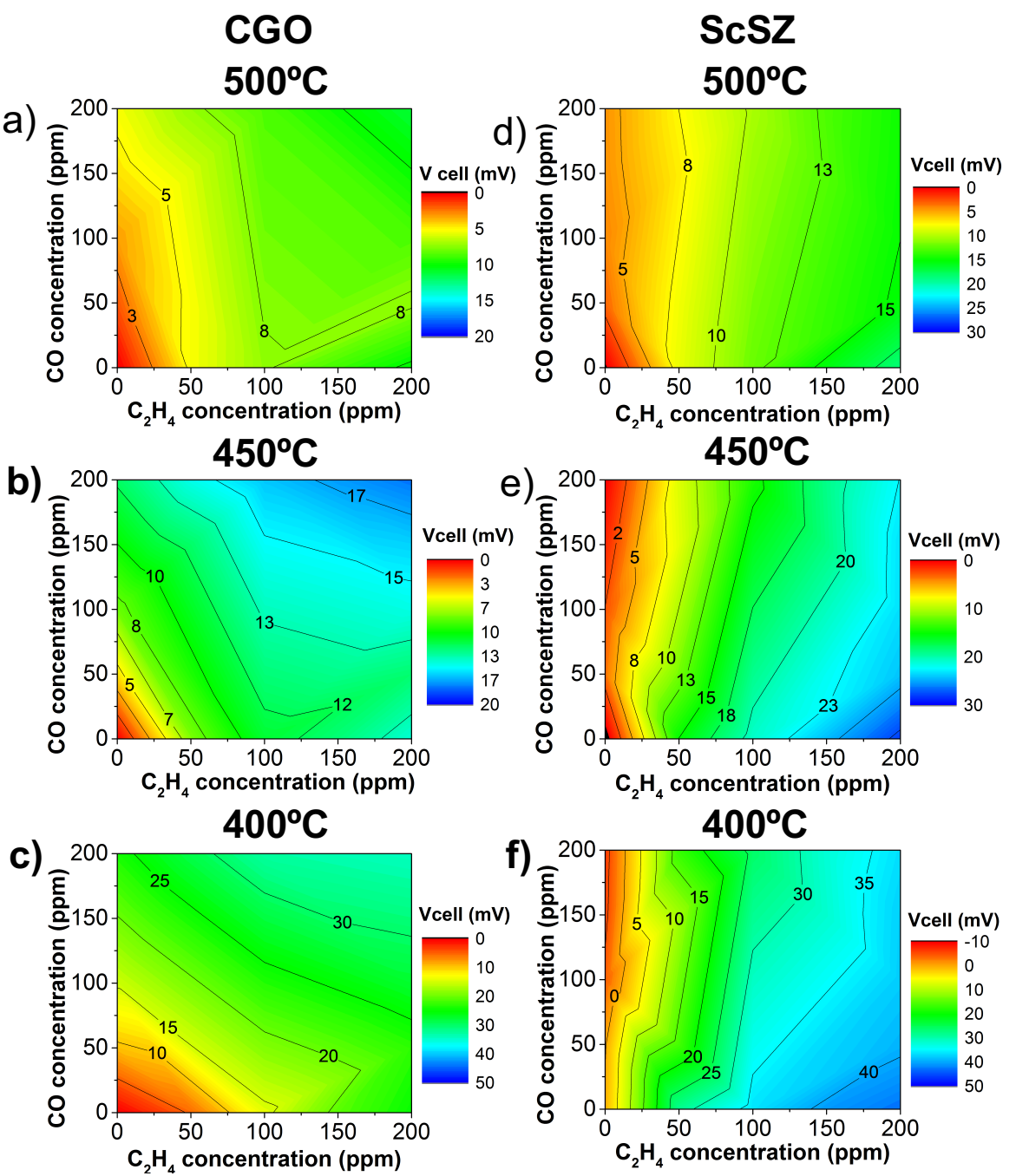

Figure 7.2 Study of the influence of the temperature on the sensor response. $V_{\text {cell }}$ sensor response as a function of carbon monoxide and ethylene concentration at several temperatures: a) $500^{\circ} \mathrm{C}$ using CGO as electrolyte, b) $500^{\circ} \mathrm{C}$ using ScSZ as electrolyte, c) $450^{\circ} \mathrm{C}$ using CGO as electrolyte, d) $450^{\circ} \mathrm{C}$ using ScSZ as electrolyte, e) $400^{\circ} \mathrm{C}$ using CGO as electrolyte and f) $400^{\circ} \mathrm{C}$ using ScSZ as electrolyte 


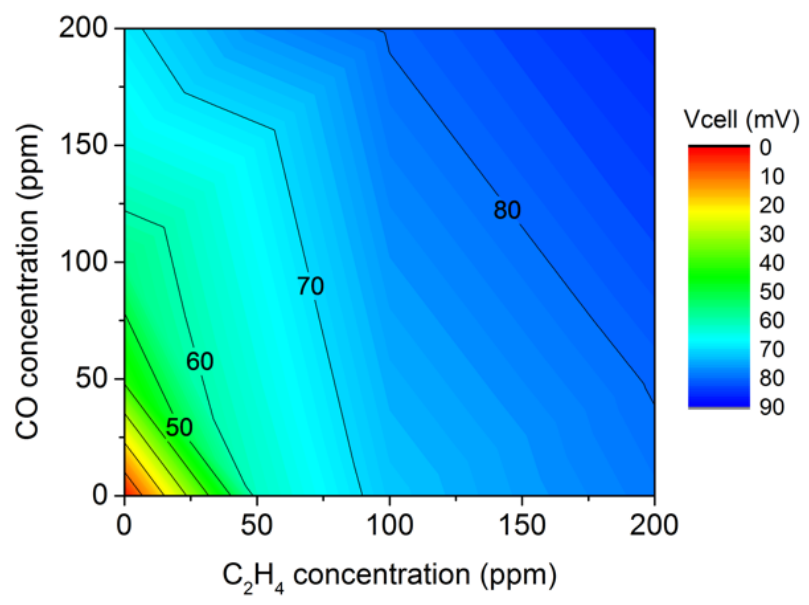

Figure 7.3. $V_{\text {cell }}$ sensor response as a function of analytes concentration at $450^{\circ} \mathrm{C}$ for device employing $8 \mathrm{YSZ}$ as electrolyte, $\mathrm{Fe}_{0.7} \mathrm{Cr}_{1.3} \mathrm{O}_{3} / 8 \mathrm{YSZ}$ as working electrode and $L S M / 8 Y S Z$ as reference electrode

a)

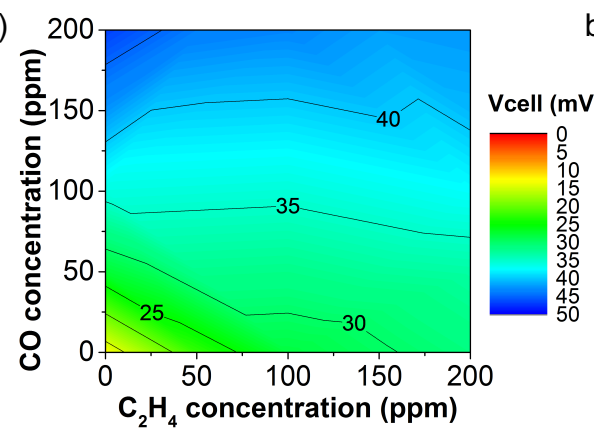

b)

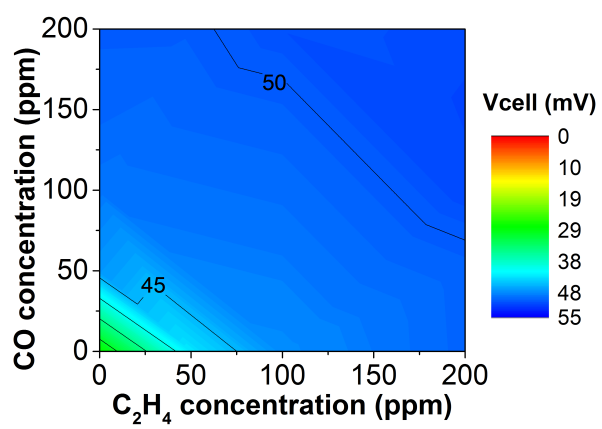

Figure 7.4. Sensor response as a function of analytes concentration when the sensor is exposed to $3 \%$ of water at $450^{\circ} \mathrm{C}$ for devices employing as electrolyte: a) CGO and b) ScSZ

\subsubsection{Surface activation of working electrode by nickel nanoparticles}

Additionally, a surface activation of the working electrode is carried out by addition of nickel nanoparticles to improve the catalytic activity as shown in chapter 5 . Thus, the nanoparticles are infiltrated by dropping the nickel solution on the surface and then it is calcinated at $550^{\circ} \mathrm{C}$ in argon for four hours and the same treatment with $5 \%$ of hydrogen.

Once the devices are infiltrated with nickel, the stability problems at $400^{\circ} \mathrm{C}$ aforementioned disappear as the response is faster but the sensor response is completely saturated above $100 \mathrm{ppm}$ of ethylene for CGO-based device and 50 
ppm of ethylene for ScSZ-based device as can observed in Figure 7.5a and Figure $7.5 \mathrm{~d}$. At $450^{\circ} \mathrm{C}$ the sensor response is akin to the response at $400^{\circ} \mathrm{C}$ and it is still saturated for both devices as depicted in Figure $7.5 \mathrm{~b}$ and Figure $7.5 \mathrm{e}$. The sensor response to ethylene is saturated above $100 \mathrm{ppm}$ of the mentioned analyte. However, above 100 ppm of ethylene it should be noticed that the sensor response is selective to ethylene with a low cross-sensitivity toward carbon monoxide for both devices. Additionally, the sensor response at $450^{\circ} \mathrm{C}$ of a device consisting of $8 \mathrm{YSZ}$ as electrolyte is also measured to compare its response to both alternatives after functionalization of the working electrode. Thus, Figure 7.6 shows that $8 Y S Z$-based device also has a saturation above 100 ppm of ethylene but, in this case, the sensor performance is poorer in terms of selectivity to ethylene as the cross-sensitivity to carbon monoxide is still high at $450^{\circ} \mathrm{C}$ even with the addition of nickel nanoparticles in the working electrode. Therefore, CGO and ScSZ can be strong candidates for application that require a detection of low concentration levels of ethylene (below 100 ppm) at low temperatures and dry conditions only.

Nonetheless, alternatives to nickel catalytic nanoparticles such as ruthenium, palladium or cobalt should be considered in order to provide a more appropriate catalytic activity at these lower temperatures. Nickel nanoparticles can have a lesser activity at temperatures below $500^{\circ} \mathrm{C}$.

When these sensors are exposed to $550^{\circ} \mathrm{C}$ after surface activation of the working electrode (Figure 7.5c and Figure 7.5f), the sensor performance is similar to $8 Y S Z-b a s e d$ device in the same conditions (figure 5.3b). For both alternative materials, the overall value of the signal is lower than in the case of the 8YSZbased device but the response trend is akin. All of them provide a selective response to ethylene with low cross-sensitivity toward carbon monoxide. Thus, the best response for both alternatives to detect up to $200 \mathrm{ppm}$ of ethylene is again $550^{\circ} \mathrm{C}$. 


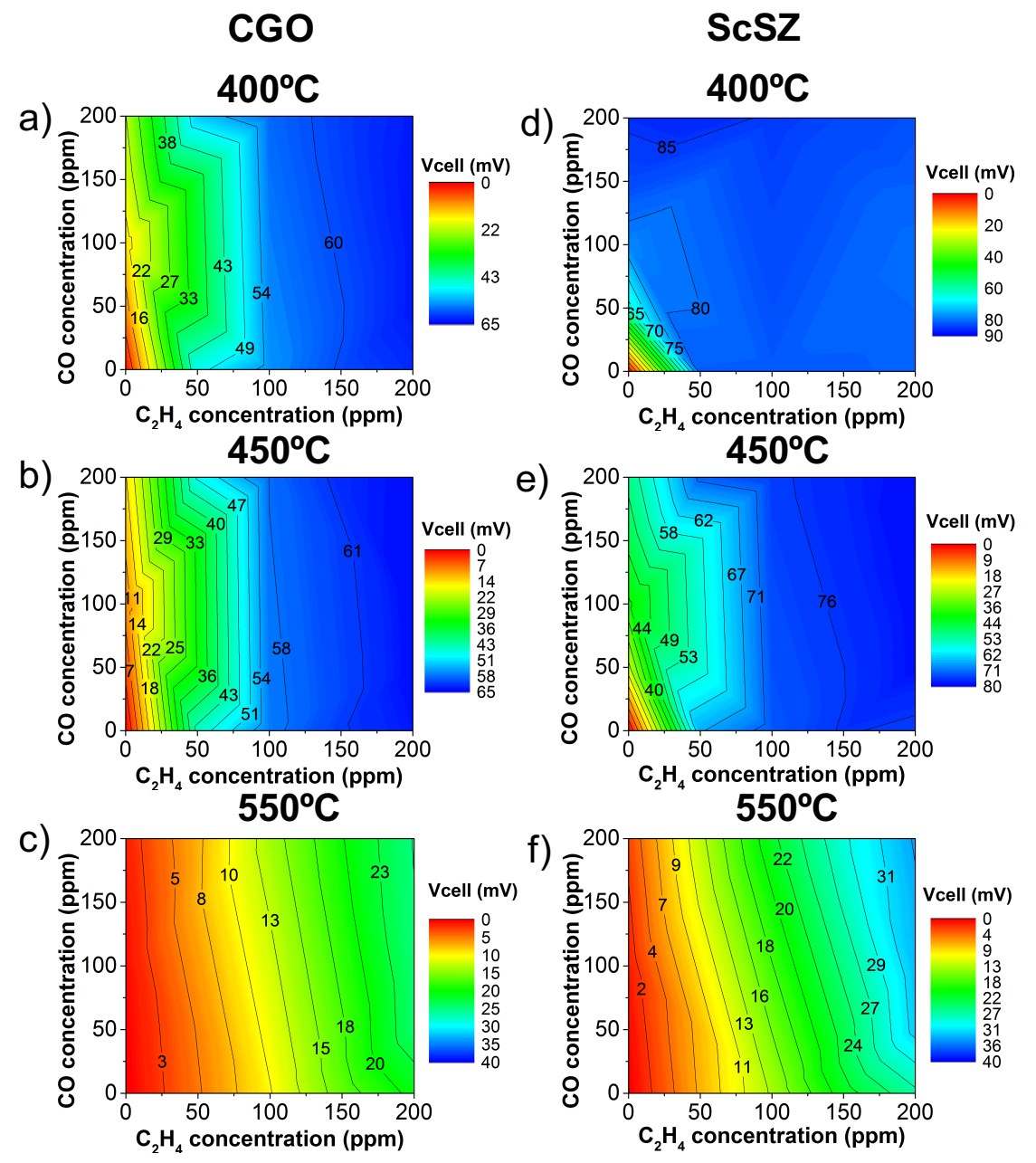

Figure 7.5 Study of temperature on the sensor response once the working electrode is infiltrated with nickel nanoparticles for CGO-based device at: a) $400^{\circ} \mathrm{C}$, b) $450^{\circ} \mathrm{C}$ and c) $550^{\circ} \mathrm{C}$ and ScSZ-based device at: d) $400^{\circ} \mathrm{C}$, e) $450^{\circ} \mathrm{C}$ and f) $550^{\circ} \mathrm{C}$

As in previous chapters, both CGO and ScSZ-based sensors are exposed to $3 \%$ of water (Figure 7.7a and Figure 7.7d respectively), $0.23 \mathrm{ppm}$ of phenanthrene (Figure $7.7 \mathrm{~b}$ and Figure $7.7 \mathrm{e}$ respectively) and $88 \mathrm{ppm}$ of methylnaphthalene (Figure $7.7 \mathrm{c}$ and Figure $7.7 \mathrm{f}$ respectively) at $550^{\circ} \mathrm{C}$ after nickel infiltration of the working electrode. Once again, the sensor performance for both alternatives are similar to the one reported for 8YSZ-based sensor in previous chapters. Both materials provide a selective response to ethylene with low cross-sensitivity 
toward carbon monoxide even when they are exposed to wet conditions and phenanthrene. Although, the signal value is lower than when $8 \mathrm{YSZ}$ is employed as electrolyte.

In the case of methylnaphthalene there is a distinct for each electrolyte material. For CGO, the addition of 88 ppm of methylnaphthalene leads to an increase of the cross-sensitivity toward carbon monoxide. This effect is analogous to the one observed for 8YSZ (figures 6.6c and 6.6d). Nevertheless, for ScSZ the sensor response also shows a decrease in its selectivity to ethylene becoming not appropriate to measure ethylene under these conditions. Thus, the sensor electrocatalytic activity should be adjusted to reduce the effect of polyaromatics within this range of concentration (80 ppm).

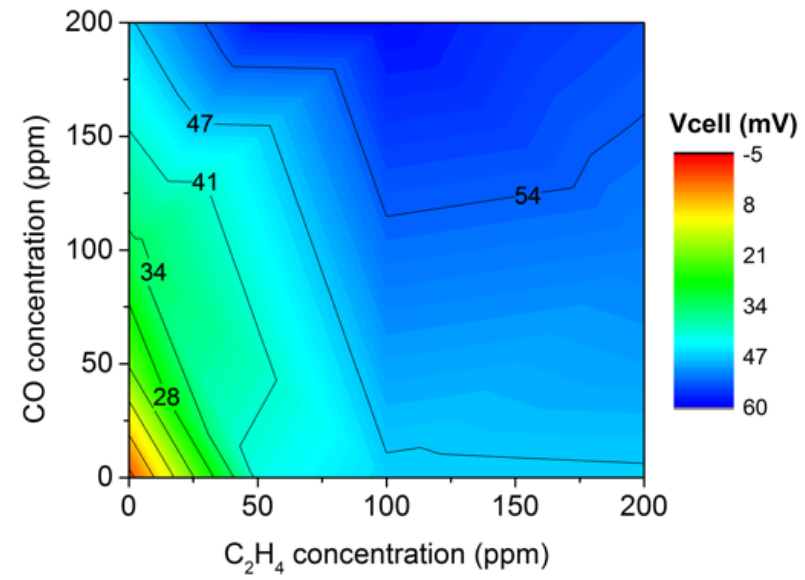

Figure 7.6 $V_{\text {cell }}$ sensor response as a function of the analyte concentration for a device consisting of $8 Y S Z$ as electrolyte at $450^{\circ} \mathrm{C}$ 
CGO

ScSZ

WATER

a)

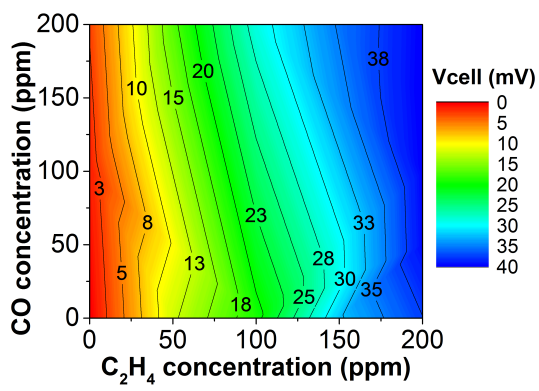

d)

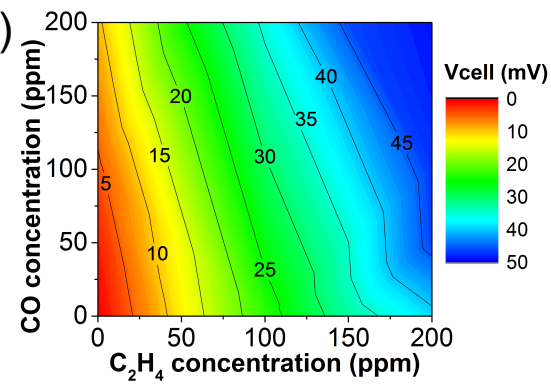

Phenanthrene

b)

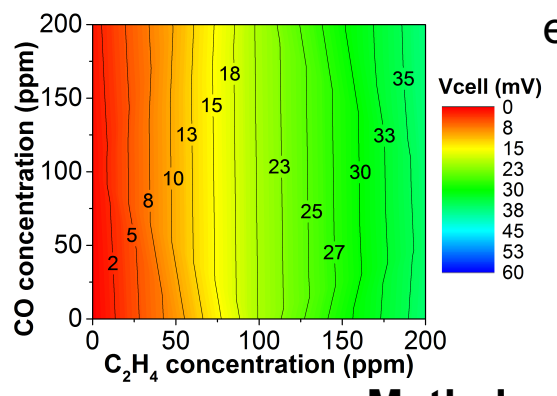

e)

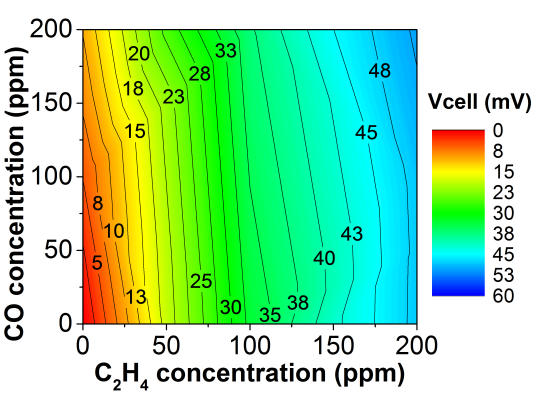

Methylnaphtalene

c)

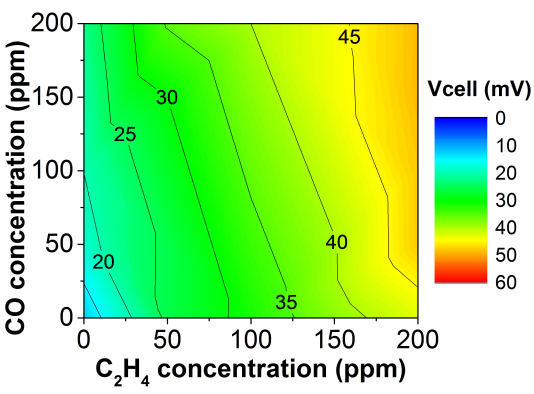

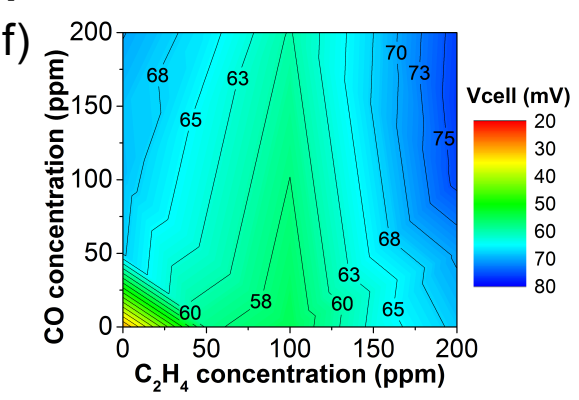

Figure 7.7 Sensor response as a function of analytes concentration after working electrode surface activation by infiltration of nickel nanoparticles for the addition of a) water, b) phenanthrene and c) methylnaphthalene in the of CGO-based device and d) water, e) phenanthrene and f) methylnaphthalene in the case of ScSZ-based device

\subsubsection{Electrochemical impedance Spectrometry}

An electrochemical impedance of the system is also performed to check the devices response at each temperature before and after nickel infiltration of the working electrode. The sensor response is evaluated in all cases for $200 \mathrm{ppm}$ of pure ethylene and carbon monoxide. 
Figure 7.8 and Figure 7.9 depict the Nyquist plot from $0.03 \mathrm{~Hz}$ to $1 \mathrm{MHz}$ for $\mathrm{CGO}$ and ScSZ-based devices at different temperatures for each analyte before and after the surface activation of the working electrode with nickel particles, respectively. Both Figure 7.8 and Figure 7.9 show that a reduction of the temperature leads to a massive increment of the contributions for both gases when compared to $550^{\circ} \mathrm{C}$. At 550 and $500^{\circ} \mathrm{C}$ the sensor response can be fitted to an equivalent electrical circuit consisting of two parallel combinations of resistance-constant phase element circuit connected in series. The first arch contribution $\left(C=10^{-5}-10^{-6} \mathrm{~F}\right)$ can be attributed to the interface electrolyte-electrode while the second arch contribution $\left(\mathrm{C}=10^{-2}-10^{-3} \mathrm{~F}\right)$ can be related to the processes taking place at the electrode. Moreover, the reduction of the temperature adds a third contribution $\left(C=10^{-7}-10^{-8} \mathrm{~F}\right)$ that can be due to an effect of the grain boundary.
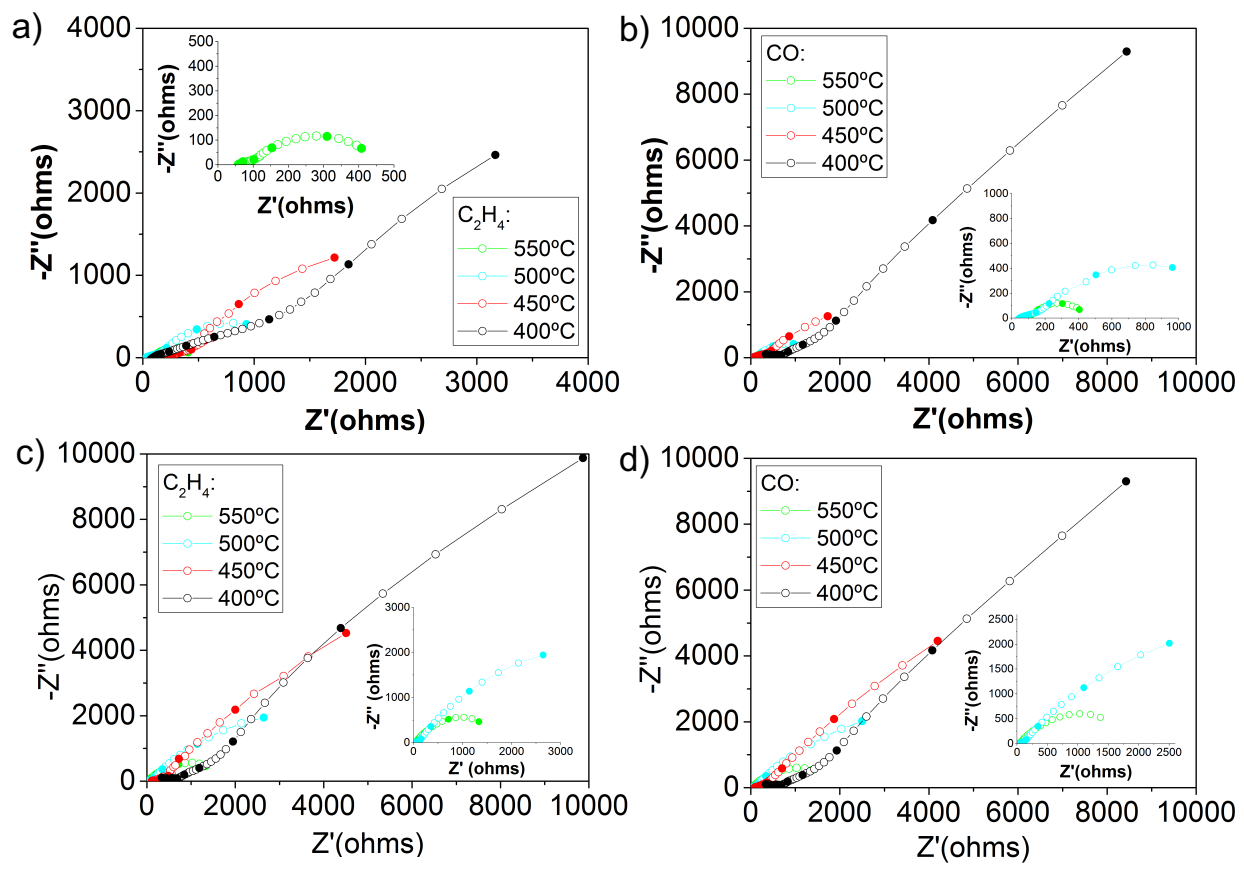

Figure 7.8 Impedance spectrometry study of the sensor performance at $550^{\circ} \mathrm{C}$ (green), $500^{\circ} \mathrm{C}$ (cyan), $450^{\circ} \mathrm{C}(\mathrm{red})$ and $400^{\circ} \mathrm{C}$ (black) of the bare sensor for CGO-based device to a) ethylene and b) carbon monoxide and for ScSZ-based device to c) ethylene and d) carbon monoxide. Inset there is depicted a wider figure of the Nyquist plot for $500^{\circ} \mathrm{C}$ and $550^{\circ} \mathrm{C}$ for each scenario 

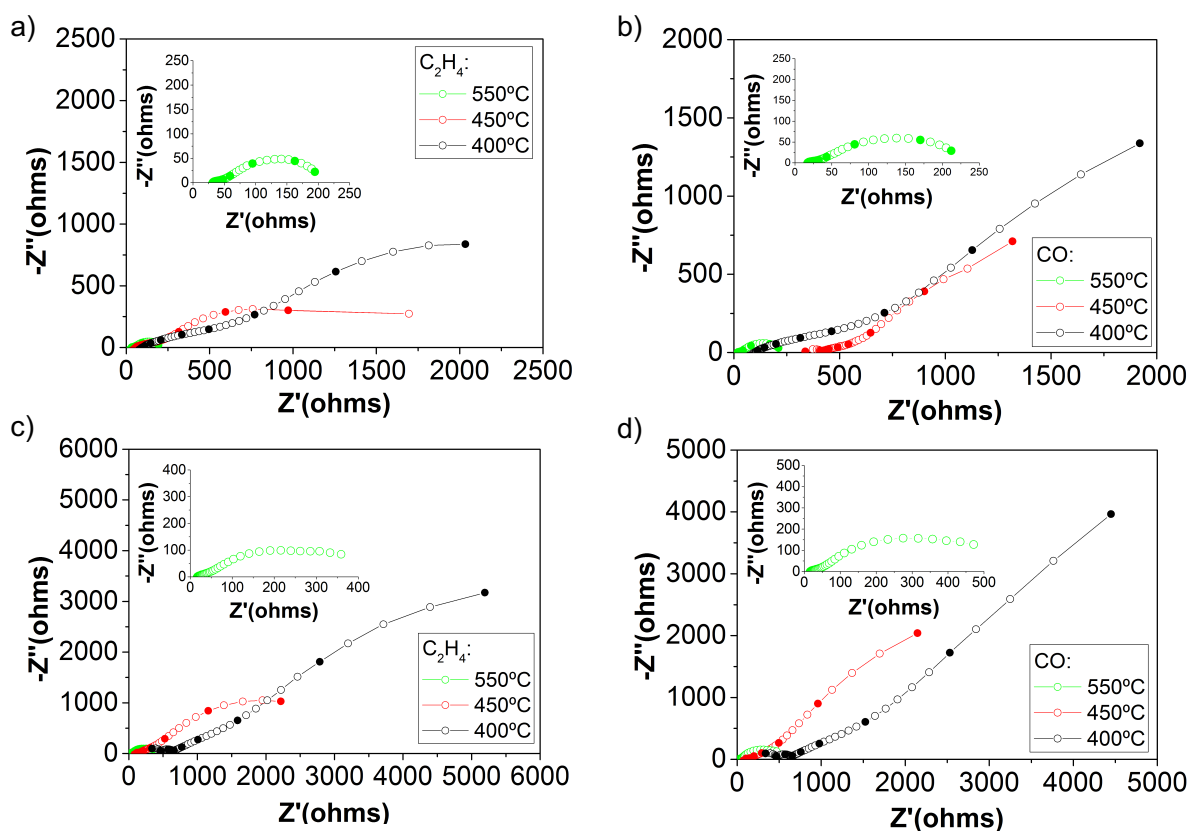

Figure 7.9 Impedance spectrometry study of the sensor performance at $550^{\circ} \mathrm{C}$ (green), $450^{\circ} \mathrm{C}$ (red) and $400^{\circ} \mathrm{C}$ (black) after infiltration of the working electrode with nickel nanoparticles for CGO-based device to a) ethylene and b) carbon monoxide and for ScSZ-based device to c) ethylene and d) carbon monoxide. Inset there is depicted a wider figure of the Nyquist plot for $550^{\circ} \mathrm{C}$ for each scenario

In the case of the bare sensor, the best results were obtained for ScSZ at lower temperatures (Figure 7.2). This can be explained because the polarization resistance for the bare ScSZ-based device to ethylene and carbon monoxide at $550^{\circ} \mathrm{C}$ and $500^{\circ} \mathrm{C}$ are quite similar, while the reduction of the temperature leads to an increase of the electrode resistance contribution (Figure 7.10c) for both analytes and therefore, to the polarization resistance (Figure 7.11b). The carbon monoxide contribution is larger than ethylene, and this could explain the best response to ethylene with relatively low cross-sensitivity toward carbon monoxide.

The results observed in Figure 7.9 for the device infiltrated with nickel is in agreement with the potentiometric results obtained (Figure 7.5), the best response was achieved for $550^{\circ} \mathrm{C}$ while the reduction of temperature leads to a saturation of the sensor response for ethylene concentration above $100 \mathrm{ppm}$. A decrease of the temperature leads to an increase of the resistance associated with the electrode for both devices and for both analytes (Figure 7.10a and Figure 7.10c), and therefore, of the polarization resistance (Figure 7.11). 
Moreover, it can be noticed that the infiltration of the working electrode with nickel has a huge effect on both electrode resistance and polarization resistance. This indicates that the catalytic reaction at the electrode is being favoured and confirms the enhancement of the response to ethylene. The electrode resistance contribution for ethylene is lower than to carbon monoxide in each case. This along with the reduced resistance observed at $550^{\circ} \mathrm{C}$ can explain the selective response to ethylene with low cross-sensitivity toward carbon monoxide. Although there is a difference in the resistance for lower temperatures, the contributions are really high when compared to $550^{\circ} \mathrm{C}$. This can be related with the saturation of the sensor as there is a massive increment of the gases contribution and therefore of the polarization resistance. This can confirm that the reaction kinetics is controlling the device, as increasing the temperature can make easier to overcome the kinetic and improving the sensor performance [22].
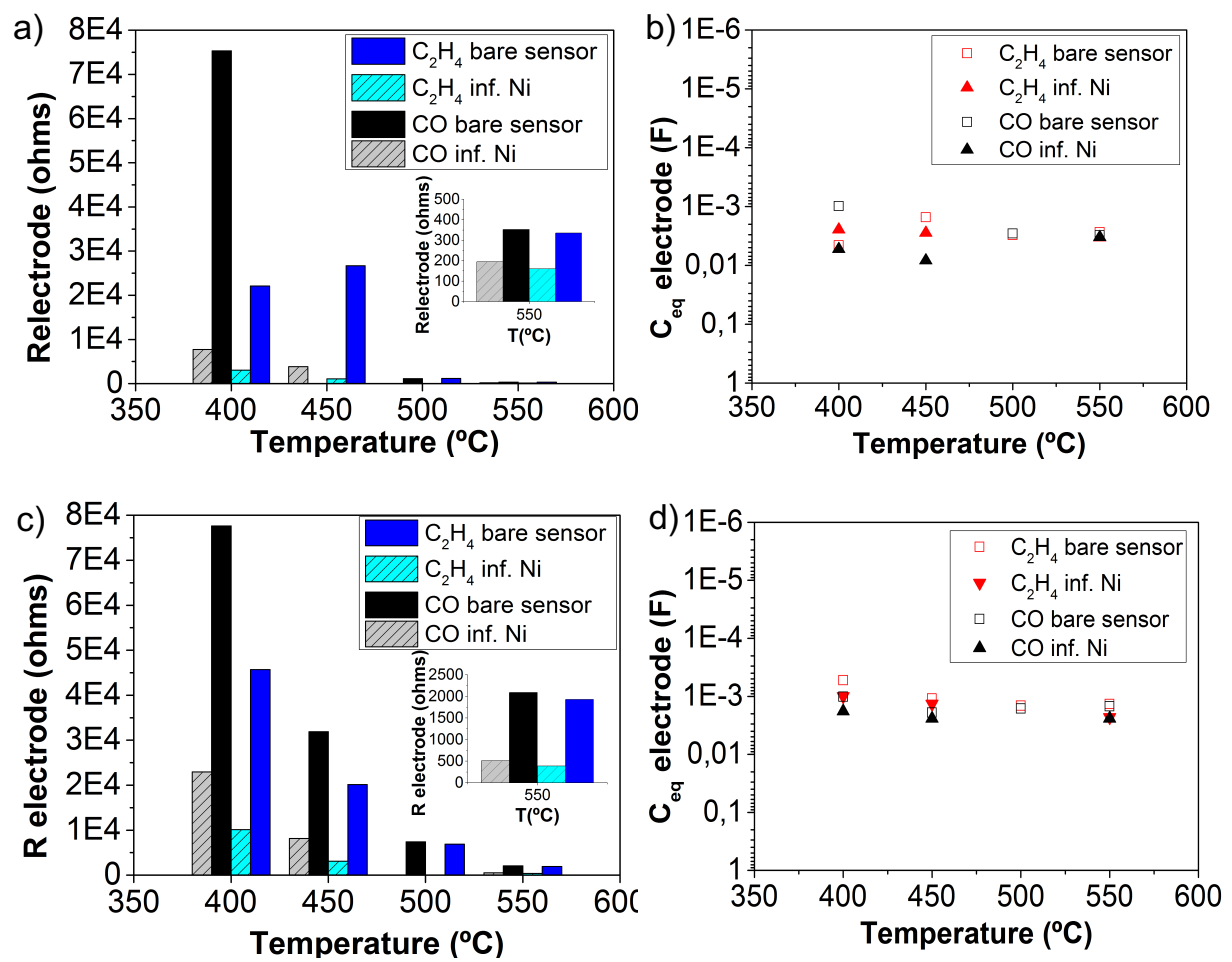

Figure 7.10 Results of the equivalent electrical circuit fitting for the CGO-based device: a) resistance of the contribution associated with the electrode and b) capacitance of the contribution associated with the electrode and ScSZ-based device: c) resistance of the contribution associated with the electrode and d) capacitance of the contribution related with the electrode 

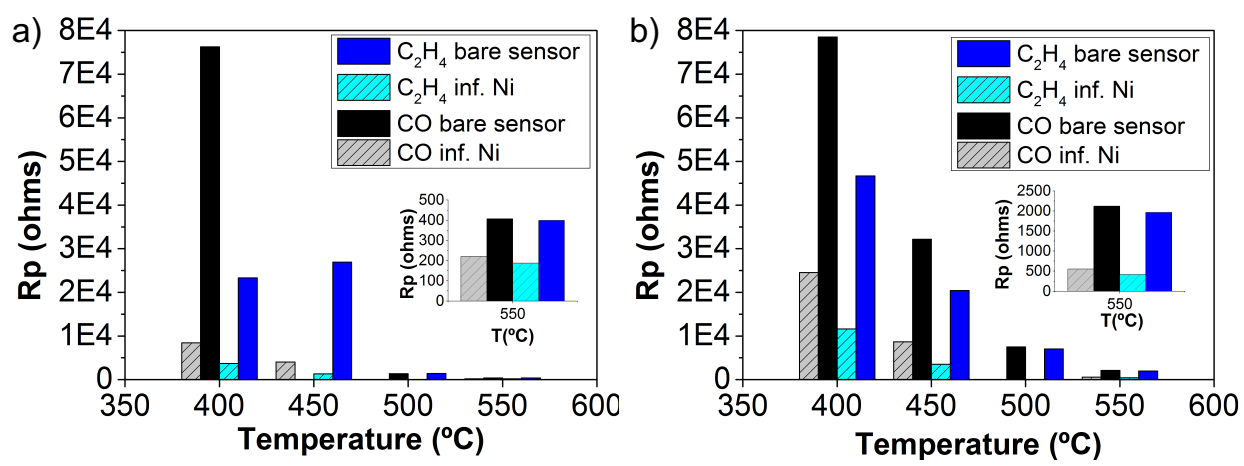

Figure 7.11 Polarization resistance obtained by the equivalent electrical circuit fitting of a) CGO-based device and b) ScSZ-based device

Finally, Figure 7.12 and Figure 7.13 show the Nyquist plots when the sensor with the working electrode infiltrated with nickel is exposed to ethylene and carbon monoxide at $550^{\circ} \mathrm{C}$ with a background of water, phenanthrene and methylnaphthalene for the CGO and ScSZ-based devices, respectively. In both cases, the effect of water has a minor impact on the response when compared to the polyaromatics. For CGO, there is an increment of the ethylene contribution while there is a reduction of the carbon monoxide contribution. On the other hand, for ScSZ both analytes contributions are reduced in the presence of water and the difference between them is lesser. The addition of phenanthrene has practically no effect on the ethylene contributions for both devices but the carbon monoxide contribution is enlarged. At last, the addition of methylnaphthalene has an impact of both analytes contributions as both of them increase notably. This can explain why the addition of water and phenanthrene has no effect on the selectivity to ethylene and cross-sensitivity toward carbon monoxide while the addition of methylnaphthalene declines the sensor performance. 

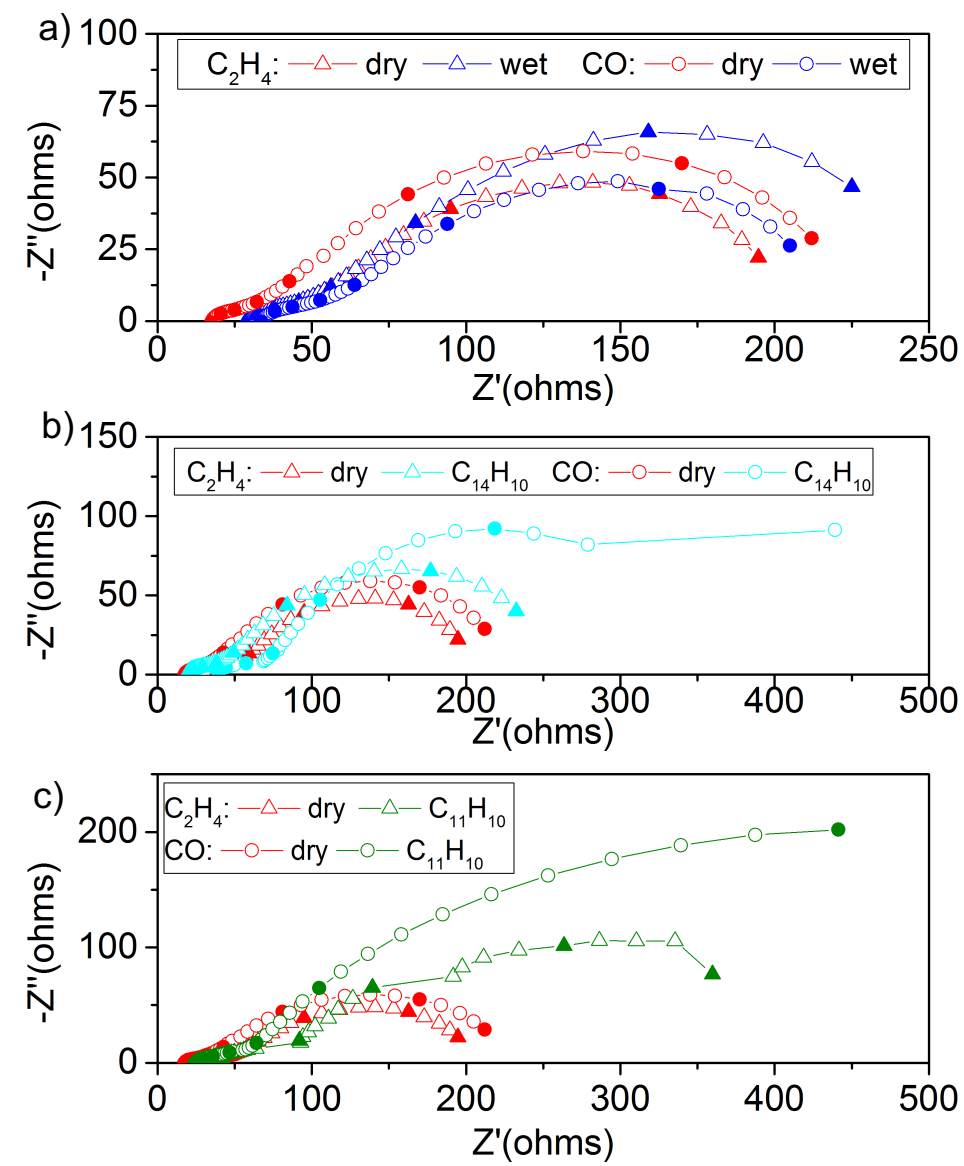

Figure 7.12 Nyquist plot of the CGO-based device after infiltration of the working electrode with nickel nanoparticles when exposed to a) water, b) phenanthrene and c) methylnaphthalene. In every case the response in dry conditions is depicted for comparison. 

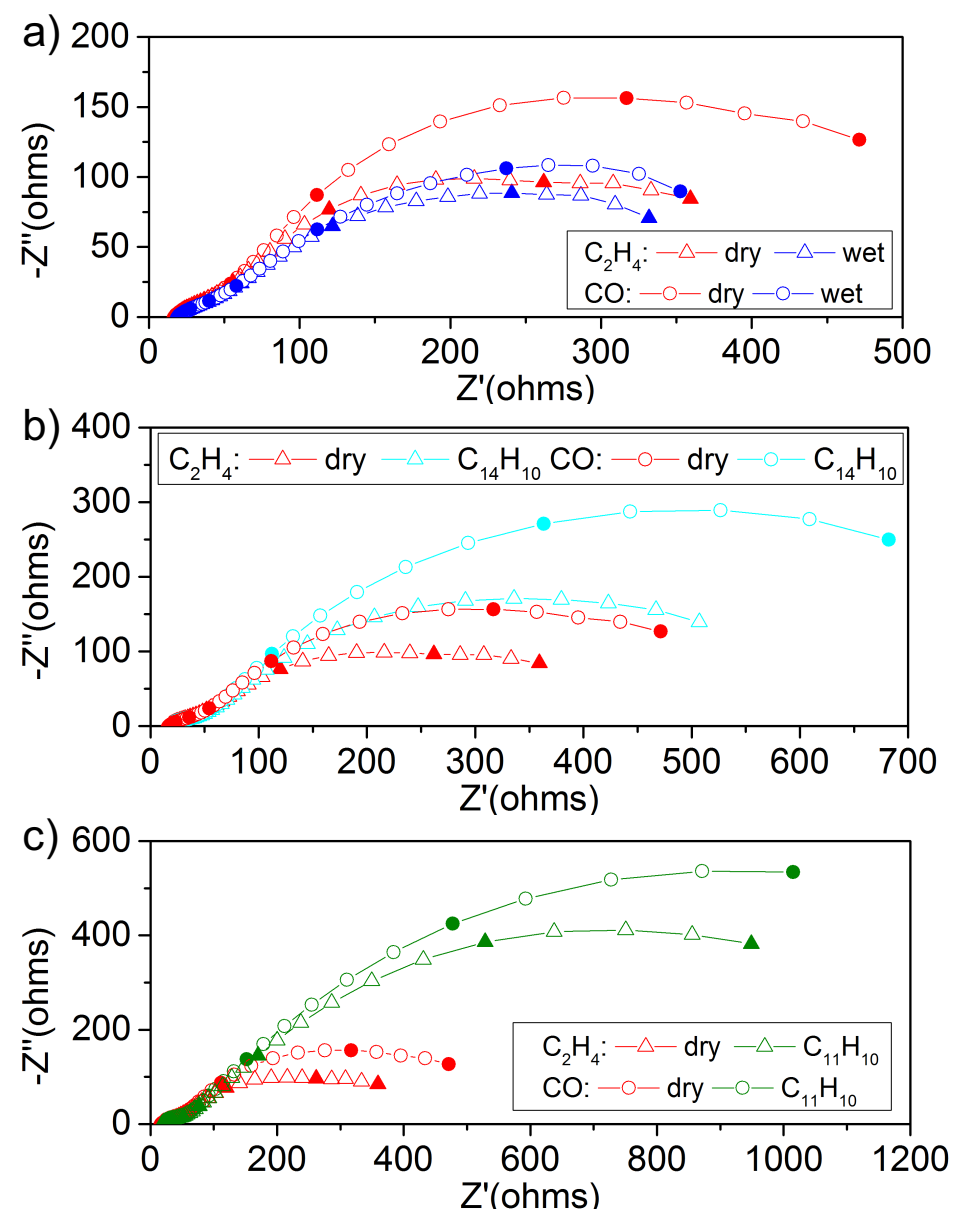

Figure 7.13 Nyquist plot of the ScSZ-based device after infiltration of the working electrode with nickel nanoparticles when exposed to a) water, b) phenanthrene and c) methylnaphthalene. In every case the response in dry conditions is depicted for comparison.

\subsection{Structural characterization}

Figure 7.14 shows a FESEM analysis of the device cross-section for both alternatives. Figure 7.14a and Figure 7.14b depicts the fracture cross-section of the working electrode revealing a good distribution of both $\mathrm{Fe}_{0.7} \mathrm{Cr}_{1.3} \mathrm{O}_{3}$ and $8 \mathrm{YSZ}$ grains, although, as seen in previous chapters, there is a difference in the grain size as $\mathrm{Fe}_{0.7} \mathrm{Cr}_{1.3} \mathrm{O}_{3}$ are bigger than $8 \mathrm{YSZ}$ grains. Nickel nanoparticles attached into the grains can be observed in Figure $7.14 \mathrm{~b}$, they are well dispersed throughout the electrode in both grains. On the other hand, Figure $7.14 \mathrm{c}$ and Figure $7.14 \mathrm{f}$ show the fracture cross-section of the reference electrode where a good distribution of both grains and an homogeneity of the grain size can be 
observed. Moreover, there is no presence of nickel nanoparticles among the reference electrode. Microstructure described is akin for both devices as working and reference electrodes are common, the thickness of the electrodes is $25 \mu \mathrm{m}$ approximately. Finally, Figure $7.14 \mathrm{~d}$ and Figure $7.14 \mathrm{e}$ depict the fracture crosssection of CGO and ScSZ electrolytes, respectively. These figures confirm that both electrolytes are fully dense.
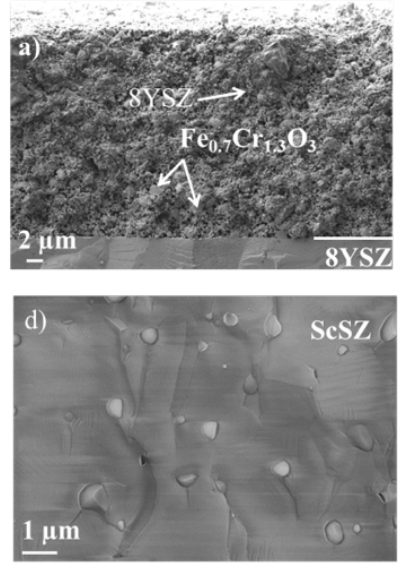
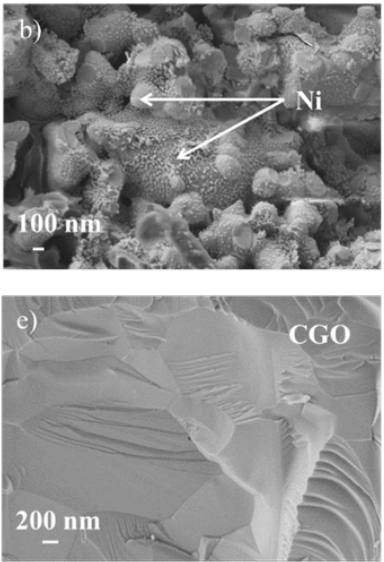
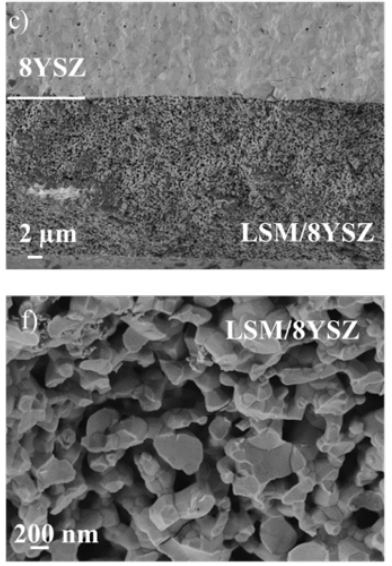

Figure 7.14 FESEM images of the device cross-section corresponding to $\mathrm{Fe}_{0.7} \mathrm{Cr}_{1.3} \mathrm{O}_{3} / 8 \mathrm{YSZ}$ as working electrode, LSM/8YSZ as reference electrode and ScSZ and CGO as alternatives to 8 YSZ as electrolyte. Working and reference electrode are common in both devices. a) WE electrode crosssection with $\mathrm{Fe}_{0.7} \mathrm{Cr}_{1.3} \mathrm{O}_{3}$ and $8 \mathrm{YSZ}$ grains. b) Detailed WE electrode cross-section where nickel nanoparticles can be appreciated. c) reference electrode cross-section with LSM and 8YSZ grains. d) Dense ScSZ electrolyte. e) Dense CGO electrolyte. f) Detailed RE electrode cross-section with LSM and $8 Y S Z$ grains and no presence of nickel nanoparticles

\subsection{Conclusions}

In this chapter, two alternatives to 8YSZ as electrolyte haven been studied: CGO and ScSZ. The aim is to check the influence of the temperature on the sensor response and consider the possibility to work at lower temperature with the two alternative electrolytes. Both of them are materials that can offer a higher ionic conductivity at lower temperatures than 8YSZ.

Sensors are exposed to a range of temperatures between 550 and $400^{\circ} \mathrm{C}$. The performance of the bare sensor shows that CGO is not suitable for ethylene detection at lower temperatures as the response is not selective and the crosssensitivity toward carbon monoxide is high. However, ScSZ proves to have a good response to ethylene with a relatively low cross-sensitivity toward carbon monoxide in dry conditions at lower temperatures. The addition of water changes the equilibrium achieved in both electrodes and modify the response to ethylene 
increasing the cross-sensitivity toward carbon monoxide. 8YSZ response at $450^{\circ} \mathrm{C}$ is also checked to ensure that the performance of a sensor employing $8 Y S Z$ is poorer at these conditions. Effectively, the sensor provides a higher cross-sensitivity toward carbon monoxide than ScSZ-based device.

After catalytic activation of the working electrode with nickel nanoparticles, both CGO and ScSZ-based devices provide a selective response to ethylene with low cross-sensitivity toward carbon monoxide within the studied range: $550-400^{\circ} \mathrm{C}$. The best response in terms of selectivity and cross-sensitivity is achieved at $400^{\circ} \mathrm{C}$ but the response time and stability are poorer. Thus, the best performance in terms of selectivity to ethylene, cross-sensitivity toward carbon monoxide and stability is achieved at $450^{\circ} \mathrm{C}$ in dry conditions. However, the sensor response is saturated for concentrations of ethylene above $100 \mathrm{ppm}$ and the addition of water increases drastically the cross-sensitivity toward carbon monoxide. Thus, this makes the sensor based on CGO or ScSZ suitable for ethylene detection only in some conditions: applications that require low concentration levels of ethylene (below 100ppm) and in dry conditions.

The devices at $550^{\circ} \mathrm{C}$ show a similar performance than $8 \mathrm{YSZ}$ although the overall signal value is lesser. Both devices are exposed to water, phenanthrene and methylnaphthalene providing a good performance under wet conditions and when there is a background of $0.23 \mathrm{ppm}$ of phenanthrene. In these cases, the sensor response remains practically unaffected in terms of selectivity and crosssensitivity. Conversely, the addition of $88 \mathrm{ppm}$ of methylnaphthalene as background gas has a dramatic effect on the sensor response as it increases the cross-sensitivity toward carbon monoxide drastically.

The electrochemical impedance spectrometry for both devices shows that a reduction of the temperature produces a notable increase of the resistance associated with the processes taking place at the electrode and therefore, the polarization resistance. In addition, the infiltration with nickel of the working electrode reduces the polarization resistance remarkably. The best response is achieved after infiltration with nickel of the working electrode at $550^{\circ} \mathrm{C}$ with selectivity to ethylene and low cross-sensitivity toward carbon monoxide, water and phenanthrene. In addition, this technique shows how the addition of methylnaphthalene has an effect on the arch contribution related with the processes taking place at the electrode and therefore, it can explain the increase in cross-sensitivity that it provides toward carbon monoxide.

This can confirm that the reaction kinetics is controlling the device, as a higher temperature helps to overcome the kinetics and therefore improve the sensor 
performance. Then, ScSZ and CGO are two strong candidates to substitute 8YSZ as electrolyte for ethylene sensing purposes at $550^{\circ} \mathrm{C}$ or at low temperature in dry conditions for detection of low levels of ethylene.

\subsection{References}

[1] L. Chevallier, E. Di Bartolomeo, M.L. Grilli, E. Traversa, High temperature detection of $\mathrm{CO} / \mathrm{HCs}$ gases by non-Nernstian planar sensors using $\mathrm{Nb} 2 \mathrm{O} 5$ electrode, Sensors Actuators B. $130 \quad$ (2008) 514-519. doi:10.1016/j.snb.2007.09.056.

[2] P. Schmidt-Zhang, U. Guth, A planar thick film sensor for hydrocarbon monitoring in exhaust gases, Sensors Actuators B Chem. 99 (2004) 258-263. doi:10.1016/j.snb.2003.11.018.

[3] N. Miura, T. Sato, S.A. Anggraini, H. Ikeda, S. Zhuiykov, A review of mixed-potential type zirconia-based gas sensors, lonics (Kiel). 20 (2014) 901925. doi:10.1007/s11581-014-1140-1.

[4] M. Yamaguchi, S.A. Anggraini, Y. Fujio, T. Sato, M. Breedon, N. Miura, Stabilized zirconia-based sensor utilizing SnO2-based sensing electrode with an integrated $\mathrm{Cr} 2 \mathrm{O} 3$ catalyst layer for sensitive and selective detection of hydrogen, Int. J. Hydrogen Energy. 38 (2013) 305-312. doi:10.1016/j.jhydene.2012.10.049.

[5] Y. Fujio, T. Sato, N. Miura, Sensing performance of zirconia-based gas sensor using titania sensing-electrode added with palladium, Solid State Ionics. 262 (2014) 266-269. doi:10.1016/j.ssi.2013.08.028.

[6] M. Mori, Y. Sadaoka, S. Nakagawa, M. Kida, T. Kojima, Development of ethanol and toluene sensing devices with a planar-type structure based on YSZ and modified Pt electrodes, Sensors Actuators B Chem. 187 (2013) 509-513. doi:10.1016/j.snb.2013.03.005.

[7] N. Miura, T. Shiraishi, K. Shimanoe, N. Yamazoe, Mixed-potential-type propylene sensor based on stabilized zirconia and oxide electrode, Electrochem. Commun. 2 (2000) 77-80. www.elsevier.nl/locate/elecom (accessed November 22, 2017).

[8] A. lio, H. Ikeda, S.A. Anggraini, N. Miura, Potentiometric YSZ-based oxygen sensor using $\mathrm{BaFeO} 3$ sensing-electrode, Electrochem. Commun. 48 (2014) 134-137. doi:10.1016/j.elecom.2014.09.004.

[9] T. Van Gestel, D. Sebold, H.P. Buchkremer, Processing of 8YSZ and CGO thin film electrolyte layers for intermediate- and low-temperature SOFCs, J.
Eur.
Ceram.
Soc.
35
(2015)
1505-1515.

doi:10.1016/J.JEURCERAMSOC.2014.11.017. 
[10] J.W. Fergus, Solid electrolyte based sensors for the measurement of $\mathrm{CO}$ and hydrocarbon gases, Sensors Actuators B Chem. 122 (2007) 683-693. doi:10.1016/j.snb.2006.06.024.

[11] A. Spirin, V. Ivanov, A. Nikonov, A. Lipilin, S. Paranin, V. Khrustov, A. Spirina, Scandia-stabilized zirconia doped with yttria: Synthesis, properties, and ageing behavior, Solid State lonics. 225 (2012) 448-452. doi:10.1016/J.SSI.2012.02.022.

[12] R.O. Fuentes, R.T. Baker, Synthesis and properties of Gadolinium-doped ceria solid solutions for IT-SOFC electrolytes, Int. J. Hydrogen Energy. 33 (2008) 3480-3484. doi:10.1016/J.IJHYDENE.2007.10.026.

[13] B. Singh, S. Ghosh, S. Aich, B. Roy, Low temperature solid oxide electrolytes (LT-SOE): A review, J. Power Sources. 339 (2017) 103-135. doi:10.1016/j.jpowsour.2016.11.019.

[14] R. Küngas, J.M. Vohs, R.J. Gorte, Effect of the lonic Conductivity of the Electrolyte in Composite SOFC Cathodes, J. Electrochem. Soc. 158 (2011) 743748. http://repository.upenn.edu/cbe_papers (accessed March 26, 2018).

[15] V. Vijaya Lakshmi, R. Bauri, A.S. Gandhi, S. Paul, Synthesis and characterization of nanocrystalline ScSZ electrolyte for SOFCs, Int. J. Hydrogen Energy. 36 (2011) 14936-14942. doi:10.1016/j.jhydene.2011.02.139.

[16] P.M. Abdala, G.S. Custo, D.G. Lamas, Enhanced ionic transport in finegrained scandia-stabilized zirconia ceramics, J. Power Sources. 195 (2010) 3402-3406. doi:10.1016/j.jpowsour.2009.12.035.

[17] J. Huang, F. Xie, C. Wang, Z. Mao, Development of solid oxide fuel cell materials for intermediate-to-low temperature operation, Int. J. Hydrogen Energy. 37 (2012) 877-883. doi:10.1016/j.ijhydene.2011.04.030.

[18] H.A. Abbas, C. Argirusis, M. Kilo, H.-D. Wiemhöfer, F.F. Hammad, Z.M. Hanafi, Preparation and conductivity of ternary scandia-stabilised zirconia, Solid State lonics. 184 (2011) 6-9. doi:10.1016/j.ssi.2010.10.012.

[19] G.Y. Cho, Y.H. Lee, S.W. Hong, J. Bae, J. An, Y.B. Kim, S.W. Cha, Highperformance thin film solid oxide fuel cells with scandia-stabilized zirconia (ScSZ) thin film electrolyte, Int. J. Hydrogen Energy. 40 (2015) 15704-15708. doi:10.1016/j.jhydene.2015.09.124.

[20] Y. Ji, J.. Kilner, M.. Carolan, Electrical conductivity and oxygen transfer in gadolinia-doped ceria (CGO)-Co3O4- $\delta$ composites, J. Eur. Ceram. Soc. 24 (2004) 3613-3616. doi:10.1016/j.jeurceramsoc.2003.12.016.

[21] J.W. Fergus, Electrolytes for solid oxide fuel cells, J. Power Sources. 162 (2006) 30-40. doi:10.1016/J.JPOWSOUR.2006.06.062. 
[22] J.W. Fergus, Sensing mechanism of non-equilibrium solid-electrolytebased chemical sensors, J. Solid State Electrochem. 15 (2011) 971-984. doi:10.1007/s10008-010-1046-4.

[23] N. Sakai, K. Yamaji, T. Horita, Y.P. Xiong, H. Kishimoto, M.E. Brito, H. Yokokawa, Effect of water on electrochemical oxygen reduction at the interface between fluorite-type oxide-ion conductors and various types of electrodes, Solid State lonics. 174 (2004) 103-109. doi:10.1016/j.ssi.2004.07.027.

[24] X. Guo, E. Vasco, S. Mi, K. Szot, E. Wachsman, R. Waser, Ionic conduction in zirconia films of nanometer thickness, Acta Mater. 53 (2005) 51615166. doi:10.1016/J.ACTAMAT.2005.07.033.

[25] N. Ma, K. Suematsu, M. Yuasa, T. Kida, K. Shimanoe, Effect of Water Vapor on Pd-Loaded SnO 2 Nanoparticles Gas Sensor, (n.d.). doi:10.1021/am509082w. 
Chapter 8

\section{Optimization of the sensor performance and mechanism of action}





\section{Optimization of the sensor performance and mechanism of action}

\subsection{Introduction}

As described in previous chapters, the device configuration comprising $\mathrm{Ni}$ activated $\mathrm{Fe}_{0.7} \mathrm{Cr}_{1.3} \mathrm{O}_{3} / 8 \mathrm{YSZ}$ as working electrode and LSM/8YSZ as reference electrode enables to ensure a proper electrochemical equilibrium between working electrode (ethylene oxidation) and reference electrode (oxygen reduction). Up to this point, it is known that both electrodes have to meet the following criteria: one electrode has to be electrocatalytic active to ethylene oxidation but inert to oxygen while the other electrode must possess the reciprocal behaviour. When each electrode is ideally selective to the described electrode reaction, the maximum open circuit voltage (OCV) is achieved. As there are several reactions going on in each electrode there are several possible contributions as schematized in Figure 8.1. Thus, the selection of materials active to the desired analyte is critical. Two major causes that can alter the sensor performance are: 1) the target reaction cannot overwhelm the reaction taking place at the reference electrode, and 2) the target analyte reacts directly with oxygen in the gas-phase or in the electrode surface [1-3].

In this chapter, the sensing mechanism will be discussed and relate to the results obtained through the present thesis. As there are several reactions occurring at each electrode, the sensor performance will differ from the ideal Nernstian behaviour and it will follow a mixed potential or non-Nernstian behaviour [4-9]. The device is controlled by the kinetics and the voltage measured is the established between the reaction more favoured kinetically in each electrode.

The effect of the triple phase boundary is evaluated to check if the selective response to ethylene achieved for $\mathrm{Fe}_{0.7} \mathrm{Cr}_{1.3} \mathrm{O}_{3} / 8 \mathrm{YSZ}$ could be ascribed mostly to a larger TPB area or it is because of the material itself. Thus, a new mixture of electronic and ionic conductor materials will be used as working electrode. LSC is chosen because it was one of the materials that provided by itself one of the most stable responses in chapter 3 . Additionally, the working electrode is further infiltrated with nickel to improve the catalytic activity of the electrode.

The effect of nitrogen dioxide will be evaluated for both LSC/8YSZ and $\mathrm{Fe}_{0.7} \mathrm{Cr}_{1.3} \mathrm{O}_{3} / 8 \mathrm{YSZ}$ configurations. Nitrogen dioxide is one the main pollutants in an exhaust gas and it can provoke an interference in the sensor response [1013]. Sensors will be exposed to $200 \mathrm{ppm}$ of nitrogen dioxide as well as to 
196

Chapter 8

changes in ethylene concentration with a fixed background of $200 \mathrm{ppm}$ of nitrogen dioxide in dry and wet conditions.

Working electrode

Reference electrode

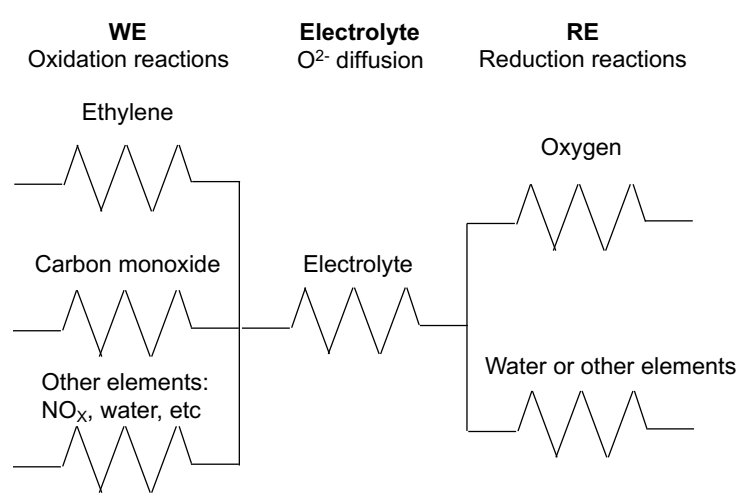

Figure 8.1 Scheme of the analyses contributions in each electrode 


\subsection{Mixed conductor electrode and $\mathrm{NO}_{2}$ effect $\mathrm{LSC} / 8 \mathrm{YSZ}$ as Working Electrode}

\subsubsection{LSC/8YSZ as working electrode}

LSC is mixed with $8 Y S Z$ (50\% vol.) and screen printed on disk shape $8 Y S Z$ electrolyte. while LSM/8YSZ is employed as reference electrode. Both electrode circular-shape with a diameter of $9 \mathrm{~mm}$. The response is checked for the bare sensor and after infiltration with $\mathrm{Ni}$ to increase the catalytic activity of the working electrode.

\subsubsection{Structural characterization}

Stability of LSC/8YSZ is checked by means of XRD analysis of the mixed LSC/8YSZ powder at $1150^{\circ} \mathrm{C}$. Figure 8.2 shows there is no reactivity between them at the sintering temperature.

Figure 8.3 shows the LSC/8YSZ//8YSZ//LSM/8YSZ device cross-section of both electrodes after measurement. Figure 8.3 a shows an homogeneous distribution of both LSC and 8YSZ grains along the working electrode, a similar grain size and a layer thickness of about $12 \mu \mathrm{m}$. A detailed view of the working electrode cross-section reveals that nickel nanoparticles are well dispersed into the electrode (Figure 8.3b). LSM and 8YSZ reference electrode has a layer thickness of about $17 \mu \mathrm{m}$ and both grains are also well distributed as can be observed in Figure $8.3 \mathrm{c}$ and Figure 8.3d.

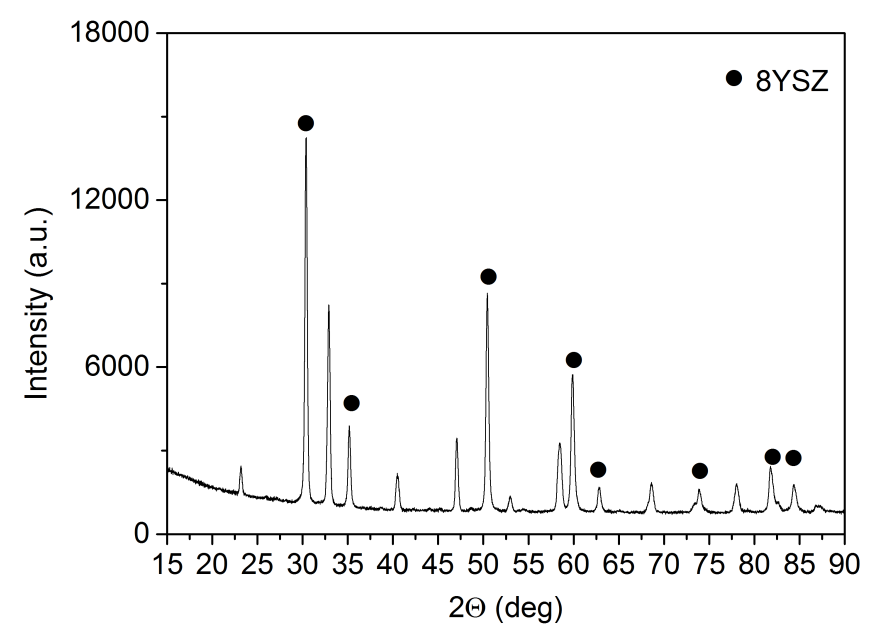

Figure 8.2 XRD analysis of LSC/8YSZ mixture at $1150^{\circ} \mathrm{C}$. Black dot indicates $8 Y S Z$ phase 

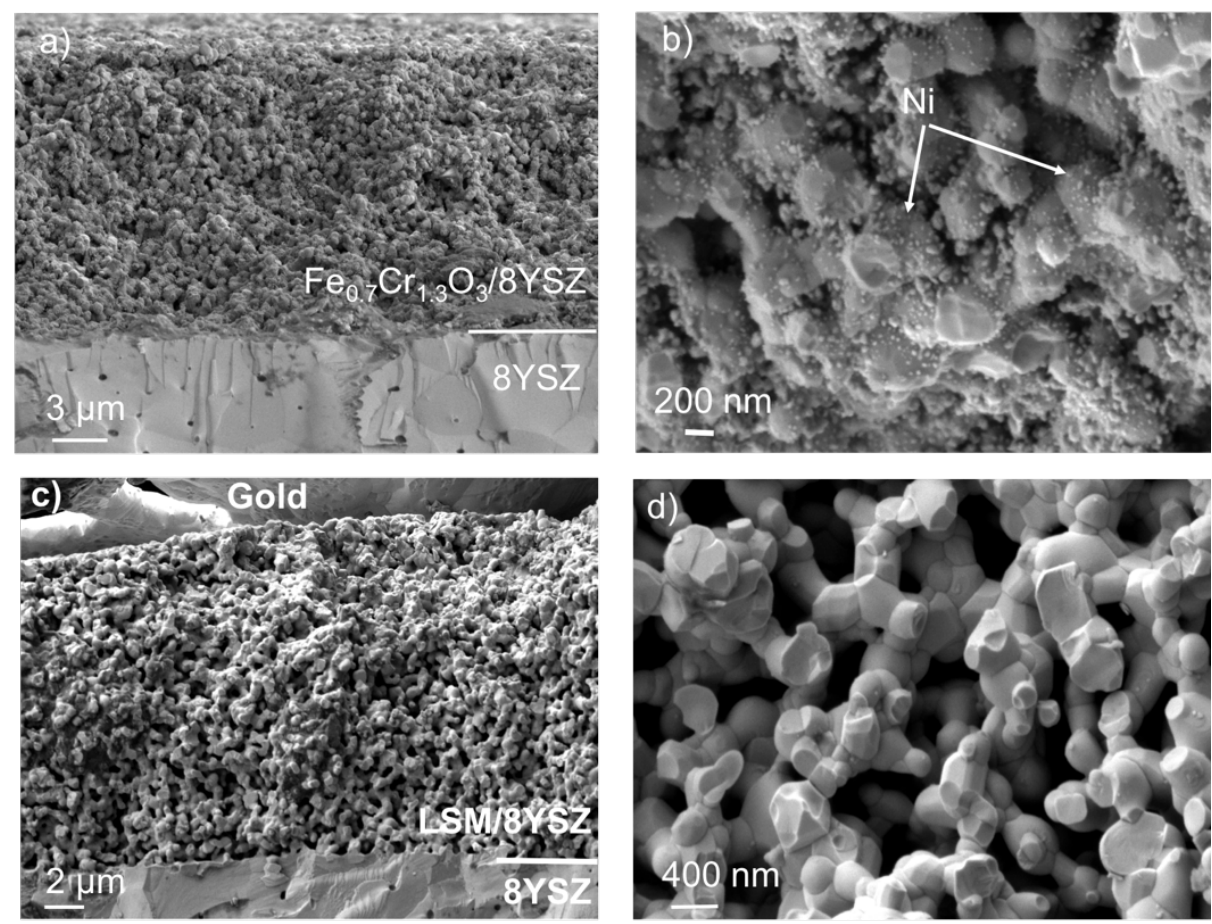

Figure 8.3 FESEM analysis of the LSC/8YSZ//8YSZ//LSM/8YSZ device cross-section after measurement. a) working electrode (LSC/8YSZ) cross-section, b) detailed view of the working electrode with nickel nanoparticles, c) reference electrode (LSM/8YSZ) cross-section and d) detailed view of the reference electrode

\subsubsection{Electrochemical characterization}

Bare sensor was exposed to changes in concentration of ethylene and carbon monoxide from 50 to $200 \mathrm{ppm}$ at $550^{\circ} \mathrm{C}$ to check the individual response. Figure $8.4 \mathrm{a}$ and $\mathrm{b}$ shows the transient response to ethylene and carbon monoxide, in both cases the response is stable and reproducible as the same response is achieved for each concentration. The voltage obtained for both analytes is similar. This can be also observed when the sensor is exposed to each analyte with a background of $200 \mathrm{ppm}$ of the other analyte (Figure 8.4c and 8.4d). The sensor response is similar for both analytes and, therefore, it is not selective to ethylene and has a high cross-sensitivity toward carbon monoxide as it happened for the bare sensor with the configuration $\mathrm{Fe}_{0.7} \mathrm{Cr}_{1.3} \mathrm{O}_{3} / 8 \mathrm{YSZ} / / 8 \mathrm{YSZ} / / \mathrm{LSM} / 8 \mathrm{YSZ}$. The sensor performance is similar to the response observed in chapter 3 when only LSC was used as working electrode. Therefore, in this configuration the addition of an ionic conductor enlarging the TPB does not influence the sensor response. Probably, this is due to the fact that LSC has a certain ionic conductivity itself and this can help to enlarge the active area when employed alone. However, the 
mixture of LSC with 8YSZ can provide a better attachment with the electrolyte and better long-term stability [14].

As in previous chapters, the working electrode is infiltrated with $\mathrm{Ni}$ to increase the catalytic activity to ethylene. After infiltration, the sensor is exposed to changes in concentration from 50 to 200 ppm of both pure ethylene and carbon monoxide as well as ethylene with 200 ppm of carbon monoxide (Figure $8.5 \mathrm{a}, 8.5 \mathrm{~b}$, and $8.5 \mathrm{c}$, respectively). Once infiltrated, exposure to ethylene provides a higher output response in terms of absolute response and sensitivity while response to carbon monoxide is lower in both terms. Thus, infiltration with nickel leads to a selective sensor to ethylene with low cross-sensitivity toward carbon monoxide in dry conditions as in the case of $\mathrm{Fe}_{0.7} \mathrm{Cr}_{1.3} \mathrm{O}_{3} / 8 \mathrm{YSZ}$ as working electrode.
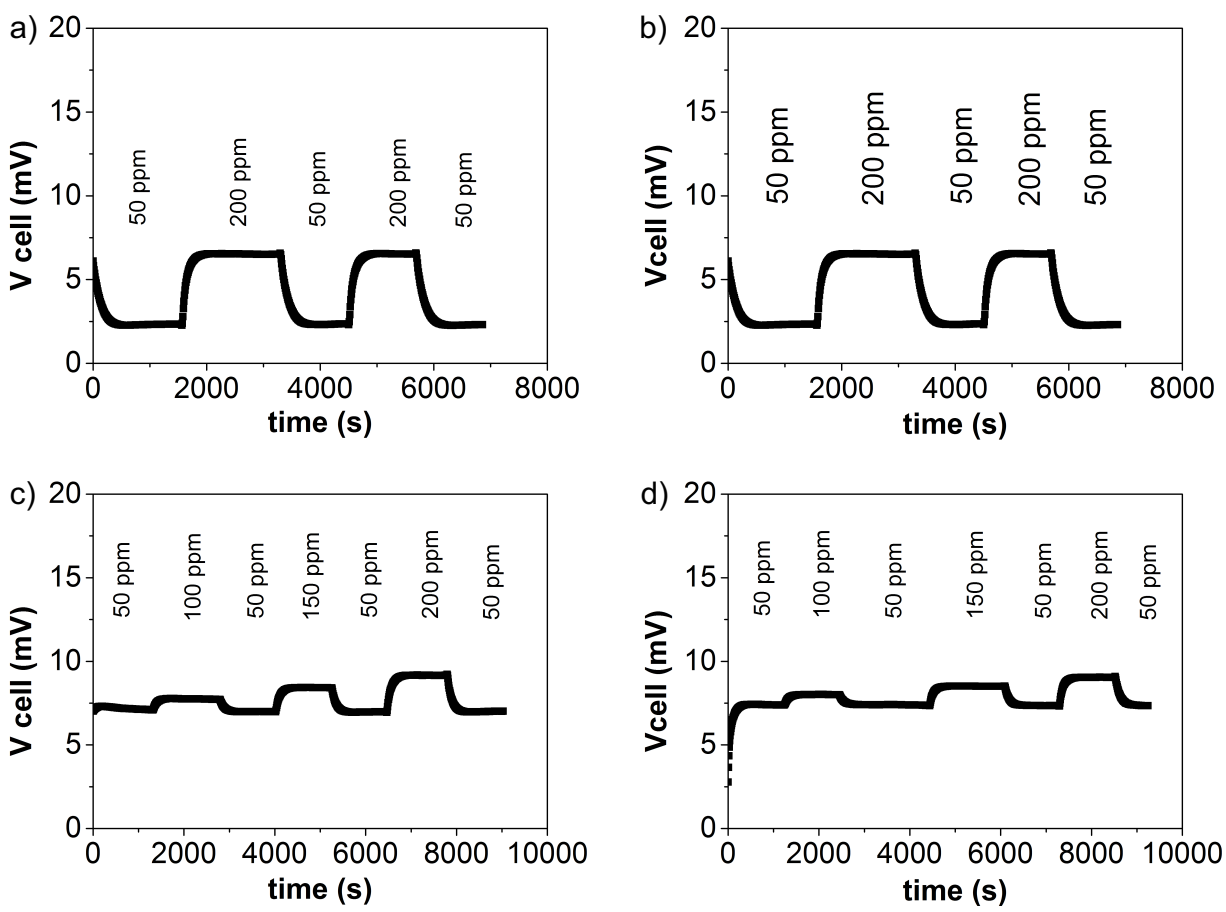

Figure 8.4 Transient response of the device when exposed to changes in concentration of: a) pure ethylene, b) pure carbon monoxide, c) ethylene with 200 ppm of carbon monoxide as background and d) carbon monoxide with 200 ppm of ethylene as background. The device consists of LSC/8YSZ//8YSZ//LSM/8YSZ 

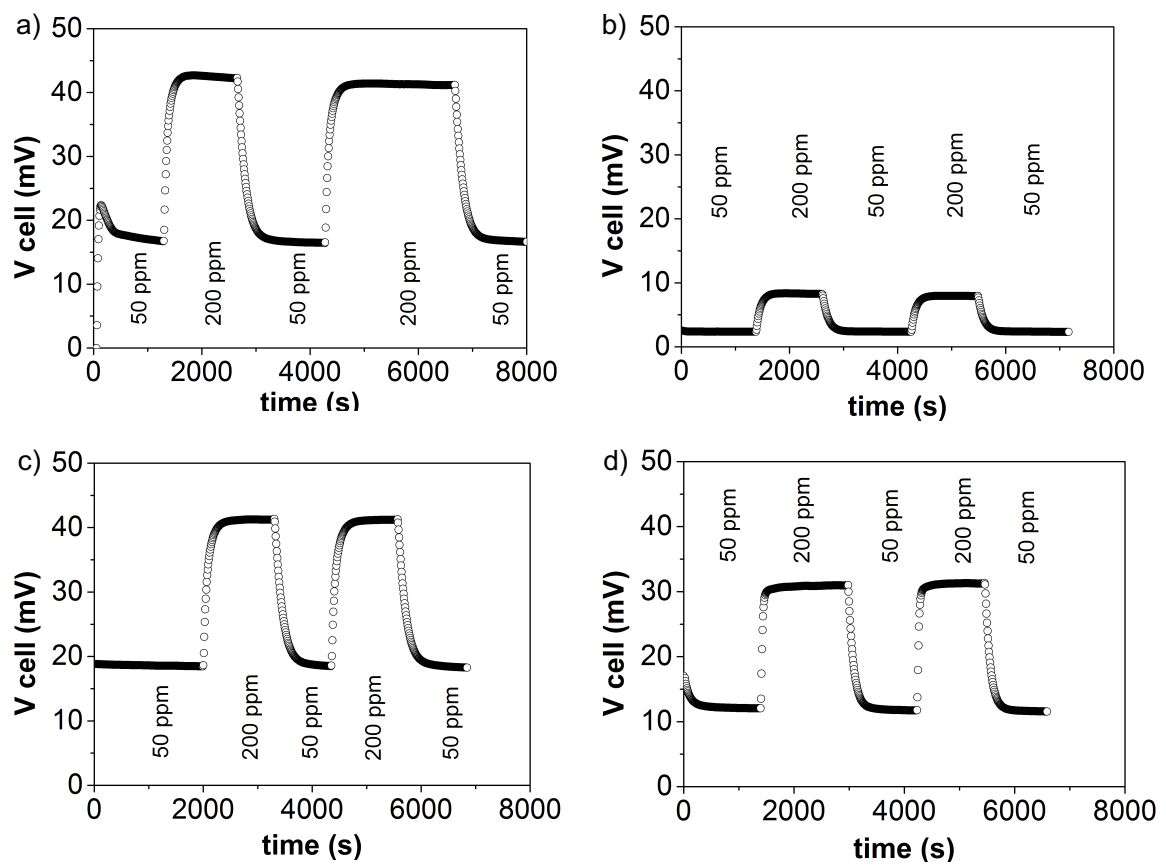

Figure 8.5 Transient response in dry conditions of the device consisting of LSC/8YSZ//8YSZ//LSM/8YSZ after infiltration of the working electrode with nickel. Response to changes in concentration of: a) ethylene, b) carbon monoxide, c) ethylene with 200 ppm of carbon monoxide as background and d) ethylene with 200 ppm of nitrogen dioxide as background

\section{Nitrogen dioxide effect}

Figure $8.5 \mathrm{~d}$ shows the response to ethylene concentration with $200 \mathrm{ppm}$ of nitrogen dioxide as a background. Although the addition of nitrogen dioxide affects the response in terms of absolute voltage, the response is still selective to ethylene with a low cross-sensitivity toward nitrogen dioxide. In all cases, the sensor response is stable and reproducible, the voltage remains constant for each concentration even with the addition of backgrounds.

The sensor is also exposed to changes of concentration of nitrogen dioxide from 50 to $200 \mathrm{ppm}$ in order to study the influence of this analyte. Figure 8.6 shows that the change in response is negative. This indicates that the reaction is working upside down: nitrogen dioxide is being reduced at the reference electrode (eq. 8.1) and the nitrogen monoxide produced could be oxidized in the working electrode (eq. 8.2). This can explain the effect on the absolute response in Figure $8.5 \mathrm{~d}$, as there could be a competitive reduction reaction between 
oxygen and nitrogen dioxide in the reference electrode and this implies a new equilibrium must be achieved.

$$
\begin{aligned}
& 2 \mathrm{NO}_{2}+4 e^{-} \rightarrow 2 \mathrm{NO}+2 \mathrm{O}^{2-} \\
& 2 \mathrm{NO}+2 \mathrm{O}^{2-} \rightarrow 2 \mathrm{NO}_{2}+4 e^{-}
\end{aligned}
$$

The addition of water (3\%) has an effect on the total value of the voltage recorded but it does not alter the sensor in terms of selectivity to ethylene and crosssensitivity. The sensor response depends on ethylene concentration and the response is reproducible as can be observed in Figure 8.7. The effect of nitrogen dioxide is lesser than in dry conditions. One possible explanation could be an increase of the oxygen exchange reaction between 8YSZ and water that provide more oxygen ions to the electrolyte [15].

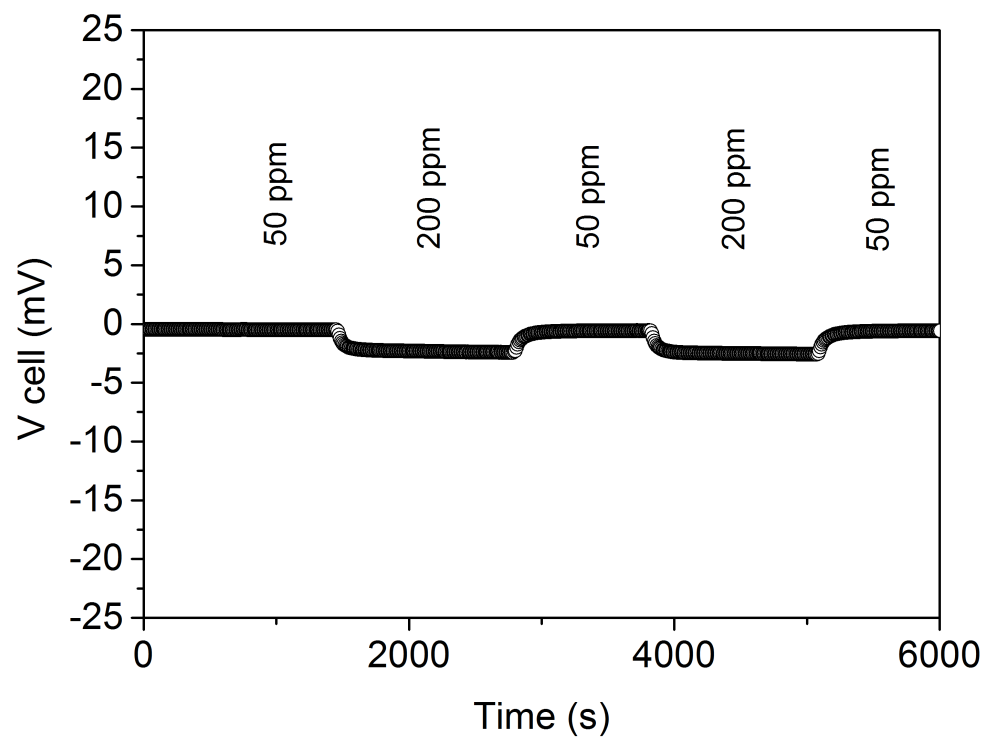

Figure 8.6 Transient response of LSC/8YSZ//8YSZ//LSM/8YSZ, after infiltration of the working electrode with nickel, when it is exposed to changes in concentration of nitrogen dioxide 

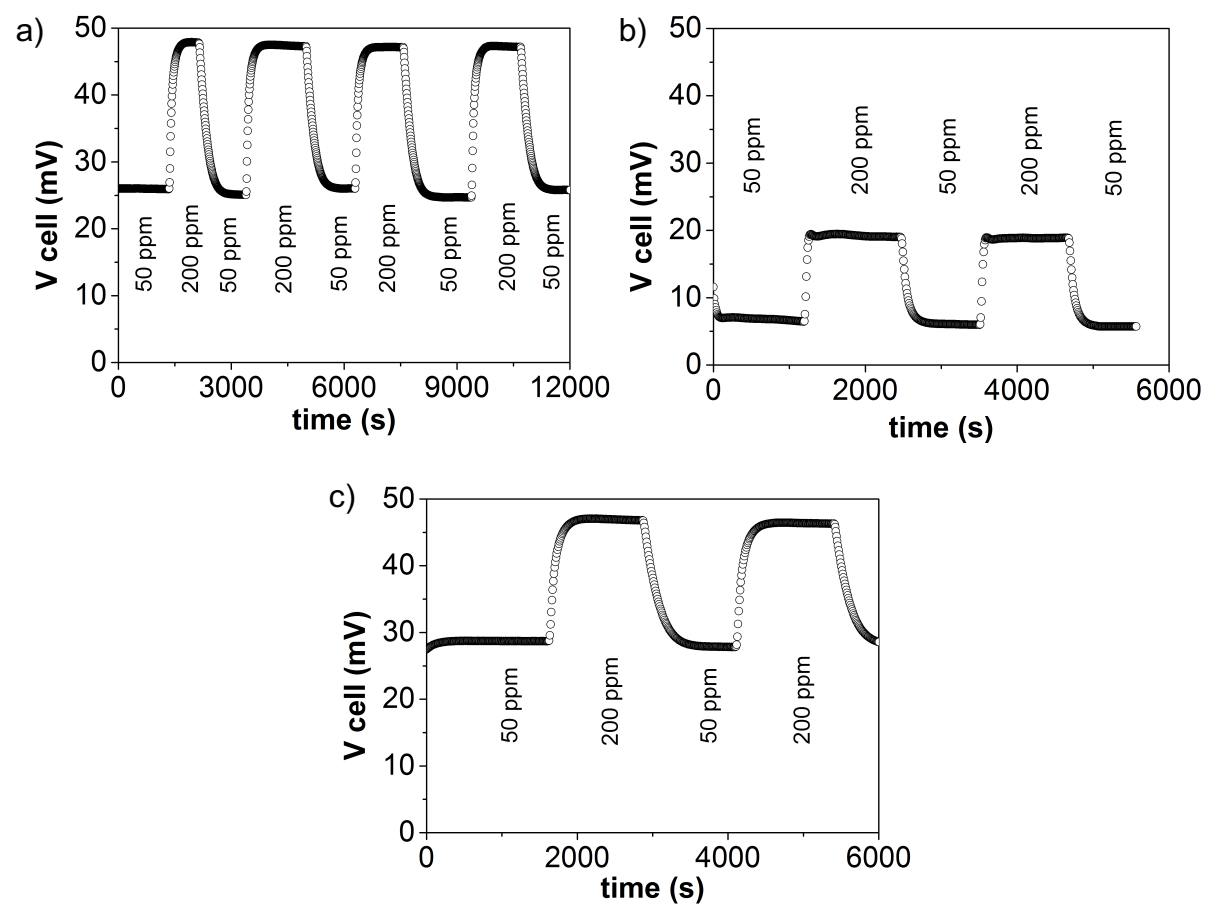

Figure 8.7 Sensor response of the LSC/8YSZ//8YSZ//LSM/8YSZ configuration, after infiltration with nickel of the working electrode, in wet conditions (3\% water) to changes in concentration of ethylene for: a) pure ethylene, and with a background of b) 200 ppm of carbon monoxide and c) $200 \mathrm{ppm}$ of nitrogen dioxide

\section{EIS analysis}

Nyquist plot (from $0.03 \mathrm{~Hz}$ to $1 \mathrm{MHz}$ ) shows two-arcs contribution (Figure 8.8). The first one, associated in previous chapters to the interface electrode-electrolyte, remains constant while the second one, associated to the electrode varies as a function of gas concentration. The contribution to ethylene is lower than to carbon monoxide in both dry and wet conditions. This can explain the better selectivity to ethylene and the low cross-sensitivity toward carbon monoxide although in wet conditions both contributions are closer. This reduction of electrode contribution for both analytes when water is added can be related to an increase of oxygen ions because of the faster oxygen exchange reaction between water and 8YSZ. This enlarge the oxygen active area in the reference electrode. The electrode contribution in 200 ppm of nitrogen dioxide is lower than in ethylene and carbon monoxide and this could be attributed to its reduction on the reference electrode competing with oxygen. 


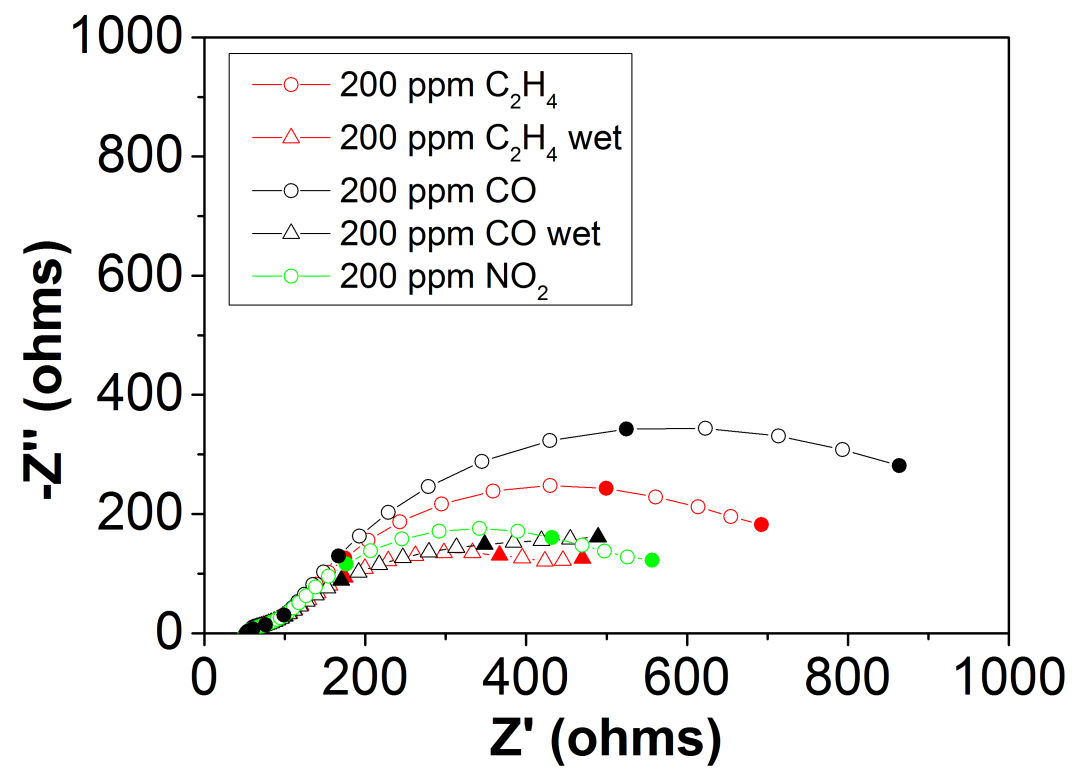

Figure 8.8 Nyquist plot for LSC/8YSZ//8YSZ//LSM/8YSZ, after infiltration with nickel of the working electrode, to several analytes in dry and wet conditions: ethylene, carbon monoxide and nitrogen dioxide

\subsection{2 $\quad \mathrm{NO}_{2}$ effect on reference configuration sensor}

As nitrogen dioxide is one the main pollutants in a car exhaust gas, it is interesting to check also the effect of this pollutant on one the best configurations achieved in the present thesis: $\mathrm{Fe}_{0.7} \mathrm{Cr}_{1.3} \mathrm{O}_{3} / 8 \mathrm{YSZ} / / 8 \mathrm{YSZ} / / \mathrm{LSM} / 8 \mathrm{YSZ}$ (after infiltration of the working electrode with nickel).

A disk-shaped $8 \mathrm{YSZ}$ is employed as electrolyte and both $\mathrm{Fe}_{0.7} \mathrm{Cr}_{1.3} \mathrm{O}_{3} / 8 \mathrm{YSZ}$ and LSM/8YSZ are screen printed in each face. The layers are circular-shaped with a diameter of $9 \mathrm{~mm}$. The working electrode $\mathrm{Fe}_{0.7} \mathrm{Cr}_{1.3} \mathrm{O}_{3} / 8 \mathrm{YSZ}$ is infiltrated with nickel and then the device is exposed to changes in concentration ethylene from 50 to $200 \mathrm{ppm}$ for pure ethylene as well as with a background of $200 \mathrm{ppm}$ of carbon monoxide and nitrogen dioxide in dry and wet conditions.

Figure 8.9 shows the response in dry conditions. In all cases, the response is reproducible and selective to ethylene. Regarding cross-sensitivity, the sensor response is not affected by carbon monoxide background and the response depends on ethylene concentration (Figure 8.9b). When nitrogen dioxide is added, there is a decrease of the total output but the sensor response remains 
selective to ethylene and depends on ethylene concentration (Figure 8.9c). Nitrogen dioxide can be competing with oxygen in the reference electrode as can be observed in Figure 8.10, and then a new equilibrium must be achieved modifying the total voltage output. Figure 8.10 shows that when the sensor is exposed to pure nitrogen dioxide the sensor response is negative. Thus, it works the other way around and nitrogen dioxide is being reduced in the reference electrode.
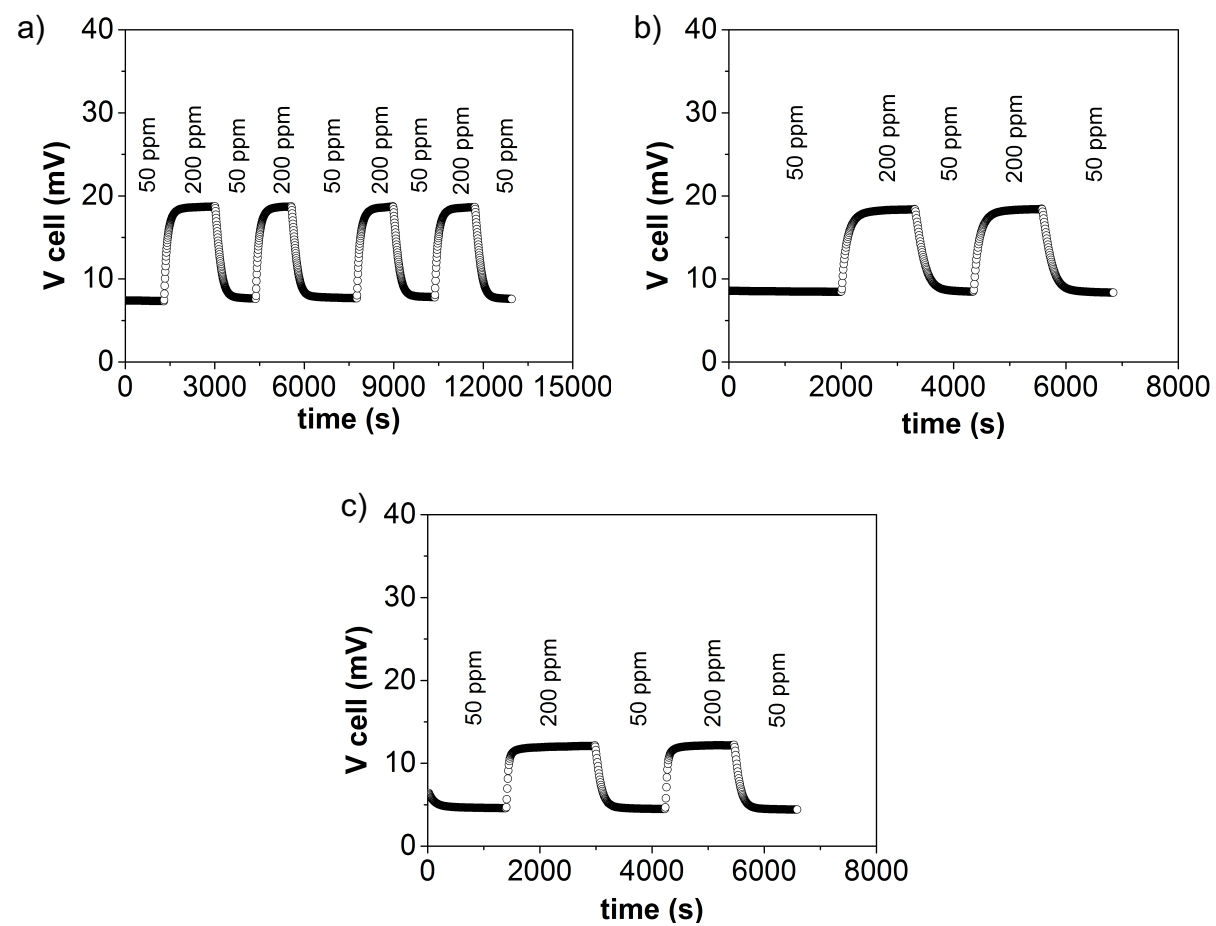

Figure 8.9 Sensor response of the $\mathrm{Fe}_{0.7} \mathrm{Cr}_{1.3} \mathrm{O}_{3} / 8 Y S Z / / 8 Y S Z / / L S M / 8 Y S Z$ configuration, after infiltration with nickel of the working electrode, in dry conditions to: a) pure ethylene and to ethylene with a background of: b) 200 ppm of carbon monoxide and c) 200 ppm of nitrogen dioxide 


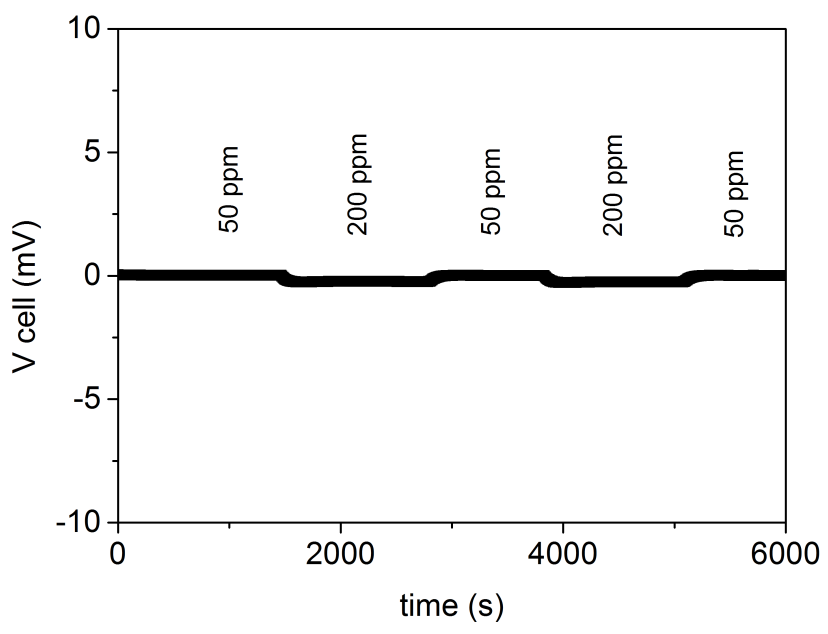

Figure 8.10 Transient response of $\mathrm{Fe}_{0.7} \mathrm{Cr}_{1.3} \mathrm{O}_{3} / 8 \mathrm{YSZ} / / 8 \mathrm{YSZ} / / \mathrm{LSM} / 8 \mathrm{YSZ}$ configuration, after infiltration of the working electrode with nickel, when it is exposed to changes in concentration of nitrogen dioxide

In wet conditions, there is a boost of the voltage recorded but the sensor performance is alike dry conditions (Figure 8.11). The sensor response is also selective to ethylene, as it depends on ethylene concentration. When carbon monoxide is added, the device still depends on ethylene concentration and thus, the cross-sensitivity toward carbon monoxide is low. On the other hand, the addition of nitrogen dioxide plus water slightly reduced the total voltage recorded although the response is still dependant on the ethylene concentration. This can be due to a competitive adsorption between water, oxygen and nitrogen dioxide on the reference electrode and therefore, changing the equilibrium achieved between working and reference electrode. 

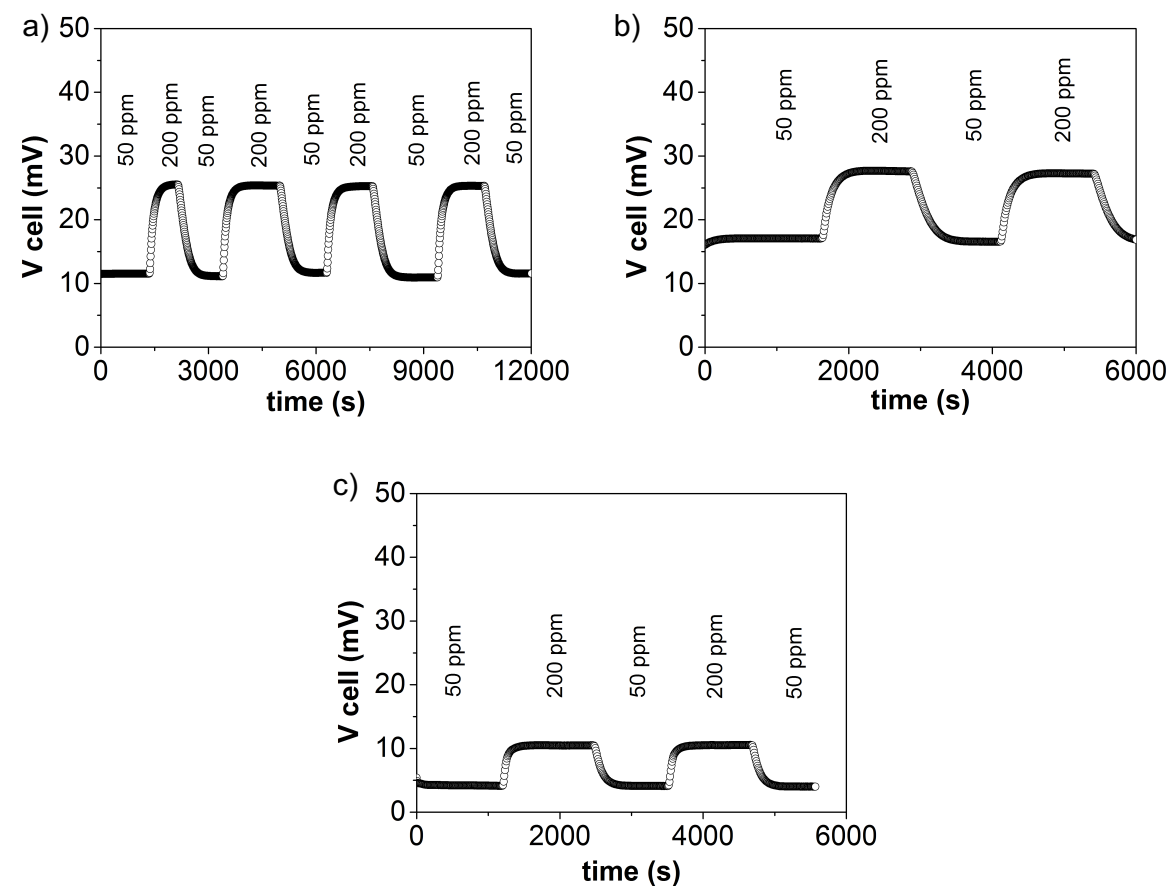

Figure 8.11 Sensor response of the $\mathrm{Fe}_{0.7} \mathrm{Cr}_{1.3} \mathrm{O}_{3} / 8 \mathrm{YSZ} / / 8 \mathrm{YSZ} / / \mathrm{LSM} / 8 \mathrm{YSZ}$ configuration, after infiltration with nickel of the working electrode, in wet conditions (3\% of water) to: a) pure ethylene and to ethylene with a background of: b) 200 ppm of carbon monoxide and c) 200 ppm of nitrogen dioxide

Impedance spectroscopy spectra shows two-arcs contributions as can be observed in Nyquist plot in Figure 8.12 from $0.03 \mathrm{~Hz}$ to $1 \mathrm{MHz}$. As aforementioned, the first arch can be associated to interface between electrodeelectrolyte, and it remains constant. The second arch can be associated to the electrode and it varies with the analyte. For both dry and wet conditions, the electrode contribution in ethylene is lower than in carbon monoxide. As aforementioned, this lesser electrode resistance (and therefore polarization resistance) can explain the better selectivity to ethylene and the low crosssensitivity toward carbon monoxide although in wet conditions both contributions are closer. Electrode contribution in 200 ppm of nitrogen dioxide is lesser than in carbon monoxide and ethylene and can be related with the activity at reference electrode. 


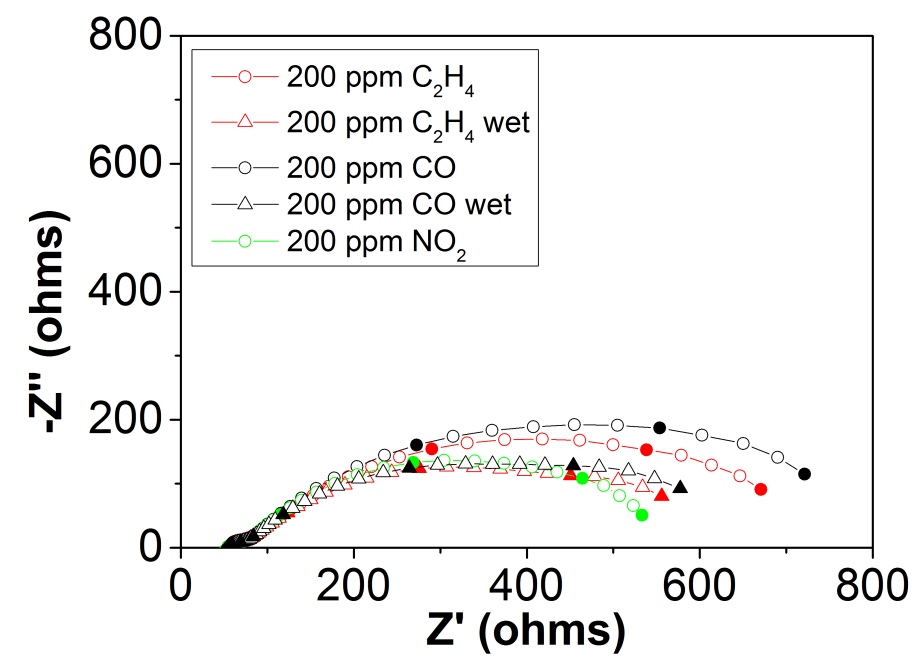

Figure 8.12 Nyquist plot for $\mathrm{Fe}_{0.7} \mathrm{Cr}_{1.3} \mathrm{O}_{3} / 8 \mathrm{YSZ} / / 8 \mathrm{YSZ} / / \mathrm{LSM} / 8 \mathrm{YSZ}$ configuration, after infiltration with nickel of the working electrode, to several analytes in dry and wet conditions: ethylene, carbon monoxide and nitrogen dioxide

\subsection{Sensor mechanism of action and discussion}

\section{Mechanism}

In this thesis, potentiometric sensors based on solid-state are developed to detect selectively ethylene in conditions where carbon monoxide, water, polyaromatic compounds or nitrogen dioxide are also present. The device consists of a solid electrolyte with pure ionic conductivity and two electrodes with high electronic conductivity. Thus, a voltage is generated between both electrodes when exposed to an analyte at the zero-current condition. This potential can be Nernstian or non-Nernstian depending on the nature of the controlling process i.e. thermodynamic or kinetic [16].

In a Nernstian device, the voltage recorded is a direct measurement of the chemical potential difference of neutral components corresponding to the mobile species in the electrolyte [6]. The reversible electrode potential is function of the activity of the reduced and oxidized species and it follows the Nernst equation (eq. 8.3), where $E^{0}$ is the standard potential, $T$ the temperature, $n$ the number of electrons involved in the electrochemical reactions, $R$ the gas constant and $F$ the Faraday's constant.

$$
E=\mathrm{E}^{0}+\frac{\mathrm{RT}}{\mathrm{nF}} \cdot \ln \frac{[\mathrm{Ox}]}{[\mathrm{Red}]}
$$


In some applications, where several species are involved, there could be deviations from this Nernstian ideal behaviour. This is the case of the detection of a certain analyte in a car exhaust gas. In this atmosphere, there are several species and therefore, there is more than one possible charge exchange process at each electrode as both electrodes are exposed to the same atmosphere i.e. several reactions can take place at the same time in the same electrode.

In this so-called mixed potential device, the potential is established when the cathodic current is equal to the anodic current (consequently, the net current is zero at the mixed potential). This potential does not follow the Nernst equation as it does not correspond to the thermodynamic equilibrium potential but to the kinetics of several reactions like electrochemical reactions in the electrode and in the interface between electrode-electrolyte as well as the gas-phase reactions through the electrode. This implies that not only the material itself but also the grain size, porosity and morphology can have an effect on the sensor response [17].

When the sensor is exposed to an analyte, a voltage is generated when a steadystate condition is achieved in the working electrode by two (or more) electrochemical reactions: the anodic reaction of the analyte or analytes (reactions 8.4 and 8.5 ) and the cathodic reaction of oxygen (reaction 8.6). The same procedure occurs in the reference electrode. Hence, the materials selection is critical to ensure a good activity of the anodic reaction to the target material in the working electrode and a good activity to oxygen in the reference electrode. The difference between both steady-state voltages in each electrode determines the voltage of the cell or device $\left(\mathrm{V}_{\text {cell }}\right)$. In summary, the sensitivity depends on the anodic reaction to the target material (and other pollutants that can provide crosssensitivity) in the working electrode, the cathodic reaction of oxygen in the working electrode and the gas-phase reaction of the target material and other pollutants.

$$
\begin{gathered}
\text { Anodic reactions } \\
\mathrm{C}_{2} \mathrm{H}_{4}+6 \mathrm{O}^{-2} \leftrightarrow 2 \mathrm{CO}_{2}+2 \mathrm{H}_{2} \mathrm{O}+12 e^{-} \\
\mathrm{CO}+\mathrm{O}^{-2} \leftrightarrow \mathrm{CO}_{2}+2 e^{-}
\end{gathered}
$$




\section{Cathodic reactions}

$$
\begin{gathered}
O_{2}(\text { gas })+V_{\ddot{0}}+4 e^{-} \leftrightarrow 2 O^{2-}(8.6) \\
N_{2}+2 e^{-} \leftrightarrow N O+O^{-2}(8.7)
\end{gathered}
$$

If only oxygen and carbon monoxide reactions are considered to simplify (reactions 8.6 and 8.5 , respectively), when both electrodes are exposed to the same atmosphere, both reactions take place at each electrode. Thus, the selection of materials with different polarization behaviours (kinetics) is essential to provide different responses, and therefore a mixed potential as can be observed in Figure 8.13a [18] where a voltage is established for both the working electrode and reference electrode [17,19], and their difference is the mixed potential. Usually, oxygen concentration is assumed to be constant, and it is considered that in the reference electrode only oxygen reduction occurs.

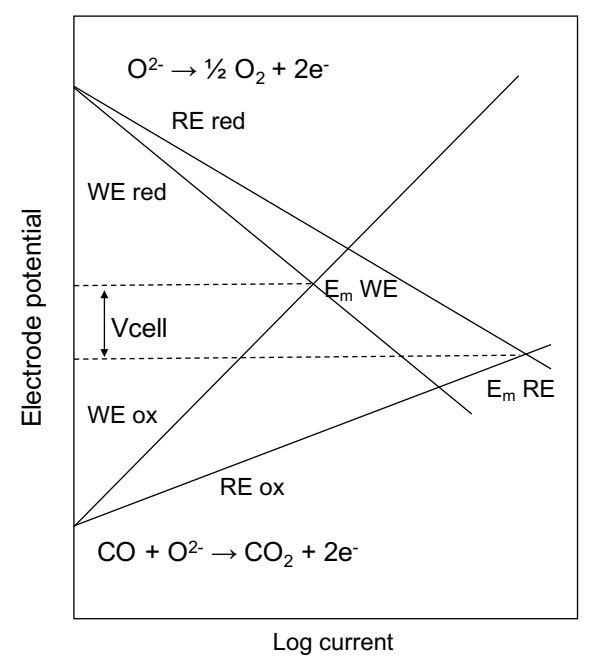

Figure 8.13 Polarization curves for obtaining the mixed potential ( $\left.V_{\text {cell }}\right)$ when $(a)$ the reactions are taking place in both working and reference electrodes and when (b) the oxygen reduction is taking place only in the reference electrode and the analyte of interest is being oxidized in the working electrode

According to Miura et al.[6,17,19] and Garzon et al.[20] the mixed potential devices can be explained by means of the Butler-Volmer equation (Taking into account the overpotential is $\left.\eta_{\text {analyte }}=E-E_{\text {analyte }}^{0}\right)$. Thus, in the mixed potential the absolute values of the current density of reactions 8.5 and 8.6 are equal. The electrical current density for reactions 8.5 and 8.6 are given by equations 8.8 and 8.9 . 


$$
\begin{aligned}
& i_{C O}=i_{C O}^{0} \exp \left[2 \alpha_{2} F\left(E-E_{C O}^{0}\right) / R T\right] \\
& i_{O_{2}}=i_{O_{2}}^{0} \exp \left[-4 \alpha_{1} F\left(E-E_{O_{2}}^{0}\right) / R T\right]
\end{aligned}
$$

Where $\mathrm{E}$ is the electrode potential, $\mathrm{F}$ the Faraday constant, $\mathrm{R}$ the gas constant, $\mathrm{T}$ temperature, $E^{0}$ potential at the equilibrium, $i^{0}$ exchange current density (absolute value of the cathodic and anodic current density in the equilibrium) and $\alpha$ the transfer coefficient. Miura et al. assumed that the exchange current densities obeys the following kinetic equations:

$$
\begin{aligned}
& i_{C O}^{0}=B_{C O} C_{C O}^{n} \\
& i_{O_{2}}^{0}=-B_{O_{2}} C_{O_{2}}^{m}
\end{aligned}
$$

In these equations, $\mathrm{C}$ is concentration and $B_{\mathrm{CO}}, B_{\mathrm{O}_{2}}, \mathrm{~m}$ and $\mathrm{n}$ are constants. The mixed potential is established when $i_{C O}^{0}$ and $i_{O_{2}}^{0}$ (equations 8.10 and 8.11, respectively) are equal in absolute value. Then, the mixed potential $\left(E_{M}\right)$ can be expressed as:

$$
E_{M}=E_{0}+m A \ln C_{O_{2}}-n A \ln C_{C O}
$$

where the constants $E_{0}$ and $A$ are:

$$
\begin{gathered}
E_{0}=\frac{R T}{\left(4 \alpha_{1}+2 \alpha_{2}\right)} \ln \frac{B_{1}}{B_{2}}+\frac{2 \alpha_{1} E_{O_{2}}^{0}+\alpha_{2} E_{C O}^{0}}{2 \alpha_{1}+\alpha_{2}} \\
A=\frac{R T}{\left(\alpha_{1}+2 \alpha_{2}\right) F}
\end{gathered}
$$

As aforementioned, if oxygen concentration is assumed to be fixed to simplify the model, then the equation 8.12 can be simplified to:

$$
E_{M}^{\prime}=E_{0}^{\prime}-n A \ln C_{C O}(8.15)
$$

The concentration of carbon monoxide can be replaced by any other analyte of interest such as ethylene taking into account that the kinetic constants will be different. Equation 8.15 is valid as far as there is a linear correlation of the $\mathrm{V}_{\text {cell }}$ and the logarithm of the analyte concentration. Ethylene shows this behaviour in the devices produced in this thesis. An example is provided in Figure 8.14, 
corresponding to the $\mathrm{Fe}_{0.7} \mathrm{Cr}_{1.3} \mathrm{O}_{3} / 8 \mathrm{YSZ} / / 8 \mathrm{YSZ} / / \mathrm{LSM} / 8 \mathrm{YSZ}$ configuration infiltrated with nickel twice in chapter 5 (the thinnest device employed in chapter 5 ).

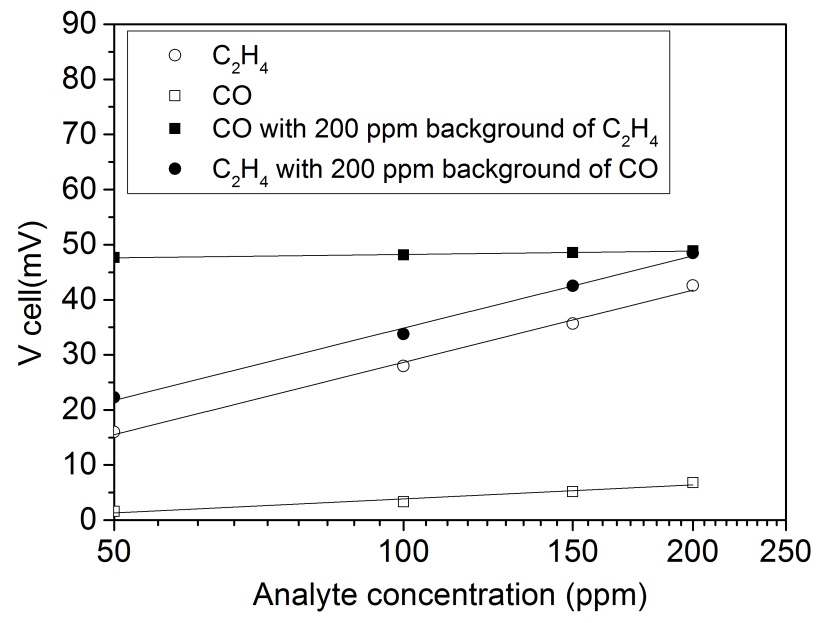

Figure 8.14 An example of the linear correlation between the mixed potential $\left(V_{\text {cell }}\right)$ and the logarithm of the analyte concentration: pure ethylene and carbon monoxide as well as with a background of 200 ppm of the other analyte. The lines indicate the linear regression fit

It should be taken into account that at $550^{\circ} \mathrm{C}$ not only the electrochemical reactions can take place at the system but also other reactions such as the heterogeneous catalysis, coke formation, water-shift reaction, etc. (equations 8.16 to 8.24 ) that can be even more favoured kinetically than the electrochemical reaction. These reactions can alter the sensor performance varying locally the analyte concentration or the long-term stability e.g. coke formation.

$$
\begin{aligned}
& \mathrm{C}_{2} \mathrm{H}_{4}+3 \mathrm{O}_{2} \rightarrow 2 \mathrm{CO}_{2}+2 \mathrm{H}_{2} \mathrm{O} \\
& \mathrm{CO}+\frac{1}{2} \mathrm{O}_{2} \rightarrow \mathrm{CO}_{2} \\
& \mathrm{H}_{2} \mathrm{O}+\mathrm{CO} \rightarrow \mathrm{CO}_{2}+\mathrm{H}_{2} \\
& \mathrm{NO}+\frac{1}{2} \mathrm{O}_{2} \rightarrow \mathrm{NO}_{2} \\
& \mathrm{CO}+3 \mathrm{H}_{2} \rightarrow \mathrm{H}_{2} \mathrm{O}+\mathrm{CH}_{4} \\
& \mathrm{H}_{2}+\mathrm{O}_{2} \rightarrow \mathrm{H}_{2} \mathrm{O}
\end{aligned}
$$




$$
\begin{aligned}
& \mathrm{C}_{2} \mathrm{H}_{4}+\mathrm{H}_{2} \mathrm{O} \rightarrow \mathrm{C}_{2} \mathrm{H}_{5} \mathrm{OH} \\
& \mathrm{C}_{2} \mathrm{H}_{4} \rightarrow \mathrm{C}+2 \mathrm{H}_{2} \\
& 2 \mathrm{CO} \rightarrow \mathrm{C}+\mathrm{CO}_{2}
\end{aligned}
$$

\section{Discussion}

According to theory, there are several ways of favouring the target reaction as summarised in Figure 8.15: increase the activity to the target anodic reaction in the working electrode (faster kinetics), reduce the activity to cathodic reaction in the working electrode and reduce the gas-phase reaction in the working electrode to the target analyte or increase this gas-phase reaction to interfering analytes. Additionally, as the gas-phase reaction can be critical, the grain size, porosity, morphology and even orientation can have an effect on the sensor response. The rate-determining step of the process can also be the diffusion of the analyte in the working electrode.

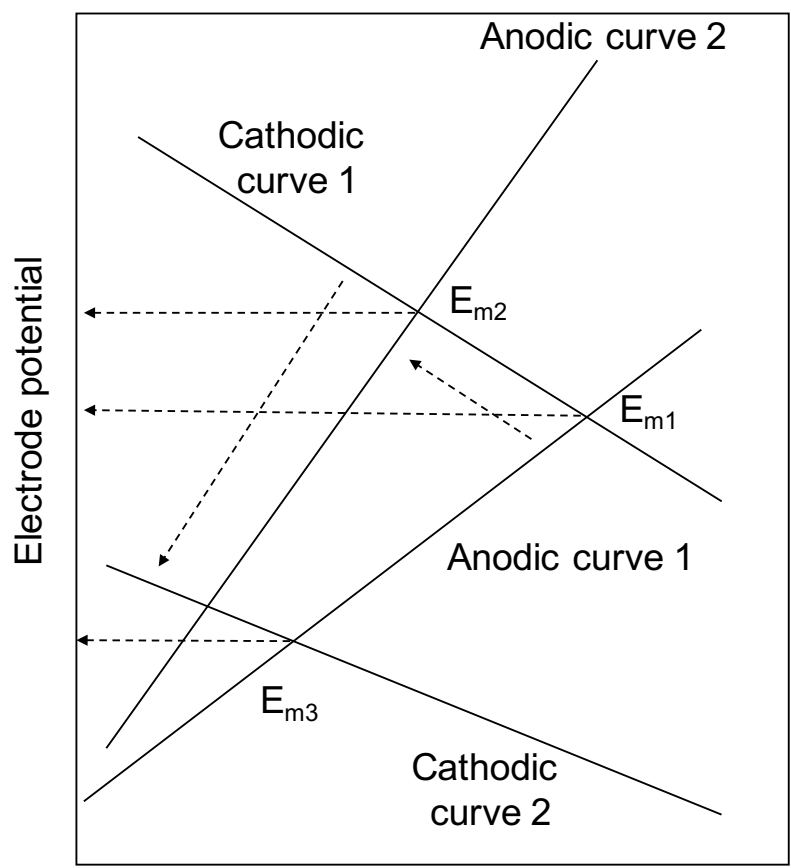

Log current

Figure 8.15 Example of the strategies that can be followed to increase the device response to the target material 
As previously stated, the devices developed in this thesis have a linear correlation between the voltage recorded and the logarithm of the analyte concentration and therefore, can be explained by the mixed potential or non-Nernstian theory employing equation 8.13 .

A summary of the diverse devices developed in this thesis and their main response-characteristics is shown in Figure 8.16. In the first generation of the sensor (Figure 8.16a), employing $\mathrm{Fe}_{0.7} \mathrm{Cr}_{1.3} \mathrm{O}_{3} / 8 \mathrm{YSZ} / / 8 \mathrm{YSZ} / / \mathrm{Pt}$, the device was selective to ethylene with low cross-sensitivity toward carbon monoxide in dry conditions. Whereas in wet conditions the cross-sensitivity to carbon monoxide increased.

a)

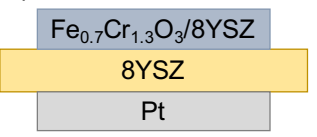

Dry conditions:

- Selective to $\mathrm{C}_{2} \mathrm{H}_{4}$

- Relatively low crosssensitivity toward $\mathrm{CO}$

Wet conditions:

- No selective to $\mathrm{C}_{2} \mathrm{H}_{4}$

- High cross-sensitivity toward $\mathrm{CO}$

e)

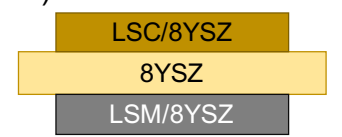

Bare sensor:

- No selective to $\mathrm{C}_{2} \mathrm{H}_{4}$

- Similar response to bare LSC

After infiltration:

- Similar behavior to

$\mathrm{Fe}_{0.7} \mathrm{Cr}_{1.3} \mathrm{O}_{3} / 8 \mathrm{YSZ}$

working electrode with

the same configuration toward $\mathrm{CO}$

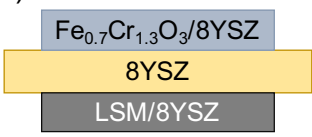

No selective to $\mathrm{C}_{2} \mathrm{H}_{4}$

High cross-sensitivity

d)

C)

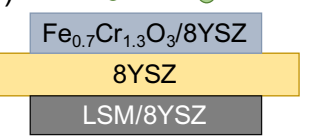

- Selective to $\mathrm{C}_{2} \mathrm{H}_{4}$

- Low cross-sensitivity toward $\mathrm{CO}$ and relatively low toward $\mathrm{H}_{2} \mathrm{O}, \mathrm{NO}_{2}$ and $\mathrm{C}_{14} \mathrm{H}_{10}$

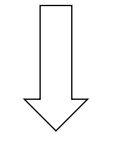

$$
\text { ScSZ or CGO }
$$

Low temperature $\left(<550^{\circ} \mathrm{C}\right)$ :

- Selective to $\mathrm{C}_{2} \mathrm{H}_{4}$ at low concentration in dry cond.

High temperature $\left(550^{\circ} \mathrm{C}\right)$ :

- Analogous behavior than 8YSZ

Figure 8.16 Summary graph of the evolution of the device developed in this thesis and their main sensing characteristics. a) first generation with platinum as reference electrode, b) second generation with LSM/8YSZ as reference electrode, c) third generation with nanocatalyst infiltration in the working electrode, d) fourth generation with CGO or ScSZ as electrolyte and f) fifth generation with LSC/8YSZ 
In the second version, the reference electrode is changed from platinum to LSM/8YSZ, a mixed conductor material (ionic and electronic) that is more active to oxygen. Hence, the cathodic reaction is favoured in the reference electrode over the anodic reaction and an enhancement of the device performance should be expected [21]. Despite these improvements, the cross-sensitivity toward carbon monoxide increased for the second version when compared to the first generation of the device (Figure 8.16b).

This can indicate that in the first version of the sensor, platinum could be promoting the heterogeneous catalysis of carbon monoxide and therefore, there is a reduction of the concentration of carbon monoxide competing in the electrochemical reaction in the working electrode. This is a possible explanation to the worsening of the device when a reference electrode more active to oxygen is employed. There are more oxygen ions flowing through the electrolyte but there is also more carbon monoxide available to be oxidized in the electrochemical reaction and therefore, the cross-sensitivity toward carbon monoxide is increased.

The problem regarding cross-sensitivity toward carbon monoxide of the second generation of devices is solved by the addition of nanocatalysts in the working electrode by means of infiltration of a solution (Figure $8.16 \mathrm{c}$ ). This improves the sensor performance increasing the selectivity to ethylene and reducing the crosssensitivity toward carbon monoxide, water, phenanthrene and nitrogen dioxide. The addition of a catalyst like nickel probably not only boost the electrochemical reaction of ethylene but also the heterogeneous catalysis of carbon monoxide $[14,22]$. Part of the ethylene can also react via heterogeneous catalysis, but still it is controlling the kinetics of the electrochemical reaction [23]. Therefore, two key factors could be improved by the infiltration of nanocatalyst: improvement of the anodic reaction in the working electrode and increase of the gas-phase reaction of elements such as carbon monoxide or polyaromatic compounds. Although part of the ethylene is also probably promoted to react through the gas-phase reaction, the electrochemical response of the device is controlled by its kinetics.

Water and nitrogen dioxide compete with oxygen in the reference electrode. As far as the oxygen ion flow is kept more and less constant, the sensor response in terms of selectivity and cross-sensitivity should not be affected as the cathodic curve is unchanged (Figure 8.15).

When other ionic conductors like CGO or ScSZ are employed as electrolytes, the sensor performance after infiltration of the working electrode at temperatures lower than $550^{\circ} \mathrm{C}$ was only satisfactory in dry conditions and for concentrations above $100 \mathrm{ppm}$. When the sensor was exposed to $550^{\circ} \mathrm{C}$, the device 
performance was similar to the $\mathrm{Fe}_{0.7} \mathrm{Cr}_{1.3} \mathrm{O}_{3} / 8 \mathrm{YSZ} / / 8 \mathrm{YSZ} / / \mathrm{LSM} / 8 \mathrm{YSZ}$ configuration (Figure $8.16 \mathrm{~d}$ ). As the mixed potential or non-Nernstian potential is a kinetic controlled process, an increase of the temperature can favour the reactions taking place at the electrode and the interface electrode/electrolyte. Moreover, catalysts more suitable for low temperature could be employed to try to boost the electrochemical reaction or remove the effect of interfering elements.

Finally, the exchange of $\mathrm{Fe}_{0.7} \mathrm{Cr}_{1.3} \mathrm{O}_{3} / 8 \mathrm{YSZ}$ with LSC/8YSZ provides a similar response before and after infiltration (figure $8.16 \mathrm{e}$ ). Before infiltrating the working electrode, the cross-sensitivity toward carbon monoxide makes the devices unsuitable for the purpose of this thesis. After infiltration with nickel nanoparticles, the performance of the device improves providing a selective response to ethylene with low cross-sensitivity to carbon monoxide, water and nitrogen dioxide. Thus, this can indicate again that the nickel nanoparticles are promoting carbon monoxide heterogeneous catalysis over ethylene and then, the ethylene electrochemical reaction is controlling the kinetics of the device.

Water addition in all devices has two effects: 1) increase of the voltage recorded and 2) reduction of the electrode contribution in the impedance spectroscopy analysis. There could be several factors for this behaviour: as observed in EIS, the lower polarization resistance in water conditions could be related to the increase of the oxygen ions in the system through water adsorption. Oxygen exchange reaction between $8 Y S Z$ and water can be favoured kinetically over the oxygen exchange between oxygen gas and 8YSZ. Thus, addition of water steam can enhance the oxygen exchange rate on the proximity to the triple phase boundaries [15]. Additionally, water-shift reaction, ethylene or carbon monoxide combustion or even ethylene reforming can be taking place [24], although the addition of water increases the voltage generated. This suggests that no gasphase or catalytic combustion is taking place because this would generate a decrease of the electrochemical reactions and, consequently, a decrease of the recorded voltage. This could point out that the enhance of the oxygen exchange rate is the most suitable explanation.

Another possibility could be that the promotion of ethylene or carbon monoxide catalytic combustion increases the temperature locally and improves the kinetics of the electrochemical reactions in the device.

In conclusion, the devices employed in this thesis follow a non-Nernstian behaviour controlled by the kinetics. The data follow a linear regression between the voltage generated and the logarithm of the analyte concentration. The strategies employed to improve activity to ethylene in the working electrode and 
the oxygen activity in the reference electrode are in agreement with the strategies to improve the device performance in a non-Nernstian device: improvement of the activity of the anodic reaction to the target gas in the working electrode (and the other way around in the reference electrode), reduce the activity of the cathodic reaction in the working electrode and reduce the gas-phase reaction to the target analyte or increase this gas-phase reaction for other interfering elements.

\subsection{Conclusions}

In this chapter, the working electrode is changed to check the influence of the addition of an ionic conductor. LSC, that was one of the materials with stable response tested in chapter 3 , is mixed with $8 \mathrm{YSZ}$ and its response is checked. The larger triple phase boundary area does not have a noticeable impact on the bare sensor response when compared to $\mathrm{Fe}_{0.7} \mathrm{Cr}_{1.3} \mathrm{O}_{3} / 8 \mathrm{YSZ}$ and LSC//8YSZ//Pt but it can have an effect on the stability of the device in the long-term operation and improve the attachment to the electrolyte. The addition of nickel nanoparticles onto the working electrode provides a similar response than the infiltrated $\mathrm{Fe}_{0.7} \mathrm{Cr}_{1.3} \mathrm{O}_{3} / 8 \mathrm{YSZ}$ (i.e. the response is selective to ethylene with low cross-sensitivity toward carbon monoxide, water and nitrogen dioxide). This makes this sensor configuration as a strong alternative for the purpose of this thesis.

The sensor employing $\mathrm{Fe}_{0.7} \mathrm{Cr}_{1.3} \mathrm{O}_{3} / 8 \mathrm{YSZ}$ as working electrode infiltrated with nickel is also exposed to nitrogen dioxide. As this configuration is one of the strongest candidates of this thesis, it is important to check its response with nitrogen dioxide because it is one of the main pollutants in a car exhaust gas. The performance of the device is similar to LSC/8YSZ, the sensor is selective to ethylene with low cross-sensitivity toward carbon monoxide, water and nitrogen dioxide.

The sensor response to analytes shows a linear correlation between voltage and the logarithm of the analyte concentration that can be related to a non-Nernstian behaviour as the sensor performance differs from the ideal Nernstian behaviour. There are several reactions taking place at each electrode and the sensor performance is controlled by the kinetics. The desired reaction must be favoured in each electrode with the selection of a proper material while the gas-phase reaction to the analyte should be decreased or increase to other interfering elements.

Addition of nanocatalysts seems to boost the gas-phase reaction of carbon monoxide. Although ethylene is also probably reacting through this gas-phase 
reaction, their kinetics control the electrochemical reaction of the device and this is the reason of its selectivity with low cross-sensitivity toward carbon monoxide and other elements. Nitrogen dioxide is probably competing with oxygen in the reference electrode for the contribution of oxygen ions while water can boost the oxygen exchange rate as its adsorption over water is higher and can increase the activity to the vicinity of the triple phase boundary.

\subsection{References}

[1] M. Yano, A. Tomita, M. Sano, T. Hibino, Recent advances in singlechamber solid oxide fuel cells: A review, Solid State lonics. 177 (2007) 33513359. doi:10.1016/J.SSI.2006.10.014.

[2] I. Riess, The significance of impeded reactions in solid state electrochemistry, Solid State lonics. $176 \quad$ (2005) 1667-1674. doi:10.1016/J.SSI.2005.04.015.

[3] I. Riess, P.J. van der Put, J. Schoonman, Solid oxide fuel cells operating on uniform mixtures of fuel and air, Solid State lonics. 82 (1995) 1-4. doi:10.1016/0167-2738(95)00210-W.

[4] N. Miura, Y. Yan, G. Lu, N. Yamazoe, Sensing characteristics and mechanism of hydrogen sulfide sensor using stabilized zirconia and oxide sensing electrode, Sensors Actuators B. 34 (1996) 367-372. doi: 10.1016/S09254005(96)01828-X

[5] N. Miura, G. Lu, N. Yamazoe, Progress in mixed-potential type devices based on solid electrolyte for sensing redox gases, Solid State lonics. 136-137 (2000) 533-542. doi:10.1016/S0167-2738(00)00411-2.

[6] C.O. Park, J.W. Fergus, N. Miura, J. Park, A. Choi, Solid-state electrochemical gas sensors, lonics (Kiel). $15 \quad$ (2009) 261-284. doi:10.1007/s11581-008-0300-6.

[7] J.W. Fergus, Electrolytes for solid oxide fuel cells, J. Power Sources. 162 (2006) 30-40. doi:10.1016/J.JPOWSOUR.2006.06.062.

[8] J. Zosel, D. Westphal, S. Jakobs, R. Müller, U. Guth, Au-oxide composites as $\mathrm{HC}$-sensitive electrode material for mixed potential gas sensors, Solid State Ionics 152-153 (2002), 525-529. doi: 10.1016/S0167-2738(02)003557

[9] L. Chevallier, E. Di Bartolomeo, M.L. Grilli, M. Mainas, B. White, E.D. Wachsman, E. Traversa, Non-Nernstian planar sensors based on YSZ with a Nb2O5 electrode, Sensors Actuators B Chem. 129 (2008) 591-598. doi:10.1016/J.SNB.2007.09.037. 
[10] H.-C. Cho, S. Takase, J.-H. Song, Y. Shimizu, Sensing behavior of solidstate impedancemetric NOx sensor using solid electrolyte transducer and oxide receptor, Sensors Actuators B. 187 (2013) 94-98. doi:10.1016/j.snb.2012.09.066.

[11] C. Balamurugan, C. Son, J. Hong, S.-J. Song, Enhanced mixed potential NOx gas response performance of surface modified and $\mathrm{NiO}$ nanoparticles infiltrated solid-state electrochemical-based NiO-YSZ composite sensing electrodes, Sensors Actuators B Chem. 262 (2018) 664-677. doi:10.1016/J.SNB.2018.01.163.

[12] A. Afzal, N. Cioffi, L. Sabbatini, L. Torsi, NOx sensors based on semiconducting metal oxide nanostructures: Progress and perspectives, Sensors Actuators B Chem. 171-172 (2012) 25-42. doi:10.1016/j.snb.2012.05.026.

[13] J. WANG, P. ElUMALAI, D. TERADA, M. HASEI, N. MIURA, Mixedpotential-type zirconia-based NOx sensor using Rh-loaded NiO sensing electrode operating at high temperatures, Solid State lonics. 177 (2006) 2305-2311. doi:10.1016/j.ssi.2005.12.023.

[14] R. Wama, V. V. Plashnitsa, P. Elumalai, T. Kawaguchi, Y. Fujio, M. Utiyama, N. Miura, Improvement in Propene Sensing Characteristics by the Use of Additives to In[sub 2]O[sub 3] Sensing Electrode of Mixed-Potential-Type Zirconia Sensor, J. Electrochem. Soc. 156 (2009) J102. doi:10.1149/1.3090168.

[15] N. Sakai, K. Yamaji, T. Horita, Y.P. Xiong, H. Kishimoto, M.E. Brito, H. Yokokawa, Effect of water on electrochemical oxygen reduction at the interface between fluorite-type oxide-ion conductors and various types of electrodes, Solid State lonics. 174 (2004) 103-109. doi:10.1016/j.ssi.2004.07.027.

[16] C.M. Mari, Non-Nernstian Solid State Gas Sensors: Operating Principles and Materials, Ionics 9 (2003) 365-369. doi: 10.1007/BF02376587

[17] N. Miura, T. Sato, S.A. Anggraini, H. Ikeda, S. Zhuiykov, A review of mixed-potential type zirconia-based gas sensors, lonics 20 (2014) 901-925. doi:10.1007/s11581-014-1140-1.

[18] J.W. Fergus, Sensing mechanism of non-equilibrium solid-electrolytebased chemical sensors, J. Solid State Electrochem. 15 (2011) 971-984. doi:10.1007/s10008-010-1046-4.

[19] N. Miura, T. Raisen, G. Lu, N. Yamazoe, Highly selective CO sensor using stabilized zirconia and a couple of oxide electrodes, Sensors Actuators B Chem. 47 (1998) 84-91. doi:10.1016/S0925-4005(98)00053-7.

[20] F.H. Garzon, R. Mukundan, E.L. Brosha, Solid-state mixed potential gas sensors: Theory, experiments and challenges, Solid State lonics. 136-137 (2000) 633-638. doi:10.1016/S0167-2738(00)00348-9. 
[21] T. Inaba, K. Saji, J. Sakata, Characteristics of an HC sensor using a Pr6011 electrode, Sensors Actuators B Chem. 108 (2005) 374-378. doi:10.1016/J.SNB.2005.01.039.

[22] T. Sato, M. Breedon, N. Miura, Reduction in Ethanol Interference of Zirconia-Based Sensor for Selective Detection of Volatile Organic Compounds, J. Electrochem. Soc. 160 (2013) B146-B151. doi:10.1149/2.007309jes.

[23] N. Miura, P. Elumalai, V. V. Plashnitsa, T. Ueda, R. Wama, M. Utiyama, Solid-State Electrochemical Gas Sensing, in: Solid State Gas Sens., Springer US, Boston, MA, 2009: pp. 1-27. doi:10.1007/978-0-387-09665-0_5.

[24] D. Lee, S.-J. Ahn, J. Kim, J. Moon, Influence of water vapor on performance of co-planar single chamber solid oxide fuel cells, J. Power Sources. 195 (2010) 6504-6509. doi:10.1016/J.JPOWSOUR.2010.03.101. 

Chapter 9

Conclusions and remarks 



\section{Conclusions and remarks}

Different materials and configurations were considered and studied throughout this thesis in order to develop a sensor selective to hydrocarbons in automotive applications. The results presented in this thesis have led to the following conclusions:

\section{1) Selection of working electrode material:}

- Several materials were tested as working electrode employing platinum as reference electrode and parameters such as sensitivity to ethylene and cross sensitivity toward carbon monoxide were evaluated.

- $\mathrm{NiO}+6 \%$ wt $\mathrm{Au}$ and $\mathrm{Fe}_{2} \mathrm{NiO}_{4}$ showed promising results for use in a carbon monoxide sensor. $\mathrm{NiO}$ provided the highest sensitivity to carbon monoxide while $\mathrm{Fe}_{2} \mathrm{NiO}_{4}$ had the fastest response.

- LSC provided a stable and reproducible response but the crosssensitivity toward carbon monoxide was too high, far from the purpose of this work.

- The best materials employed as working electrode for ethylene detection were: $\mathrm{ZnCr}_{2} \mathrm{O}_{4}$ and $\mathrm{Fe}_{0.7} \mathrm{Cr}_{1.3} \mathrm{O}_{3} / 8 \mathrm{YSZ}$. $\mathrm{ZnCr}_{2} \mathrm{O}_{4}$ was discarded because its slow response and lack of long-term stability, and the response was not reproducible. Thus, the configuration $\mathrm{Fe}_{0.7} \mathrm{Cr}_{1.3} \mathrm{O}_{3} / 8 \mathrm{YSZ} / / 8 \mathrm{YSZ} / / \mathrm{Pt}$ was selected as the strongest candidate.

- $\mathrm{Fe}_{0.7} \mathrm{Cr}_{1.3} \mathrm{O}_{3}$ is mixed with $8 \mathrm{YSZ}$ to ensure a proper attachment to the electrolyte. Moreover, this provided a larger triple phase boundary area i.e. the active sites where the reaction takes place.

2) Water and polyaromatic hydrocarbons influence on sensor response. Reference electrode improvement strategies:

- The addition of water increased the sensitivity of the $\mathrm{Fe}_{0.7} \mathrm{Cr}_{1.3} \mathrm{O}_{3} / 8 \mathrm{YSZ} / / 8 \mathrm{YSZ} / / \mathrm{Pt}$ sensor to carbon monoxide but the cross-sensitivity toward carbon monoxide was so high enough that made it not suitable for selective detection of ethylene.

- The addition of methylnaphthalene, phenanthrene and toluene had a similar effect. Phenanthrene addition increased the cross-sensitivity toward carbon monoxide while methylnaphthalene and toluene superimposed their signal to both ethylene and carbon monoxide responses.

- The reference electrode was changed from platinum to a mixed ionicelectronic material: LSM/8YSZ. This material is more active to 
oxygen and should increase the activity of the electrode to oxygen reduction. Once exchanged, the sensor performance became worse as the cross-sensitivity toward carbon monoxide increased.

- Platinum could be promoting catalytic reaction of carbon monoxide in the first-generation sensor. This reduced the carbon monoxide able to compete in the electrochemical reaction providing a more selective response to ethylene.

- The increase of cross-sensitivity toward carbon monoxide when phenanthrene was added in $\mathrm{Fe}_{0.7} \mathrm{Cr}_{1.3} \mathrm{O}_{3} / 8 \mathrm{YSZ} / / 8 \mathrm{YSZ} / / \mathrm{Pt}$ configuration could be also due to the catalytic reaction of phenanthrene with platinum over carbon monoxide. This would provide more carbon monoxide able to compete in the electrochemical reaction.

- Working electrode must be optimised to improve the kinetics of ethylene and increase its selectivity while reducing cross-sensitivity toward carbon monoxide.

\section{3) Optimization of the working electrode through surface activation by nanocatalyst deposition}

- The working electrode is infiltrated with several nanosized metals. Nickel, ruthenium, titanium or aluminium provided a selective response to ethylene with low cross-sensitivity toward carbon monoxide in dry conditions.

- A second infiltration of the aforementioned elements with nickel (excepts ruthenium) led to a device selective to ethylene and with low crosssensitivity toward carbon monoxide and water.

- Niobium, palladium and barium, despite providing a response selective to ethylene in dry conditions (although the overall response is lower), failed to provide a selective response in wet conditions.

- Addition of nanocatalyst improved the sensor performance. These particles probably not only boosted the electrochemical reaction to ethylene but also increased the gas-phase reaction to carbon monoxide. Thus, less carbon monoxide competed in the electrochemical reaction and ethylene kinetic controlled the process.

- Electrochemical impedance electroscopy analysis showed that ethylene contribution was lower after nanocatalyst addition. The addition of water decreased the contribution for both analytes except for niobium. This could be due to a higher exchange rate of oxygen in the vicinities of the triple phase boundary at the reference electrode with the adsorbed water. 
In the case of niobium, it could be promoting secondary reactions with the analytes.

\section{4) Influence of 8YSZ electrolyte thickness on the sensor performance}

- After infiltration of the working electrode with nickel, the potentiometric characterization revealed that in dry conditions ethylene sensitivity remained constant in the range 0.1 to $0.8 \mathrm{~mm}$ of electrolyte thickness. The sensitivity decreased when the thickness was increased further than $0.8 \mathrm{~mm}$. The addition of a background of carbon monoxide reduced the sensitivity from 0.1 to $0.6 \mathrm{~mm}$, kept it constant in the range $0.6-0.8 \mathrm{~mm}$ and decreased again from 0.8 to $1.2 \mathrm{~mm}$.

- Sensitivity to carbon monoxide increased with the electrolyte thickness. When ethylene was introduced as background the carbon monoxide sensitivity remained constant. Ethylene was controlling the kinetics of the device.

- The thinnest device provided a higher difference between ethylene and carbon monoxide sensitivity and therefore it showed a slightly higher selectivity to ethylene and lower cross-sensitivity toward carbon monoxide.

- Addition of water led to a slightly increase of both analytes sensitivity. The trend was similar to dry conditions but in this case, there was a slightly larger reduction of ethylene sensitivity and increased of carbon monoxide sensitivity 0.1 to $0.6 \mathrm{~mm}$.

- Addition of phenanthrene had a similar trend than dry conditions. The sensor response remained almost unaffected by the addition of this compound. On the other hand, methylnaphthalene had an effect on the sensor response and decreased the sensitivity to both analytes when the electrolyte thickness was increased. The reduction of ethylene sensitivity was higher.

- Electrochemical impedance spectroscopy analysis revealed that there are two contributions: one related to the interface electrode-electrolyte that remained almost constant and therefore independent of the electrolyte thickness, and a second one related to the electrode processes that decreased when the electrolyte thickness was increased. Therefore, the polarization resistance also decreased when the electrolyte thickness was increased. An increase of the polarization resistance was expected as the ohmic losses are lower when the electrolyte is thinner.

- The difference between ethylene and carbon monoxide resistance associated to the electrode processes (and the polarization resistance) 
was higher in the thinnest device. This is in agreement with the potentiometric characterization.

\section{5) Alternatives to $8 \mathrm{YSZ}$ as electrolyte}

- ScSZ-based sensor proved to have a good performance at 400 and $450^{\circ} \mathrm{C}$ as bare sensor. It provided a relatively low cross-sensitivity toward carbon monoxide in dry conditions. The addition of water increased the cross-sensitivity toward carbon monoxide. On the other hand, CGO and 8YSZ-based devices failed to provide a good sensor performance at lower temperature than $550^{\circ} \mathrm{C}$.

- After catalytic activation with addition of nickel nanoparticles in the working electrode, the best response in terms of selectivity and crosssensitivity was achieved at $400^{\circ} \mathrm{C}$ but the response was too slow and the stability was poor. The best performance was then achieved at $450^{\circ} \mathrm{C}$ for concentration below 100 ppm of ethylene in dry conditions. At higher concentrations of ethylene, the device became saturated.

- At $550^{\circ} \mathrm{C}$ after nickel infiltration, both CGO and ScSZ-based devices provided a similar performance than 8YSZ-based device. The response was selective to ethylene with low cross-sensitivity toward carbon monoxide, water and phenanthrene. Addition of methylnaphthalene had an effect on the sensor performance increasing the cross-sensitivity toward carbon monoxide.

- This increase in the sensor performance with temperature could indicate that the kinetics are controlling the mechanism of the device and a higher temperature leads to an increase of the ethylene kinetics.

- Electrochemical impedance spectroscopy analysis backed this statement, the polarization resistance increased drastically when the temperature was reduced.

\section{6) Optimization of the sensor performance and mechanism of action}

- The effect of employing a mixed ionic-electronic material as working electrode was evaluated. Comparison between LSC and LSC/8YSZ showed no great difference in the sensor behaviour: in both cases there was carbon monoxide cross-sensitivity. This could be due to the fact that LSC has itself certain ionic conductivity. However, mixing with 8YSZ can have an effect on terms of long-term stability.

- Addition of nitrogen dioxide showed an upside-down response in terms of signal. This confirmed that nitrogen dioxide was competing with oxygen in the reference electrode to provide oxygen ions. 
- After infiltration of LSC/8YSZ with nickel, the sensor performance was similar to $\mathrm{Fe}_{0.7} \mathrm{Cr}_{1.3} \mathrm{O}_{3} / 8 \mathrm{YSZ} / / 8 \mathrm{YSZ} / / \mathrm{LSM} / 8 \mathrm{YSZ}$. The response was selective to ethylene with low cross-sensitivity toward carbon monoxide, water and nitrogen dioxide.

- Device configuration $\mathrm{Fe}_{0.7} \mathrm{Cr}_{1.3} \mathrm{O}_{3} / 8 Y S Z / / 8 Y S Z / / L S M / 8 Y S Z$ was also exposed to nitrogen dioxide after infiltration of the working electrode. The device provided a selective response to ethylene with a certain low crosssensitivity to pure nitrogen dioxide and nitrogen dioxide plus water. In this case, nitrogen dioxide also provided an upside-down signal confirming that this compound was competing with oxygen in the reference electrode.

- The devices response showed a linear correlation between voltage recorded and logarithm of the analyte concentration that confirmed a nonNernstian or mixed potential behaviour. According to this theory, the kinetics were controlling the device mechanism of action.

- According to theory, there are several ways to increase the sensor performance: increasing the anodic reaction to the target analyte or reducing the cathodic reaction in the working electrode, reducing the gasphase reaction to the analyte or promoting the gas-phase reaction of interfering pollutants. The same is valid for the reference electrode but promoting the oxygen cathodic reaction.

- In this thesis, several of these actions were employed like using a reference electrode active to oxygen (LSM/8YSZ) or increasing the working electrode activity by the addition of nanocatalyst that could boost the anodic reaction to ethylene, or increasing the gas-phase reaction to carbon monoxide and other pollutants.

The aim of the present thesis was to develop a sensor device to detect selectively hydrocarbons in conditions like a car exhaust gas. Ethylene was selected as the target analyte as it is one of the most common hydrocarbons in an exhaust gas. Conditions like a car exhaust gas implies that the device has not only to detect ethylene but also to cope with other pollutants or elements such as carbon monoxide, water, nitrogen dioxide, polyaromatics, etc. In this thesis, several configurations have led to a satisfactory response in terms of selectivity to ethylene and low cross-sensitivity toward other pollutants after catalytic activation strategies.

The following configurations have proved to provide an outstanding performance for ethylene sensing purposes at $550^{\circ} \mathrm{C}$ after catalytic activation of the working electrode in conditions similar to a car exhaust gas: WE//8YSZ//LSM/8YSZ (WE $=\mathrm{Fe}_{0.7} \mathrm{Cr}_{1.3} \mathrm{O}_{3} / 8 \mathrm{YSZ}$ or LSC/8YSZ), $\mathrm{Fe}_{0.7} \mathrm{Cr}_{1.3} \mathrm{O}_{3} / \mathrm{CGO} / / \mathrm{CGO} / / \mathrm{LSM} / 8 \mathrm{YSZ}$ and 
$\mathrm{Fe}_{0.7} \mathrm{Cr}_{1.3} \mathrm{O}_{3} / 8 \mathrm{YSZ} / / \mathrm{ScSZ} / / \mathrm{LSM} / 8 \mathrm{YSZ}$. Nickel, titanium and aluminium and more specifically the combination of any of them with a second addition of nickel, are the strongest candidates for the catalytic activation of the working electrode as they provided a sensor able to work in dry and wet conditions.

CGO and ScSZ-based devices after infiltration of the working electrode with nickel provide a sensor that can work at lower temperature in dry conditions for applications that require a low ethylene or hydrocarbons concentration (below $100 \mathrm{ppm})$.

The application of catalytic strategies on the working electrode and the optimization of the reference electrode with an active material to oxygen lead to devices more adequate for sensing in exhaust gases than herein reported. Usually, reported sensors are not exposed to more than one analyte whilst the devices in this thesis are able to provide promising results in harsh conditions where more than one analyte is present. 


\section{Acronyms}

\begin{tabular}{|c|c|}
\hline $\begin{array}{l}\text { Acronyms and } \\
\text { symbols }\end{array}$ & Definition \\
\hline $8 Y S Z$ & $8 \%$ mol yttria-stabilized zirconia \\
\hline CARB & California Air Resources Board \\
\hline CGO & $\mathrm{Ce}_{0.8} \mathrm{Gd}_{0.2} \mathrm{O}_{2-\delta}$ \\
\hline $\mathrm{DOC}$ & Diesel oxidation catalyst \\
\hline DPF & Diesel particle filter \\
\hline E & Electrode potential \\
\hline$E^{0}$ & Potential at the equilibrium \\
\hline EIS & Electrochemical Impedance spectroscopy \\
\hline$E_{m}$ & Mixed potential \\
\hline $\mathrm{F}$ & Faraday Constant \\
\hline FESEM & Field Emissions Scanning Electron Microscopy \\
\hline $\mathrm{i}$ & Current density \\
\hline $\mathrm{i}_{0}$ & Exchange current density \\
\hline
\end{tabular}




\begin{tabular}{|c|c|}
\hline LEV & Low Emission Vehicle \\
\hline LSC & $\mathrm{La}_{0.87} \mathrm{Sr}_{0.13} \mathrm{CrO}_{3}$ \\
\hline LSM & $\mathrm{La}_{0.8} \mathrm{Sr}_{0.2} \mathrm{MnO}_{3}$ \\
\hline $\mathrm{n}$ & electrons \\
\hline OBD & On-Board diagnosis \\
\hline OCV & Open circuit voltage \\
\hline $\mathrm{R}$ & Gas constant \\
\hline RE & Reference electrode \\
\hline $\mathrm{R}_{\mathrm{p}}$ & Polarization resistance \\
\hline SCR & Selective catalytic reduction \\
\hline $\operatorname{ScSZ}$ & Scandia-stabilized zirconia \\
\hline SEM & Scanning electron microscopy \\
\hline SOFC & Solid oxide fuel cells \\
\hline $\mathrm{T}$ & Temperature \\
\hline $\mathrm{t}$ & time \\
\hline TEM & Transmission electron microscopy \\
\hline
\end{tabular}




\begin{tabular}{|c|l|}
\hline TPB & Triple phase boundary \\
\hline US EPA & United States Environmental Protection Agency \\
\hline$V_{\text {cell }}$ & Voltage of the device \\
\hline WE & Working electrode \\
\hline XPS & X-Ray photoelectron spectroscopy \\
\hline XRD & X-Ray diffraction \\
\hline$Z^{\prime}$ & Imaginary impedance \\
\hline$Z^{\prime \prime}$ & Real impedance \\
\hline$\alpha$ & Transfer coefficient \\
\hline
\end{tabular}





\section{Figures list}

Figure 1.1 Scheme of defects in a molecule. a) Frenkel defect with one cation missing. b) Schottky defect with a pair of ions missing

Figure 1.2 Concentration of ionic defects vs $\mathrm{pO}_{2}$ when: a) Oxygen Frenkel defects dominates $\left.\left(K_{F}>K_{e}\right), b\right)$ intrinsinc ionization dominates $\left(K_{e}>K_{F}\right)$

Figure 1.3 Face-centered cubic structure where the cations occupy the face-centered positions and the corners of the unite cell while the anions occupy the tetrahedral sites.

Figure 1.4 Perovskite unit cell whit A cation in green, B cations in blue and oxygen ions surrounding $B$ cations in red. 29

Figure 1.5 Usual sensor geometries employed in the literature: a) both electrodes are in the same side facing each other and b)two-sided configuration where each electrode is placed on one side. 30

Figure 1.6 Sensor mechanism at the reference electrode for several electrode configurations: a) pure electronic electrode, b) ionic and electronic conductivity and c) mixed ionic-electronic conductivity. A similar mechanism is employed in the working electrode where the target gas is oxidized and provides the electrons employed in the reference electrode.

Figure 1.7 Diesel exhaust system. The system consists of a diesel oxidation catalyst for the un-burned gases, a diesel particle filter for removing particulate matters and selective catalytic reduction to reduce $\mathrm{NO}_{x}$ to nitrogen (source: Volkswagen) 34 Figure 1.8 Diesel exhaust gas typical composition. Pollutants represents only a 1\% of the total emissions. [79]. 36

Figure 1.9 On-road hydrocarbon emissions measured in Caldecott tunnel in the San Francisco Bay during 2006 [81]. 37

Figure 2.1 Scheme of the co-precipitation method for pure solid oxide formation ...........55

Figure 2.2 Scheme of the sol-gel or Pechini route for pure solid oxide formation ..............56

Figure 2.3 Methodology for the fabrication of solid disk-shape electrolytes .....................57

Figure 2.4 Methodology for the deposition of the catalytic layer over both faces of the electrolyte. .58

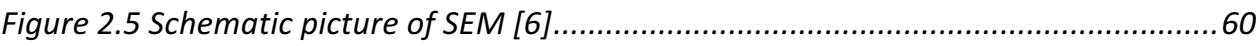

Figure 2.6 Schematic figure of TEM. 60

Figure 2.7 Schematic picture of Bragg's Law where diffraction of X-rays on a crystalline material can be observed [11]...............................................................................61 Figure 2.8 The fourteen Bravais lattices. Image extracted from [12] .............................62 Figure 2.9 Methodology for individual sensors in the first reactor...................................66 Figure 2.10 Multi-sensor device: a) Top face with four working electrodes on it and b) back face with one common reference electrode. 
Figure 2.11 Methodology for multisensory and individual sensors in the second reactor 67 Figure 2.12 Impedance results as function of the imaginary and real impedance. Inset represents the equivalent electrical circuit that fits the EIS measurement response [16].69 Figure 2.13 Scheme of the connection between the sensor and the Autolab PGSTAT101 and FRA32M module

Figure 2.14 Schematic view of the first reactor for measurement of individual samples.. 71 Figure 2.15 Schematic view of the reactor for multi-sensing. Four channels are available to measure four sensors at the same time.

Figure 3.1 Scheme of the sensor device that consists of a dense 8YSZ electrolyte with several materials as working electrode (top face) and platinum as reference electrode (bottom face).....

Figure 3.2 X-Ray diffraction patterns of the materials studied at room temperature once they are synthesized. 80

Figure 3.3 SEM image of the device cross-section corresponding to $\mathrm{Fe}_{0.7} \mathrm{Cr}_{1.3} \mathrm{O}_{3} / 8 \mathrm{YSZ}$ as WE and Pt as RE. a) WE cross section where $\mathrm{Fe}_{0.7} \mathrm{Cr}_{1.3} \mathrm{O}_{3}$ and $8 \mathrm{YSZ}$ grains can be observed. b) WE interface between $\mathrm{Fe}_{0.7} \mathrm{Cr}_{1.3} \mathrm{O}_{3}$ and 8YSZ. c) Complete device with both electrodes and the $1.1 \mathrm{~mm}$-thick 8YSZ electrolyte. d) RE cross section where Pt layer and interface with $8 Y S Z$ can be observed.

Figure 3.4 SEM image of the device cross-section corresponding to several materials employed as working electrode showing the interface between the working electrode and 8YSZ electrolyte for several materials: a) $\mathrm{FeNiO}_{4}$, b) $\mathrm{ZnCr}_{2} \mathrm{O} 4$, c) $\mathrm{LSM}$, d) LSC and e) NiO+6\%wt Au surface view.

Figure 3.5 Device consisting of $\mathrm{ZnCr}_{2} \mathrm{O}_{4} / / Y 8 S Z / / P t$. Sensor response to: a) several concentrations of ethylene $(400,600,800$ and 1000 ppm) where a lineal response can be observed. B) 400 ppm of carbon monoxide. c) 400 ppm of nitrogen dioxide.

Figure 3.6 Sensor response for device consisting of $\mathrm{Fe}_{2} \mathrm{NiO}_{4} / / 8 \mathrm{YSZ} / / \mathrm{Pt}$. Changes in response with change in concentration from: a) 400 to $800 \mathrm{ppm}$ of ethylene. b) 400 to $1000 \mathrm{ppm}$ of ethylene. c) 400 to $800 \mathrm{ppm}$ of ethylene with a background of $400 \mathrm{ppm}$ of carbon monoxide. d) 400 to $1000 \mathrm{ppm}$ of ethylene with a background of $400 \mathrm{ppm}$ of carbon monoxide. .85

Figure 3.7 Sensor responses for device consisting of $\mathrm{Fe}_{2} \mathrm{NiO}_{4} / / 8 \mathrm{YSZ} / / \mathrm{Pt}$ to a) $400 \mathrm{ppm}$ of carbon monoxide and b) 400 ppm of nitrogen dioxide

Figure 3.8 Sensor response for device consisting of NiO+5\%wt Au//8YSZ//Pt. Changes in response for 20 minutes with change in concentration from: a) 50 to 100, 150 and 200 ppm of ethylene. b) 50 to 100, 150 and 200 ppm of carbon monoxide. c) 50 to 200 ppm of ethylene with a background of $50 \mathrm{ppm}$ of carbon monoxide. d) 50 to $200 \mathrm{ppm}$ of carbon monoxide with a background of 50 ppm of ethylene.... .87 Figure 3.9 Sensor response for device consisting of LSC//8YSZ//Pt. Changes in response with change in concentration for 20 minutes from: a) 50 to 100, 150 and 200 ppm of 
ethylene, b) 50 to 100, 150 and $50 \mathrm{ppm}$ of carbon monoxide, c) 50 to $200 \mathrm{ppm}$ of ethylene with a background of $50 \mathrm{ppm}$ of carbon monoxide and d) 50 to $200 \mathrm{ppm}$ of carbon monoxide with a background of 50 ppm of ethylene..... . .88

Figure 3.10 Sensor response for device consisting of LSM//8YSZ//Pt. Changes in response with change in concentration for 20 minutes from: a) 50 to 100, 150 and 200 ppm of ethylene, b) 50 to 100, 150 and $200 \mathrm{ppm}$ of carbon monoxide, c) 50 to $200 \mathrm{ppm}$ of ethylene with a background of $50 \mathrm{ppm}$ of carbon monoxide and d) 50 to $200 \mathrm{ppm}$ of carbon monoxide with a background of $50 \mathrm{ppm}$ of ethylene. Most of the scenarios there is no stable response

Figure 3.11 Sensor response for device consisting of $\mathrm{Fe}_{0.7} \mathrm{Cr}_{1.3} \mathrm{O}_{3} / 8 \mathrm{YSZ} / / 8 \mathrm{YSZ} / / \mathrm{Pt}$. Changes in response for changes in concentration of: a) 50 to 100, 150 and 200 ppm of ethylene, b) 50 to 100, 150 and 200 ppm of ethylene with a background of 200 ppm of carbon monoxide. c) 50 to 100, 150 and 200 ppm of carbon monoxide and d) 50 to 100, 150 and 200 ppm of carbon monoxide with a background of 200 ppm of ethylene. 90 Figure 3.12 Impedance spectrometry study in $\mathrm{Ar}+6 \% \mathrm{O}_{2}$ and: a) $400 \mathrm{ppm}$ of carbon monoxide and 400 ppm of ethylene employing $\mathrm{ZnCr}_{2} \mathrm{O}_{4}$ as $\mathrm{WE}$, b) 200 ppm of carbon monoxide and 200 ppm of ethylene employing LSM as WE, c) 200 ppm of carbon monoxide and 200 ppm of ethylene employing NiO+6\%wt Au as WE and d) 400 ppm of carbon monoxide and 400 ppm of ethylene employing $\mathrm{Fe}_{2} \mathrm{NiO}_{4}$ as WE.

Figure 3.13 Impedance spectrometry study for Ar+6\% $\mathrm{O}_{2}, 200 \mathrm{ppm}$ of ethylene and 200 ppm of carbon monoxide with $\mathrm{Fe}_{0.7} \mathrm{Cr}_{1.3} \mathrm{O}_{3} / 8 \mathrm{YSZ}$ as WE. a) Nyquist plot and b) bode plot92 Figure 3.14 Radar chart with the main characteristics of the sensor output: sensitivity or sensor gain to ethylene defined as $\mathrm{mV} / \mathrm{ppm}$, response time, stability (Applying the following criteria: 100 for stable response and 0 for noisy response), Sensitivity or sensor gain to carbon monoxide defined as $\mathrm{mV} / \mathrm{ppm}$ and carbon monoxide cross sensitivity as a percentage defined as the sensitivity to carbon monoxide divided by the addition of the sensitivities to carbon monoxide and ethylene....

.94

Figure 3.15 Sensor response of the device with configuration $\mathrm{ZnCr}_{2} \mathrm{O}_{4} / 8 Y S Z / P t$ for the second methodology. Sensor is exposed to: a) 50 ppm of carbon monoxide and b) changes in concentration of ethylene from 50 to 200 ppm. .94 Figure 4.1 Response curves for changes in concentration in wet conditions (3\% of water) of: a) ethylene, b) ethylene with 200 ppm of carbon monoxide background, c) carbon monoxide and d) carbon monoxide with 200 ppm of ethylene background. Each change in concentration has 20 minutes of duration and it goes from 50 to 100, 150 and 200 ppm. The sensor consists of $\mathrm{Fe}_{0.7} \mathrm{Cr}_{1.3} \mathrm{O}_{3} / 8 \mathrm{YSZ} / / 8 \mathrm{YSZ} / / \mathrm{Pt}$ and the working temperature is $550^{\circ} \mathrm{C}$ with $6 \%$ of oxygen and $3 \%$ of water. 103 Figure 4.2 Sensor response (Vcell) as a function of analyte concentration for: a) ethylene and b) carbon monoxide. The effect of the background of the second analyte (200 ppm) 
and water (3\%) is also shown. Each point corresponds to the mean of the respective 20 minutes change in response. 104

Figure 4.3 Contour plot displaying the sensor response (Vcell) as a function of the analytes concentration when a $3 \%$ of water is added to sensor configuration $\mathrm{Fe}_{0.7} \mathrm{Cr}_{1.3} \mathrm{O}_{3} / 8 \mathrm{YSZ} / / 8 \mathrm{YSZ} / / \mathrm{Pt}$.. 105

Figure 4.4 Impedance spectrometry study in dry and wet conditions for $\mathrm{Ar}+6 \% \mathrm{O}_{2}$ base gas, 200 ppm of ethylene and 200 ppm of carbon monoxide. a) Nyquist plot with water effect and $b$ ) bode plot with water effect 106

Figure 4.5 Response curves with a fixed concentration of $0.16 \mathrm{ppm}$ of phenanthrene for changes in concentration) of: a) ethylene, b) ethylene with 200 ppm of carbon monoxide background, c) carbon monoxide and d) carbon monoxide with 200 ppm of ethylene background. Each change in concentration has 20 minutes of duration and it goes from 50 to 100,150 and $200 \mathrm{ppm}$. The sensor consists of $\mathrm{Fe}_{0.7} \mathrm{Cr}_{1.3} \mathrm{O}_{3} / 8 \mathrm{YSZ} / / 8 \mathrm{YSZ} / / \mathrm{Pt}$ and the working temperature is $550^{\circ} \mathrm{C}$ with $6 \%$ of oxygen and $0.16 \mathrm{ppm}$ of phenenthrene........ 108 Figure 4.6 Sensor response curves for two changes of 20 minutes adding: a) methylnaphthalene (88.16 ppm) and b) toluene (28947.37). The sensor consists of $\mathrm{Fe}_{0.7} \mathrm{Cr}_{1.3} \mathrm{O}_{3} / 8 \mathrm{YSZ} / / 8 \mathrm{YSZ} / / \mathrm{Pt}$ working at $550^{\circ} \mathrm{C}$ and a $6 \%$ of oxygen. 108

Figure 4.7 Response curves for changes in concentration of ethylene in dry conditions after the exposure of the sensor to polyaromatic hydrocarbons. Each change in concentration has 20 minutes of duration and it goes from 50 to 100, 150 and 200 ppm. The sensor consists of $\mathrm{Fe}_{0.7} \mathrm{Cr}_{1.3} \mathrm{O}_{3} / 8 \mathrm{YSZ} / / 8 \mathrm{YSZ} / / \mathrm{Pt}$ and the working temperature is $550^{\circ} \mathrm{C}$ with $6 \%$ of oxygen without water and/or PAHs 109 Figure 4.8 Raman spectra of the $\mathrm{Fe}_{0.7} \mathrm{Cr}_{1.3} \mathrm{O}_{3} / 8 \mathrm{YSZ}$ working electrode with gold layer as current collector before and after being exposed to polyaromatic hydrocarbons 110

Figure 4.9 X-ray diffraction patter of LSM used as reference electrode at room temperature once it is synthesized. 112

Figure 4.10 SEM image of the reference electrode cross-section corresponding to LSM/8YSZ with gold layer current collector on top. A good attachment to the electrolyte can be observed as well as a good distribution of both grains. 112

Figure 4.11 Response curves for the sensor configuration $\mathrm{Fe}_{0.7} \mathrm{Cr}_{1.3} \mathrm{O}_{3} / 8 \mathrm{YSZ} / / 8 \mathrm{YSZ} / / \mathrm{LSM} / 8 \mathrm{YSZ}$ for changes in concentration of: a) ethylene, b) ethylene with 200 ppm of carbon monoxide background, c) carbon monoxide and d) carbon monoxide with 200 ppm of ethylene background. Each change in concentration has 20 minutes of duration and it goes from 50 to 100, 150 and 200 ppm. The tests are carried out at $550^{\circ} \mathrm{C}$ with $6 \%$ of oxygen.

Figure 4.12 Contour plot displaying the sensor response (Vcell) as a function of the analytes concentration in dry conditions to sensor configuration $\mathrm{Fe}_{0.7} \mathrm{Cr}_{1.3} \mathrm{O}_{3} / 8 \mathrm{YSZ} / / 8 \mathrm{YSZ} / / \mathrm{LSM} / 8 \mathrm{YSZ}$ 114 
Figure 4.13 Impedance spectrometry study for the sensor configuration $\mathrm{Fe}_{0.7} \mathrm{Cr}_{1.3} \mathrm{O}_{3} / 8 Y S Z / / 8 Y S Z / / L S M / 8 Y S Z$. Nyquist plot for $\mathrm{Ar}+6 \%$ of $\mathrm{O}_{2}$ base gas, $200 \mathrm{ppm}$ of ethylene and 200 ppm of carbon monoxide is depicted. 115

Figure 5.1 Design and pictures of the multi-device designed. a) The section shows the design of the multi-sensor with holes to attach the wires b) Cross section of the designed multi-sensor device. On top face, the working electrode $\left(\mathrm{Fe}_{0.7} \mathrm{Cr}_{1.3} \mathrm{O}_{3} / 8 \mathrm{YSZ}\right)$ with gold layers as current collector can be observed. On the other face, there is one common reference electrode (LSM/8YSZ) with a gold layer as current collector. c) $\mathrm{Fe}_{0.7} \mathrm{Cr}_{1.3} \mathrm{O}_{3} / 8 \mathrm{YSZ}$ channel with gold layer. d) Back face with LSM/8YSZ common reference electrode and gold layer. 125

Figure 5.2 Bare sensor response of several channels to ethylene and carbon monoxide concentrations. Responses are normalized to compare among different channels and devices 126

Figure 5.3 Sensor response after: a) First nickel infiltration in dry conditions. b) second nickel infiltration in dry conditions. c) Second nickel infiltration in wet conditions.........128 Figure 5.4 Sensor response after infiltration with ruthenium. 129 Figure 5.5 Sensor response after: a) First titanium infiltration in dry conditions. b) second infiltration with nickel in dry conditions. c) Second infiltration with nickel in wet conditions. 131

Figure 5.6 Sensor response after: a) First aluminium infiltration in dry conditions. b) second infiltration with nickel in dry conditions. c) Second infiltration with nickel in wet conditions. 132

Figure 5.7 Sensor response after: a) First niobium infiltration in dry conditions. b) second infiltration with nickel in dry conditions. c) Second infiltration with nickel in wet conditions. 133

Figure 5.8 Sensor response after: a) First barium infiltration in dry conditions. b) second infiltration with nickel in dry conditions. c) Second infiltration with nickel in wet conditions.

Figure 5.9 Sensor response after: a) First palladium infiltration in dry conditions. b) second infiltration with nickel in dry conditions. c) Second infiltration with nickel in wet conditions. 135

Figure 5.10 EIS results for nickel infiltration and additional infiltration with nickel at $550^{\circ}$ C. a) Nyquist plot and b) Bode plot for 200 ppm of ethylene. c) Nyquist plot and d) Bode plot for 200 ppm of carbon monoxide. e) Equivalent electrical circuit. 137 Figure 5.11 EIS results for titanium infiltration and additional infiltration with nickel at $550^{\circ} \mathrm{C}$. a) Nyquist plot and b) Bode plot for $200 \mathrm{ppm}$ of ethylene. c) Nyquist plot and d) Bode plot for 200 ppm of carbon monoxide. e) Equivalent electrical circuit. 138 
Figure 5.12 EIS results for aluminium infiltration and additional infiltration with nickel at $550^{\circ} \mathrm{C}$. a) Nyquist plot and b) Bode plot for $200 \mathrm{ppm}$ of ethylene. c) Nyquist plot and d) Bode plot for 200 ppm of carbon monoxide. e) Equivalent electrical circuit.

Figure 5.13 EIS results for niobium infiltration and additional infiltration with nickel at $550^{\circ} \mathrm{C}$. a) Nyquist plot and b) Bode plot for $200 \mathrm{ppm}$ of ethylene. c) Nyquist plot and d) Bode plot for 200 ppm of carbon monoxide. e) Equivalent electrical circuit. 140 Figure 5.14 Nyquist plot for the bare channel before infiltrating with ruthenium at $550^{\circ} \mathrm{C}$. Inset can be observed the sensor response to 200 ppm of ethylene and carbon monoxide after infiltrating with ruthenium at 550ㄷ

Figure 5.15 Equivalent electrical circuit fitting results for the first infiltration (inf. I) with each material and the second common infiltration with nickel (inf. II): a) Resistances for 200 ppm of ethylene b) Capacitance for 200 ppm of ethylene. c) Resistances for 200 ppm of carbon monoxide. d) Capacitances for 200 ppm of carbon monoxide. In the case of nickel titanium and aluminium there are only two contributions ( $R_{\text {interface }}$ and $R_{\text {electrode }}$ ) while in the case of niobium there is an additional contribution related with electrode ( $R_{\text {electrode_1 } 1)}$ 141

Figure 5.16 Polarization resistance to ethylene and carbon monoxide for first infiltration with each material (inf. I) as well as for the second common infiltration with nickel (inf. II) 142

Figure 5.17 FESEM image of the working electrode (a) and images of the different working electrodes infiltrated with: b) nickel, c) titanium, d) aluminium, e) niobium, f) ruthenium, g) palladium and h) barium. In all cases the infiltrated nanoparticles can be observed 144

Figure $5.18 \mathrm{Ni2p3/2}$ XPS deconvoluted spectra for the working electrode of the device after potentiometric measurement (top) and for fresh powder impregnated with nickel (bottom). There are three contributions: $\mathrm{Ni}$ (red) and Ni oxides (cyan and green) 145

Figure $6.1 V_{\text {cell }}(\mathrm{mV})$ sensor response for the thinner device $(0.1 \mathrm{~mm})$ as a function of analytes concentration for: a) bare sensor in dry conditions, b) after nickel infiltration in dry conditions, c) after second nickel infiltration in dry conditions, d) bare sensor in wet conditions, e) after nickel infiltration in wet conditions, f) after second nickel infiltration in wet conditions 155

Figure $6.2 V_{\text {cell }}(\mathrm{mV})$ sensor response for the $0.6 \mathrm{~mm}$ thickness electrolyte device as a function of analytes concentration for: a) bare sensor in dry conditions, b) after nickel infiltration in dry conditions, c) after second nickel infiltration in dry conditions, d) bare sensor in wet conditions, e) after nickel infiltration in wet conditions, f) after second nickel infiltration in wet conditions.... 155

Figure $6.3 V_{\text {cell }}(\mathrm{mV})$ sensor response for the $0.8 \mathrm{~mm}$ thickness electrolyte device as a function of analytes concentration for: a) bare sensor in dry conditions, b) after nickel infiltration in dry conditions, c) after second nickel infiltration in dry conditions, d) bare 
sensor in wet conditions, e) after nickel infiltration in wet conditions, f) after second nickel infiltration in wet conditions.....

Figure $6.4 V_{\text {cell }}(\mathrm{mV})$ sensor response for the $1.2 \mathrm{~mm}$ thickness electrolyte device as a function of analytes concentration for: a) bare sensor in dry conditions, b) after nickel infiltration in dry conditions, c) after second nickel infiltration in dry conditions, d) bare sensor in wet conditions, e) after nickel infiltration in wet conditions.... 156 Figure 6.5 Example of $V_{\text {cell }}$ sensor response as a function of analyte concentration. This example corresponds to the thinner electrolyte, although the sensor performance is similar for all devices. Full red square indicates changes in concentration of ethylene while empty red squares indicates changes in concentration of ethylene with 200 ppm of carbon monoxide as background. On the other hand, full green dot indicates changes in concentration of carbon monoxide while green full dots indicates the changes in concentration of carbon monoxide with 200 ppm of ethylene as background.....

Figure 6.6 Sensor sensitivity as a function of the thickness of the electrolyte $(0.1,0.6,0.8$ and $1.2 \mathrm{~mm}$ ) for pure ethylene and carbon monoxide as well as response with a background of 200 ppm of each analyte and background of phenantrene and methy/naphthalene. Sensitivity is represented for: a) dry conditions, b) wet conditions, c) phenanthrene presence (0.23 ppm) and d) methylnaphthalene presence (88 ppm) ......159 Figure 6.7 Electrochemical Impedance Spectroscopy study for the devices after the addition of nickel nanoparticles. Devices are exposed to $200 \mathrm{ppm}$ of ethylene and carbon monoxide in dry conditions as well as wet conditions. The EIS spectra is shown for each thickness: a) $0.1 \mathrm{~mm}$, b) $0.6 \mathrm{~mm}$, c) $0.8 \mathrm{~mm}$ and d) $1.2 \mathrm{~mm}$. The devices response can be fitted to an equivalent circuit consisting of two parallel combination of resistanceconstant phase element (R-CPE) circuits connected in series as shown in e). 160 Figure 6.8 Equivalent electrical circuits fitting results as a function of thickness: a) Polarization resistance $(R p)$. b) resistance related to the contribution of the interface electrode-electrolyte. c) capacitance of the contribution related to the interface electrode-electrolyte. d) resistance related to the contribution of the catalytic processes occurring on the electrode. e) capacitance related to the contribution of the catalytic processes occurring on the electrode 162

Figure 6.9 Electrochemical Impedance Spectrometry study for the devices after nickel infiltration on the working electrode when the sensor is exposed to $200 \mathrm{ppm}$ of ethylene or carbon monoxide with a background of $0.23 \mathrm{ppm}$ of phenanthrene or $0.88 \mathrm{ppm}$ of methylnaphthalene. The EIS spectra is shown for each thickness: a) $0.1 \mathrm{~mm}$, b) $0.6 \mathrm{~mm}$, $0.8 \mathrm{~mm}$ and d) $1.2 \mathrm{~mm}$ 163

Figure 6.10 FESEM images of the fracture cross-section of the device for each electrolyte thickness: a) $0.1 \mathrm{~mm}$, b) $0.6 \mathrm{~mm}, \mathrm{c}) 0.8 \mathrm{~mm}$ and d) $1.2 \mathrm{~mm}$ 165 Figure 6.11 Detailed views of the fracture cross-section of the full dense electrolyte for commercial electrolyte from Kerafol (a) and one of the prepared electrolytes 
corresponding to the electrolyte with a thickness of $0.6 \mathrm{~mm}(\mathrm{~b})$. The rest of the prepared electrolytes has the same structural characteristics.....

Figure 6.12 FESEM images of the fracture cross-section of: a) interface between working electrode and electrolyte, $b$ ) detailed view of the working electrode, c) interface between reference electrode and electrolyte and d) detailed view of the reference electrode. All images belong to the thinner device $(0.1 \mathrm{~mm})$ as an example. The rest of devices present similar electrodes structures 166

Figure $7.1 V_{\text {cell }}$ sensor response as a function of ethylene and carbon monoxide concentration at 550ㄷ for devices employing as electrolyte: a) CGO and b) ScSZ. $\mathrm{Fe}_{0.7} \mathrm{Cr}_{1.3} \mathrm{O}_{3} / 8 \mathrm{YSZ}$ is employed as working electrode and $L S M / 8 Y S Z$ as reference electrode

Figure 7.2 Study of the influence of the temperature on the sensor response. $V_{\text {cell }}$ sensor response as a function of carbon monoxide and ethylene concentration at several temperatures: a) 500C using CGO as electrolyte, b) 500C using ScSZ as electrolyte, c) $450^{\circ} \mathrm{C}$ using CGO as electrolyte, d) $450^{\circ} \mathrm{C}$ using SCSZ as electrolyte, e) 400ㄷ using CGO as electrolyte and f) $400^{\circ} \mathrm{C}$ using $\mathrm{ScSZ}$ as electrolyte 176

Figure 7.3. $V_{\text {cell }}$ sensor response as a function of analytes concentration at $450^{\circ} \mathrm{C}$ for device employing $8 \mathrm{YSZ}$ as electrolyte, $\mathrm{Fe}_{0.7} \mathrm{Cr}_{1.3} \mathrm{O}_{3} / 8 \mathrm{YSZ}$ as working electrode and LSM/8YSZ as reference electrode.

Figure 7.4. Sensor response as a function of analytes concentration when the sensor is exposed to $3 \%$ of water at $450^{\circ} \mathrm{C}$ for devices employing as electrolyte: a) CGO and b) SCSZ 177

Figure 7.5 Study of temperature on the sensor response once the working electrode is infiltrated with nickel nanoparticles for CGO-based device at: a) $400{ }^{\circ} \mathrm{C}$, b) $450{ }^{\circ} \mathrm{C}$ and c) $550^{\circ} \mathrm{C}$ and SCSZ-based device at: d) 400C, e) 450C and f) $550^{\circ} \mathrm{C}$

Figure $7.6 V_{\text {cell }}$ sensor response as a function of the analyte concentration for a device consisting of $8 Y S Z$ as electrolyte at $450^{\circ} \mathrm{C}$. 180

Figure 7.7 Sensor response as a function of analytes concentration after working electrode surface activation by infiltration of nickel nanoparticles for the addition of a) water, b) phenanthrene and c) methylnaphthalene in the of CGO-based device and d) water, e) phenanthrene and f) methylnaphthalene in the case of ScSZ-based device .... 181 Figure 7.8 Impedance spectrometry study of the sensor performance at 550ㄷ (green), $500^{\circ} \mathrm{C}$ (cyan), $450^{\circ} \mathrm{C}$ (red) and $400^{\circ} \mathrm{C}$ (black) of the bare sensor for CGO-based device to a) ethylene and b) carbon monoxide and for ScSZ-based device to c) ethylene and d) carbon monoxide. Inset there is depicted a wider figure of the Nyquist plot for $500^{\circ} \mathrm{C}$ and $550^{\circ} \mathrm{C}$ for each scenario 182

Figure 7.9 Impedance spectrometry study of the sensor performance at $550^{\circ} \mathrm{C}$ (green), $450^{\circ} \mathrm{C}$ (red) and $400^{\circ} \mathrm{C}$ (black) after infiltration of the working electrode with nickel nanoparticles for CGO-based device to a) ethylene and b) carbon monoxide and for SCSZ- 
based device to c) ethylene and d) carbon monoxide. Inset there is depicted a wider figure of the Nyquist plot for $550^{\circ} \mathrm{C}$ for each scenario

Figure 7.10 Results of the equivalent electrical circuit fitting for the CGO-based device: a) resistance of the contribution associated with the electrode and b) capacitance of the contribution associated with the electrode and ScSZ-based device: c) resistance of the contribution associated with the electrode and d) capacitance of the contribution related with the electrode. 184

Figure 7.11 Polarization resistance obtained by the equivalent electrical circuit fitting of a) CGO-based device and b) ScSZ-based device 185

Figure 7.12 Nyquist plot of the CGO-based device after infiltration of the working electrode with nickel nanoparticles when exposed to a) water, b) phenanthrene and c) methylnaphthalene. In every case the response in dry conditions is depicted for comparison. 186

Figure 7.13 Nyquist plot of the ScSZ-based device after infiltration of the working electrode with nickel nanoparticles when exposed to a) water, b) phenanthrene and c) methylnaphthalene. In every case the response in dry conditions is depicted for comparison.

Figure 7.14 FESEM images of the device cross-section corresponding to $\mathrm{Fe}_{0.7} \mathrm{Cr}_{1.3} \mathrm{O}_{3} / 8 \mathrm{YSZ}$ as working electrode, LSM/8YSZ as reference electrode and SCSZ and CGO as alternatives to 8YSZ as electrolyte. Working and reference electrode are common in both devices. a) WE electrode cross-section with $\mathrm{Fe}_{0.7} \mathrm{Cr}_{1.3} \mathrm{O}_{3}$ and $8 \mathrm{YSZ}$ grains. b) Detailed WE electrode cross-section where nickel nanoparticles can be appreciated. c) reference electrode crosssection with LSM and 8YSZ grains. d) Dense ScSZ electrolyte. e) Dense CGO electrolyte. f) Detailed RE electrode cross-section with LSM and 8YSZ grains and no presence of nickel nanoparticles 188

Figure 8.1 Scheme of the analytes contributions in each electrode 196 Figure 8.2 XRD analysis of $L S C / 8 Y S Z$ mixture at $1150^{\circ} \mathrm{C}$. Black dot indicates $8 Y S Z$ phase 197

Figure 8.3 FESEM analysis of the LSC/8YSZ//8YSZ//LSM/8YSZ device cross-section after measurement. a) working electrode (LSC/8YSZ) cross-section, b) detailed view of the working electrode with nickel nanoparticles, c) reference electrode (LSM/8YSZ) crosssection and d) detailed view of the reference electrode. 198 Figure 8.4 Transient response of the device when exposed to changes in concentration of: a) pure ethylene, b) pure carbon monoxide, c) ethylene with $200 \mathrm{ppm}$ of carbon monoxide as background and d) carbon monoxide with 200 ppm of ethylene as background. The device consists of LSC/8YSZ//8YSZ//LSM/8YSZ. 199

Figure 8.5 Transient response in dry conditions of the device consisting of LSC/8YSZ//8YSZ//LSM/8YSZ after infiltration of the working electrode with nickel. Response to changes in concentration of: a) ethylene, b) carbon monoxide, c) ethylene 
with 200 ppm of carbon monoxide as background and d) ethylene with 200 ppm of nitrogen dioxide as background.

Figure 8.6 Transient response of LSC/8YSZ//8YSZ//LSM/8YSZ, after infiltration of the working electrode with nickel, when it is exposed to changes in concentration of nitrogen dioxide 201

Figure 8.7 Sensor response of the LSC/8YSZ//8YSZ//LSM/8YSZ configuration, after infiltration with nickel of the working electrode, in wet conditions (3\% water) to changes in concentration of ethylene for: a) pure ethylene, and with a background of b) 200 ppm of carbon monoxide and c) 200 ppm of nitrogen dioxide. 202

Figure 8.8 Nyquist plot for LSC/8YSZ//8YSZ//LSM/8YSZ, after infiltration with nickel of the working electrode, to several analytes in dry and wet conditions: ethylene, carbon monoxide and nitrogen dioxide. 203

Figure 8.9 Sensor response of the $\mathrm{Fe}_{0.7} \mathrm{Cr}_{1.3} \mathrm{O}_{3} / 8 \mathrm{YSZ} / / 8 Y S Z / / L S M / 8 Y S Z$ configuration, after infiltration with nickel of the working electrode, in dry conditions to: a) pure ethylene and to ethylene with a background of: b) 200 ppm of carbon monoxide and c) 200 ppm of nitrogen dioxide 204

Figure 8.10 Transient response of $\mathrm{Fe}_{0.7} \mathrm{Cr}_{1.3} \mathrm{O}_{3} / 8 \mathrm{YSZ} / / 8 \mathrm{YSZ} / / \mathrm{LSM} / 8 \mathrm{YSZ}$ configuration, after infiltration of the working electrode with nickel, when it is exposed to changes in concentration of nitrogen dioxide. 205

Figure 8.11 Sensor response of the $\mathrm{Fe}_{0.7} \mathrm{Cr}_{1.3} \mathrm{O}_{3} / 8 Y S Z / / 8 Y S Z / / L S M / 8 Y S Z$ configuration, after infiltration with nickel of the working electrode, in wet conditions (3\% of water) to: a) pure ethylene and to ethylene with a background of: b) 200 ppm of carbon monoxide and c) 200 ppm of nitrogen dioxide. 206

Figure 8.12 Nyquist plot for $\mathrm{Fe}_{0.7} \mathrm{Cr}_{1.3} \mathrm{O}_{3} / 8 \mathrm{YSZ} / / 8 \mathrm{YSZ} / / \mathrm{LSM} / 8 \mathrm{YSZ}$ configuration, after infiltration with nickel of the working electrode, to several analytes in dry and wet conditions: ethylene, carbon monoxide and nitrogen dioxide. 207

Figure 8.13 Polarization curves for obtaining the mixed potential ( $\left.V_{\text {cell }}\right)$ when $(a)$ the reactions are taking place in both working and reference electrodes and when (b) the oxygen reduction is taking place only in the reference electrode and the analyte of interest is being oxidized in the working electrode 209 Figure 8.14 An example of the linear correlation between the mixed potential $\left(V_{\text {cell }}\right)$ and the logarithm of the analyte concentration: pure ethylene and carbon monoxide as well as with a background of 200 ppm of the other analyte. The lines indicate the linear regression fit. 211

Figure 8.15 Example of the strategies that can be followed to increase the device response to the target material. 212 Figure 8.16 Summary graph of the evolution of the device developed in this thesis and their main sensing characteristics. a) first generation with platinum as reference electrode, b) second generation with LSM/8YSZ as reference electrode, c) third 
generation with nanocatalyst infiltration in the working electrode, d) fourth generation with CGO or SCSZ as electrolyte and f) fifth generation with $L S C / 8 Y S Z$ as an alternative to the working electrode 



\section{Tables list}

Table 1.1 Region dependent equations for defect species concentration in Frenkel disorder oxides ............................................................................................................24

Table 1.2 Diesel exhaust composition for a Mercedes-Benz 1.7L turbocharged engine [80]

36

Table 1.3 Table of polycyclic aromatic hydrocarbons listed by EPA as priority pollutants [83] .37

Table 1.4 Evolution of the European gas exhaust emission limit over the years from EURO 1 to EURO 6 for petrol and diesel cars [89] .38

Table 1.5 Gas exhaust emission limits for a) EPA's TIER 3 and b) CARB's LEV III [98] ........39

Table 2.1 Bravais lattices parameters

Table 3.1 List of materials studied for the selective response of ethylene with platinum as reference electrode .79

Table 5.1 Infiltration carried out in each channel. A complete electrochemical characterization is performed after the first infiltration and then, another complete electrochemical characterization is carried out after the addition of the second infiltration 



\section{Scientific Contribution}

\section{$\underline{\text { Publications }}$}

- L. Navarrete, F. Toldra-Reig, J.M. Serra and S. Somacescu. $\mathrm{SnO}_{2}$ and $\mathrm{Ce}$ modified $\mathrm{SnO}_{2}$ mesostructured for selective ethanol detection. Proceedings of IEEE sensors 39 (2014), pp. 297-300

- C. Solís, F. Toldra-Reig, M. Balaguer, S. Somacescu, J. García-Fayos, E. Palafox and J.M. Serra, Mixed ionic-electronic conduction in $\mathrm{NiFe}_{2} \mathrm{O}_{4}-$ $\mathrm{Ce}_{0.8} \mathrm{Gd}_{0.2} \mathrm{O}_{2-\delta}$ nanocomposite thin films for oxygen separation, ChemSusChem 11 (2018) 2818-2827. Doi: 10.1002/cssc.201800420

- F. Toldra-Reig and J.M. Serra, Development of potentiometric sensors for $\mathrm{C}_{2} \mathrm{H}_{4}$ detection, sensors 18 (2018), 2292. Doi: 10.3390/s 18092992

- F. Toldra-Reig and J.M. Serra, Surface functionalization of $\mathrm{Fe} 0.7 \mathrm{Cr} 1.3 \mathrm{O} / 8 \mathrm{YSZ}$ electrode in a potentiometric sensor to detect $\mathrm{C} 2 \mathrm{H} 4$ selectively, submitted for publication

- F. Toldra-Reig, D. Pastor and J.M. Serra, Influence of solid-electrolyte material in a potentiometric sensor for ethylene detection, submitted for publication

\section{Congress participation}

- S. Escorihuela, S. Escolástico, R. Murciano, F. Toldra-Reig, A. Martínez and J.M. Serra. Selective addition of $\mathrm{H}_{2}$ through a palladium membrane in a Fischer-Tropsch synthesis reactor. $16^{\text {th }}$ Network Young Membrains Conference. Valencia, Spain (2018)

- F. Toldra-Reig and J.M. Serra. Catalytic activation of electrodes for selective detection of ethylene. III encuentro jóvenes investigadores de la SECAT. Flash oral presentation. Valencia, Spain (2018)

- J. García-Fayos, M. Balaguer, F. Toldra-Reig, A. Represa and J.M. Serra, OTMs Surface modification by means of dual-phase materials deposition: oxygen permeation optimization under oxyfuel environments. Oral presentation. $15^{\text {th }}$ International Conference on Inorganic Membranes. Dresden, Germany (2018)

- F. Toldra-Reig and J.M. Serra, lonic conductor device for selective detection of hydrocarbons on diesel exhaust gases. Oral presentation. $15^{\text {th }}$ Conference of the European Ceramic Society. Budapest, Hungary (2017)

- F. Toldra-Reig, J. García-Fayos and J.M. Serra. Sputtered thin film protective layers for the operation of OTMs in oxyfuel-like environments. Poster. $15^{\text {th }}$ Conference of the European Ceramic Society. Budapest, Hungary (2017) 
- F. Toldra-Reig and J.M. Serra. Multi-sensor ionic device for selective detection of ethylene with low cross-sensitivity. 14th International Conference on Inorganic Membranes. Atlanta, USA (2016)

- L. Navarrete, F. Toldra-Reig, J.M. Serra and S. Somacescu. $\mathrm{SnO}_{2}$ AND ce modified $\mathrm{SnO}_{2}$ mesostructured for selective ethanol detection. Poster.Summer School: Ionic and protonic conducting ceramic membranes for Green energy applications. Valencia, Spain (2015)

- F. Toldra-Reig and J.M. Serra. Multi-sensor device for HC and $\mathrm{CO}$ detection in diesel exhaust gas. $14^{\text {th }}$ Conference of the European Ceramic Society. Toledo, Spain (2015)

- L. Navarrete, F. Toldra-Reig, J.M. Serra and S. Somacescu. $\mathrm{SnO}_{2}$ AND ce modified $\mathrm{SnO}_{2}$ mesostructured for selective ethanol detection. Poster. IEEE sensors 2014. Valencia, Spain (2014) 


\section{Acknowledgments}

First of all, I would like to thank Jose M. Serra for giving me the chance to do my $\mathrm{PhD}$ in his research group at the ITQ and for his helpful and valuable advices and guidance. I want to thank as well to the whole ITQ staff because they are an important, yet not always visible, part of the development of our work. The Spanish Ministry of Education, Culture and Sport is also acknowledged, as this thesis would not be possible without the funding from the FPU scholarship.

I would like to thank also Ainara Aguadero and her team (Richard, Andrea, Federico, and colleagues) for accepting me to do my research stage at the Imperial College of London and allowing me to learn other techniques as well as how research is developed in other foreign research institutes. It has been a great experience!

And, of course, I would like to thank all my fellow colleagues: Álvaro, Cecilia, Cyril, David, Julio, Jorge, Juan B., Juan E., Laura, María B., María F., María V., Marwan, Mateusz, Nuria, Raquel, Sandra, Sara, Sebastián, Sonia, Vicente, and all the people that visited us for short periods of time, because they have helped me in one way or another over all these years. All of them have been an important part of this thesis. Not only they are a key work factor, but also they are a relief for those stressful moments and we had a lot of funny moments that I really appreciate. This kind of things really make life easier.

At last but not least, I would like to thank my parents, my sister and Jenn for all their help, support and comprehension during these years, supporting me when I needed. 